This item was submitted to Loughborough's Research Repository by the author.

Items in Figshare are protected by copyright, with all rights reserved, unless otherwise indicated.

\title{
The application of a microprocessor to engine cylinder disablement
}

PLEASE CITE THE PUBLISHED VERSION

PUBLISHER

(C) A. Manias

LICENCE

CC BY-NC-ND 4.0

REPOSITORY RECORD

Manias, Anthony. 2013. "The Application of a Microprocessor to Engine Cylinder Disablement". figshare. https://hdl.handle.net/2134/11908. 


\section{LLoughborough University}

This item was submitted to Loughborough University as an MPhil thesis by the author and is made available in the Institutional Repository (https://dspace.Iboro.ac.uk/) under the following Creative Commons Licence conditions.

\section{Ccreative \\ $\begin{array}{lllllllllllllllllllll}\mathrm{C} & \mathrm{O} & \mathrm{M} & \mathrm{M} & \mathrm{O} & \mathrm{N} & \mathrm{S} & \mathrm{D} & \mathrm{E} & \mathrm{E} & \mathrm{D}\end{array}$}

Attribution-NonCommercial-NoDerivs 2.5

You are free:

- to copy, distribute, display, and perform the work

Under the following conditions:

Attribution. You must attribute the work in the manner specified by the author or licensor.

Noncommercial. You may not use this work for commercial purposes.

No Derivative Works. You may not alter, transform, or build upon this work.

- For any reuse or distribution, you must make clear to others the license terms of this work.

- Any of these conditions can be waived if you get permission from the copyright holder.

Your fair use and other rights are in no way affected by the above.

This is a human-readable summary of the Leqal Code (the full license).

Disclaimer

For the full text of this licence, please go to: http://creativecommons.org/licenses/by-nc-nd/2.5/ 

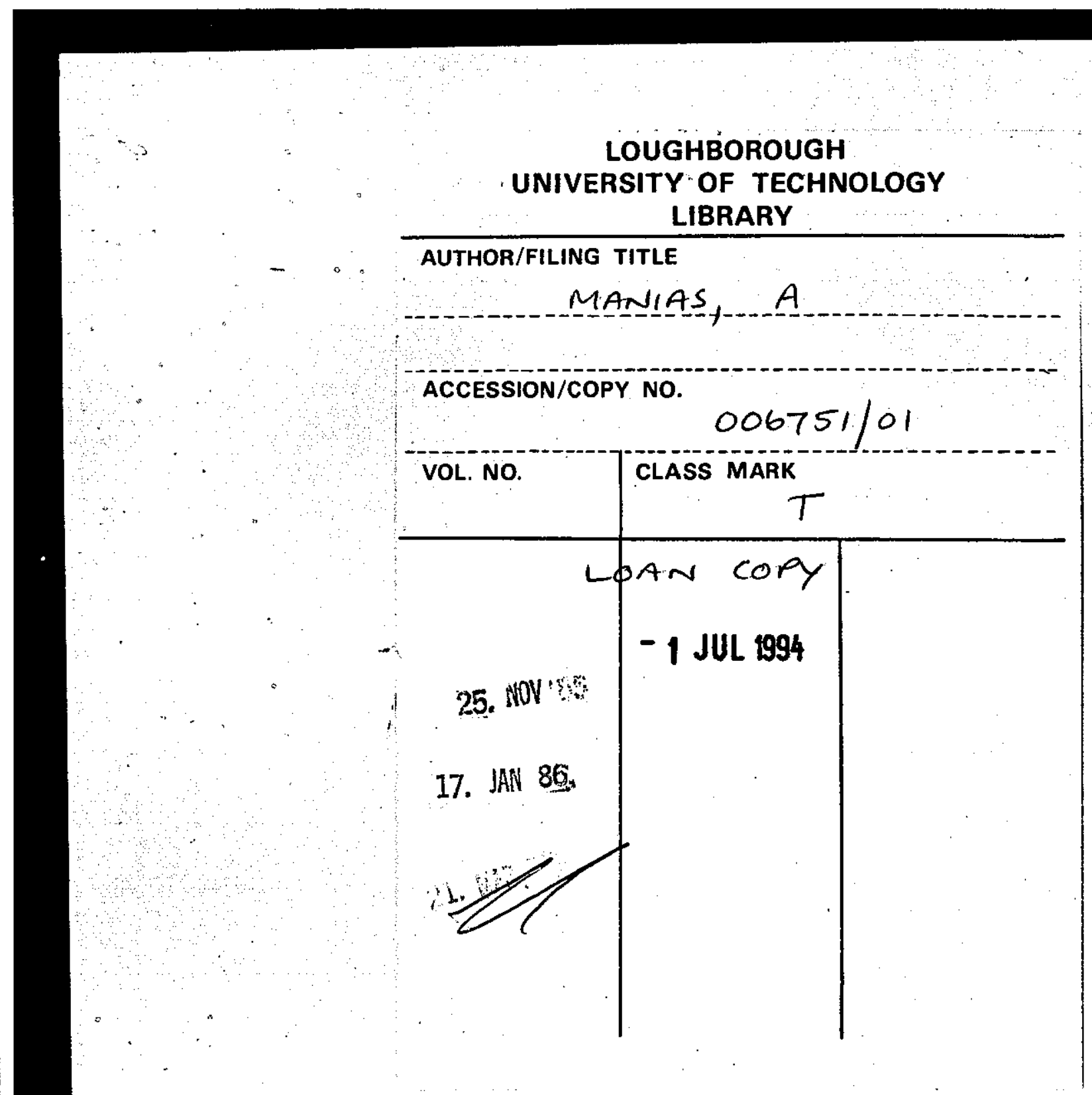

000.675101

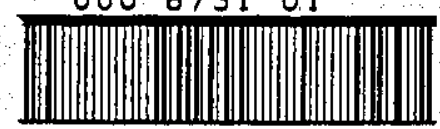

This book was bound by

\section{Badminton Press}

18 Half Croft, Syston, Leicester, LE7 8LD

Telephone: Leicester (0533) 602918. 


\title{
THE APPLICATION OF A MICROPROCESSOR TO
}

\section{ENGINE CYLINDER DISABLEMENT}

by
Anthony Manias B.Tech/Hon.
Senior Development Engineer
JAGUAR CARS Ltd.

\begin{abstract}
A Master's Thesis
Submitted in partial fulfilment of the requirements for the award of

Master of Philosophy of the Loughborough University of Technology
\end{abstract}

- loth April 1985

C by A. Manias 1985 


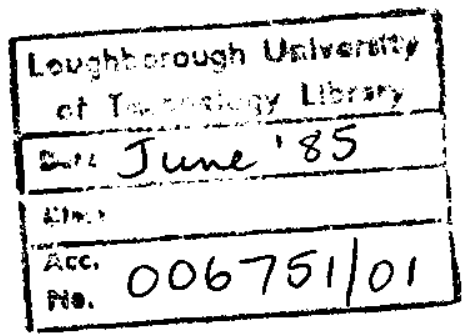


The author wishes to thank the following persons for their invaluable assistance with this research.

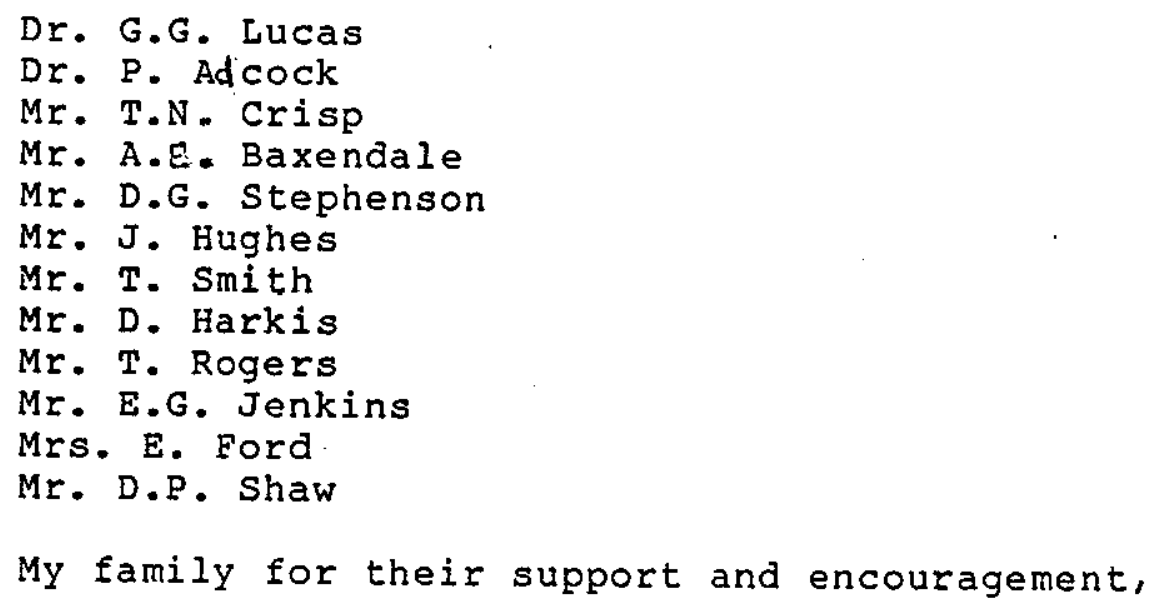

All technicians and University staff who helped with the work. 


\begin{tabular}{|c|c|}
\hline S.I. & Spark Ignition \\
\hline C.I. & Compression Ignition \\
\hline CSo & Cylinder Shut-off \\
\hline FSO & Fuel Shut-off \\
\hline Vso & Valve Shut-off \\
\hline ECM & Electronic Control Module \\
\hline ECU & Electronic Control Unit \\
\hline NVH & Noise, Vibration and Harshness \\
\hline $\mathrm{N}$ & Engine speed rpm. \\
\hline $\mathbf{P}$ & $\mathrm{kW}$ or bhp. \\
\hline $\mathbf{T}$ & Torque $\quad \mathrm{Nm}$ or $1 \mathrm{bft}$. \\
\hline FC & Euel Consumption $\mathrm{Kg} / \mathrm{hr}$ or $\mathrm{lb} / \mathrm{hr}$. \\
\hline BSFC & $\begin{array}{r}\text { Brake specific Euel consumption } g / k \text { whr } \\
\text { or } 1 \mathrm{~b} / \mathrm{bhphr} .\end{array}$ \\
\hline$\tau$ & Inlet Manifold Pressure $\mathrm{kN} / \mathrm{m}^{2}$ or $\mathrm{mmHg}$. \\
\hline$t$ & Time sec. \\
\hline f & Frequency \\
\hline A & Correction Factor (Engine Performance) \\
\hline
\end{tabular}


The power output of a spark ignition, internal combustion engine is normaliy controlled by the use of a throttle on the air intake system. As a result, the part-load efficiency of the engine suffers when compared with the compression ignition engine.

A microprocessor development system was adapted for use with the electronic fuel injection of a 6 cylinder, spark ignition engine in order to selectively disable any number of individual cylinders by interrupting the fuel flow from the injectors of those cylinders. The system allows any number and combination of cylinders to be disabled cyclically, with the view of keeping all cylinders hot and minimising engine vibration.

The theory of cylinder disablement, and work published in this field are discussed in this Thesis. Also included are the results of engine testing carried out to determine the economy gains possible with cylinder deactivation, and to investigate the behaviour of a cylinder under disablement, and subsequent reactivation by control of its injector. The relationship between cylinder deactivation sequence and engine vibration, and means of minimising the amplitude of that vibration were also investigated, and the results obtained discussed, together with the results of limited emission and fuel consumption testing of a vehicle fitted with cylinder disablement.

The main conclusions reached at the end of this research were:

(i) The use of a microprocessor system, in conjunction with electronic fuel injection to disable cylinders by control of their injectors is an effective way of implementing cylinder disablement.

(ii) Fuel economy gains achieved varied from over $50 \%$ at idle to 25 - 458 at light load, steady state conditions, with actual vehicle tests returning almost $40 \%$ fuel economy over the European 04 Test driving cycle, accompanied by moderate increases in exhaust poliutants.

(iii) Engine vibration, resulting from the imbalance of the non-firing cylinders can be reduced to acceptable levels by arranging the disabled cylinders according to their firing order and engine speed, as shown in this thesis. 
Finally, the possibilities of expanding the microprocessor - development system used for this research, to incorporate the additional disablement control features, are discussed and recommendations made, based on the results of the research. 
NOTATION

SUMMARY

SECTION 1. INTRODUCTION....................... 1

Cylinder Disablement..................... 2

SECTION 2. LITERATURE SURVEY................... 5

Cylinder Disablement Systems............... 6

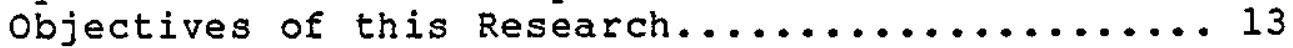

SECTION 3. EQUIPMENT and TEST PROCEDURES............. 14

Engine............................ 14

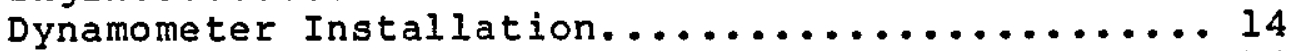

Cylinder Disablement System............... 15

Cylinder Pressure Measurement.............. 17

Engine Vibration Measurement............... 18

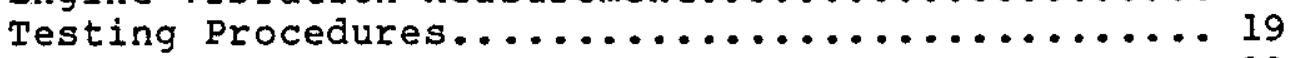

Engine Performance...................... 19

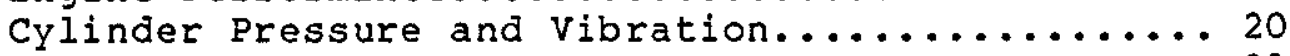

Vehicle Testing....................... 21

SECTION 4. TEST RESULTS and DISCUSSION.............. 22

Engine Performance Results................ 22

Cylinder Disablement and Reactivation......... 25

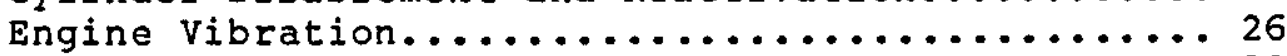

Vehicle Test Results.................... 30

SECTION 5. CONCLUSIONS....................... 33

Expanding the "HEKTOR" CSo system.................. 35

REFERENCES............................... 38

FIGURES.................................

ARPENDICES :

APPX. I. Formulae......................... 112

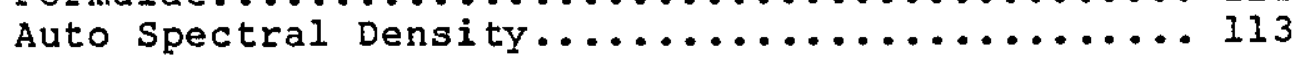

APPX. II. "The Application of a Microprocessor to Engine Cylinder Disablement"

A Paper presented to XX FISITA Congress

on $6-11$ May $1984 \mathrm{GGL} / \mathrm{JH} / \mathrm{AM} \ldots \ldots \ldots \ldots \ldots \ldots \ldots$. $\ldots \ldots$

APPX. III. Bosch L-Jetronic Fuel Injection System -

Principle of Operation................... 125

APPX. IV. Product Specification of TOSHIBA TMP8085A and

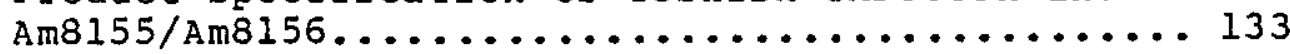


Page No.

APPX. V. "HEKTOR" Microprocessor Development System -

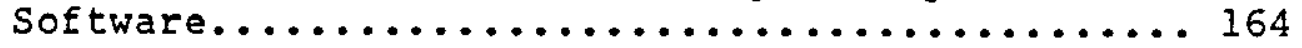

APPX. VI. Specification and Calibration of Pressure

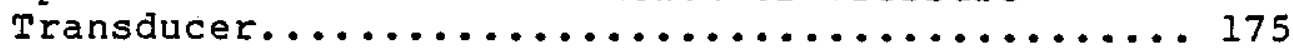

APPX. VII. Specification and Calibration of vibration

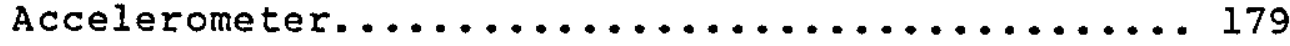


1.INTRODUCTION 


\section{INTRODUCTION}

The spark ignition engine, as fitted to the vast majority of passenger vehicles today, has enjoyed over eighty years of continuous development. The principle of operation of the engine has not changed in that time, implementing the otto cycle to the best of its ability. Advances in the field of materials technology, and a better understanding of the processes taking place inside the combustion chamber, have pushed the power output/ displacement ratio to increasingly higher limits. As a result, today's top FI racing engines with the aid of forced induction and high octane fuels, can deliver almost 1000 bhp from just 1.5 litres under race qualifying conditions.

With passenger vehicles however, ease of manufacture, cost, fuel economy and reliability are the key factors in the design of an engine for the volume market. In particular, the increasing awareness of the value of the remaining oil reserves of this planet both in economic and social terms, highlighted by the oil price crisis of the early '70's, has urged motor manufacturers to design and produce engines that deliver the required power to give acceptable performance, while at the same time be very efficient in the way they use fuel under all driving conditions.

This drive to make the spark ignition engine more fuel efficient has resulted in major developments in all areas of engine construction and operation, and these can be categorised as follows:

\section{(i) Improvements in Mechanical Efficiency}

eg. Low friction lubricants and bearings, lighter internal moving parts, specially coated friction surfaces etc.

(ii) Improvements in Thermodynamic Efficiency

eg. High compression, better combustion chamber design, lean-burn engines etc.

(iii) Electronic Engine Management systems

eg. Microprocessor based control of all engine systems for precise metering of fuel and ignition, under all conditions.

(iv) Alternative Fuels

eg. LPG, alcoholes, NG, LNG, hydrogen.

(v) Modular Engines

eg. Variable displacement engines, Cylinder disablement. 
The work described in this Thesis concerns this last means of improving the fuel economy of engines, and in particular, cylinder disablement.

\section{CYLINDER DISABLEMENT}

Cylinder disablement, or Cylinder shut-off (CSo) as is commonly referred to, is a concept that has existed since the early days of the motor car. It is based. on the fact that the full power of the engine in a vehicle is needed only on relatively rare occasions such as hill climbing, full throttle accelerations and overtaking. For most of its life the passenger vehicle operates in the part load and idle conditions, particularly so if the engine capacity is large and delivers adequate torque at small throttle openings.

The spark ignition engine has achieved dominance worldwide as a drive unit for passenger. cars over the diesel because of its high power to displacement, volume and weight ratios, higher maximum speed, smooth and low-noise operation, and low cost per unit of power output. The thermodynamic efficiencies of both engines at maximum power are comparable, however, the efficiency of the $S$. I. engine reduces more rapidly at part load and transient conditions(1).*

The reason for this is the method of controlling the power output of the $S$. I. engine, namely by varying the quantity of air/fuel mixture by means of a throttle. Consequently, at part loads and idle the engine operates with very low inlet manifold pressures incurring high losses and low efficiency associated with the gas cycle. One possible solution is to deactivate some of the cylinders, the number of active cylinders being adapted to the performance requirements of the engine, and thus operating at optimum efficiency.

This concept was utilised as early as 1916 on the Enger Twin-Unit Twelve, an American touring car powered by an overhead-valve $\mathrm{V}-12$ engine(2). A large lever on the steering column operated a system of linkage and cams, blocking open the exhaust valves on one bank and shutting off the fuel supply to the cylinders of that bank. However, the low cost of fuel at that time made the economy gains seem insignificant with this complex system, and the Enger Motor Car Company ceased operations in 1917.

The principle of cSo can be implemented in various ways depending on the configuration of the engine, available space, and the complexity and cost involved. Past and present systems can essentially be split into three main categories:

(i) Power Unit Disablement

* Numbers in parentheses indicate references at end of Thesis. 


\section{(ii) Valve Shut-of \\ (iii) Fuel "}

Power unit disablement involves parallel operation of primary and auxiliary power units coupled together. With complete disengagement of the aux. "power unit under part load, friction and pumping losses in that unit are avoided. This concept, although taking the principle of CSo to its full extent, has the major disadvantage of complexity, and hence cost of the coupling and synchronization of the two engines and transmission control.

The disablement of inlet and/or exhaust valves constitutes a more realistic approach to cSo. This is generally accomplished by electromechanically, or hydraulically isolating the valves from the camshaft while in the 'closed' position. This restricts the pumping work to the active cylinders, while at the same time it results in the general dethrottling of the engine at part load and hence better efficiency.

Fuel shut-off represents the simplest method of CSo, involving purely engine-based measures of stopping fuel to the deactivated cylinders and specific adaptation of engine controls. It is performed with electronic fuel injection systems via a corresponding control of the injectors, and with mechanical systems through additional valves between fuel pump and injectors.

In the cases of both valve and fuel shut-off the effective dethrottling of the engine is achieved through separate control of the main, or additional throttles by mechanical means, such as a camplate on the throttle linkage, or electrically by the use of a stepper motor. In all cases a microprocessor is used to control the cylinder deactivation sequences and to intervene in the engine controls so as to provide smooth delivery of power under all conditions. 
2. LITERATURE SURVEY 
over the last decade there has been a revived interest in the subject of cylinder disablement as a means of increasing the fuel economy of existing S. I. engines. Virtually every major car manufacturer has looked at the possibility of adapting current engines in their model range to run on fewer cylinders by devising additional or, in some cases new engine control systems. In many cases this has been done to the larger capacity engines, where the benefits of cSo are more apparent. The principle has been applied to most engine configurations, from a large V-16 diesel engine of 50 litres displacement from Cummins, which idles on eight cylinders(3), to the small Suzuki SSC three-cylinder two-stroke unit of 0.539 litres, which operates on two cylinders at light load conditions(4).

When cylinders are deactivated on a S. I. engine it is desirable to retain even spacing between firing intervals, in order to maintain a smooth delivery of torque over the complete cycle of the engine. Figure 1 shows the positions of deactivated cylinders on various engine configurations, based on the firing order of those engines. Cylinder disablement therefore, is favoured with multi-cylinder engines, particularly those of the v-configuration.

When cSo is accomplished by deactivating the inlet and exhaust valves of an engine the pumping losses incurred are minimised. In each deactivated cylinder the unchanged charge is merely compressed and expanded by the action of the piston, with the only energy consumed directed to normal frictional losses and compression heat lost through the cylinder walls. In addition, cooling of that cylinder is minimised, with shorter subsequent reactivation time and lower emissions of unburned hydrocarbons.

Figure 2 shows a valve disablement mechanism developed by the Eaton Corporation(5) and installed in the GM Cadillac 6.0 litre models in 1981(6). The mechanism consists of a solenoid acting on a blocker plate, and mounted on the rocker arm studs of the over-head valve pushrod engine, with one solenoid acting on both inlet and exhaust valves. In the 'active' mode, shown at left in Fig. I, the selector body is prevented from moving upward by contact between projection on the body and the blocking plate above it. The rocker arm fulcrum point is held down by the blocking plate and the body, and the valves operate as normal.

On activation of the selector, as shown at the right of Fig. 2 , the blocking plate is rotated by the solenoid to align small openings in the plate with corresponding projections on the body. As the rocker arm is raised by the pushrod, its fulcrum point is moved to the tip of the valve stem as the body is no longer restrained by the blocker plate. The rocker arm pivots about the top of the valve stem, and the valve is effectively disabled. 
The selector mechanism can only change operating mode during rest periods of both valves. When deactivation occurs therefore, a combustible charge is trapped and ignited but, since the valves are closed, following the power stroke the spent gases are prevented from escaping. For the following few strokes the piston re-compresses the burned gases, creating sharp pressure spikes in the cylinder. Due to blow-by past the piston rings, the (gauge) pressure inside the cylinder eventually reaches an equilibrium situation whereby pressures are positive during the compression and negative during expansion.

This CSo system uses inlet manifold pressure to sense the load requirements of the engine, via a manifold vacuum sensor whose signal, together with other signals relaying engine speed, throttle position, coolant temperature and transmission gear, is fed to an electronic control unit (ECU). The ECU then increases or decreases the number of active cylinders according to power demands, keeping the inlet manifold vacuum to between 2 and 12 ins. Hg. In this way, the $V-8$ engine can operate on $4,5,6,7$, or 8 cylinders, with the system automatically switching to 4-cylinder operation during idle. On the production version of this system however, the engine operated only in the 8,6 , or 4 cylinder mode, to avoid excessive vibration from too uneven firing intervals. In the 4-cylinder mode, the engine behaves like a 90-deg. $\mathrm{V}-4$, with no inherent imbalance. In the 6 -cylinder mode however, it operates as a $90-$ deg. $v-6$, which has inherent imbalance in the form of a secondary rocking couple. Consequently, the engine mounting system was redesigned to dampen these secondary vibrations effectively.

The above system was fitted by Eaton Corp. in a 1977 Mercury V-8 engined experimental vehicle, with no changes made to the carburetion or E.G.R systems. The vehicle returned fuel economy improvements ranging from 10-15\% during light acceleration/ Highway cruise to over $40 \%$ at idle conditions, with lower levels of $\mathrm{HC}$ and $\mathrm{CO}$ emissions, but higher levels of Nox. The production version on the cadillac also claimed similar improvements.

The Mitsubishi Motor Corporation also introduced a vehicle in 1982 which incorporated CSo by valve disablement, applied to their 1.4 litre in-line four cylinder engine in the Mirage model(7). A microprocessor unit controls engine operation between two and four cylinders, according to signals from sensors for inlet manifold pressure, gear in use, coolant temperature, engine speed, and vehicle road speed. Figure 3 shows the principle of operation and an outline of the system.

Small hydraulic cylinders built in the rocker arms actuate small forked plates controlling spring-loaded plungers which act on the valve stem. Under normal operation the plunger is held rigidly by the plate, and the valve can be opened by the action of the rocker arm. When the cylinder is disabled, oil pressure pushes the fork so as to enable the plunger to pass through it. As a result, the valve remains closed while the plunger moves in 
the rocker arm. With this system installed, improvements in fuel economy of $25 \%$ over the Japanese 10-mode city cycle, and $15 \%$ at constant $60 \mathrm{~km} / \mathrm{h}$ are reported.

Intake and exhaust valve control using an on-board computer was applied to a 5.8 litre Ford $\mathrm{V}-8$ vehicle, whose engine management systems were recalibrated to enable the engine to operate on the most efficient number of cylinders under all conditions(8). Again, the valve disablement system developed was similar to the Eaton system, allowing the engine to work on eight cylinders (hard acceleration), to zero cylinders under deceleration. Emission levels during transition periods between four and eight cylinder operation, under three different load conditions, showed an overall decrease in $\mathrm{HC}, \mathrm{CO}$ and NOx levels in CSo mode under idle and light load conditions, with Nox increasing slightly under higher loads, as shown in Figure 4. A spike on the HC levels was also recorded as the engine was switched from four to eight cylinders, the severity of which was counteracted by the subsequent lower overall levels.

Research at the Institute of Vocational Training in Japan also showed that significant fuel economy gains are available at part load with valve deactivation, on a 6-cylinder $S$. I. engine(9). In particular, the power for activating the inlet and exhaust valves, and the pumping power for the inlet were measured and the results related to the decrease in fuel consumption by valve disablement. Simple fuel cut-off was also compared with valve disablement, and was found to be nearly as effective, as shown in Figure 5. It was also reported that idling on three cylinders decreased the level of vibration from the engine, thought to be due to the apparent volume increase of the inlet manifold for the active cylinders, adding to the slight increase in volumetric efficiency by the wider throttle opening required to maintain idle speed in the 3-cylinder mode.

Valve disablement, and also fuel shut-off, were tested on a Mercedes 5.0 litre $v-8$ engine equipped with electronic fuel injection(10, 11). This application featured a throttle compensation system whereby the relationship between the accelerator pedal angle, indicative of load requirement, and the angle of the throttle valve was governed by an electronic unit controlling a stepper motor. In this way, the throttle valve angle was adapted to the engine conditions, using engine speed as a parameter, as shown in Figure 6. The ECU also received signals from a number of sensors monitoring such engine parameters as speed, temperature and gear selected, activating the optimum number of cylinders between eight, six and four. Fuel consumption tests at idle, constant speed and urban driving, with both valve and fuel shut-off, resulted in the economy gains shown in Figure 7. In addition, reductions of approximately $30 \%$ in fuel consumption were achieved over the European 04 City Cycle. 
The multi-displacement concept can be applied using valve disablement, or fuel cut-off. Due to the complexity, and the relatively small additional economy gains available by the former, the Ford Motor $C o$. chose the latter method in applying CSo to their 2.8 litre $v-6$ engine(12). The engine, equipped with Bosch L-Jetronic fuel injection, supplemented by Ford's own EEC IV engine management system, was essentially divided into two banks, each constituting a separate engine. The right bank, engine $1_{i}$ operated full time, while the left bank, engine 2 , came into operation at higher load demands.

Two separate inlet manifolds were used, each with its own intake on a twin-throttle body. It is here that this application of cSo is of importance, for the two throttle valves are controlled by a common camplate which is connected to the accelerator pedal. In this way the delivery of power from each engine is controlled automatically to provide smooth transition between three and six cylinder operation. Figure 8 shows the installation of the camplate.

As the accelerator pedal is depressed the camplate rotates, it opens the full-time engine 1 throttle up to an angle of $43 \mathrm{deg}$.', corresponding to a camplate angle of $37 \mathrm{deg}$. At this point the engine 1 throttle begins to close as engine 2 throttle begins to open. At $67 \mathrm{deg}$. camplate rotation the two throttles are fully synchronized, and the engine behaves as a six-cylinder. This throttle valve relationship is illustrated in Figure 9.

The intake system for each engine was designed for optimum performance in the operating range of that engine. The engine management system controls all engine functions, including fuel injection to each cylinder, engine changeover and idle speed. With this system, separate ignition characteristics are provided for each engine, to ensure operation at peak efficiency. On the three-cylinder mode the throttle valve of the disabled engine is held open by a solenoid, so as to minimise pumping losses. When the throttle is closed and the vehicle decelerating, fuel cut-off takes place until engine speed drops to $1100 \mathrm{rpm}$, when engine $l$ is switched on and the engine idles on three-cylinders. The idle speed in this case is slightly higher than normal, at 900 rpm.

It is reported that, despite the sophisticated control of this engine, it is essentially a three-cylinder engine under cSo mode. The effect on torque output, shown in Figure 10, caused certain excitations on the driveline of the test vehicle, calling for further research in the NVH aspect of the installation. However, fuel consumption gains experienced with this system, coupled with reasonable emission levels over the Euro 04 Cycle-shown in Figures 11 and 12 respectively, make this cSo system a future production possibility. 
Another major motor manufacturer. to use fuel cut-of for cylinder disablement is Alfa Romeo, with their 2.0 litre fuel injected engine(13, 14). In disablement mode, periodic switching occurs every 200 crankshaft revolutions between paired cylinders 1,4 and 2,3 . This gives an even $360 \mathrm{deg}$. rotation between firing strokes, on the 4-cylinder engine. Cso is controlled by Alfa's Electronic Control Module (ECM), which also controls ignition timing. An outline of the system is shown in Figure 13.

Inputs to the EMC are from sensors for engine speed, throttle valve angle, and water, oil and air temperature. Four cylinder operation is maintained above $3,800 \mathrm{rpm}$ and/or throttle angles beyond $40 \mathrm{deg}$. Engines equipped with this dual-mode system were fitted on a number of taxi cars, which reported fuel economy gains between $16 \%$ and $18 \%$, compared with the standard-engined vehicles.

When cylinders are deactivated for a long period of time, the subsequent cooling, and possible oil accumulation in the combustion chamber tends to make reactivation of those cylinders a relatively slow process, with detrimental effects on both driveability and emissions in the form of unburned hydrocarbons. One way of minimising this effect is by cycling of the disabled cylinders, as in the dual-mode system described above. The BMW Motor Company however devised a system whereby the exhaust gases from the active cylinders are directed to the inlets of the disabled ones, in their $323 i$ 6-cylinder engine fitted with CSo $(15,16)$.

The inlet manifolds of the front and rear 3-cylinder groups of the in-line engine are split, with separate throttles. Fuel injection and ignition is controlled separately by the BMW Motronic computer for each group of cylinders. In addition, the synchronisation of the two throttles is also automatic, for smooth power delivery under cSo. When three cylinders are disabled, exhaust gases bypass the throttle in the internally split manifold, and are used to fill the inactive cylinders. Apart from outside air, exhaust gases are particularly suitable for this purpose since, with increased throughput, their low density also reduces the pumping work of the disabled cylinders. Figure 14 shows the principle of this system. Fuel savings of up to $25 \%$ in the European 04 City Cycle test are reported with this system, with the vehicle operating on the three-cylinder mode for 858 of the time, under normal driving.

The same principle of exhaust gas recirculation, combined with cylinder disablement was one of the features shown in the Toyota FX-1 concept vehicle in 1984. A twin-turbocharged 24-valve six cylinder engine was equipped with the Company's Modulated Displacement system (MDS), which redirected exhaust gases to the three inactive cylinders, under fuel cut-off cso. With this engine, Figure 15, fuel gains of more than $10 \%$ were obtained over the Japan 10 Mode emission test procedure. 
The principle of dividing a large capacity engine into two smaller capacity ones, both operating at higher, and hence more efficient, loads than normal was also adopted by porsche in their experimental $v-8$ engine(17). The 4.6 litre engine was split into two $V-4$, engines with separate inlet and exhaust systems, with cylinders $1-4-6-7$ operating all the time, Figure 16.

This arrangement offers the advantage of each crank pin carrying one working and one non working cylinder, under CSo. This, while it provides for even firing intervals it also ensures even heat distribution along the engine under disablement mode. The fuel injection system is Bosch L-Jetronic utilizing twin airflow meters, one for each separate inlet manifold, with its own throttle. The synchronization of the twin throttles was accomplished by a camplate system, similar to that used by Ford in the $3 \times 6$ Engine. For engine 1 to operate efficiently at low engine speeds and engine 2 at the higher speed range of the engine, the two intake manifolds were designed accordingly, with longer inlet tracts for engine 1 resulting in more torque at low rpm. By differentiating valve lift curves, valve sizes and exhaust pipe configuration for each engine, this resulted in an engine that operates at virtually peak efficiency throughout its speed range.

In order for a CSo system to be viable, it has to offer, in addition to worthwhile fuel economy gains, acceptable emission levels for compliance with legislation in the market it is aimed for. In principle, the reduced exhaust gas volume from the engine under disablement, assuming constant exhaust quality, should relate to a corresponding decrease in pollutants. In practise however, increased levels of certain pollutants, such as NOx due to higher load operation and HC during reactivation of cut-off cylinders, have to be dealt with using additional measures. In the Porsche application these measures take the form of separate fuelling and ignition for each engine, and using the air throughput from the deactivated part of the engine to aid oxidisation of $C O$ and the burning of residual HC in the exhaust, similar to an airpump system. For catalyst application the Company devised a twin-catalyst system, shown in Figure 16 , each catalyst being fed with the exhaust from one engine. With this arrangement, during four-cylinder operation the exhaust gas from engine 1 is purified twice, with catalyst $A$ in conjunction with the oxygen sensor acting as a 'three-way catalyst'. The system is adjusted so that catalyst A converts mainly Nox emissions, the remaining $H C$ and CO emissions, together with air from engine 2 being post-oxidized in catalyst 2 . At the same time, the hot gas from engine 1 preheats oxygen sensor $B$ and catalyst $B$, prior to activation of sensor $B$ on switching over from four to eight cylinder operation. In this way, a porsche 928 vehicle fitted with such a system was able to comply with the 1980 Federal Emission Legislation, while returning a $23 \%$ fuel economy gain during the CVS City Cycle, with a $15 \%$ improvement in the Highway Test. 
Finally, cylinder disablement has also been applied to the famous Jaguar V-12 engine, first by the company and currently by an independent engineering concern(18). Taking advantage of the firing order of the V-12 -see Figure 1 , one bank of cylinders is shut-off by deactivating those injectors. At the same time, the add-on control unit opens the throttle of that bank to minimise pumping losses and oil pull-over. Other refinements of this system include the widening of the initial injector pulses on reactivation of the disabled bank of cylinders, in order to give the cooler cylinders a rich mixture start, returning to normal injection timing soon after. The vacuum signal to the automatic gearbox is also regulated under CSo, to provoke early upchange points which would otherwise be occuring on light throttle with 12-cylinder operation.

One disadvantage with this system is the absence of automatic cSo control, the 6 or 12-cylinder running being selected by the driver via a foot switch. However, significant reductions in fuel consumption are reported with constant 6-cylinder operation, as shown in Figure 17.

From the work covered so far, it is clear that considerable gains in fuel economy are offered by the application of cso on production $S$. I. engines. The concept of cylinder disablement can be implemented to its full extent by redesigning existing powerplants to operate constantly under higher, and hence more efficient loads. In addition, emission levels can be reduced by refining cSo control, and designing exhaust catalyst systems to take advantage of the increased throughput of air from the deactivated cylinders. Although systems of varying complexity have been devised to minimise the pumping losses of an engine with disabled cylinders, the application of even simple fuel cut-off, where one injector per cylinder is provided, can reduce the fuel consumption at part-load quite effectively.

The research programme covered in this Thesis was initiated by the author while undergoing Industrial Training at JAGUAR CARS Lta., in the final year of the Automotive Engineering and Design course at L.U.T. During that period it was suggested to the Company that the final year project for the course could take the form of an investigation into cylinder disablement of the Company's 6 cylinder fuel injected engine, as a variation on earlier work on the $v-12$ engine, as mentioned above. As a result, on completion of the four-year course, it was also decided to continue the research on a part-time basis.

Consequently, and further to previous work covered in the Final Year Project Report by the author( academic year 1980-1981), the following objectives were set for the continuation of the work: 
At the beginning of the research work, the following objectives were set:

(i) To establish a microprocessor-based system to enable selective cylinder disablement, via fuel shut-off, on an electronically fuel injected six cylinder $S$. I. engine.

(ii) To carry out tests, using the system, to establish the gains in fuel economy attainable with cSo.

(iii) To investigate the possibility of sequential cyl. disablement as a means of reducing vibration amplitude of the power unit on its mounts.

The investigation was carried out at the Transport Technology Department of Loughborough University of Technology, on an engine supplied by the Emission Control Development Department of JAGUAR CARS Ltd., Browns Lane Plant, Coventry. The research has taken the form of part-time attendance at L.U.T. with some of the work carried out at JAGUAR CARS Ltd., over the period January 1982 to December 1984.

The results of testing during that period, together with conclusions drawn and recommendations concerning further investigation are included in this Thesis. In addition, a paper was written on the subject, titled "The Application of a Microprocessor to Engine Cylinder Disablement" by Dr. G. G. Lucas, J. Hughes and A. Manias for the XX FISITA Congress in Vienna (6-11 May 1984), presented by Mr. Hughes and included in Appendix II. 


\section{EQUIPMENT AND TEST PROCEDURES}




\section{ENGINE}

The engine used for this investigation is the Jaguar 6-cylinder XK6 unit, similar to that introduced in the XK120 Model in 1948 . Through the years the basic design has remained largely unchanged, the engine used being of the following specification:

$\begin{array}{ll}\text { Number of cylinders } & 6 \text { in-line } \\ \text { Bore } & 92.07 \mathrm{~mm} \\ \text { Stroke } & 106 \mathrm{~mm} \\ \text { Cubic capacity } & 4235 \mathrm{cc} \\ \text { Compression ratio } & 7.8: 1 \\ \text { Ignition timing } & 14 \text { deg. btdc. at idle } \\ \text { Firing order } & 1,5,3,6,2,4 \text { No.1 at rear }\end{array}$

The engine is of cast iron block construction, with al uminium alloy cylinder head and twin chain-driven overhead camshafts, acting directly on the inlet and exhaust valves. The test engine was fitted with a five-speed manual gearbox, with direct fourth and overdrive top gear ratios. Fuelling was by Bosch L-Jetronic electronic fuel injection, of the moving-flap air meter type, with conventional electronic ignition and throttle edge vacuum advance by Lucas distributor.

The fuel injection system is described in detail in Appendix III.

\section{DYNAMOMETER INSTALLATION}

The engine and gearbox were installed on a test bed equipped with an eddy current dynamometer of the following specification:

Dynamometer

Maximum Volts

Maximum Amps

Maximum bhp
'Heenan-Dynamatic' MkII

$90 \mathrm{~V}$ dc.

$8 \mathrm{~A}$

300 at $6000 \mathrm{rpm}$.

A 'total loss' water cooling system was provided, and a Plint fuel measuring rig used to monitor fuel consumption, as shown in Figure 18. The re-routing of the fuel line from the injection pump to the fuel rail through the cooling water of the test bed was a necessary modification to cure fuel vapour-lock problems encountered during extensive engine testing, caused by high fuel temperatures. 
Figure 19 shows the layout of the engine installation on the test bed, including the cylinder disablement control system and equipment for measuring and analysing engine vibration and cylinder pressures, as described below.

\section{CYLINDER DISABLEMENT SYSTEM}

The means of deactivating the injectors of individual cylinders took the form of opti-coupled silicon-controlled rectifiers (SCR), connected in series with the injectors. These act as electronic switches between each of the six injectors and the ECU. Figure 20 shows the circuitry involved, with side $A$ being the control side, and side $B$ connected in series with the injector power supply. These switches are convenient to use as they react very quickly allowing rapid switching of the injectors.

Optically Isolated S.C.R :

$\begin{array}{ll}\text { Diode (side A) } & \text { S.C.R (side B) } \\ \text { Max. Current } 60 \mathrm{~mA} & 300 \mathrm{~mA} \text { (rms) } \\ \text { Max. Voltage } 6 \mathrm{~V} & 400 \mathrm{~V} \\ \text { Isolation Voltage } 1500 \mathrm{~V} & \end{array}$

The operation of the SCR is based on the fact that the only time side $B$ allows current through it-thus activating the injector on signal from the ECU- is when there is a current flowing through side A. Once activated, side $B$ remains conductive as long as there is a current flowing through it. It follows therefore, that by providing a controlled signal to side $A$, and by having one SCR per injector, cylinder disablement could be effected.

Initially, during the Final Year project period of this work the control of the SCRs was achieved by a Hewlett Packard $2114 \mathrm{~B}$ general purpose minicomputer, permitting interfacing with realtime devices. This system is shown in Figure 21, and proved adequate for initial work on CSo. For this investigation however, it was deemed necessary to utilise the flexibility, cost and space advantages offered by a modern microprocessor based controlled. system for the disablement of cylinders, also being nearer to the concept of a production unit capable of installation in a vehicle.

The basis of the cSo system became therefore a microprocessor development system, forming part of the OPEN UNIVERSITY "Microprocessor Course for Engineers", a self-teaching course 
undertaken in the early part of this research, first to gain knowledge in the field of microprocessor systems and programming in Assembly Language, and second to enable the use of the development board supplied in implementing cSo.

The development board, termed "HEKTOR", is based on the Toshiba TMP8085A new generation 8-bit parallel central processing unit, the product specification of which is detailed in Appendix IV. For programming there is $4 \mathrm{~K}$ RAM available on the standard board, extended by $0.25 \mathrm{~K}$ of RAM with a specially designed and built interface board based on the : Am8156 RAM and Input/output chips (see Appendix IV), enabling HEKTOR to communicate with the SCRs, and hence with the injectors on the engine. A monitor, tape recorder and a printer completed the main cso control system, as shown in Figure 22 .

The interface chip provides three I/O ports $A, B$ and $C$, of which port $A$ is used for controlling the six SCRs. This control is achieved by the six least-significant bits of an 8-bit binary word output to the SCR. Using parallel connections between I/O port and SCR, word bit 0 represents 'injector-off', and bit $I$ 'injector-on', for example:

$\begin{array}{lll}\text { Hex } & \text { Binary } & \text { Effect } \\ 3 \mathrm{~F} & 00111111= & \text { All } 6 \text { cylinders active } \\ 38 & 00111000= & \text { First } 3 \text { cylinders } 1,2,3 \text { disabled }\end{array}$

In this way, consecutive words stored in the computer memory represent cyclic disablement sequences, each sequence output to the SCRs occuring on arrival of an interrupt signal from the engine. This signal is provided by a slotted disk and an opto-switch mounted on the crankshaft damper (see Figure 19), incurring an intercupt once every revolution of the engine crankshaft, with other interrupts provided manually via the keyboard.

Since the Bosch fuel injection allows for one fuel injection per revolution of the engine, with all six injectors firing simultaneously and therefore delivering half the required amount of fuel (see Appendix III), it follows that for the disablement of an injector over the complete thermodynamic cycle of the engine- two revolutions of the crankshaft, a particular cso sequence must be output twice consecutively. This was a result of obtaining an interrupt signal from the crankshaft, a more convenient place with this engine than the distributor or camshaft drives, either of which would give one interrupt signal per thermodynamic cycle. This was accepted for simplicity of the equipment, and is easily catered for by extra sequences in the memory. 
The software for the CSo system was written in 8085 Assembler Language, and it was designed to allow the operator to input disablement sequences in direct binary form as described above, with the last six bits entered representing cylinders 'on' and 'off'. This input is converted to hexadecimal form and stored in memory for later retrieval and output to the SCRs, on command from the system. The process can also be reversed, with the program converting hex. to binary form, and displaying it as such on the monitor for inspection/alteration of the sequences. Although provision was made for an input from the throttle, representing load demand via throttle angle and utilising the $A / D$ converter, limitations in HEKTOR's RAM capacity did not allow this to be implemented. Instead, the selection of cSo sequences was accomplished from the keyboard, by reading the voltage output from a throttle pot indicating throttle position. The cylinder disablement program and flowchart are shown in Figures 23 and 24 respectively, with a detailed description of the software given in Appendix $V$.

\section{CYLINDER PRESSURE MEASUREMENT}

In order to obtain information on the changes in cylinder pressures under different engine operating conditions, a KISTLER quartz type miniature pressure transducer was mounted on the cylinder head, communicating with the combustion chamber of cylinder No. 1 at the rear of the engine.

\section{KISTLER Pressure Transducer}

Measuring range

Maximum pressure

Sensitivity

operating temperature range
0 to 250 bar

350 bar

$14 \mathrm{pc} / \mathrm{bar}$

-80 to $350 \mathrm{deg} \cdot \mathrm{C}$

(A complete specification and calibration is given in Appendix VI).

The signal from the pressure transducer was put through a KISTLER TYpe 5007 charge amplifier, and then passed through a $A / D$ converter and stored in a LSI 11/23 microcomputer, for subsequent transfer to a PDP $11 / 34$ minicomputer for analysis, as shown in Figure 19. This data logging system was set up by a research assistant also working on the project, Mr. J. Hughes, primarily for obtaining data on cylinder pressure waveforms in conjunction with an engine vibration simulation program written to predict engine vibration output, under cso operation (see FISITA Paper in Appendix II). 
The pressure inside the cylinder provided an excellent means of determining the effectiveness of injector deactivation as a way of disabling a cylinder, when observed against time and engine revolutions, and this was achieved by analysing the time-domain pressure characteristics, in a way similar to the vibration analysis method described below.

\section{ENGINE VIBRATION MEASUREMENT}

A means of comparing the effects of different disablement sequences on the engine vibration was required, and to this end a D.J.BIRCHALL konic general purpose accelerometer was used, mounted on the side of the cylinder head near the front of the engine and forward of the engine mounts, in a plane giving near maximum vibration amplitudes in yaw and roll, the most important factors in engine vibration isolation.

D.J.BIRCHALL A/20/T Accelerometer

$\begin{array}{ll}\text { Charge mode } & \text { Konic } \\ \text { Charge sensitivity } & 28 \mathrm{pc} / \mathrm{g} \\ \text { Temperature range } & -55 \text { to } 300 \mathrm{deg} \text {. C } \\ \text { Max. continuous sine acce?. } & 1000 \mathrm{~g}\end{array}$

(The specification and calibration sheets are given in Appendix VII).

The accelerometer signal was amplified with a UNHOLTZ-DICKIE D22 Series Special Vibration Analysis charge amplifier, and then recorded with a SANGAMO 3500 tape recorder on 1 ins. magnetic tape. A calibration signal from a BRÜEL.KJ AR Type 4921 Accelerometer Calibrator was always recorded at the beginning of each session, the complete recording then passed through anti-alising filters and $a$ A/D converter for input to the PDP $11 / 34$ minicomputer.

Once in the computer, the vibration data were analysed using an available Frequency Analysis software package called 'DATS'. This package, in addition to offering sophisticated graphics facilities for displaying and plotting the data, it included a 'Auto Spectral Density' module (ASD) which was used for representing the vibration data in terms of amplitude with frequency. Figure 25 outlines the general procedure followed in logging and analysing vibration data. A number of problems were encountered in this area, mainly concerning charge amp drift characteristics causing a distortion of the mean amplitude value which should of course be zero. This necessitated correction of the mean value of the datafiles before display of the 'raw' vibration signal and subsequent $A S D$ analysis. 


\section{TESTING PROCEDURES}

\section{Engine Performance}

The nominal performance figures for the Jaguar XK4.2 Litre engine are given as:

$$
\begin{aligned}
& \text { Maximum Power } \\
& \text { Maximum Torque }
\end{aligned}
$$

$$
\begin{aligned}
& 153 \mathrm{~kW}(205 \mathrm{bhp}) \text { at } 5000 \mathrm{rpm} \\
& 321 \mathrm{Nm}(237 \mathrm{lbft}) \text { at } 3750 \mathrm{rpm}
\end{aligned}
$$

Since cylinder disablement benefits lie within the idle to maximum torque speed range, the engine was tested at idle, 750 $\mathrm{rpm}$, and between $1000 \mathrm{rpm}$ and $4000 \mathrm{rpm}$. Standard engine testing procedures were followed, measuring the following parameters at constant engine speeds:

$\begin{array}{lll}\text {-Dynamometer Load } & w & \text { in lbs. } \\ \text {-Inlet Manifold pressure } & \tau & \text { in mmig. } \\ \text {-Time taken for a given ammount } & \\ \text { of fuel to be consumed } & t \quad \text { in sec. }\end{array}$

The above procedure was repeated at $250 \mathrm{rpm}$ increments and values for power, torque, brake mean effective pressure, and brake specific fuel consumption were calculated using the formulae detailed in Appendix I. The results were plotted to produce complete engine performance maps, both under normal 6-cylinder and CSo modes. A program was written to assist with the calculations, Figure 26, and the data for the engine performance maps were generated with a mainframe program developed at Jaguar Cars for the interpolation and cross-ploting of such data.

The road load curves superimposed on the maps represent the vehicle power requirements at steady speeds, and were obtained from the Road Load Data shown in Figure 27, for the Jaguar model fitted with this engine. From this information the load curves shown in Figure 28 were compiled, and include the corresponding dynamometer loads in both direct fourth and overdrive fifth gear ratios, only the former being used in the engine tests.

The engine performance was checked periodically on the test bed, and any necessary adjustments, including routine servicing, were carried out following Jaguar-specified procedures. 
Cylinder Pressure and Vibration

Channels 1 and 2 on the SANGAMO 3500 recorder were used to record the accelerometer and pressure transducer outputs respectively, with voice channel A used for notation purposes. The signals were monitored at all times using a 4-channel storage oscilloscope, the recording procedure being as follows:

(i) Warm up equipment before data acquisition

(ii) Transducer sensitivities set on the charge amplifiers according to calibration curves-this was checked with the accelerometer using a calibrator.

(iii) All connections Freon gas-sprayed, to minimise drift.

(iv) Charge amp. time constant set to 'Long', giving minimum drift, and amp. set to 'Reset' mode when not sampling.

(v) With the tape recording the charge amps. were set in 'Operate' mode for data sampling, and the recording played back and checked for attenuation errors, with any necessary adjustments to recorder gain and zero controls made.

(vi) A calibration signal consisting of a pure sine wave of $100 \mathrm{~Hz}$ and $+/-1 \mathrm{~V}$ peak amplitude was recorded at the beginning of each recording, and used as a baseline for any corrections necessary when later analysing the signals on the computer.

(vii) Finally, the transducer signals were recorded and notes. made of all equipment settings.

Pressure and vibration data were thus obtained under the following conditions:

a) Engine vibration at constant $45 \mathrm{kph}$ and $80 \mathrm{kph}$, giving engine speeds of $1220 \mathrm{rpm}$ and $2180 \mathrm{rpm}$ in direct fourth gear and overdrive respectively, and at road load conditions with the engine operating on:

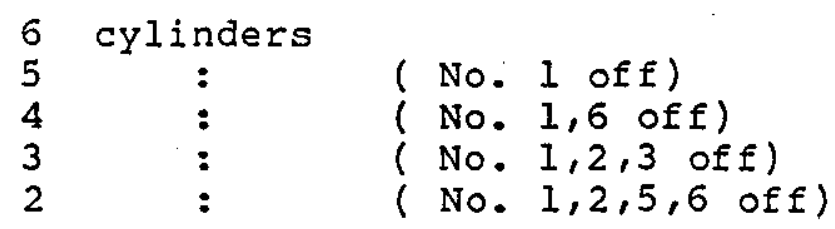

The results provided a means of comparing vibration amplitude levels of the major harmonics at two representative vehicle cruising speeds, and the engine under all cSo modes. 
b) Cylinder pressures were obtained at various engine speeds and loads, within the operating range of cso between idle and $4000 \mathrm{rpm}$, light to medium 6-cylinder loads, in order to study the following:

(i) Cyclic variation in peak cylinder pressures

(ii) Behaviour of a cylinder when its injector is deactivated and then reinstated.

\section{Vehicle Testing}

A Jaguar vehicle with an engine specification similar to the engine on the test bed was tested at the Emission control Department of JAGUAR CARS Ltd., Coventry. The vehicle was fitted with a means of disabling the injectors on the engine, enabling operation on any combination of cylinders.

The test procedure followed was the standard European 04-Cycle Test, consisting of four identical consecutive driving cycles, as shown in Figure 29, with exhaust emission levels and fuel consumption recorded. The Test has two phases, one comprising of the combined results of the first and second cycles, and the other of the last two cycles, giving Bag 1 and Bag 2 emission and fuel consumption results. Normally the vehicle would be tested from a 'cold-start' condition, having been heat-soaked overnight at a controlled ambient of $25 \mathrm{deg}$. C. In this case however, it was required to compare results with the engine operating under first, all six cylinders, and then with cylinder cut-off in operation.

The test vehicle therefore was first fully warmed up on the rolling road, and then put through the Euro Test, running on all six cylinders for the first Bag, and on 3-cylinders $(1,2,3)$ at idle and cruises, and 4-cylinders $(1,2,5,6)$ for the accelerations in the driving Cycles, in the second Bag. The idle speed of the engine on 3-cylinders was maintained the same as for the 6-cyl. mode, at 750 rpm.., by bypassing the extra-air valvel see Appendix III) with a controlled air bleed.

While the vehicle was fitted with cSo the opportunity was taken to assess the driveability under both steady-state and transient (acceleration) conditions on the road. The results and conclusions of these tests are included in the following Sections of the Thesis. 
4. TEST RESULTS AND DISCUSSION 


\section{ENGINE PERFORMANCE RESULTS}

The engine was tested following the procedures outlined earlier, and baseline 6-cylinder results obtained, followed by results with cylinder disablement applied by statically deactivating a number of cylinders from one to four, their positions determined according to the firing order of the engine so as to give as evenly spaced firing intervals as possible.

Figures 30 to 34 show the fuel consumption loops obtained, and by combining them with the full load torque curves the engine performance maps shown in Figures 35 to 39 were constructed, for the engine running on $6,5,4,3$ and 2 cylinders respectively.

The fuel economy advantages of cSo lie in the low-to-medium load areas of the operating range of the engine for the reasons discussed earlier, and this fact is clearly shown by comparing brake specific fuel consumption values in those areas with the engine operating under different modes of CSo. Further testing at these high b.s.f.c. gradients, under constant speed vehicle road load conditions (see Figure 27), yielded the following results :

\begin{tabular}{l|rrrrrrr}
\hline $\begin{array}{c}\text { ENGINE OPERATING } \\
\text { MODE }\end{array}$ & 50 & 60 & 70 & 80 & 90 & 100 & 110 \\
\hline & & & & & \\
6-cyl. b.s.f.c. & 870 & 760 & 650 & 555 & 515 & 500 & 455 \\
5-cyl. " & 790 & 670 & 550 & 450 & 430 & 420 & 410 \\
4-cyl. " & 495 & 470 & 460 & 460 & 430 & 405 & 395 \\
3-cyl. " & 640 & 525 & 480 & 465 & 465 & 450 & 390 \\
2-cyl. " & 655 & 560 & 485 & 450 & 445 & 500 & -
\end{tabular}

Note: b.s.f.c. values shown in $\mathrm{g} / \mathrm{kW} \mathrm{hr}$.

From the figures above the fuel economy gains shown in Figure 40 are deduced, and the following points are apparent:

(i) Higher fuel consumption gains are available with CSo at low speeds and loads.

(ii) As more cylinders are disabled the economy gains tend to decrease, with the exception of 5-cylinder operation. 
(iii) With 5, 4 and 3-cylinder operation the decrease in economy gain is haulted at 85 to $100 \mathrm{~km} / \mathrm{hr}$, and in the case of 3-cylinders it is reversed above those vehicle speeds.

The first and second points follow from the basic principle of cylinder disablement in that the effect of dethrotting the engine, and hence increasing its efficiency, is greater at low speeds and loads where normally the 6-cylinder engine runs on very small throttle openings. At higher speeds and loads, corresponding to wider throttle angles, the gains in efficiency available by dethrottling the engine with CSo are reduced to a point where the remaining active cylinders approach maximum power conditions. The extra fuel enrichment required at these conditions diminishes any fuel consumption benefits offered by cylinder deactivation.

As more cylinders are disabled the power required to overcome frictional losses in the engine tends to remain the same $(1,10)$. As a result, the dethrottling effect of disabling too few cylinders, giving small increases in throttle angle, may be partly offset by the proportional increase of the power required as a percentage of that delivered by the remaining cylinders, to overcome those frictional losses. The power lost from the disabled cylinders would tend to amplify that effect, until enough cylinders were deactivated, the subsequent greater dethrottling effect overcoming the effect of relative increased frictional losses. This could explain the reason for the relatively low economy increases returned with only 1 cylinder disabled at low speeds, as shown by the 5-cylinder curve in Figure 40 .

The reason for the variation in economy gains at higher speeds, mentioned in the final point, can be traced to the operational principles of the fuel injection system, detailed in Appendix III.:

The air drawn in by the engine operating on all 6 cylinders passes through the air meter enabling the control unit of the injection system to calculate the optimum fuel requirements of the engine. When the injectors of some cylinders are deactivated the remaining active cylinders operate at a higher load, corresponding to a higher throughput of air through the air meter. Some of this air is drawn in by the inactive cylinders but the control unit calculates and delivers injector pulses as if all the cylinders are operating at the same load. However, if we assume that both active and disabled cylinders draw in the same volume of air per stroke, the calculated fuel requirement for each cylinder will be the same as the actual requirement since the injector pulse width is determined by the quantity of air drawn in per engine stroke. The active cylinders therefore will receive the correct ammount of fuel, while the ECU pulses to the injectors of the disabled cylinders will have no effect. 
A similar argument applies to the ignition advance delivered by the distributor under CSo, with the disabled cylinders receiving the correct advance for the speed and inlet manifold vacuum they are operating at.

Having made the reasonable assumption of equal air flows through both active and disabled cylinders, it is clear that this is only an approximation since factors such as effective inlet manifold volume and exhaust pipe configuration will change the resonant qualities of the engine, as all cylinders share a common inlet manifold and exhaust system. As a result it is believed that at certain engine speeds, the application of cso causes a slightly wrong air/fuel mixture to be calculated by the ECU. If the main reason is due to inlet and exhaust system resonance characteristics as stated, then the discrepancies will be more apparent near maximum torque engine speeds, as indeed is the case in Figure 40 .

Tests were carried out with the engine at idle to determine economies attainable with cso at this condition. The results, shown in Figure 41 , showed gains ranging from $14 \%$ to over $100 \%$ in idling with 5 cylinders and 1 cylinder respectively. The high levels of engine vibration experienced with only 1 cylinder active however, make the latter gain unattainable in practice, the engine idling with the least vibration amplitudes in the 3-cylinder mode, with either cylinders $1,2,3$ or $4,5,6$ active.

The engine was also tested with cyclic cylinder disablement, the number of disabled cylinders remaining the same, but their positions being varied every few cycles of the engine. It was found that as the cycling frequency approached half the engine speed frequency, that is the thermodynamic cycle frequency of the engine, power output began to fall-off slightly and specific fuel consumption increased. This was found to be the result of some cylinders receiving half the required fuel and consequently. misfiring. The reason for this lies in the way the injectors are triggered (Appendix III). With the Bosch L-Jetronic injection, half the required fuel is delivered every revolution of the engine by all the injectors. With rapid cso cycling therefore, some cylinders received half the required ammount of fuel on either deactivation or reactivation, the result of the fuel injection timing and cyclic cSo not being synchronized on a cycle-to-cycle basis. If however, the cycling of cut-off cylinders was done after a few cycles were completed, it was found that the effect of this mis-timing was not apparent.

The position of the disabled cylinders was found to play a significant part in the Hydrocarbon emissions of the whole engine. For example, with the engine running on four cylinders, it was found that, out of the three possible cSo. sequences based on the firing order, that is No.'s 1,6 or 2,5 or 3,4 cylinders 
deactivated, the lowest overall HC levels were obtained with cylinders 3 and 4 disabled. This is thought to be due to the tendency of a disabled cylinder to draw-in fuel vapour present in the inlet manifold, this effect being more pronounced if the deactivated cylinders are surrounded by active cylinders than if they are next to each other. The small ammount of fuel thus entering the inactive cylinder is not enough to form a combustible mixture, and it results in unburned Hydrocarbons in the exhaust gases.

\section{CYLINDER DISABLEMENT AND REACTIVATION}

The pressures inside cylinder No. 1 were measured and recorded, as described in the previous section, in order to study the behaviour of a cylinder when its injector is deactivated while the engine is running. In particular, it was desirable to investigate any delays that may occur in reactivating the cylinder following both short and prolonged periods of disablement, with the view of adjusting rapid cyclic disablement sequences accordingly, in addition to the effects of injection and cSo asynchronicity discussed above.

Figure 42 shows a typical cylinder pressure diagram obtained during low speed, light load conditions. The four phases of the thermodynamic cycle of the engine are clearly shown, with the induction stroke A, compression B, firing with flame front reaching the transducer at $C$, and finally exhaust stroke $D$. The reason for pressure peak $C$ being lower than the compression pressure peak $B$ is that by the time the combustion pressure wave reaches the transducer, which was positioned some distance from the spark plug, the cylinder pressure has been reduced due to the downward travel of the piston on its power stroke. With better cylinder filling at higher loads the pressure peak due to the combustion is far higher than that of the compression pressure, as shown in Figure 43 .

With cSo operative, the cylinders of the engine would be deactivated under light to medium loads, in order to incur higher load operation of the remaining cylinders. Pressure diagrams were taken therefore under these conditions, at speeds ranging from low idle (just over $600 \mathrm{rpm}$ ) to $3500 \mathrm{rpm}$, covering the operating range of CSo. The computer plots obtained are shown in Figures 44 to 50 for the deactivation of the cylinder, and Figures 51 to 57 for its reactivation under the same engine speeds and loads.

First, from the deactivation diagrams it was found that when the injector of the cylinder was deactivated, that cylinder was disabled on the following, and subsequent power strokes, with no delay apparent under all speeds and loads tested. Second, on reactivation the cylinder appeared to fire normally on the next power stroke, following induction with the injector re-enabled. 
Also, subsequent power strokes showed no greater cycle-to-cycle pressure variation than under normal operation. This would tend to indicate that cylinder disablement by injector deactivation could be implemented with rapid cycling of the disabled cylinders, provided the sequences are synchronized with the fuel injection timing, as discussed earlier.

Finally, it was found that when the cylinder was inactive for prolonged periods, and at various engine speeds and loads, its reactivation was always instant. Under vehicle operation however, particularly with an engine which has covered high mileage, it is expected that oil pull-over by the disabled cylinder could cause spark plug fouling over repeated long periods of inactivity(18), in addition to excessive cooling of the cylinder walls, and resulting in misfire on reactivation.

\section{ENGINE VIBRATION}

The accelerometer signal was analysed using the Auto spectral Density (ASD) Function available with "DATS" on the PDP 11/34 computer in the Department. The program uses ensemble averaging of Fourier Transforms of overlapping sections of the input data to compute the ASD of a real-time history (Appendix I). The ASD of a signal is the mean square value of the signal distributed as a function of frequency, the output being in Units $/ \mathrm{Hz}$. In this case, one Unit is equal to a $\mathrm{Ig}$ level of acceleration.

The highest frequency of the first harmonic of the vibration from a 6 cylinder engine with a top speed of $6000 \mathrm{rpm}$ is:

$$
\frac{6000}{60} \times \frac{1}{2} \times 6=300 \mathrm{~Hz} .
$$

The engine vibration frequency spectrum therefore was analysed in the 0 to $300 \mathrm{~Hz}$ range, with particular attention given to high amplitude-low frequency harmonics caused by cylinder deactivation, bearing in mind that the natural frequency of the Jaguar engine on its mounts is approximately $17 \mathrm{~Hz}$.

The results of the frequency analyses are shown in the form of ASD diagrams in Figures 58 to 61 , showing vibration levels at 1220 rpm-road load, and Figures 62 to 65 at $2180 \mathrm{rpm}-r o a d$ load, corresponding to actual vehicle speeds of $45 \mathrm{~km} / \mathrm{hr}$ and $80 \mathrm{~km} / \mathrm{hr}$ in direct 4 th gear respectively, and with the engine under different cso modes. 
The mean square acceleration values can be thought of as proportional to displacement at those frequencies if the engine is treated as a simple mass suspended on springs. In order to compare vibration severity with various numbers of cylinders active, the m.s. acceleration levels of the major harmonics are square-rooted, and compared, with the acceleration levels at those frequencies with normal 6-cylinder operation. When this is done, the following results are obtained:

\begin{tabular}{|c|c|c|c|c|c|c|}
\hline $\begin{array}{c}\text { Engine Operating } \\
\text { Mode }\end{array}$ & $\begin{array}{l}\text { Order } \\
\text { of } \\
\text { Harmonic }\end{array}$ & $\begin{array}{c}1220 \mathrm{rpm}, \\
\mathrm{g}\end{array}$ & $\begin{array}{c}45 \mathrm{~km} / \mathrm{hr} \\
\mathrm{Hz}\end{array}$ & 2180 & $\begin{array}{l}\text { rpm, } \\
g^{-}\end{array}$ & $\begin{array}{c}80 \mathrm{~km} / \mathrm{hr} \\
\mathrm{Hz}\end{array}$ \\
\hline $6-c y l i n d e r s$ & $\begin{array}{l}\text { lst } \\
2 \mathrm{nd}\end{array}$ & $\begin{array}{l}2.8 \\
1.4\end{array}$ & $\begin{array}{r}60 \\
120\end{array}$ & & $\begin{array}{l}3.0 \\
1.5\end{array}$ & $\begin{array}{l}108 \\
216\end{array}$ \\
\hline 5-cylinders & $\begin{array}{l}\text { Ist } \\
2 \mathrm{nd}\end{array}$ & $\begin{array}{l}4.0 \\
2.5\end{array}$ & $\begin{array}{l}10 \\
20\end{array}$ & & $\begin{array}{l}2.7 \\
1.0\end{array}$ & $\begin{array}{l}18 \\
36\end{array}$ \\
\hline 4-cylinders & $\begin{array}{l}\text { Ist } \\
\text { 2nd }\end{array}$ & $\begin{array}{l}9.4 \\
2.8\end{array}$ & $\begin{array}{l}20 \\
40\end{array}$ & & $\begin{array}{l}2.1 \\
1.0\end{array}$ & $\begin{array}{l}36 \\
72\end{array}$ \\
\hline 3-cylinders & $\begin{array}{l}\text { Ist } \\
2 \mathrm{nd}\end{array}$ & $\begin{array}{l}8.8 \\
2.2\end{array}$ & $\begin{array}{l}30 \\
60\end{array}$ & & $\begin{array}{l}3.2 \\
2.0\end{array}$ & $\begin{array}{r}54 \\
108\end{array}$ \\
\hline 2-cylinders & $\begin{array}{l}\text { lst } \\
2 \mathrm{nd}\end{array}$ & $\begin{array}{r}10.0 \\
5.3\end{array}$ & $\begin{array}{l}20 \\
40\end{array}$ & & $\begin{array}{l}5.2 \\
1.7\end{array}$ & $\begin{array}{l}36 \\
72\end{array}$ \\
\hline
\end{tabular}

From the acceleration levels shown it is clear that high amplitude harmonics are introduced at low frequencies even in the higher engine speed, when one cylinder is disabled. In this particular case, with the lst major harmonic at $18 \mathrm{~Hz}$ for 5 -cylinders running at $2180 \mathrm{rpm}$, the frequency is very close to the natural frequency of the engine on its mounts, and this was apparent during testing to obtain vibration signals at that speed, with the engine amplitude increasing as the resonant speed was reached. In contrast, the engine mounts performed well at higher frequencies even when the acceleration levels were high, as is the case with 3-cylinder operation at $1220 \mathrm{rpm}$.

As a result therefore, of observing engine vibration and relating those observations to the figures above, it can be stated that the engine could be operated under cSo with minimum penalties in excessive vibration if the major harmonic frequencies could be kept away from the natural frequency range of the mounting system, say 15 to $20 \mathrm{~Hz}$. 
A relationship was found therefore, to relate the number of deactivated cylinders at any speed to the major harmonic frequencies caused by cSo:

$$
\text { Engine speed frequency }=\frac{\mathrm{N}}{60} \mathrm{~Hz} \quad \mathrm{~N}=\mathrm{rpm} \text {. }
$$$$
\text { Engine cycle frequency }=\frac{\mathrm{N}}{60 \times 2}=\frac{\mathrm{N}}{120} \mathrm{~Hz}
$$

For a 6 cylinder 4-stroke engine,

$$
\text { Cylinder firing freq. }=\frac{\mathrm{N}}{60 \times 2} \times 6=\frac{\mathrm{N}}{20} \mathrm{~Hz}
$$

For $D=$ Number of deactivated cylinders,

$$
\text { lst major harmonic freq. } F=\frac{N \times D}{120} \mathrm{~Hz} \text { for } \mathrm{D}=1,2,3
$$

Now, in the case of 4 cylinders disabled, a lower frequency harmonic is introduced because of the 2 firing cylinders, such that:

$$
\begin{aligned}
\text { lst major harmonic freq. } F & =\frac{N \times D}{120} \times \frac{I}{2} \\
F & =\frac{N}{60} \text { Hz } \quad \text { for } D=4
\end{aligned}
$$

Here, the case where 5 cylinders are disabled is considered impractical and is therefore ignored.

Using the information above it is possible to calculate the engine speed ranges, for each disablement mode, where the major harmonics occur between 15 and $20 \mathrm{~Hz}$. This done with the position of the disabled cylinders arranged for even firing order intervals of the highest frequency, for example:

6-cylinder firing order

5-cylinders

4-cylinders $\begin{array}{llllll}1 & 5 & 3 & 6 & 2 & 4\end{array}$

( any cylinder disabled)

$$
\begin{array}{lllllll} 
& 1 & 5 & - & 6 & 2 & - \\
\text { or } & - & 5 & 3 & - & 2 & 4 \\
\text { or } & 1 & - & 3 & 6 & - & 4
\end{array}
$$


3-cylinders

2-cylinders

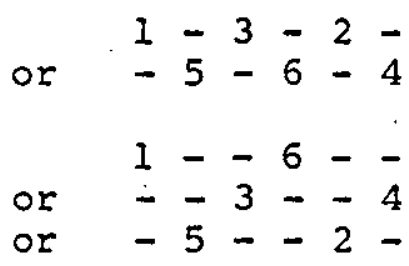

We have therefore,

5-cyl. active:

$D=1$

$$
\frac{\mathrm{N} \times 1}{120}=15 \mathrm{~Hz}
$$

Thus the lower engine speed limit is $\quad N_{L}=1800 \mathrm{rpm}$.

similarly,

$$
\frac{N \times 1}{120}=20 \mathrm{~Hz} \text { so } \mathrm{N}_{u}=2400 \mathrm{rpm} \text {. }
$$

4-cyl. active: $\quad D=2, \quad N_{L}=900 \mathrm{rpm}$.

$$
\text { and } \mathrm{N}_{U}=1200 \mathrm{rpm} \text {. }
$$

3-cyl. active: $\quad \mathrm{D}=3, \quad \mathrm{~N}_{L}=600 \mathrm{rpm}$.

$$
\text { and } \mathrm{N}_{\mathrm{v}}=800 \mathrm{rpm} \text {. }
$$

2-cyl. active: $\quad D=2$ (considering the lowest freq. harmonic) $\mathrm{N}_{\mathrm{L}}=900 \mathrm{rpm}$.

$$
\text { and } \mathrm{N}_{U}=1200 \mathrm{rpm} \text {. }
$$

Since the second order harmonics occur at twice the first order frequency, the lower engine speed values are reduced by half. Furthermore, assuming the lowest practical engine speed is 600 $\mathrm{rpm}$ ( low idle), and the maximum cso operating engine speed is $3500 \mathrm{rpm}$, the operating ranges of CSo at variaus modes become:

$$
\begin{aligned}
& 5 \text {-cylinders range : } 2400 \text { to } 3500 \text { rpm. } \\
& \text { 4-cylinders " : } 1200 \text { to } 3500 \mathrm{rpm} \text {. } \\
& \text { 3-cylinders " : } 800 \text { to } 3500 \mathrm{rpm} \text {. } \\
& 2 \text {-cylinders " : } 1200 \text { to } 3500 \mathrm{rpm} \text {. }
\end{aligned}
$$

It can be seen that the above results could be stored in the microprocessor memory of the cSo system, and the appropriate number of cylinders disabled at any given speed and load, for minimum excitation of the engine on its mounts. 
Figure 66 shows the Results sheet from the hot European 04-Cycle Emission Test carried out on the vehicle. Bag 1 and Bag 2 tests were completed under identical conditions except with Bag 2 CSo was operating, the vehicle running on 3 cylinders at idle and the light-load cruises part of the driving cycles, and 4 cylinders during accelerations, as described in the last Section.

of importance are the figures for the mass emissions levels per Bag tested, of Hydrocarbons, oxides of Nitrogen, and Carbon Monoxide constituents, and of course the overall fuel consumption figures per Bag.

The results show that fuel consumption with cso was decreased from $13.3 \mathrm{mpg}$ to $18.5 \mathrm{mpg}$, representing a gain in economy of 39\%. This was achieved with the simple method of manually disabling the injectors from inside the vehicle, and periodically rotating the disabled cylinders in order to maintain similar temperatures on all cylinders during the test.

The emission levels show the following trends, with cylinder disablement in operation:

$$
\begin{array}{lrl}
\text { Hydrocarbons } & \text { HC : Increased by } 24 \% \\
\text { Oxides of Nitrogen } & \text { NOx : Increased by } 43 \% \\
\text { Carbon Monoxide } & \text { CO : Decreased by } 38 \%
\end{array}
$$

Considering $C O$ first, its reduction with cSo is due to the oxidisation effect, in the exhaust, of the extra air pumped by the inactive cylinders, the effect being similar to an air injection pump system. Nox increases are mainly due to the higher combustion temperatures experienced in the active cylinders working at higher loads, with Nox formation being aided by the presence of extra oxygen in the exhaust.

The increases in the HC emissions can be atrributed to various factors, stemming mainly from the simplicity of the method of implementing cylinder disablement in this case. The main reason is believed to be the drawing-in of fuel vapour, present in the inlet manifold, by the inactive cylinders. The air/fuel mixture thus formed is too weak to burn, and the result is high levels of unburned Hydrocarbons in the exhaust gas.

Another likely reason for the increase in HC is the possibility of the fuel injection system being slightly affected by the disablement of cylinders, as discussed earlier in this section, resulting in mixtures varying either side of stoichiometric. This could be determined by looking at the fuelling of individual cylinders with CSo in operation, by way of sample 
probes in the exhaust ports of the cylinder, and analysing its exhaust gas composition. This has not been done here due to time and equipment considerations.

Also, the condition of the engine in the vehicle tested was not very representative, the vehicle having covered high mileage on testing, as indicated by the high emission levels of Bagl, under normal 6-cylinder operation.

Extensive research on CSo by other manufacturers however, has shown that it is possible to overcome the emission level increases due to CSo using current, well established emission control techniques(12, 15, 17).

Finally, the test vehicle was assessed for driveability with cylinder disablement in operation, both by the author and colleagues in the Engine and Powertrain Development Dept. of JAGUAR CARS Ltd. The results are purely subjective, based on the opinions of the drivers, some of whom carry out frequent driveability assessments on prototype and production vehicles as part of their function within the Company.

Following limited driving sessions, comparisons were made between driveability, throttle response and vibration levels felt from inside the vehicle first, on 6-cylinders, and then with cylinder disablement using the techniques described earlier. General conclusions reached included the following:

(i) Unexpectedly low, and almost fully acceptable levels of vibration were experienced in the car, with CSo in operation, the most noticeable difference being the change in exhaust note, particularly under load.

(ii) When cylinders were switched over, either to increase or decrease the number of active cylinders according to power requirements, the transitions were felt only slightly, similar to an automatic transmission gear change. If too many cylinders were switched over at high loads however, the change in engine power was more apparent.

(iii) Even with manual transmission, any harshness due to engine torque fluctuations under cso was well isolated by the engine mountings, at least at low vehicle speeds.

(iv) With complete injector disablement under deceleration conditions with closed throttle, giving fuel cut-off on standard L-Jetronic injection, it was found that smooth engine reinstatement could be achieved by reactivating cylinders gradually, as engine speed approached idle. The result was similar to 'soft' reinstatement, a case where some injection systems weaken the mixture prior to full fuel injection reinstatement, to prevent vehicle 'shunt'. 
5. CONCLUSIONS 
The engine performance results have shown that a spark ignition engine, fitted with electronic fuel injection, can be made to return high fuel economy gains with the application of cylinder disablement. These gains are at their highest at idle, and the low-to-medium speed and load operating ranges of the engine, and represent fuel consumption reductions of an order otherwise unattainable without major redesign of the engine and its control'systems.

From the results of this investigation into the application of cylinder disablement, the following conclusions can be drawn:

1. Fuel cut-off by the deactivation of the injectors on an engine with electronic fuel injection system, constitutes an effective means of dethrottling the engine at light loads.

2. The disablement, and subsequent reactivation of a cylinder by controlling its injector, appears to be instantaneous, under engine testing conditions; however, some delay could be experienced under actual driving conditions.

3. The L-Jetronic fuel injection system appears to compensate well for the deactivated cylinders in providing the correct fuelling to the active part of the engine, possibly requiring minor fuelling trim adjustments in order to keep the air/fuel mixture close to stoichiometric, at steady-state conditions.

4. The increase in specific load of the active cylinders, with the engine under cso, can reduce the specific fuel consumption of the engine, from over $50 \%$ at idle to 20 - $40 \%$ approximately at light load, constant speed operation.

5. Engine vibration caused by cSo, can be reduced by:

(i) Arranging the disabled cylinders according to their firing order, to give evenly spaced firing intervals, and

(ii) Controlling the total number of disabled cylinders at any given engine speed, according to the findings of Section 4 , to minimise excitation of the engine on its mounts.

6. Limited testing on a vehicle fitted with simple cylinder disablement showed the following:

(i) Fuel economy improvements of almost 408 are possible under city driving conditions. 
(ii) Increases in $\mathrm{HC}$ and NOx emissions experienced with CSo are of a relatively small order, and capable of being reduced to acceptable levels using existing emission control techniques, and better cSo control.

(iii) Vibration levels experienced while driving the vehicle with cSo in operation, were very tolerable, suggesting that the implementation of CSo with a more refined, microprocessor-based system could result in the reduction of vibration to levels acceptable in a luxury passenger vehicle.

The use of a microprocessor development system in cylinder disablement showed the advantages of such a system in this application, namely:

- Flexibility and adaptability of the microprocessor system, giving the designer considerable freedom in tailoring the system to suit the exact requirements of the engine under cSo.

- Hardware compatability with current and future engine management system, based on central processing units.

- Low unit cost and volume, making the system viable for mass production.

Considering cylinder disablement sequences, it has been shown that the number of active cylinders should be varied with engine speed for minimum vibration. In addition to this, the system could also provide rapid cyclic rotation of the disabled cylinders. However, that would introduce out of balance major harmonics at even lower frequencies, resulting in large amplitude vibrations as the natural frequency of the engine mounting system was approached.

As a result, it was concluded that rotation of the disabled cylinders, at all cSo modes, should occur periodically so as to maintain all cylinders warm, but without promoting further out of balance vibration. Thus, it is suggested that the rotating frequencies should be less than the minimum frequency that would cause vibration amplification, that is $15 \mathrm{~Hz}$. In practice, it was found that the disabled cylinders could be cycled with a period of a few seconds, without detriment to engine performance and therefore avoiding further excitation of the engine on its mounts. 
The HEKTOR microprocessor development system has the potential to form the basis for a sophisticated CSo system, provided its user memory is increased by at least a factor of 2 , giving $8 \mathrm{k}$ RAM in total, as opposed to the $4.25 \mathrm{k}$ RAM available at present. This increase in memory is necessary to accomodate the CSo program that would be required if all the features of cSo control suggested by the results of this research were to be incorporated into the system.

Figure 67 shows the next stage of the microprocessor system, suggested as a more complete cso system for the engine tested.

Here, additional inputs to the microprocessor consist of engine coolant temperature, inlet manifold pressure, and a stepper motor position and actuation on the throttle valve, intervening with the physical link between the accelerator pedal and the throttle. The following method of cylinder disablement control is therefore suggested, based on the work covered:

The number of cylinders active at any time should be dependent on:

(i) Engine Temperature

(ii) Engine speed

(iii) Engine Load

The above parameters to be measured, and their effects on cSo control to be in the following way:

(i) Engine Temperature : The desired effect of the engine temperature is to inhibit cSo when the engine is cold. To this end, a simple two-state temperature switch could be used in the engine coolant, providing a 'CSo-enable' signal to the microprocessor, once operating temperature is reached.

(ii) Engine speed : The current opto-switch arrangement on the engine could be be used by the microprocessor for the calculation of engine speed, based on the time intervals between interrupts.

(iii) Engine Load : The load requirements of the engine could be sensed by a pressure transducer in the inlet manifold, providing an analogue signal to the control system, which is proportional to manifold pressure and hence load.

Operation : With the CSo control system enabled by the signal 
from (i), the number of cylinders could then be decided by the microprocessor based on the information from signals (ii) and (iii). The optimum number of cylinders would then be disabled according to tables stored in the system's memory, and compiled for the optimum fuel economy and vibration characteristics as described in section 4 of this Thesis.

The wider throttle angles required when some cylinders are deactivated could be provided by the cSo system in a similar fashion, utilising a stepper motor connected to the throttle valve, and controlled by the microprocessor system. In this case, the accelerator pedal input to the throttle would be supplemented by the output of the stepper motor, effectively compensating for disabled cylinders automatically, without any driver input.

This throttle compensation system would require additional testing to determine optimum throttle positions for different cSo modes, and could also be used for increasing the engine speed when idling on say, three cylinders, by opening the throttle to a set position. Taking this concept further, this throttle compensation could be incorporated in a modern idle speed control system, as part of the engine management.

Finally, cylinder disablement control in this form could also be used with fuel injection systems utilising closed-loop feedback systems to maintain stoichiometric air/fuel ratio, Figure 68 . With these systems a sensor is used to detect exhaust gas oxygen content, the sensor's voltage output characteristics being such that a step change in voltage occurs with a small change in oxygen concentration corresponding to either side of stoichiometric conditions. This voltage change is sensed by the injection control system, and is used to maintain correct fuelling at all driving conditions, this being necessary with exhaust catalytic converter applications.

In order for the oxygen sensor to operate effectively, its position in the exhaust system must be such as to allow the sensor(s) to detect a representative proportion of the exhaust gas from each cylinder of the engine, while at the same time being kept at operating temperatures, around $600 \mathrm{deg}$. C.

When CSo is applied to an engine with an oxygen sensor feedback system therefore, the extra air in the exhaust due to disabled cylinders will give the wrong information to the sensor, suggesting a very lean mixture and therefore resulting in incorrect fuelling to the active cylinders. This problem can be avoided in several ways, one method involving seperate exhaust systems for the active and disabled parts of the engine(17). However, this method does not allow for rotating the disabled cylinders, as discussed earlier, and tends to be complex and expensive.

In the case of the Jaguar power unit used for this research, and 
in common with most in-line 6 cylinder engines employing feedback systems, the oxygen sensor is positioned in the 'Y' junction of the exhaust down-pipe, near the exhaust manifolds and prior to the first catalyst, as shown in Figure 69. It is suggested therefore that, for CSo application the sensor is replaced with 2 sensors mounted slightly upstream of the ' $Y$ ' junction, each sensing exhaust gas from the front and rear 3-cylinder groups respectively.

The disablement modes in this case would allow for operation of the front cylinder group, cylinders $1,2,3$, or the rear group $4,5,6$, with the fuel injection control system switching between the appropriate. oxygen sensors. Both sensors would be kept warm by periodic cycling of the cylinder groups.

This application of CSo is entirely in line with the findings of this research since the $3-c y l i n d e r$ cSo range extends, in terms of vibration qualities, from $800 \mathrm{rpm}$ to the maximum operating CSo speed of $3500 \mathrm{rpm}$. The fuel economy benefits possible with 3 or 6 cylinders are still considerable, with maximum gains of 328 possible (see section 4 ). The only disadvantage in this case would be the inability to switch individual cylinders gradually under power demand, and thus minimising torque fluctuations. One advantage gained by the use of CSo with catalyst systems is the air injection effect resulting from the pumping of the inactive cylinders, promoting oxidisation of exhaust pollutants.

With the world markets turning to lead-free fuels and catalysts for the passenger vehicles, in the interests of air pollution control, it is important that any fuel economy systems, researched for possible production applications in the future, take account of this trend. The cylinder disablement system suggested here could meet that requirement by the methods described above. 


\section{REFERENCES}

1. "The development potential of spark-ignition engines" Prof. Dr.-Ing. H: Forster Automotive Engineer Apri1/May 1980 pp 23-26

2. "Two in One engine"

J. Dunne

Popular Science January 1977

3. "Cummins KTA-3067 Engine"

J. H. Garrett

SAE 800668

4. "Suzuki variable cylinder engine aims at fuel economy" Automotive Engineering August 1981, Vol.89, No.8 pp 92-93

5. "A New Approach to Variable Displacement" L. Givens

Automotive Engineering May 1977 , Vol.85, No.5 pp 30-34

6. "Cadillac introduces $v-8-6-4$ engine"

Automotive Engineering October 1980, Vol.88, No.10 pp 52-53

7. "Mitsubishi Orion-MD-A New Variable Displacement Engine" T. Nakagami and T. Fukui

SAE 831007

8. "Variable Displacement by Engine Valve Control"

B. Bates, J. M. Dosdall and D. H. Smith

SAE 7801.45

9. "Cylinder Cut of of 4-Stroke Cycle Engines at Part-Load and Idle"

E. Watanabe and I. Fukutani

SAE 820156

10. "Fuel Economy Improvements for an Engine Concept with Cylinder Shutof $f$ "

$J$. Abthoff, H-D Schuster and G. Wollenhaupt

MTZ July/August 1980-in German (MIRA Translation 53/80)

11. "Cylinder cut-off for oHC $v-8$ "

Automotive Engineering January 1980 p 40

12. "The Ford $3 \times 6$ Engine Program"

Dr. D. Stojek and D. Bottomley

Proceedings International Symposium on Automotive

Technology \& Automation (ISATA), Cologne

19-23 September 1983 pp 111-126

13. "Dual-Mode engine alternates paired cylinders"

D. Scott

Automotive Engineering February 1982, Vol.90, No.2 pp 93-94 
14. "Power in pairs"

Autocar w/e 15 January 1983

15. "Cylinder Shut-off System in BMW Six-Cylinder Engines" M. Bartels

MTZ July/August 1981 pp 289-290

16. "Simplified dual-mode engine near production"

Automotive Engineering July 1981, Vol.99, No.7 pp 80-81

17. "Possibilities of Saving Fuel by Switching off Cylinders" $K$. Schellman and $W$. Schmid

Proceedings First International Fuel Economy Conference at Washington D.C October 31-November 11979 pp 220-225

18. "Economy Cat"

J. Miles

Autocar w/e 21 August 1982

19. "Fundamentals of Automotive Balance"

W. Thomson

Mechanical Engineering Publications 1978

20. "Balancing of Engines"

W. E. Dalby

Fourth Edition

21. "Vibration Engineering; A Practical Treatise on the Balancing of Engines, Mechanical Vibration and Vibration Isolation"

W. K. Wilson

Griffin 1959

22. "The Testing of Internal Combustion Engines"

A. B. Greene and G. G. Lucas

English University Press Ltd. 1969

23. "The High speed Internal Combustion Engine"

H. R. Ricardo

Fourth Edition 1953

24. "Microprocessor Fundamentals"

F. Halsall and P. F. Lister

Pitman Press 1980

25. "Comparing Alternative Methods of Improving Fuel Economy" S. Luchter

SAE 779001 
FIGURES 
V 12

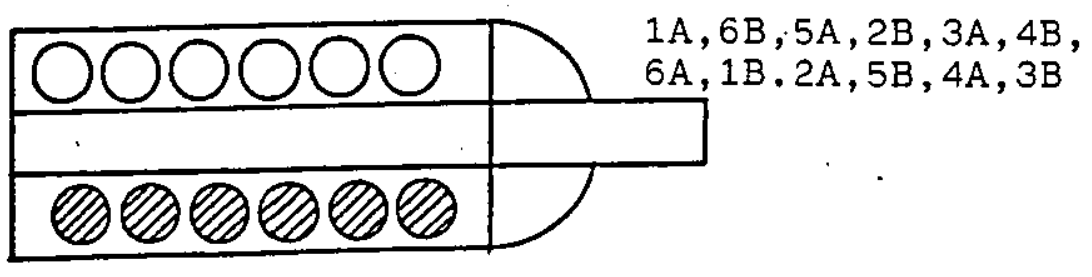

v8

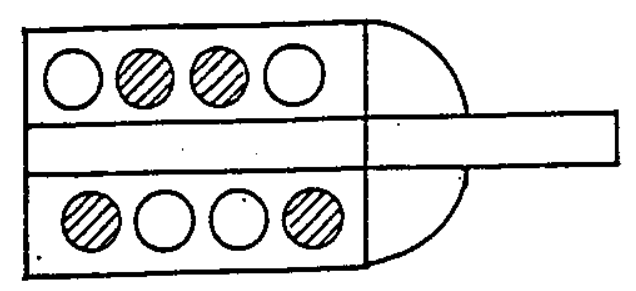

15486372

6

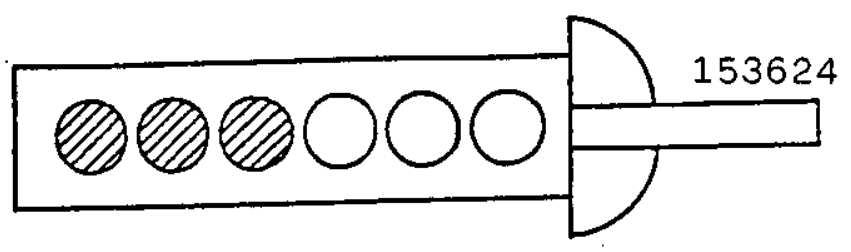

4

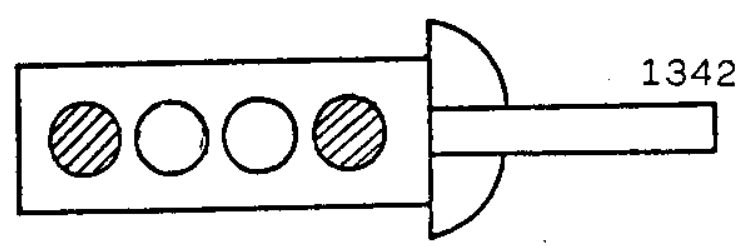

Fig 1 Disabled Cylinder Configurations on Various Engines Based on Firing Order. 


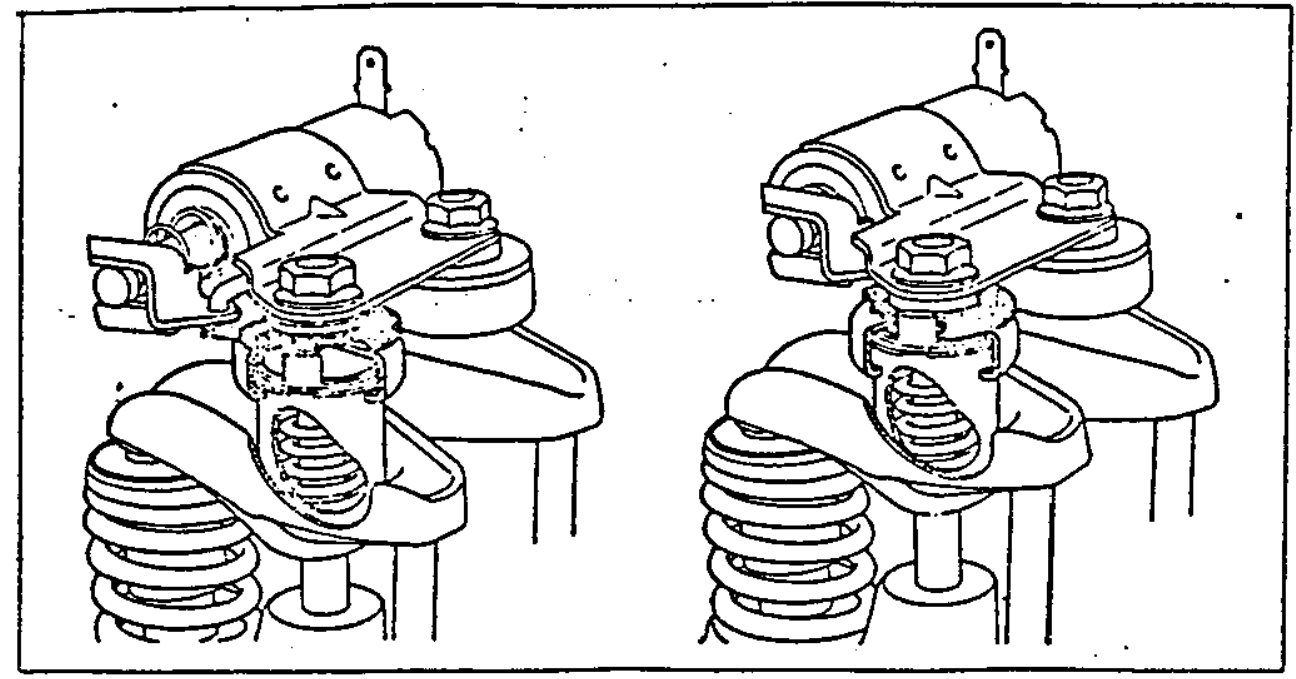

Valve Disablement

cII. $\triangle$ CIITS

CII. IUCIIT

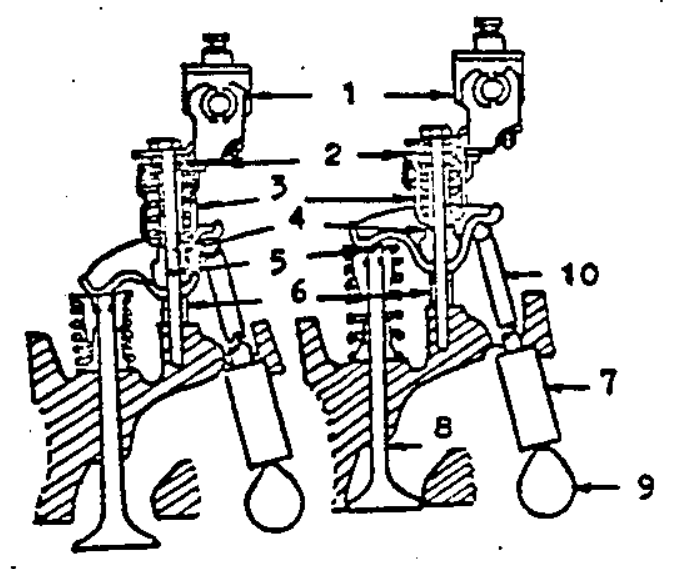

1 Solenold

2 Blocker Plate

3 Body

4 Pivot

5 Pulcrum

6 Pedestal

7 Valve wfter

8 Valre

$9 \mathrm{Cam}$

10 Pushrod

Mechanical (GM)

Fig 2 The EAToN Valve Disablement Technique. 

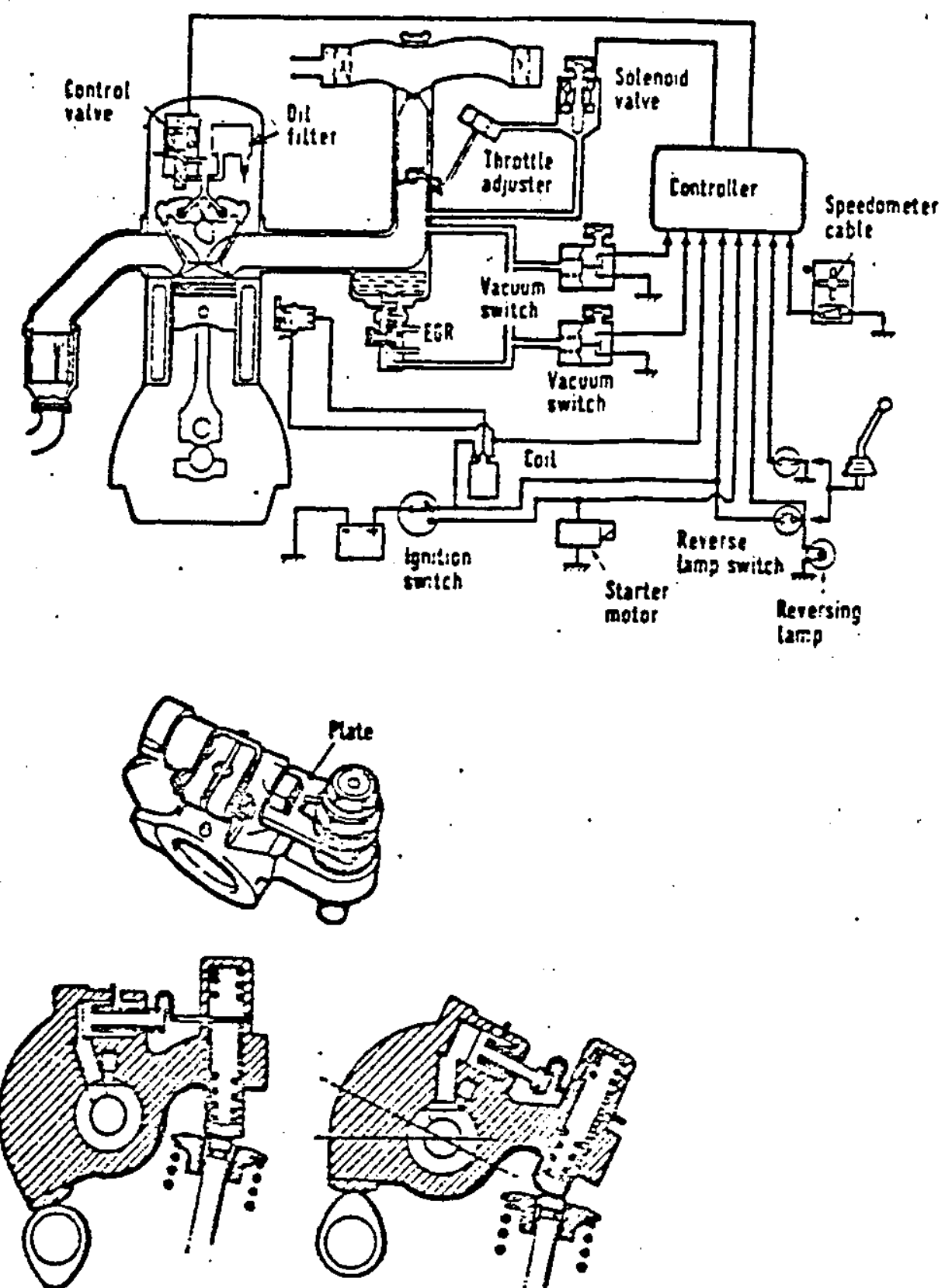

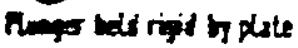

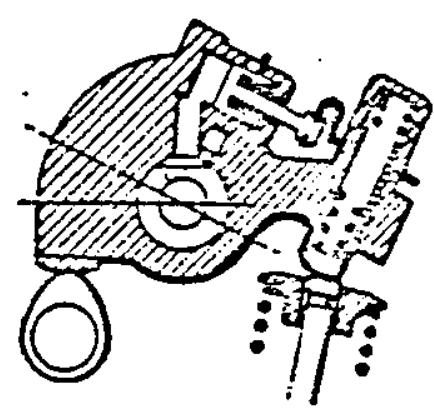

Mtorger able to 10 through dite

\section{Hydraulic (Mitsubishi)}

Fig 3 The Mitsubishi Colt Modulated Displacement System. 


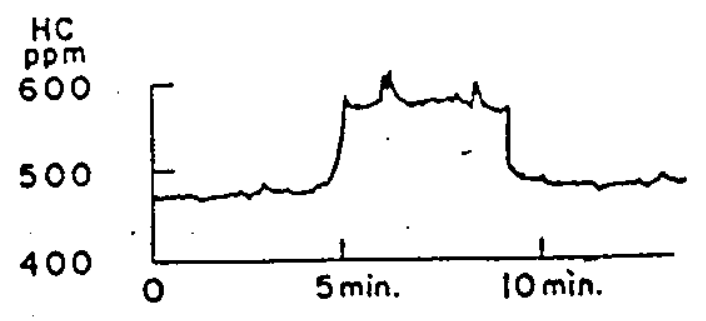

$\frac{4 \text { CYLINDER }}{23} \frac{8 \text { CYLINDER }}{32} \frac{4 \text { CYLINDER }}{-}$

$\begin{array}{lllll}\text { FUEL } & .23 & 32 & - & \\ \text { HC } & .28 & .47^{\circ} & - & \\ \text { CO } & .29 & .55 & - & \\ \text { NO } & .1 & .1 & -\end{array}$

(oll mass flow volues in groms per minute)
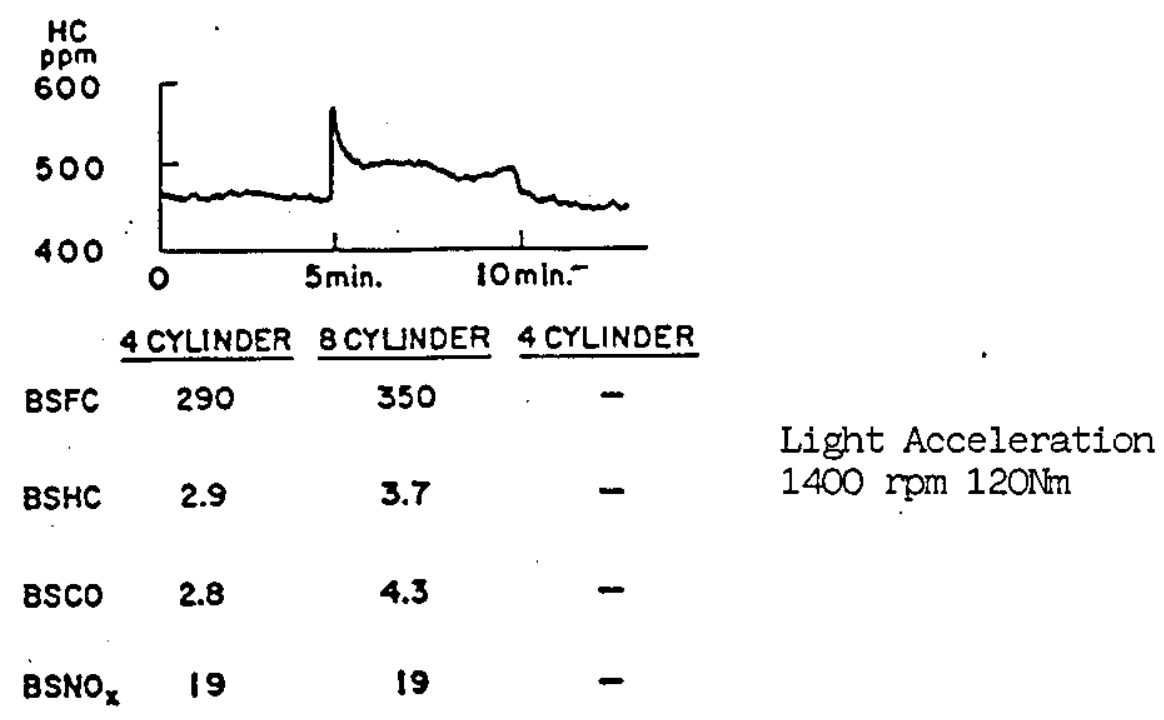

(oll broke specific volues in groms pee kilowatt hour)

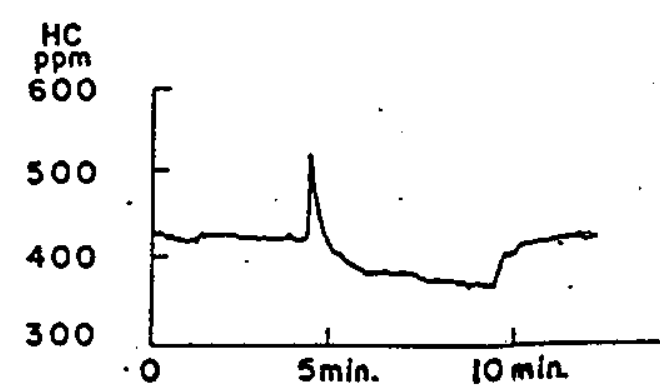

4 CYLINOER 8 CYLINDER 4 CYLINDER

$\begin{array}{llllll}\text { BSFC } & 305 & 395 & - & \\ \text { BSHC } & 2.8 & 3.2 & - & \text { Road load } \\ \text { 8SCO } & 3.9 & 7.1 & - & 1800 \mathrm{rpm} 100 \mathrm{Nm} \\ \text { BSNOX } & 26 & 18 & - & \end{array}$

(all broke specific volues in grams per kilowott hour)

Fig 4 Enissions from Ford 5.OL V8 with CSO 


\section{6 cyl S.l. engine}

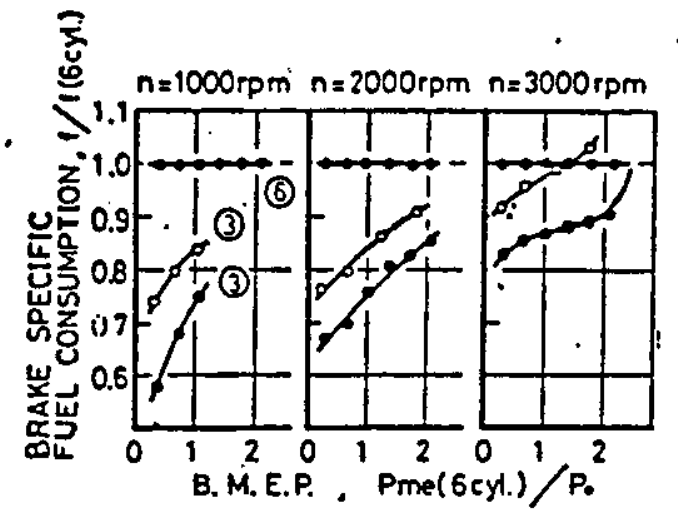

$0:$ FUEL CUTOFF $\bullet$ :CYLINDER CUTOFF

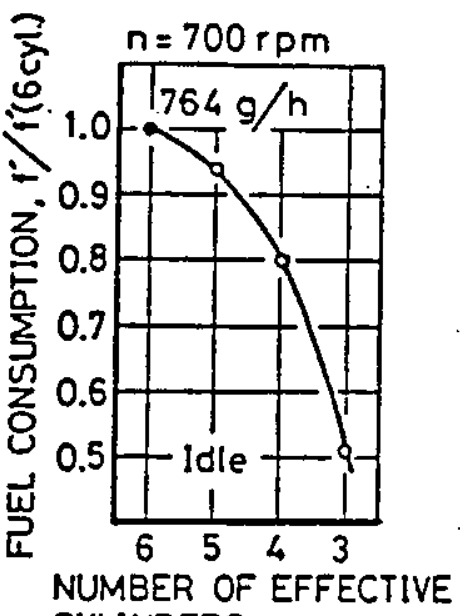

CYLINDERS, $z$

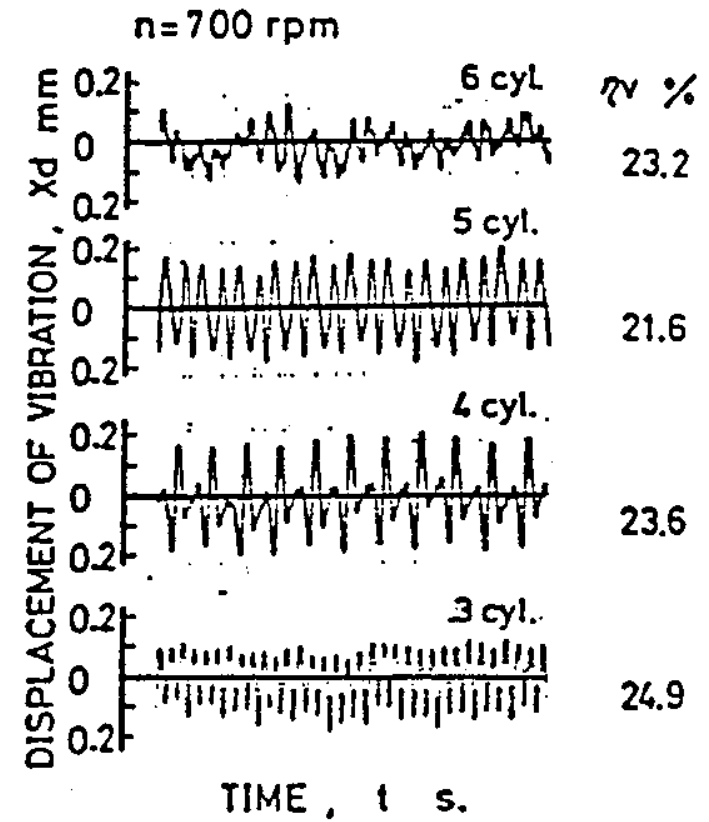

Fig 5 Six-cylinder 2L Engine Fuel Economy with cso. 

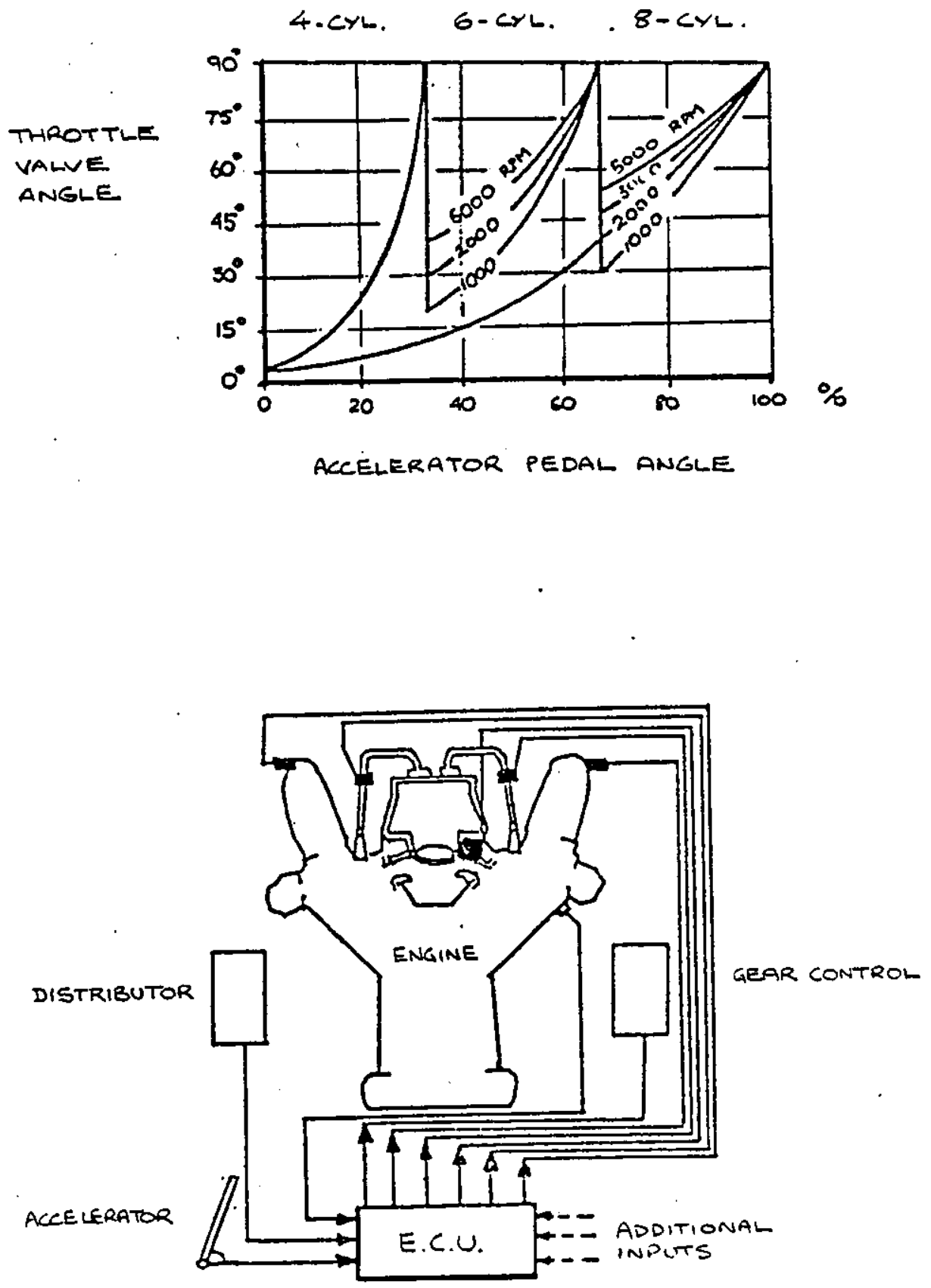

Mercedes Benz $500 \mathrm{SE}$

Fig 6 The Mercedes Cylinder Disablement System 

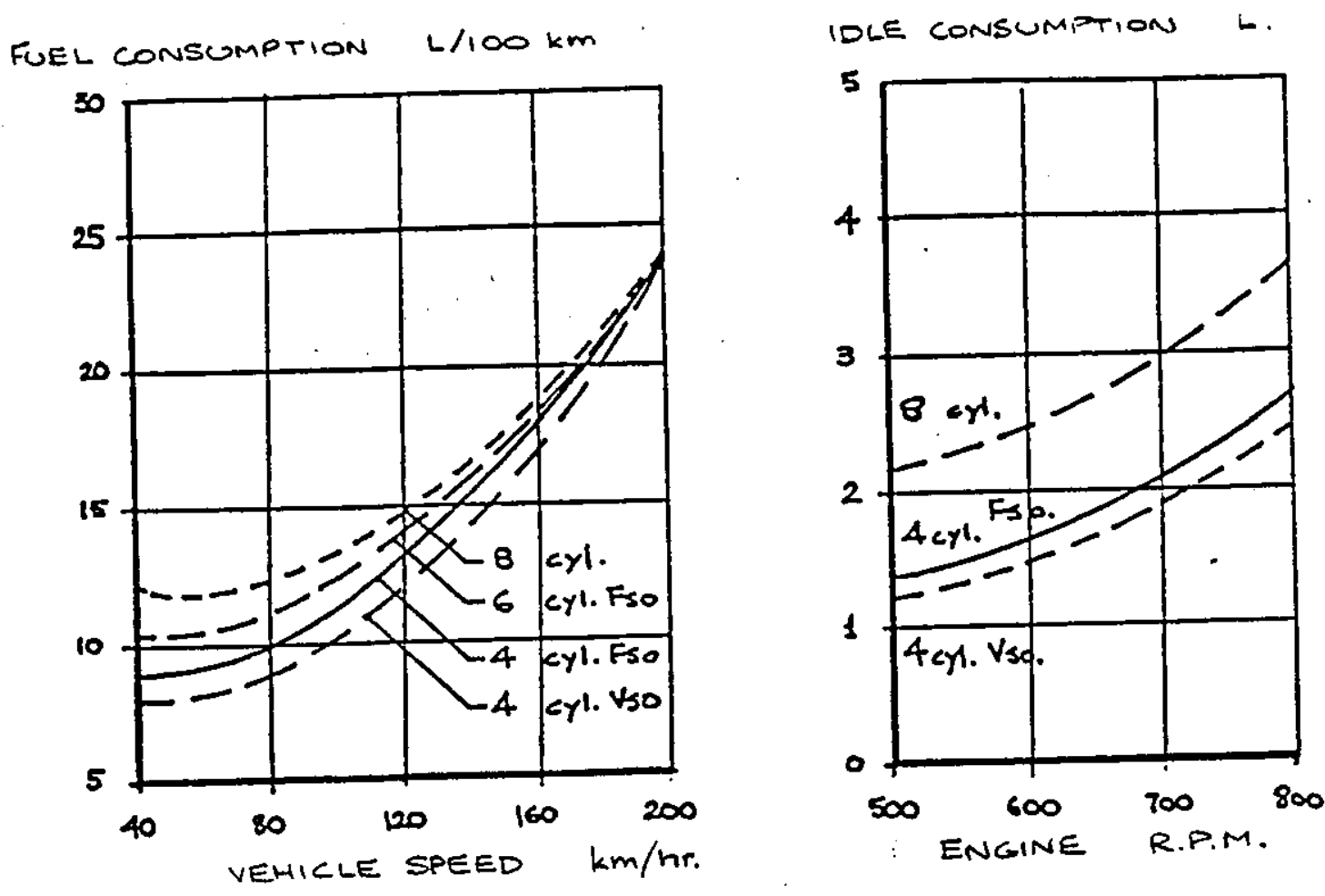

FuEL CONSUMPTION $L / 100 \mathrm{~km}$.

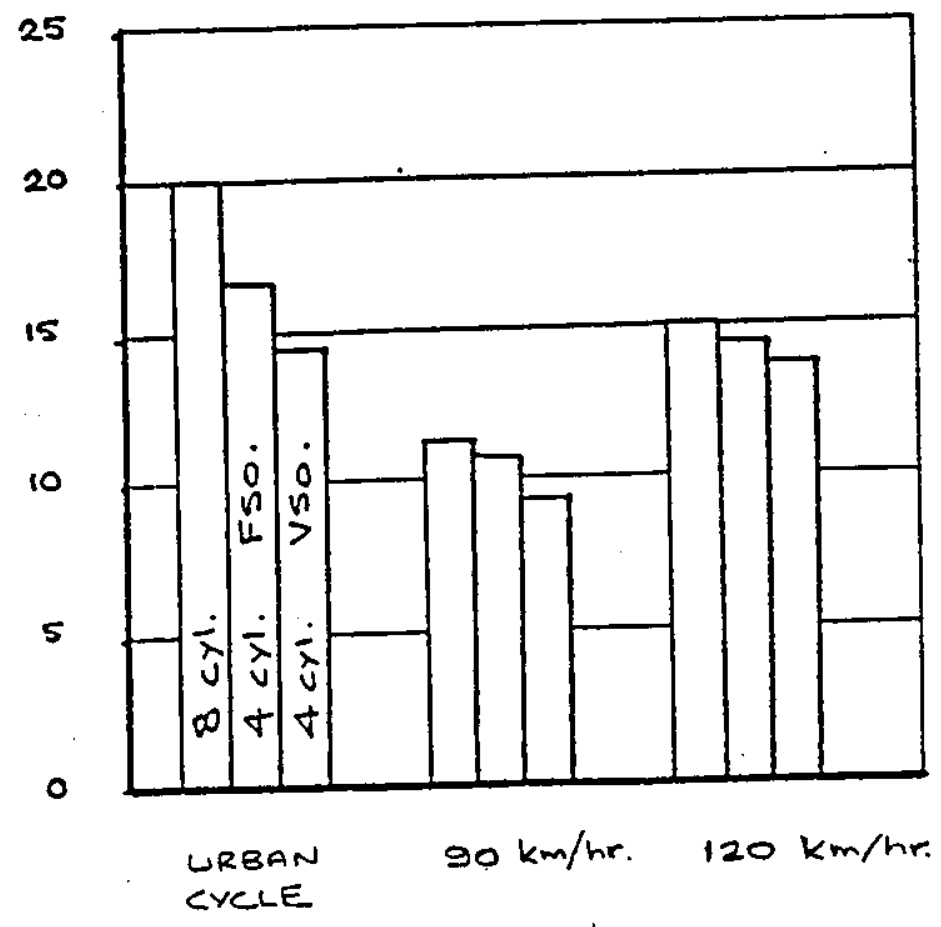

Vso: Valve shut-off

Fso: Fuel shut-off

(Merc. Benz)

Fig 7 Mercedes Benz 500 SE Fuel Consumption 


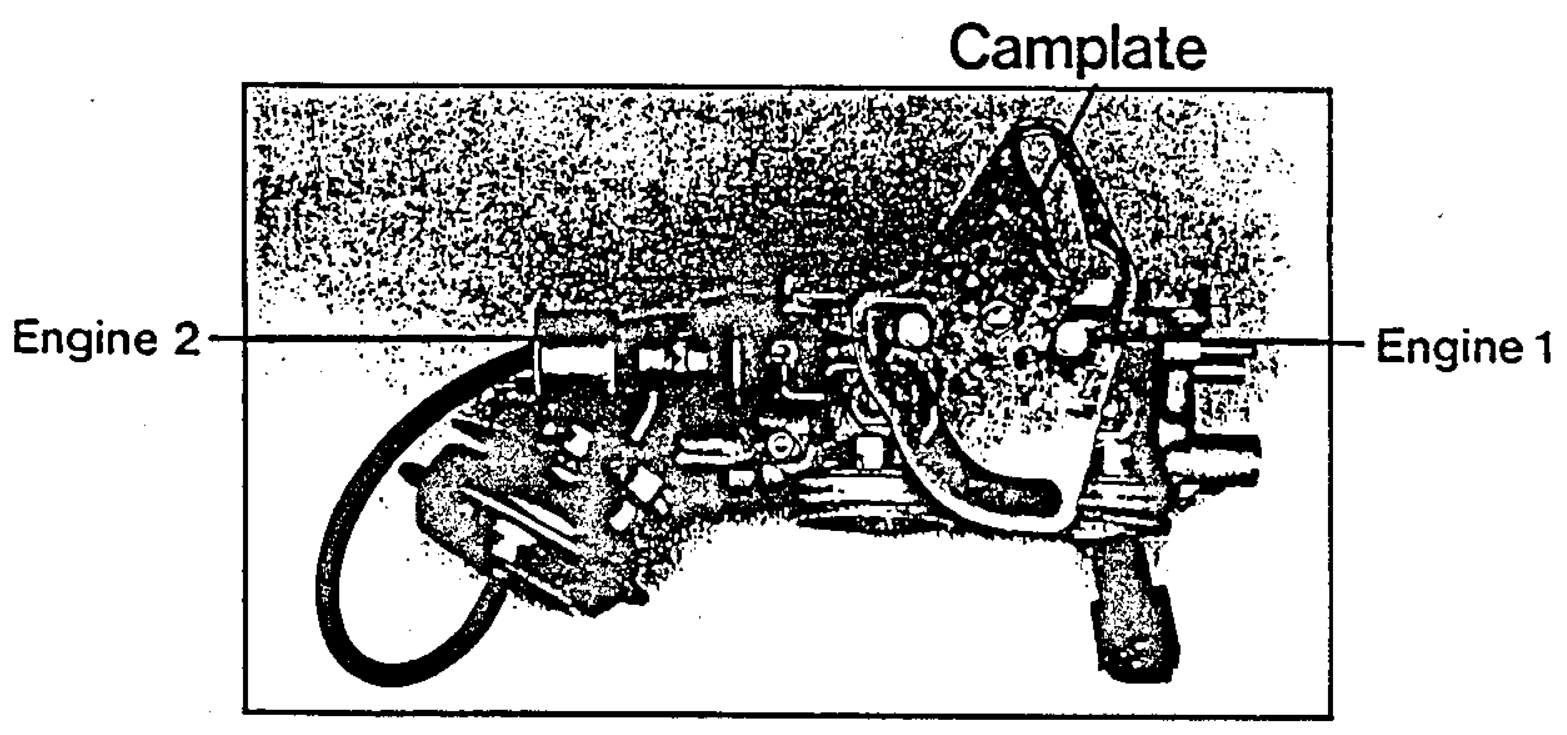

Fig 8 FORD $3 \times 6$ Throttle Body and Camplate. 

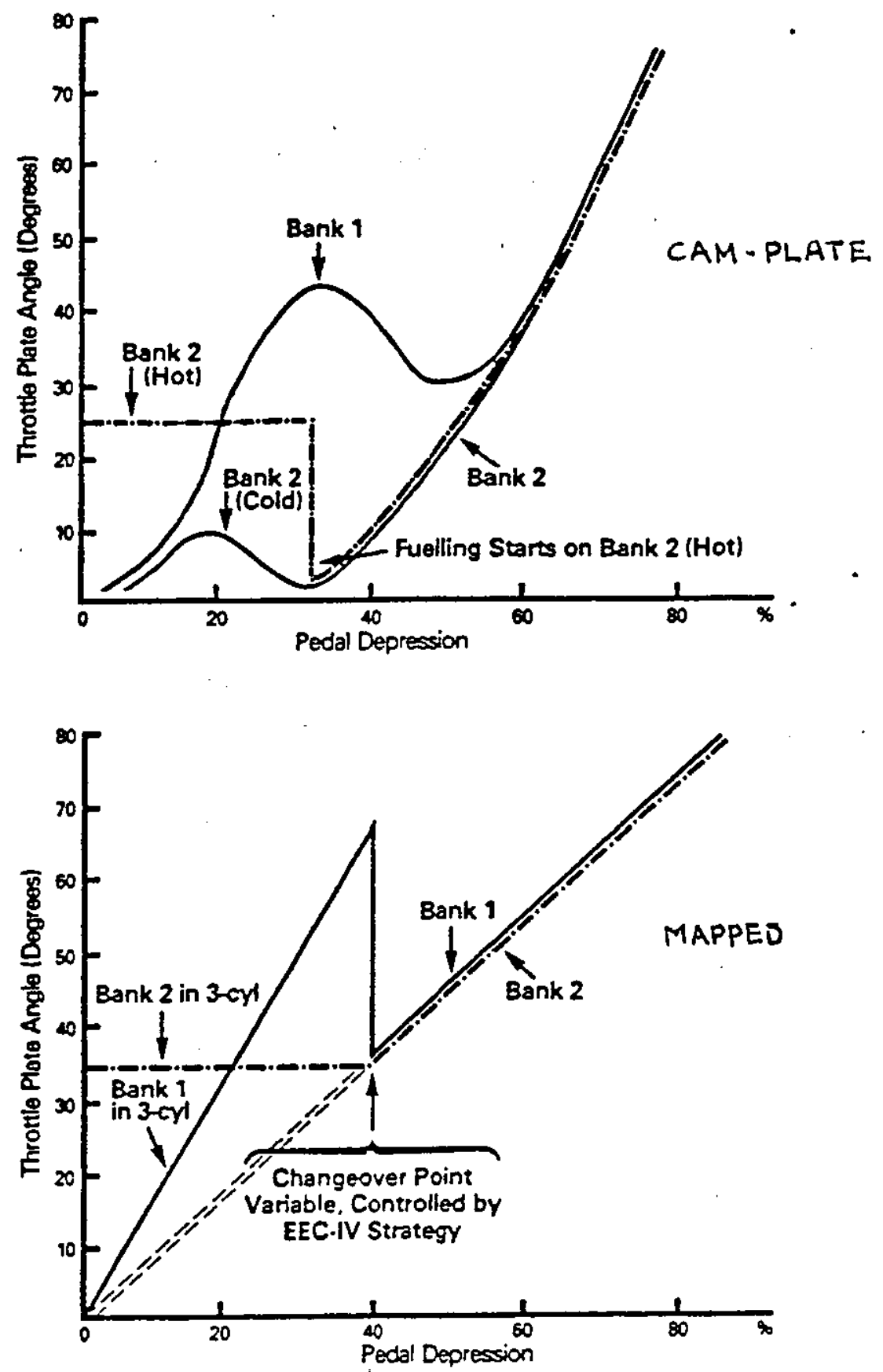

Fig 9 FORD $3 \times 6$ Engine Throttle Pedal/Valve Angle Relationship. 


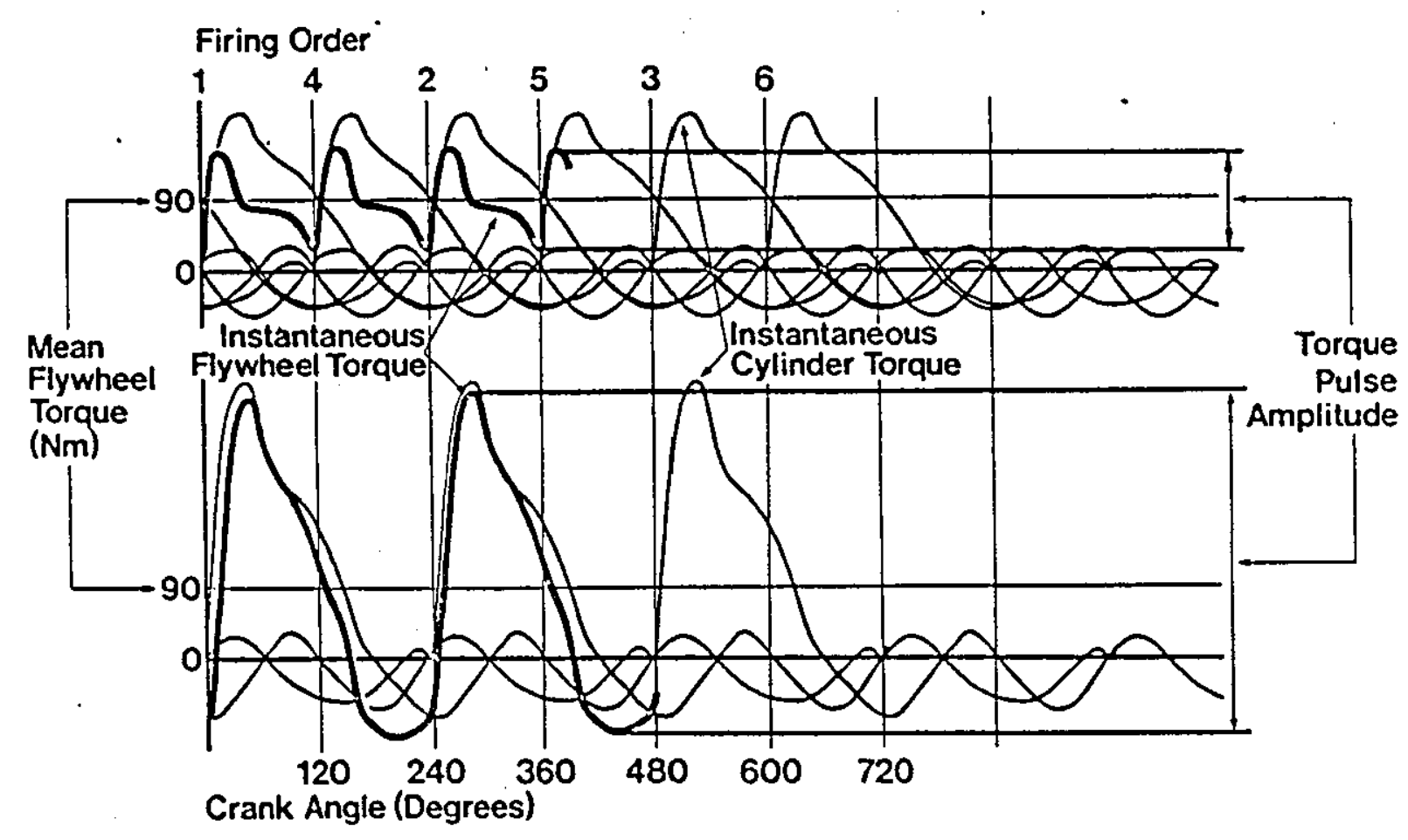

Fig 10 FORD $3 \times 6$ Cso Effect on Torque. 


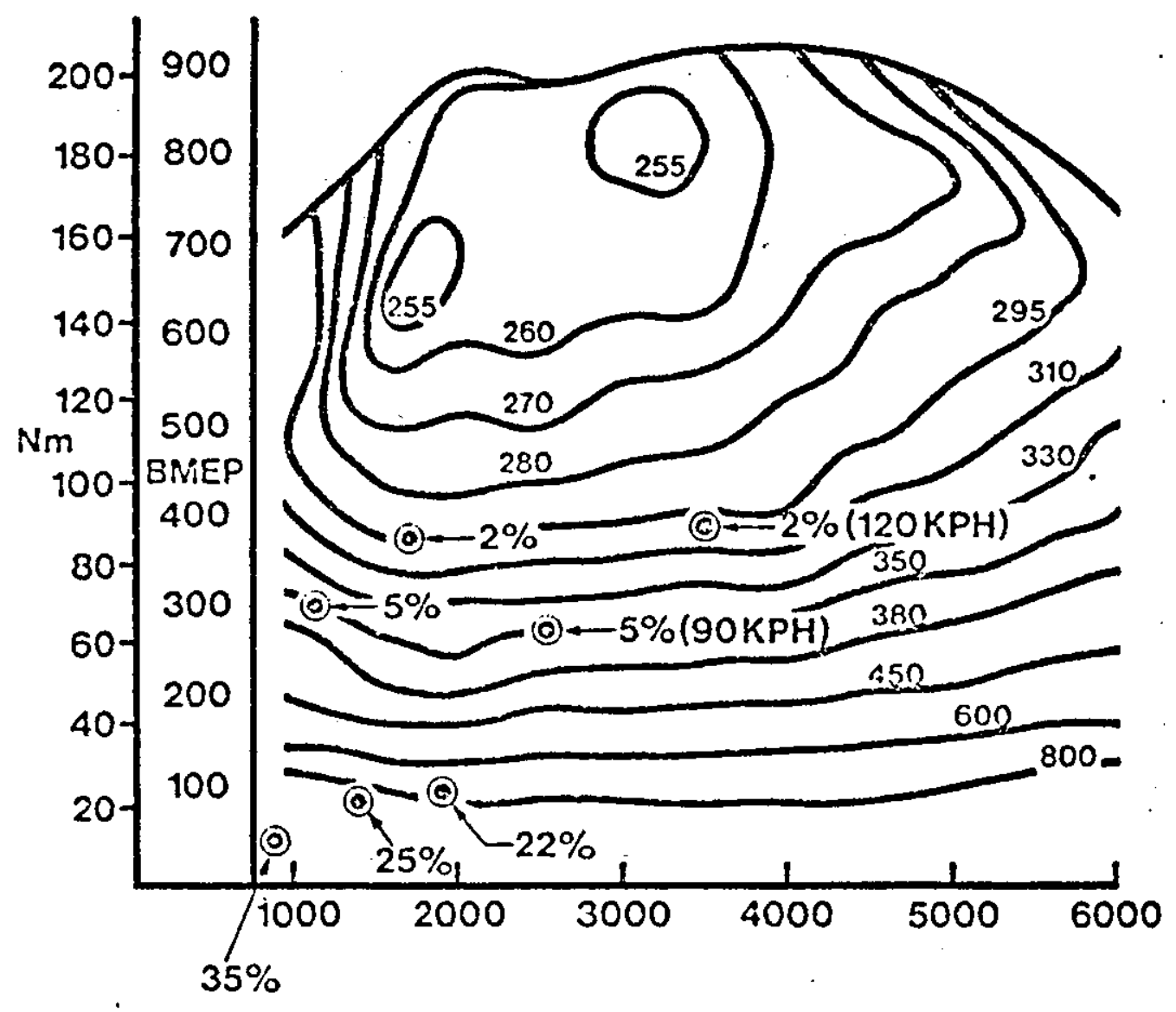

FE. Benefits -

ELA Mapping Points

Fig 11FORD $3 \times 6$ Fuel Economy Benefits. 


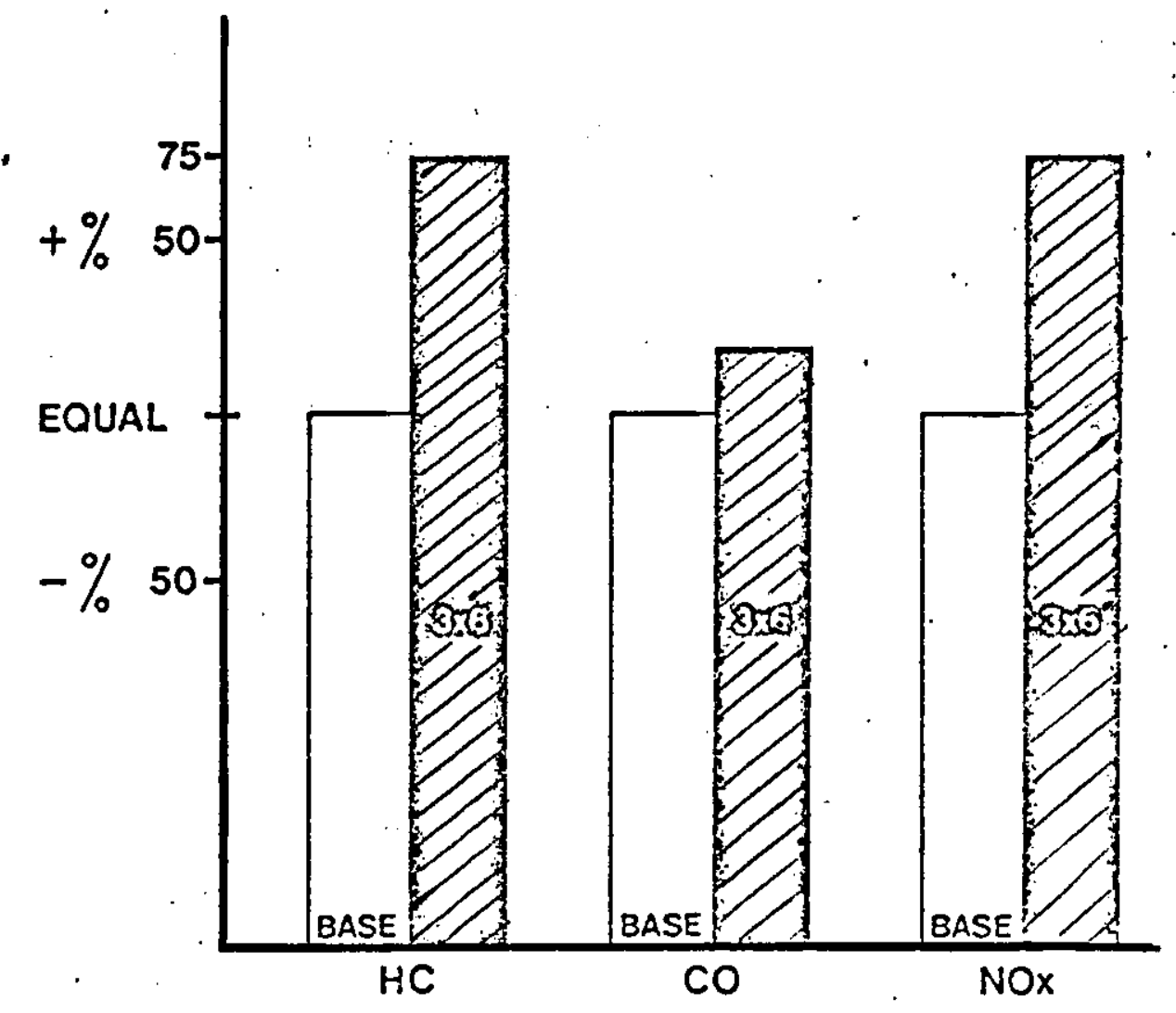

Emission Effect -

ECE Cold Test

Fig 12 FORD $3 \times 6$ Euro-04 Cycle Emissions. 
Electronic Molor Control Moduie
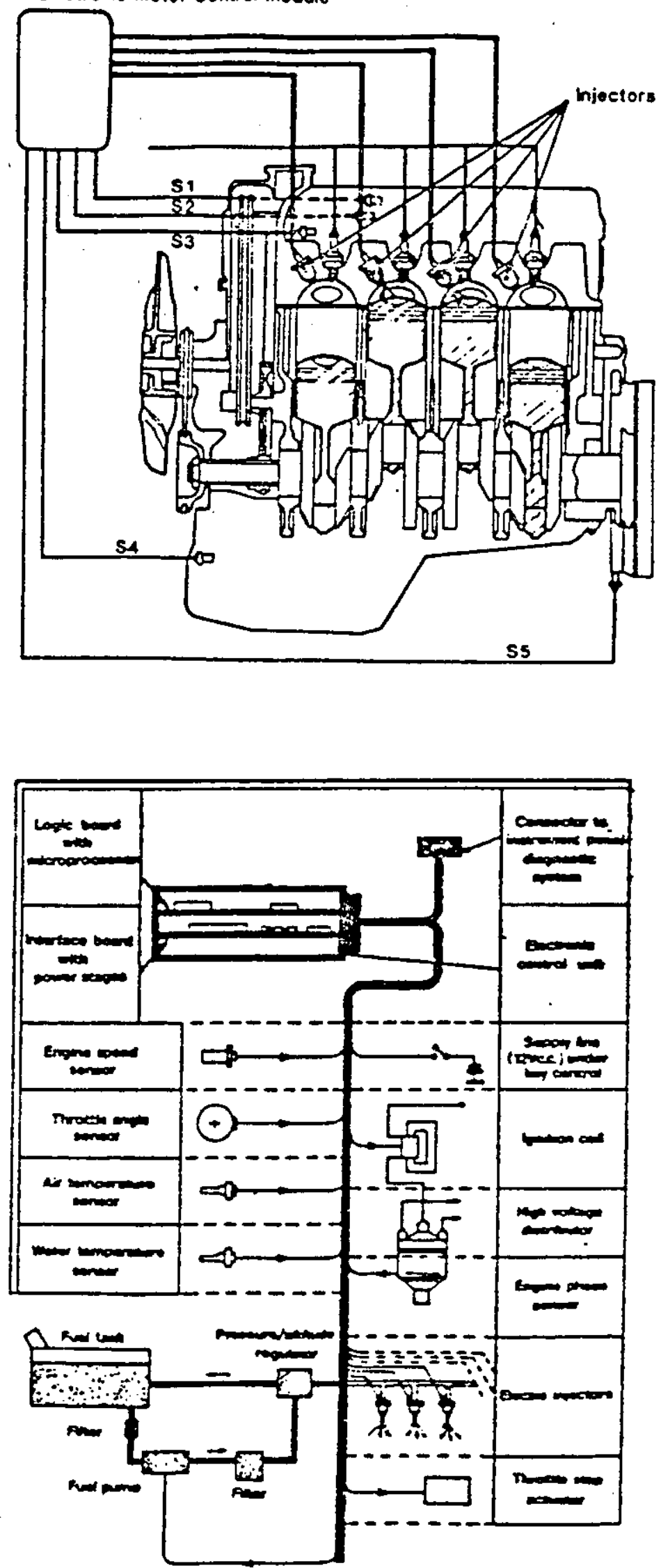
S.F.C. IMPROVEMENT
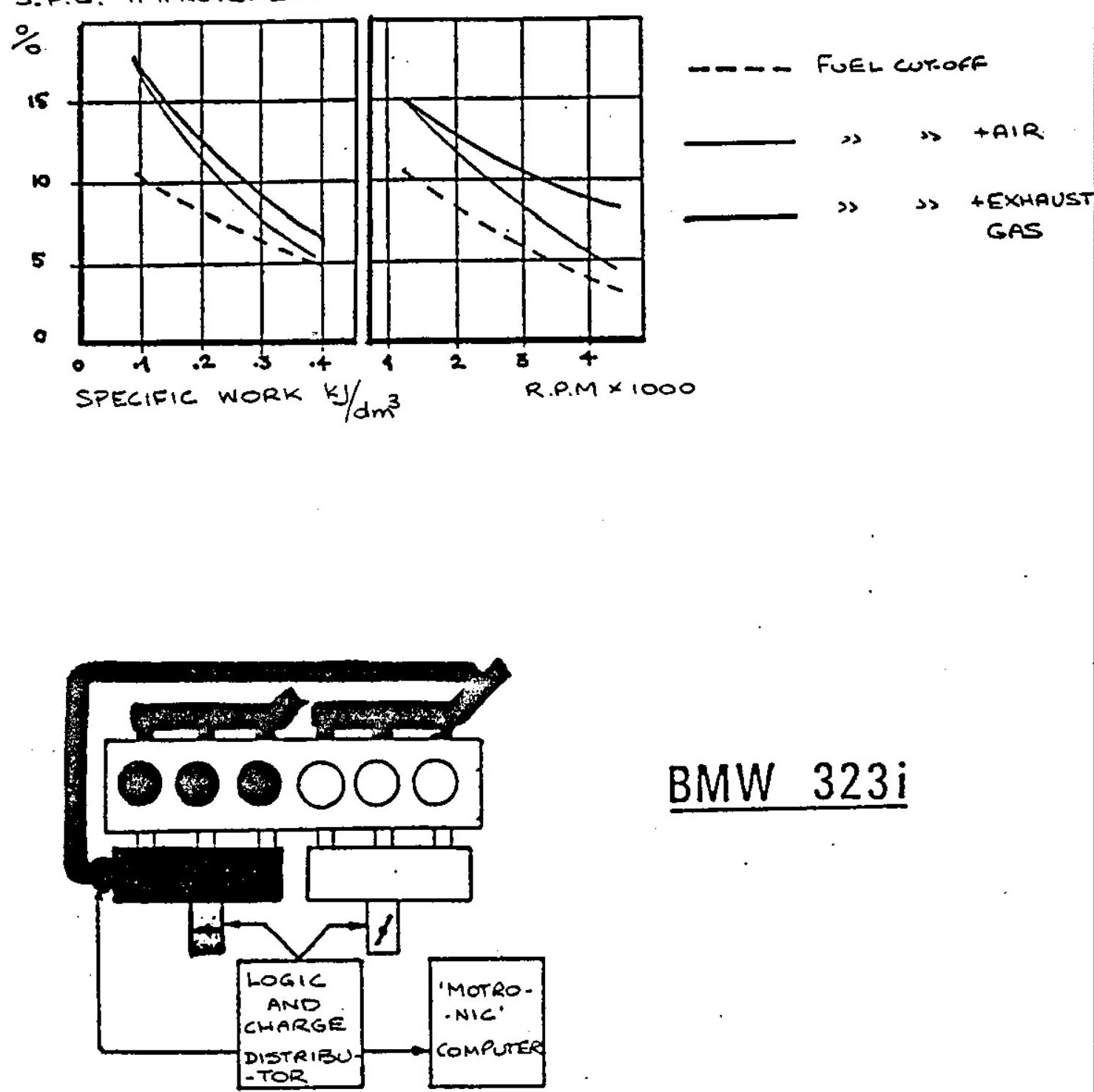

BMW 323i

Fig 14 EGR System Combined with Cso. (BMW) 


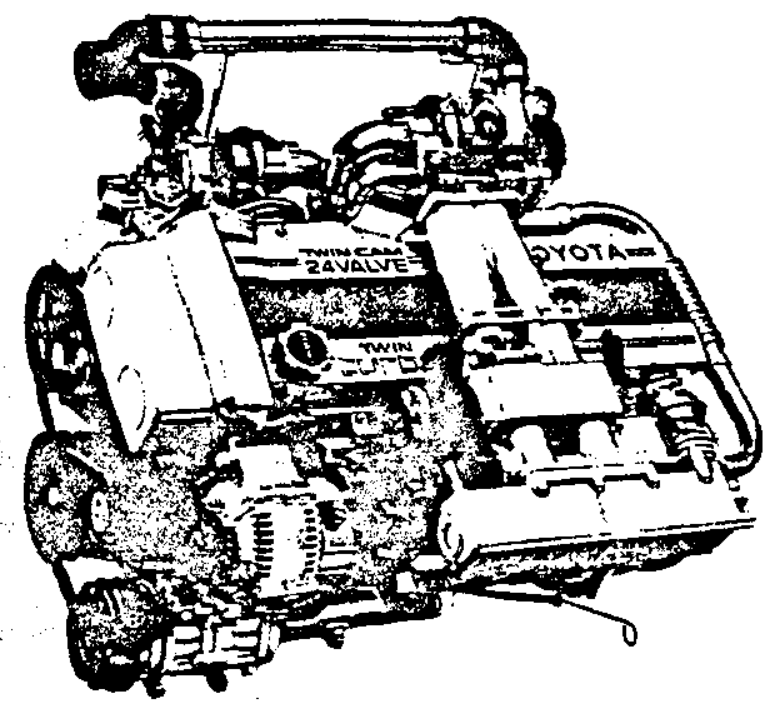

Twin Turbochargers with Intercooler System

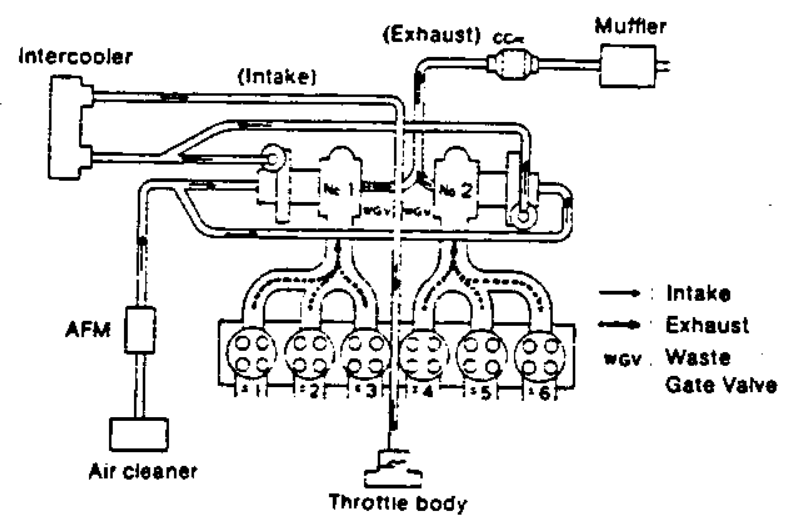

Fig 15 The Toyota FX-1 Modulated Engine. 

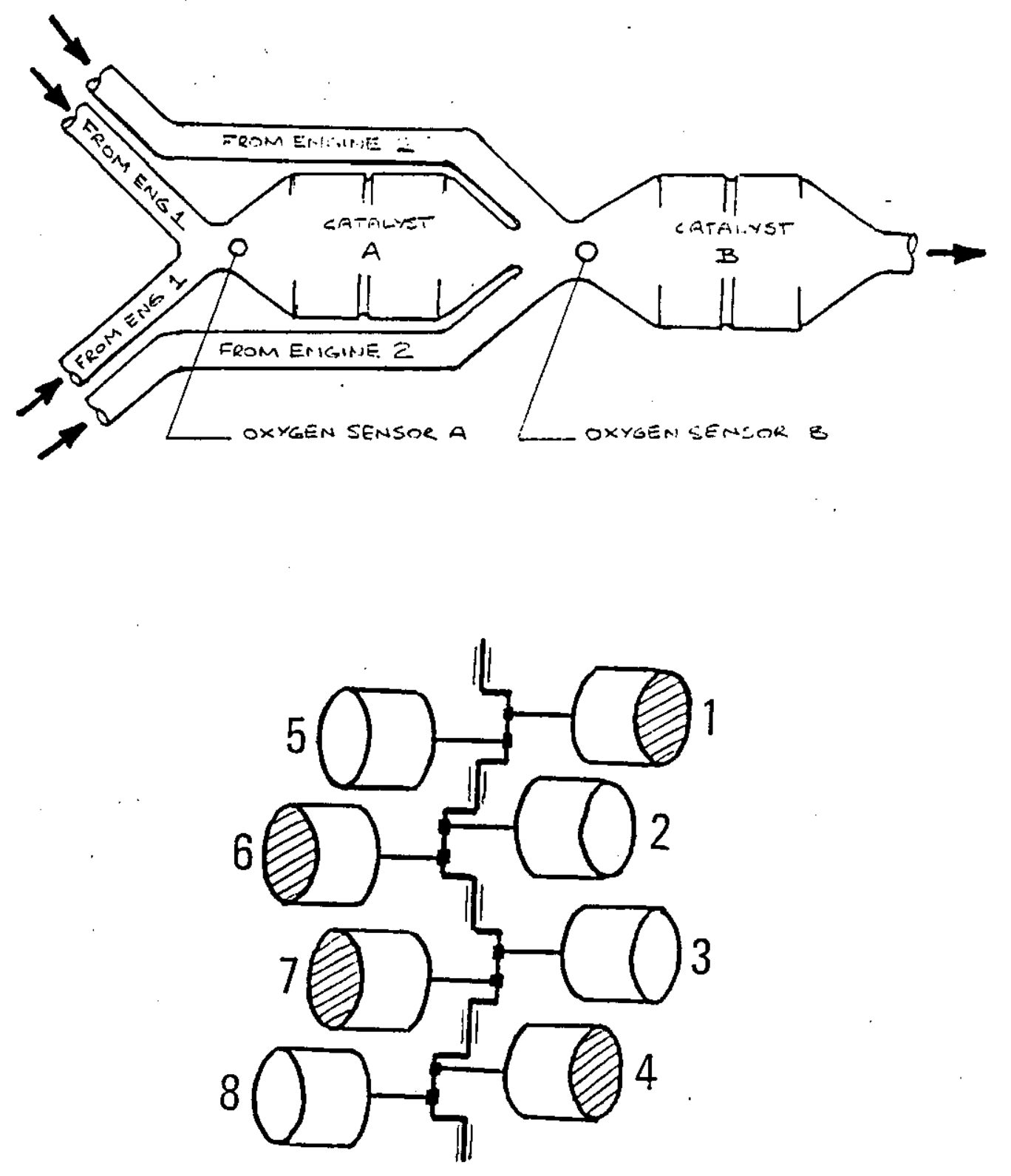

Fig 16 The Porsche V-8 CSo Mode and Emission Control. 
FUEL ECONOMY M.P.G.

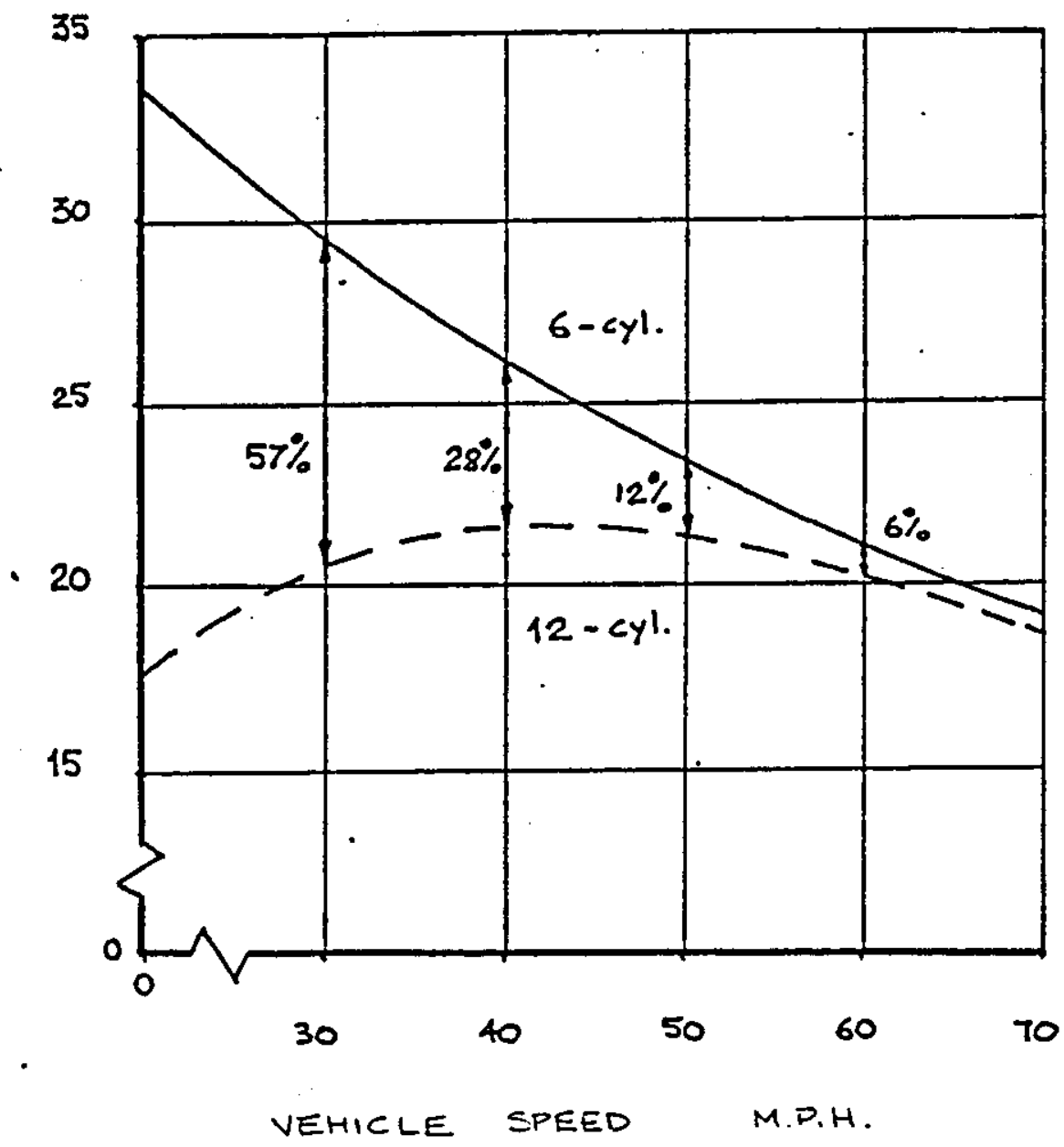

Jaguar XJ12

Fig 17 Jaguar split-V12 Engine Fuel Economy Improvements 
'Plint'

Fuel Measuring

Equipment

Fuel from

Tanks
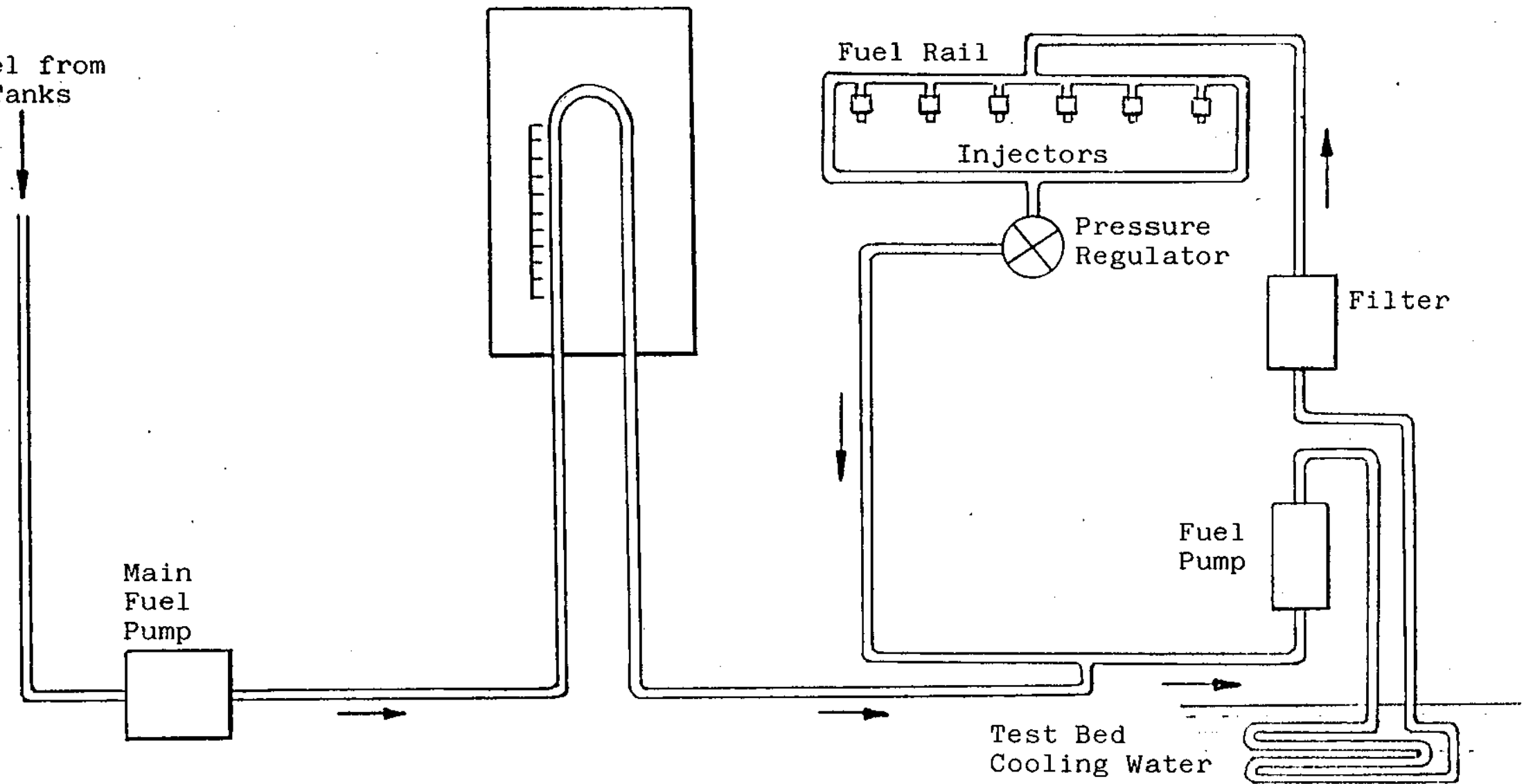

FIG 18 Fuel Supply System - LUT Test Bed 


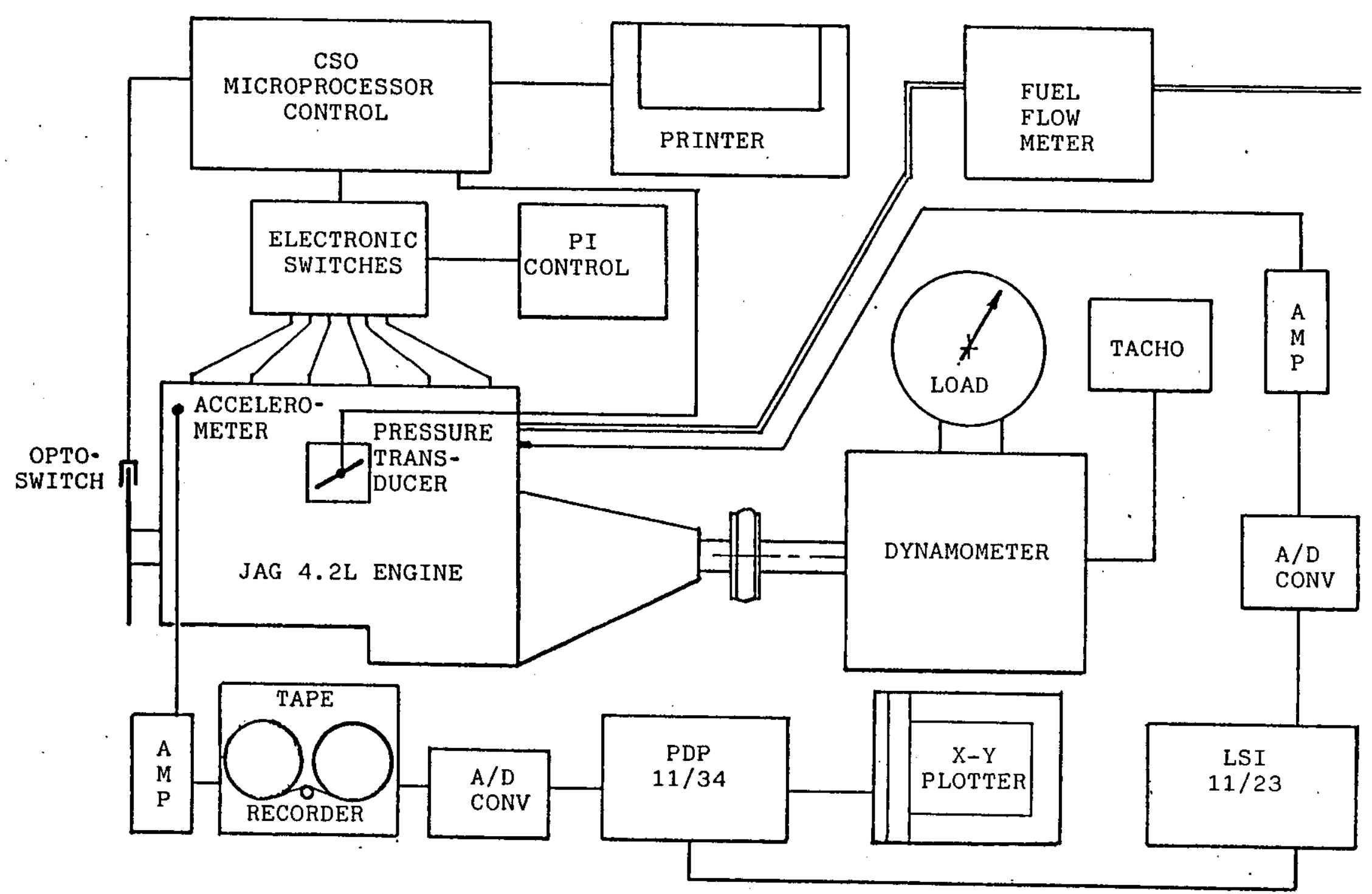

Fig 19 JAG 4.2L: LUT Test Bed Apparatus. 


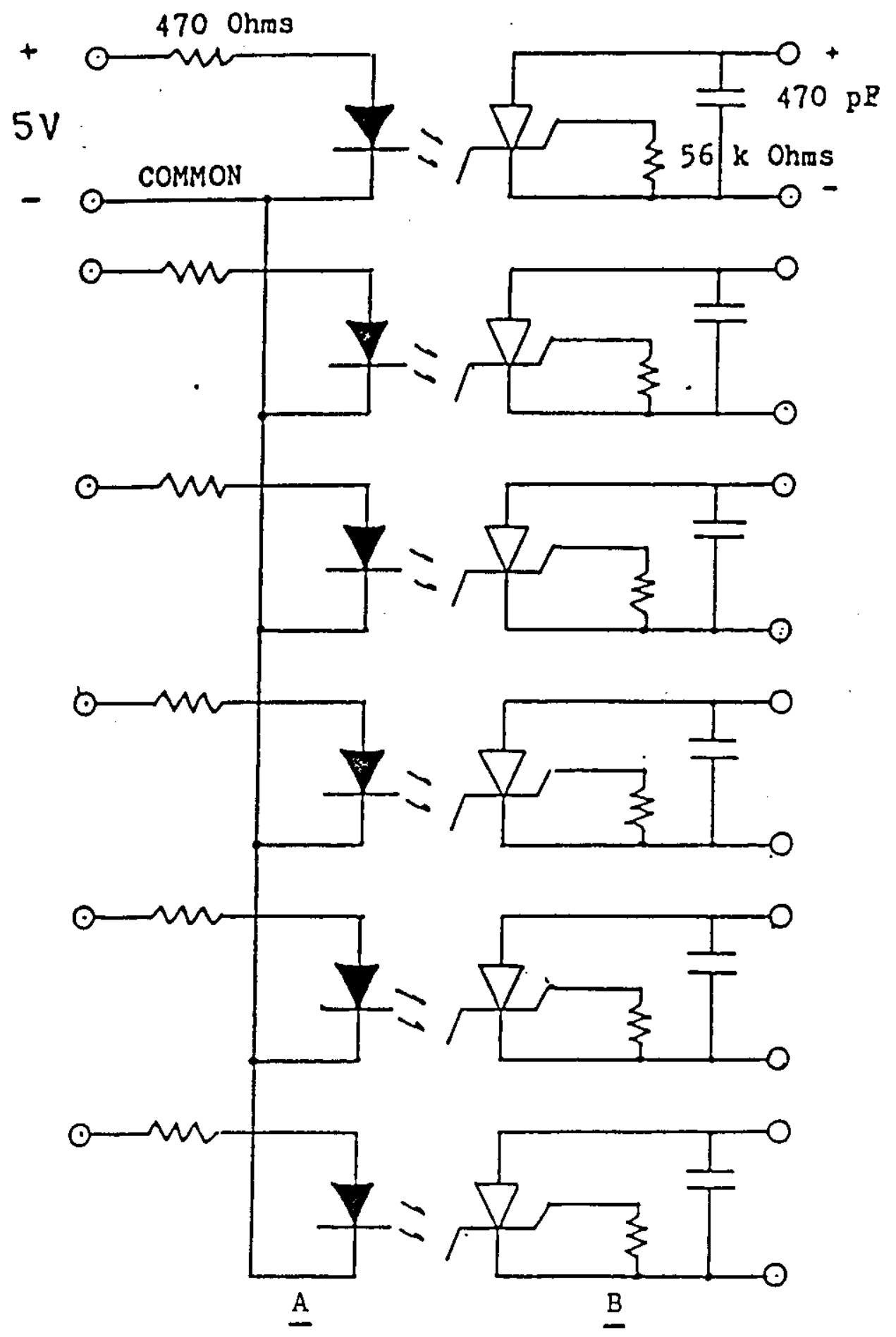

Fig 20 - Silicon-Controlled Rectifier (SCR) 


\section{Initial CSo System at L.U.T}

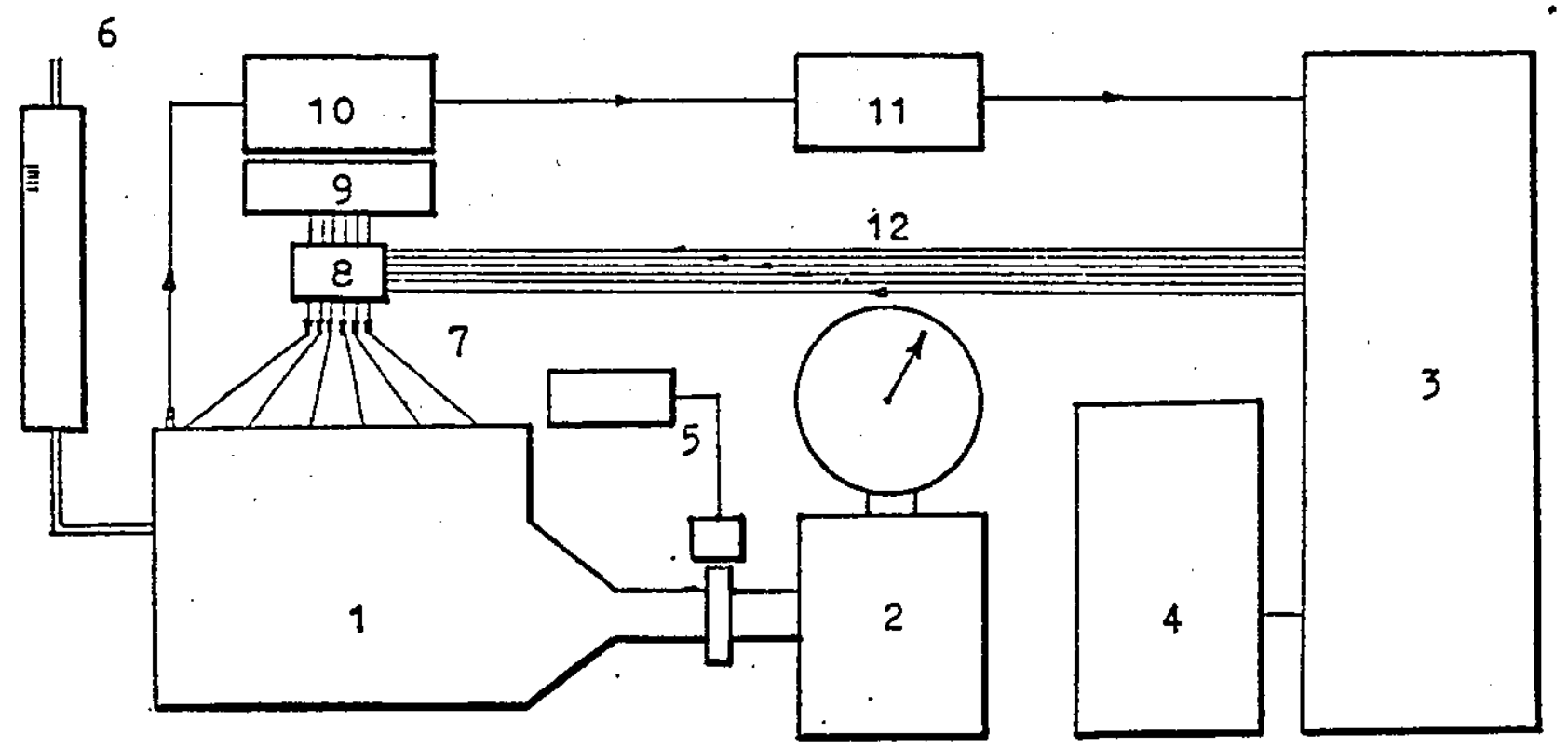

1. ENGINE

2. DYNAMONETER

3. MINICONPUTER

4. TELETYPE

5. REV. COUNTER

6. FUEI FLOW METER
7. INJECTOR POWER IJINES

8. EIECTRONIC SWITCHES

9. EIEC. CONTROI UNIT

10. INTERRUPT SIGNAL EUFFER

11. PUISE SHAPER

12. DISABIEMENT CONTROL SIGRAIS

Fig21.Stage 1. Minicomputer-based Cso (HP 2114B). 


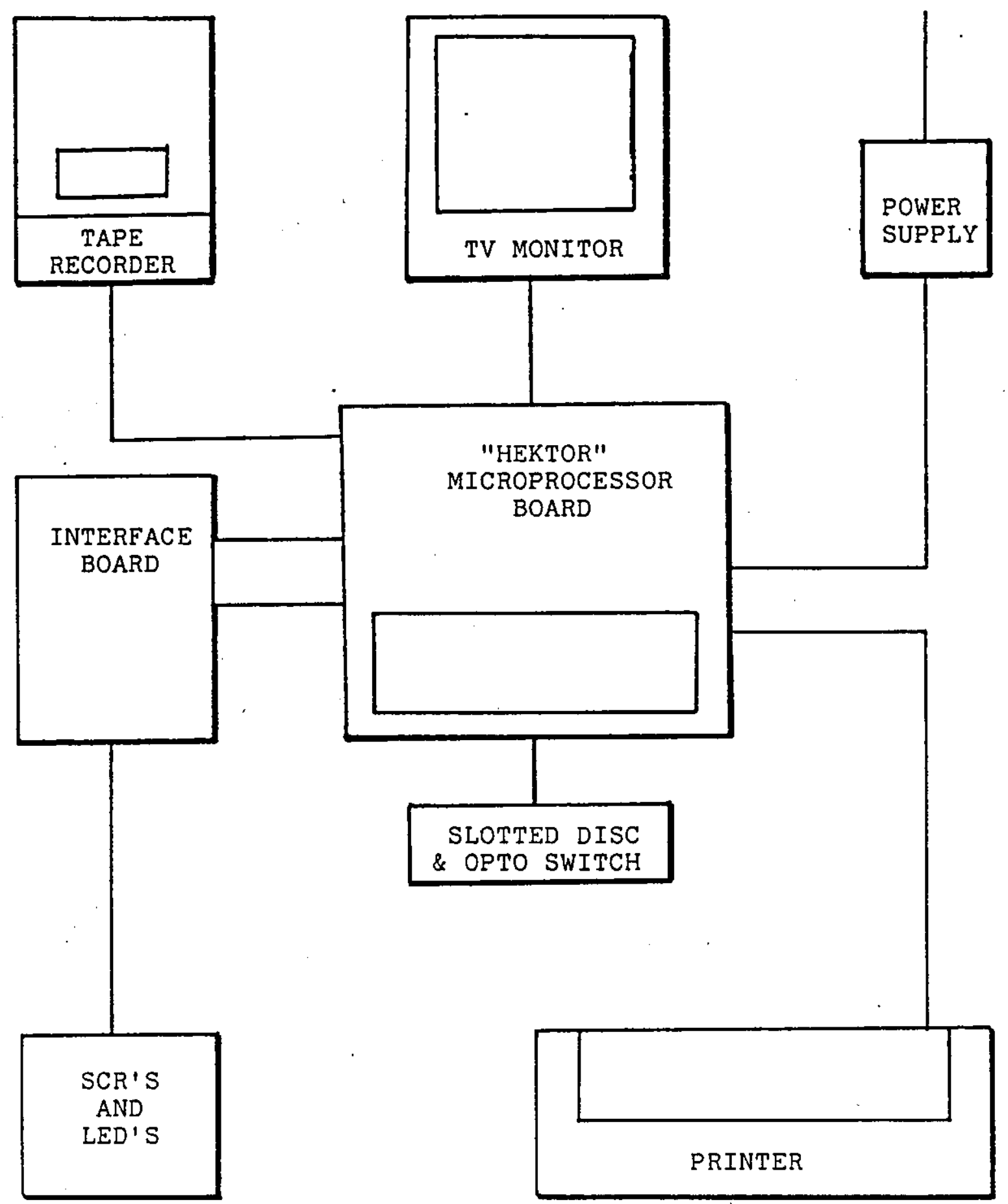

Fig 22.HEKTOR Microprocessor Development system. 


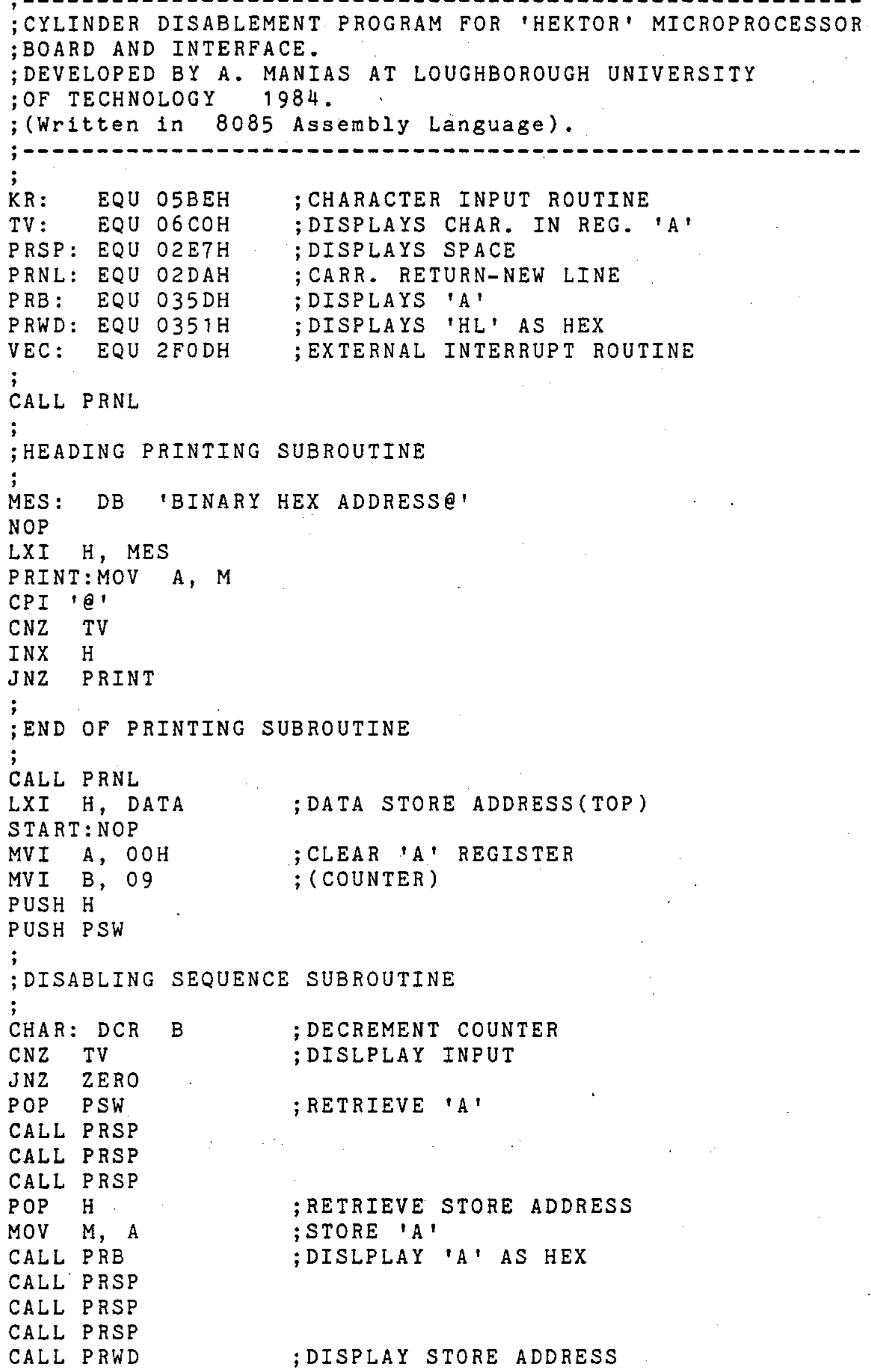




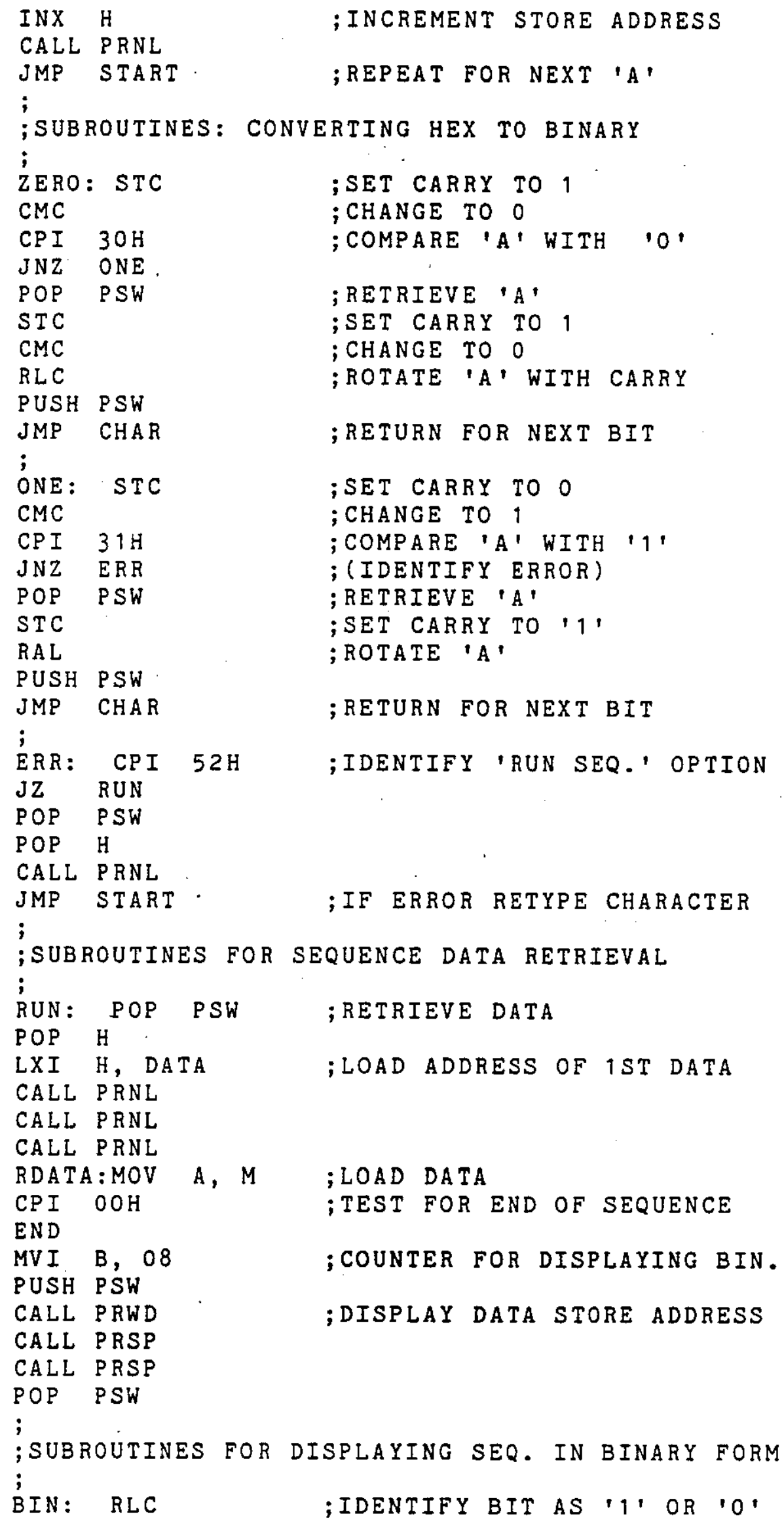




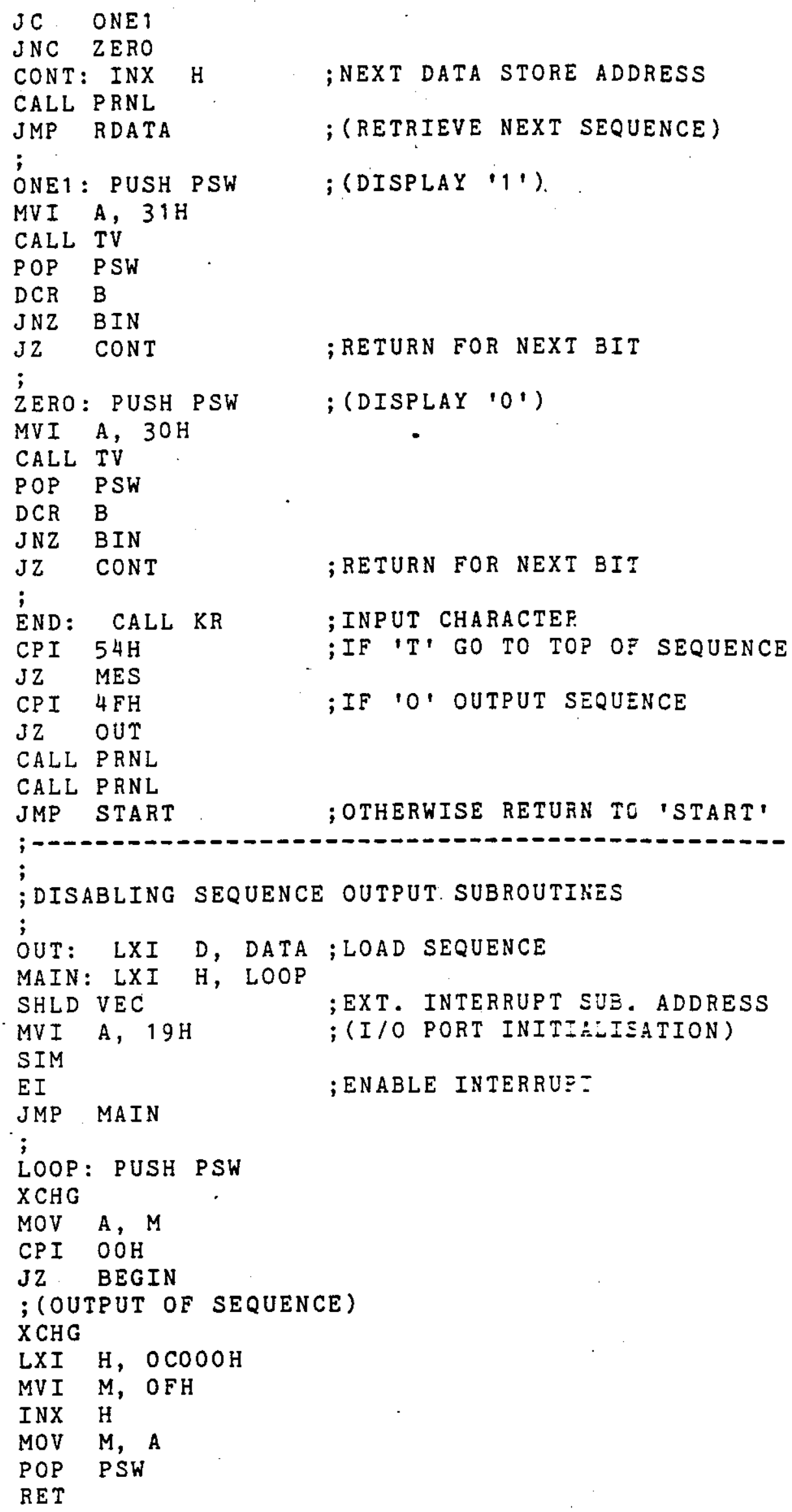


Fig 23. (Cont'd)

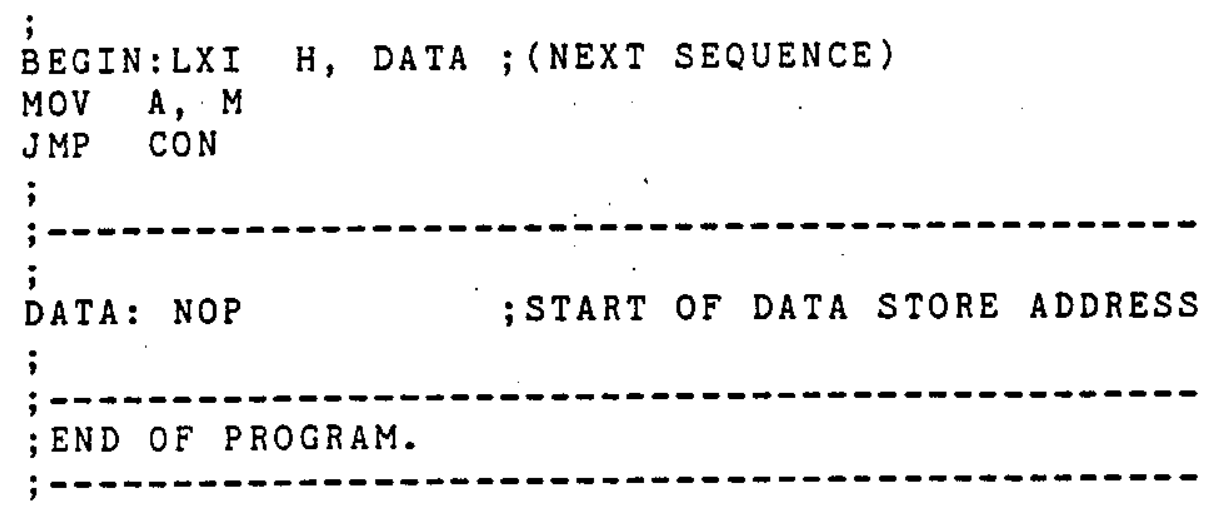




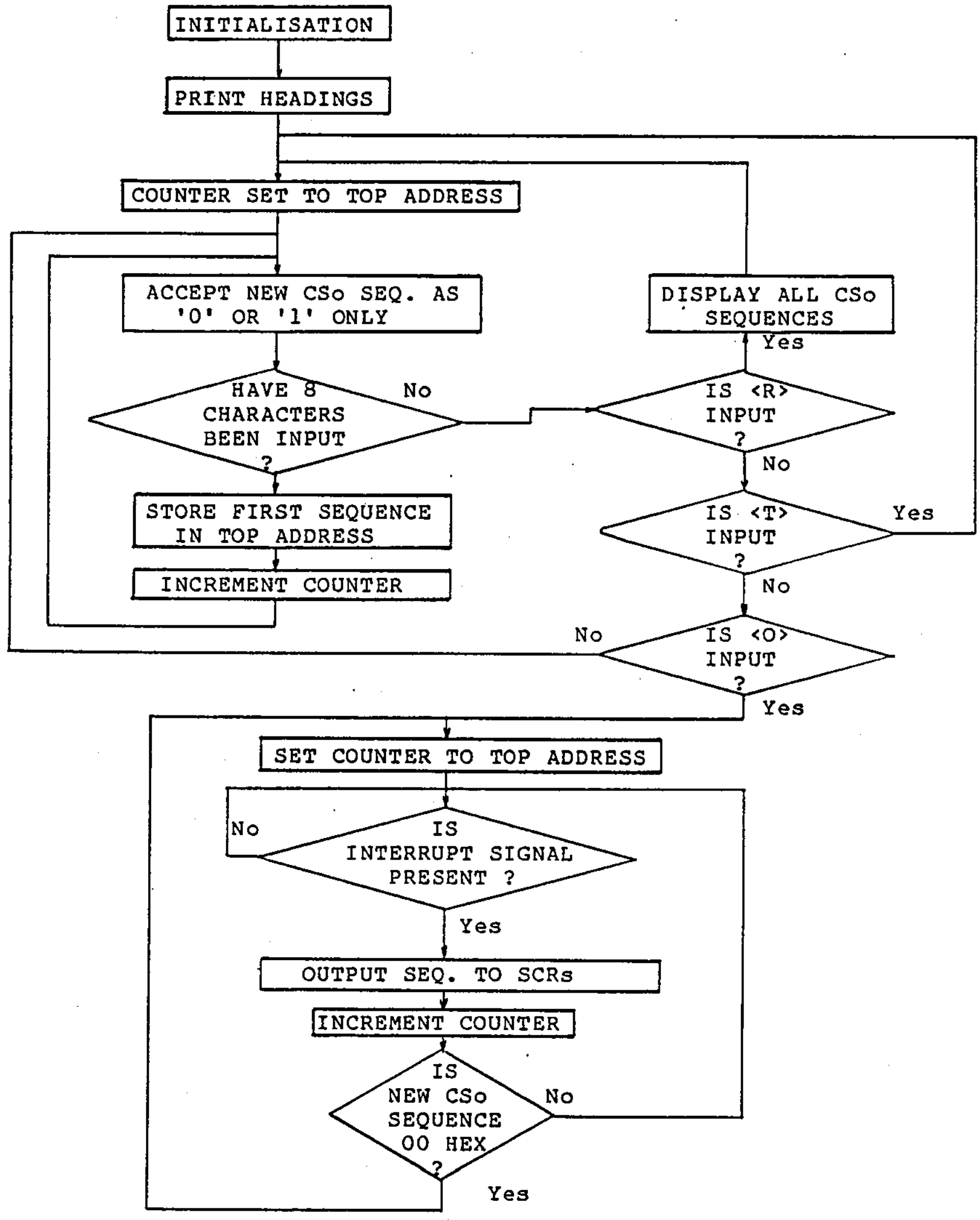

Fig 24 CSo Program Flowchart 


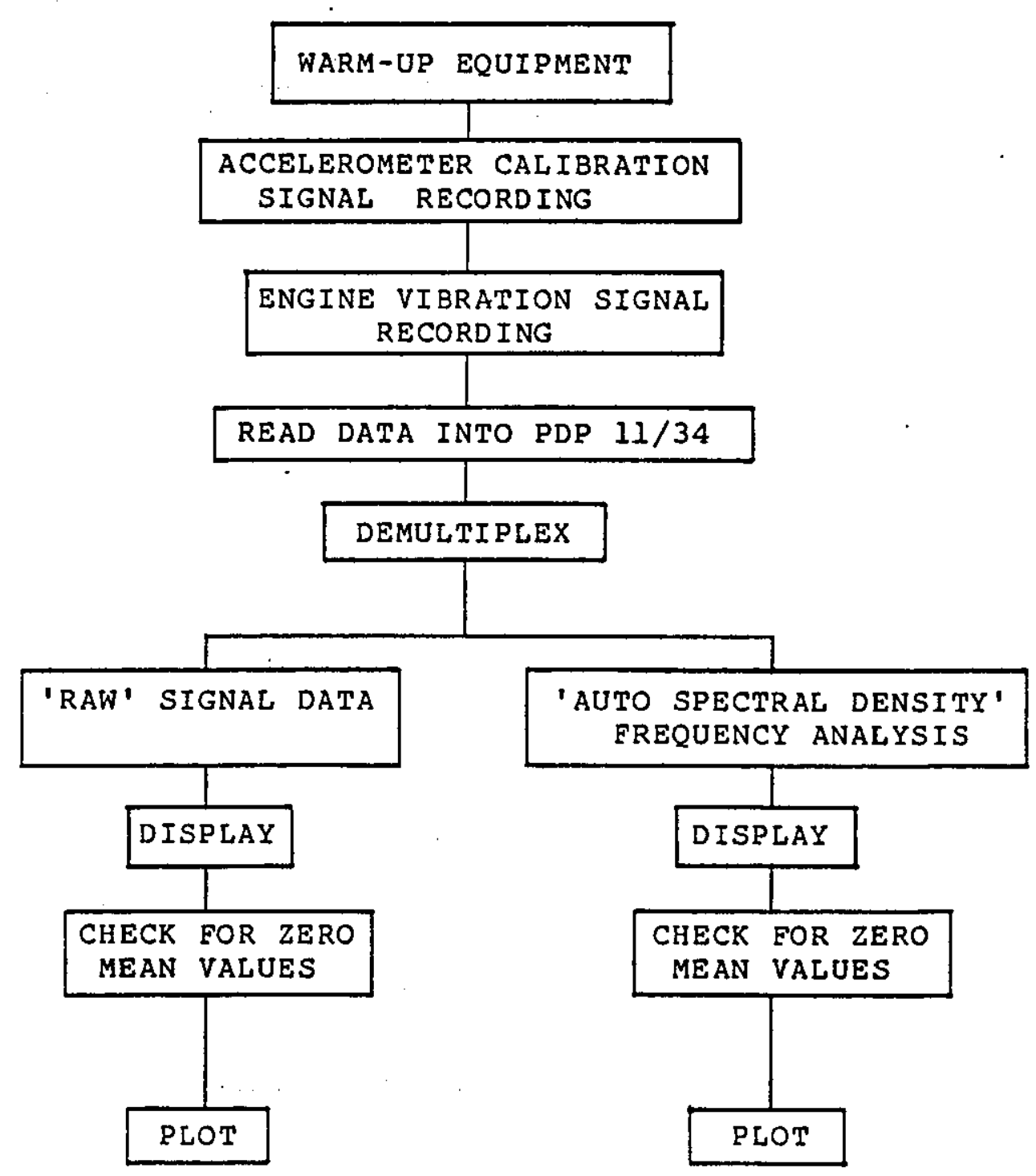

Fig 25. Engine Vibration Data Analysis using DATS Software on PDPI1/34 Minicomputer. 


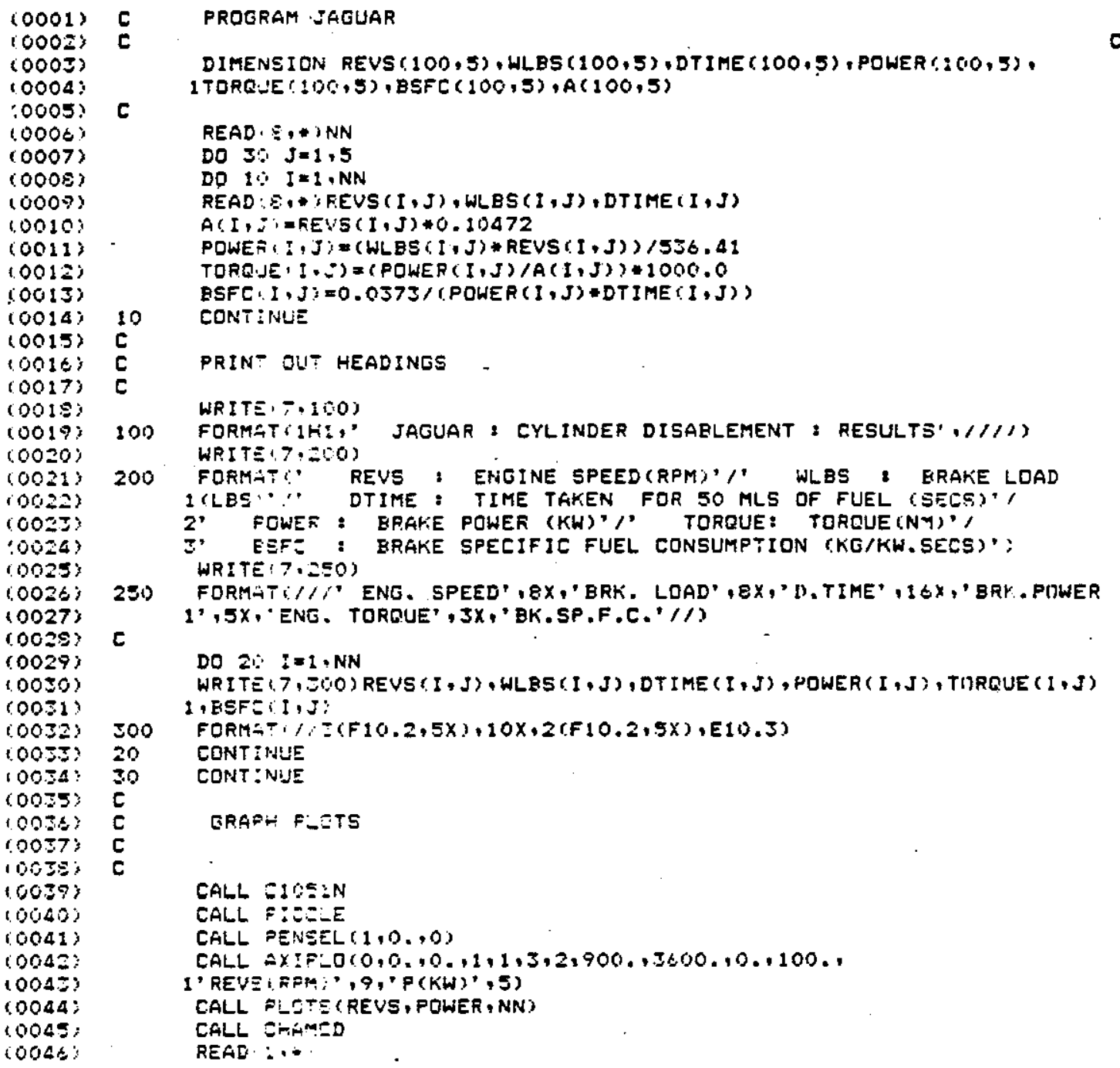

Fig.26.L.U.T Mainframe Results Calculations Program (PRIME). 
(0047)

(0048)

(0049)

(0050)

$(0051)$

(0052)

(0053)

(0054)

(0055)

(005e)

(0057)

$10055:$

(0057)

(0060)

$(0061)$

(006)

(0065)

(0064)

(Dot5)

(006)

$0067)$

(0068)

(0067)

(0070)

(0071:

(0072)

(007)?

(0074)

(0075)

roo7t)

i0077)

(0078)

$(0079)$

10080:

(00s 1 )

coos?

iones;

(0054)

(ones)

(Dose)

co0s7:

1008:

(0055)

(Dos)

$(0091)$

(0092)

(009))

(0094:

10095 :

cooge;

(0097)

(0095)

1009:;

(0100)

(0101)

(0102)

$1010 \mathrm{I}$

$10104:$

CO105:

(010\%:

(0107)

$10105 ;$

C . CALL AXIPLOC0,0,0.0,1,1,3,3,900,.3600.,50.,300..

1 'REVS (RPM) , 9 ,'TORQ(NM), B)

CALL PLQTS (REVS, TORQUE , NN)

CALL CHAMOD

READ: $1: \div ;$

c

CALL PICCLE

CALL AXIPLOC0,0.10.11,1,3,2,900,13600,10.00005,0.000:\%.

1 'REVS (RPM;",9,'BSFC',4)

CALL PLOTE (REUS, BSFC, NN)

CALL CHAMOD

READ $1: \cdots:$

CALL PICCIE

CALL AXIPLOC0,0.10,11,1,4,2,0.1100,10.00005,0.00015,

1'POWER (KW:',9,'BSFC',4)

CALL PLOTS2 (POWER,BSFC, NN)

CALL CHAMCD

READ : i, *;

CALL DEVEPID

CALL EXIT

C

SUEREUTINE PLOTS (XMAT, YMAT,N)

DIMENSION XMAT $(100,5)$, YMAT $(100,5), X(100), Y(100), 15 Y M(5)$ DATA isYri, $3,4,5,6,71$

DO $1: j=i, 5$

NSYM = [SYMi:J)

DO $20:=2, N$

$X(I)=X M A T, I, J)$

$Y(I\}=Y M A T\{I, J)$

20 CONT INUE

CALL SFAEYM(X,Y,N,NSYM,O)

CALL ERACUR $(X, Y, N)$

CALL ORIT: $3,1,1)$

10 CONTINUE

RETURNA

END

C

SUBROUTINE PLOTS2 (XMAT, YMAT,N)

c

DIMENSION XMAT $(100,5), Y M A T(100,5), X(100), Y(100), 15 Y M(5)$

DATA ISYMI3,4,5,6,71

DO $1: \because:=1,5$

NSYM $=I S Y M(T)$

DO $2: j=1, N$

$X(J)=X M A T)(J, I)$

$Y(J)=T \operatorname{MAT} T(J, 1)$

20 CDNT INUE

CALL GRASYM $(X, Y, N, N S Y M, O)$

CALL GRACUR $(X, Y, N)$

CALL $3 \bar{Y}: 3,1,1$

10 CONT:NHE

RETIj:?:

END

Fig26. (Cont'd) 
VEHICLE : JAGUAR 4.2 Litre Manual, 3.31 Final Drive Direct 4 th Gear and Overdrive Top.

\begin{tabular}{|c|c|c|c|c|}
\hline $\mathrm{mph}$ & $h p-4 t h$ & $\mathrm{rpm}-4 \mathrm{th}$ & $h p-5 t h$ & $\mathrm{rpm}-5 \mathrm{th}$ \\
\hline 10 & 1.66 & 435 & 1.71 & 365 \\
\hline 20 & 3.76 & 870 & 3.88 & 725 \\
\hline 30 & 6.72 & 1305 & 6.93 & 1090 \\
\hline 40 & 10.98 & 1740 & 11.33 & 1450 \\
\hline 50 & 17.02 & 2180 & 17.50 & 1815 \\
\hline 60 & 25.36 & 2615 & 26.17 & 2180 \\
\hline 70 & 36.31 & 3050 & 37.47 & 2540 \\
\hline 80 & 50.49 & 3485 & 52.10 & 2905 \\
\hline 90 & 68.30 & 3920 & 70.45 & 3265 \\
\hline 100 & 90.27 & 4355 & 93.15 & 3630 \\
\hline 110. & 118.13 & 4790 & 121.91 & 3990 \\
\hline 120 & 155.39 & 5225 & 160.35 & 4355 \\
\hline
\end{tabular}

Fig 27 Road Load and Engine Speed Data - Jaguar 4.2L. 


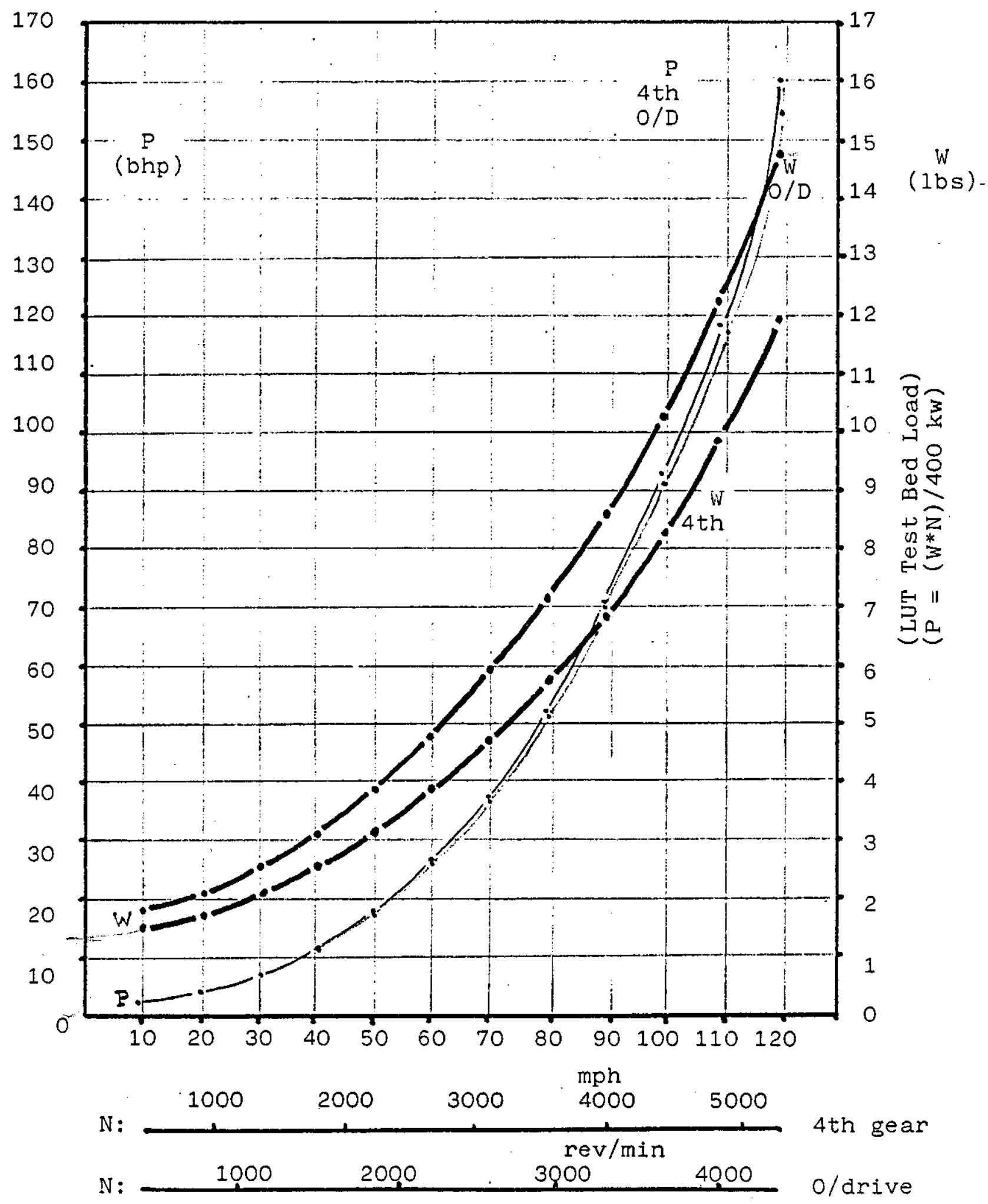

Fig28.JAG 4.2L: Road Load curves in 4 th and $O / D$ Gears. 


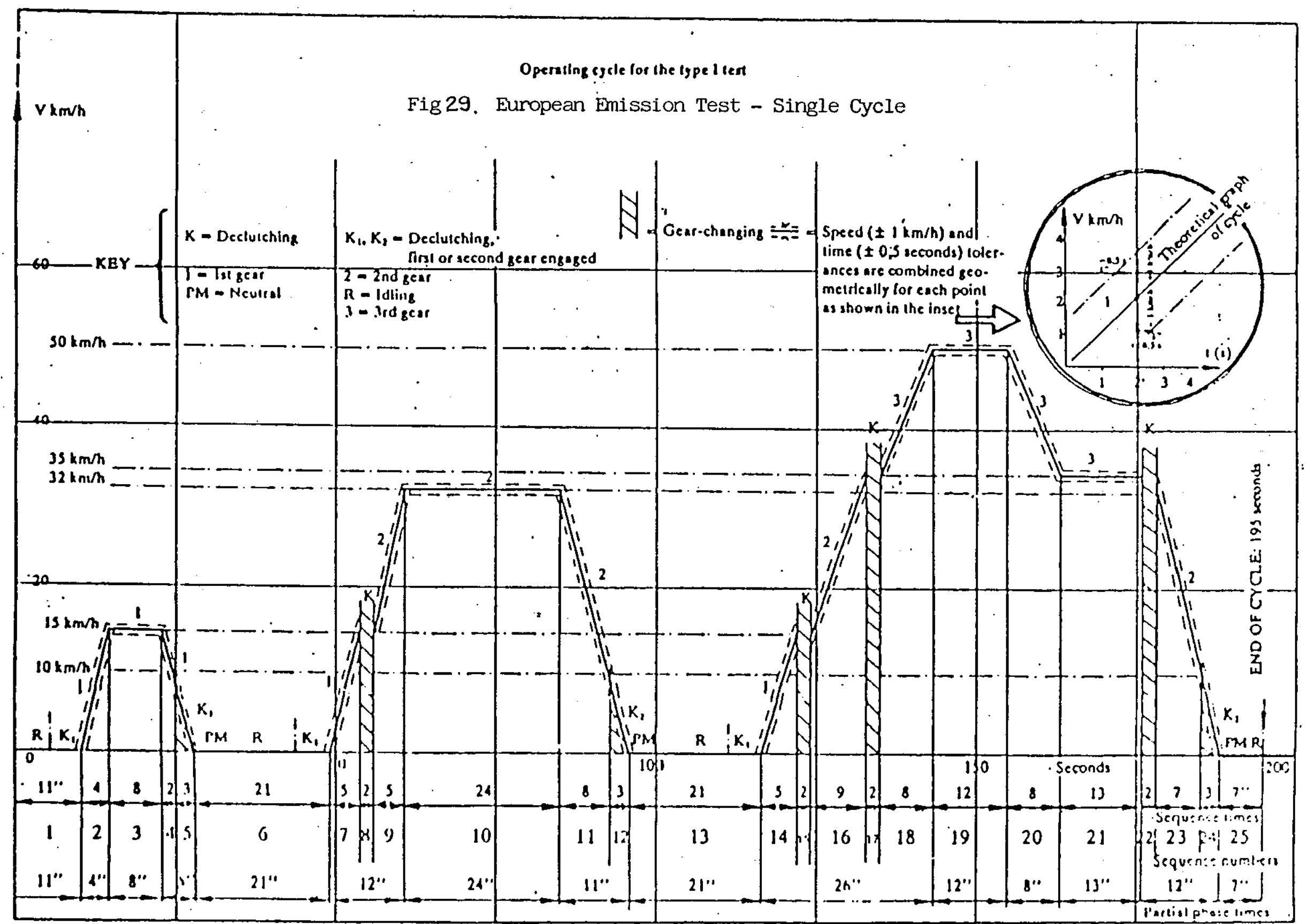




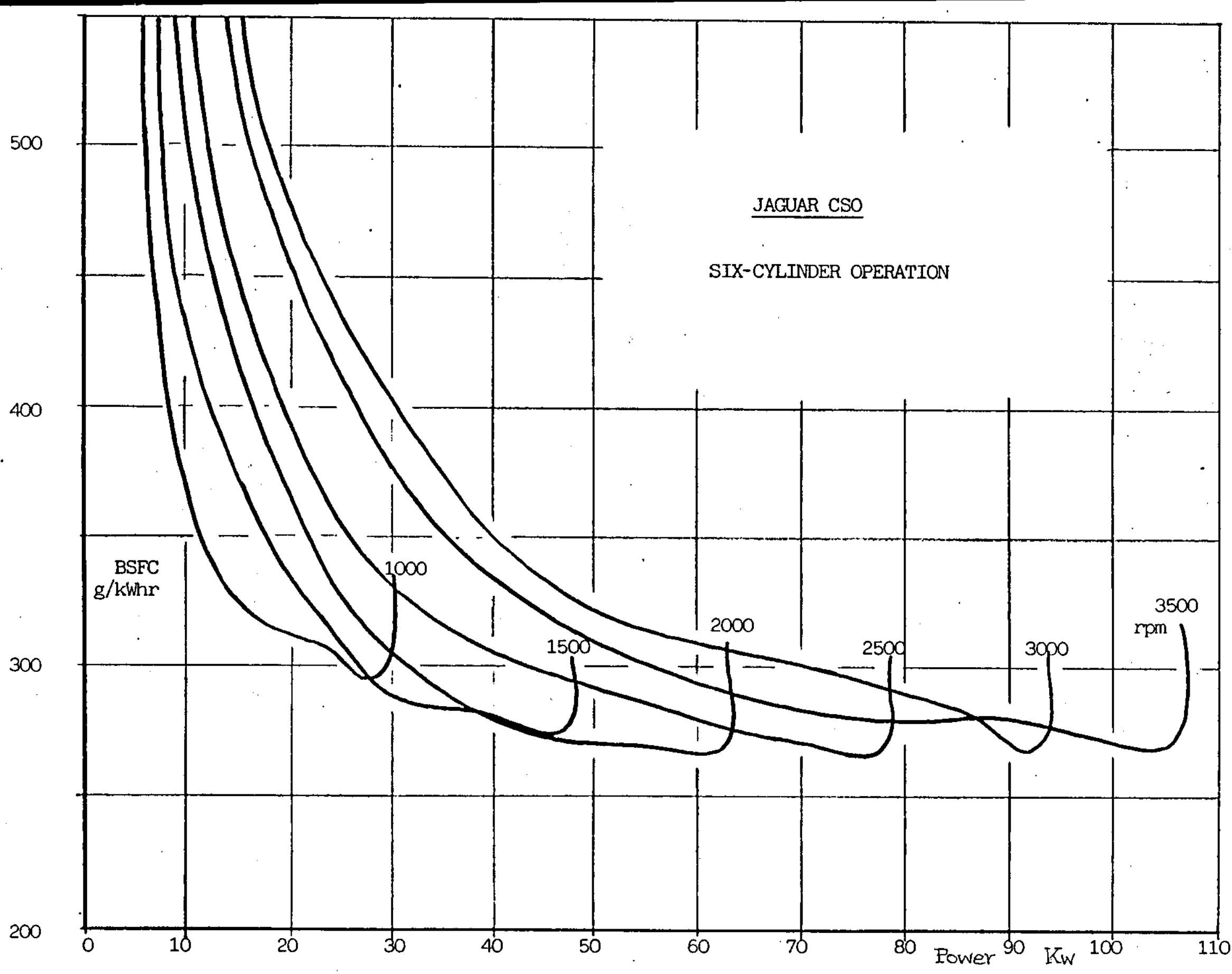

Fig30. Fuel

Consumption Loops 


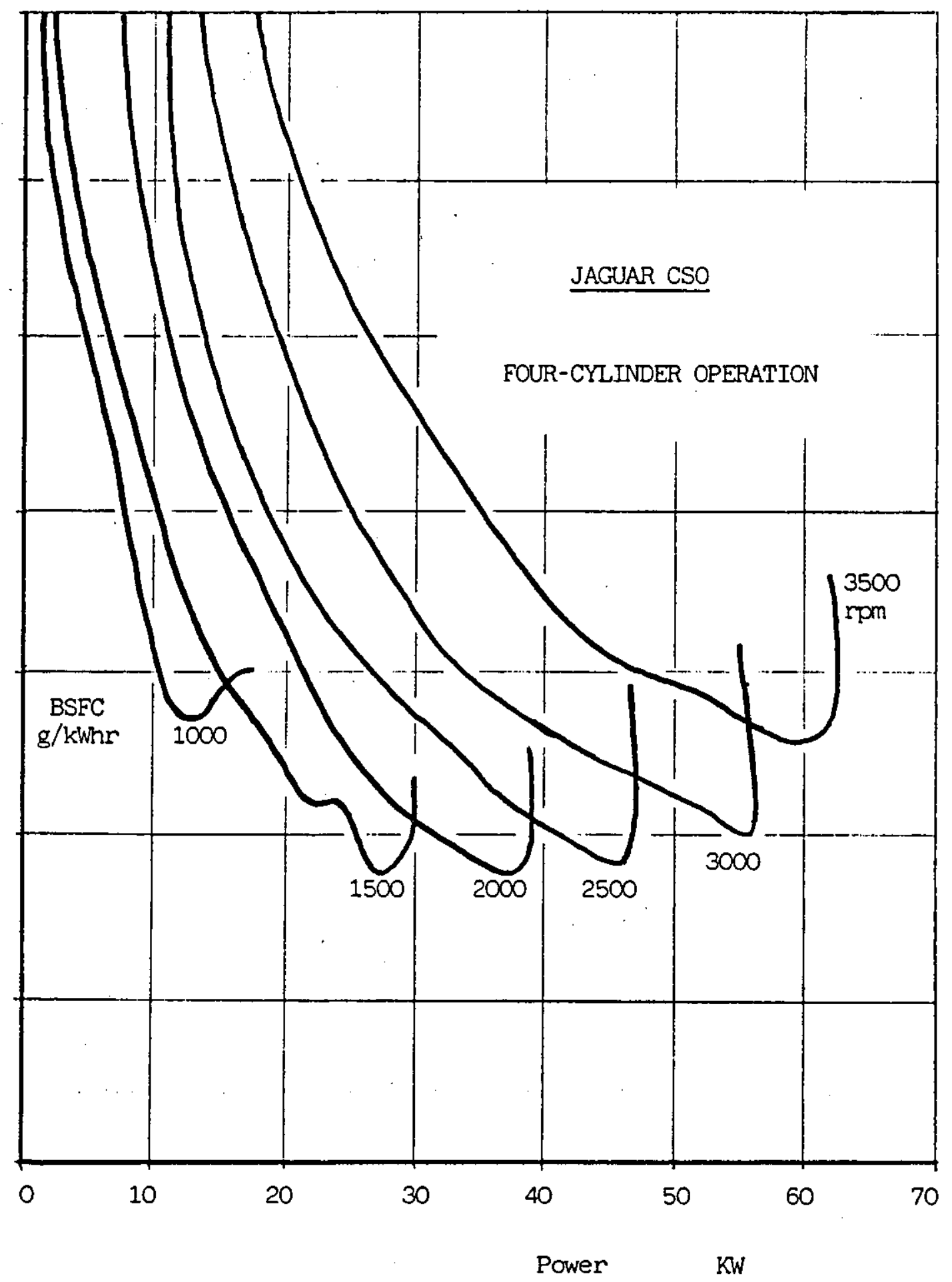

Fig: 32. Fuel Consumption Loops 


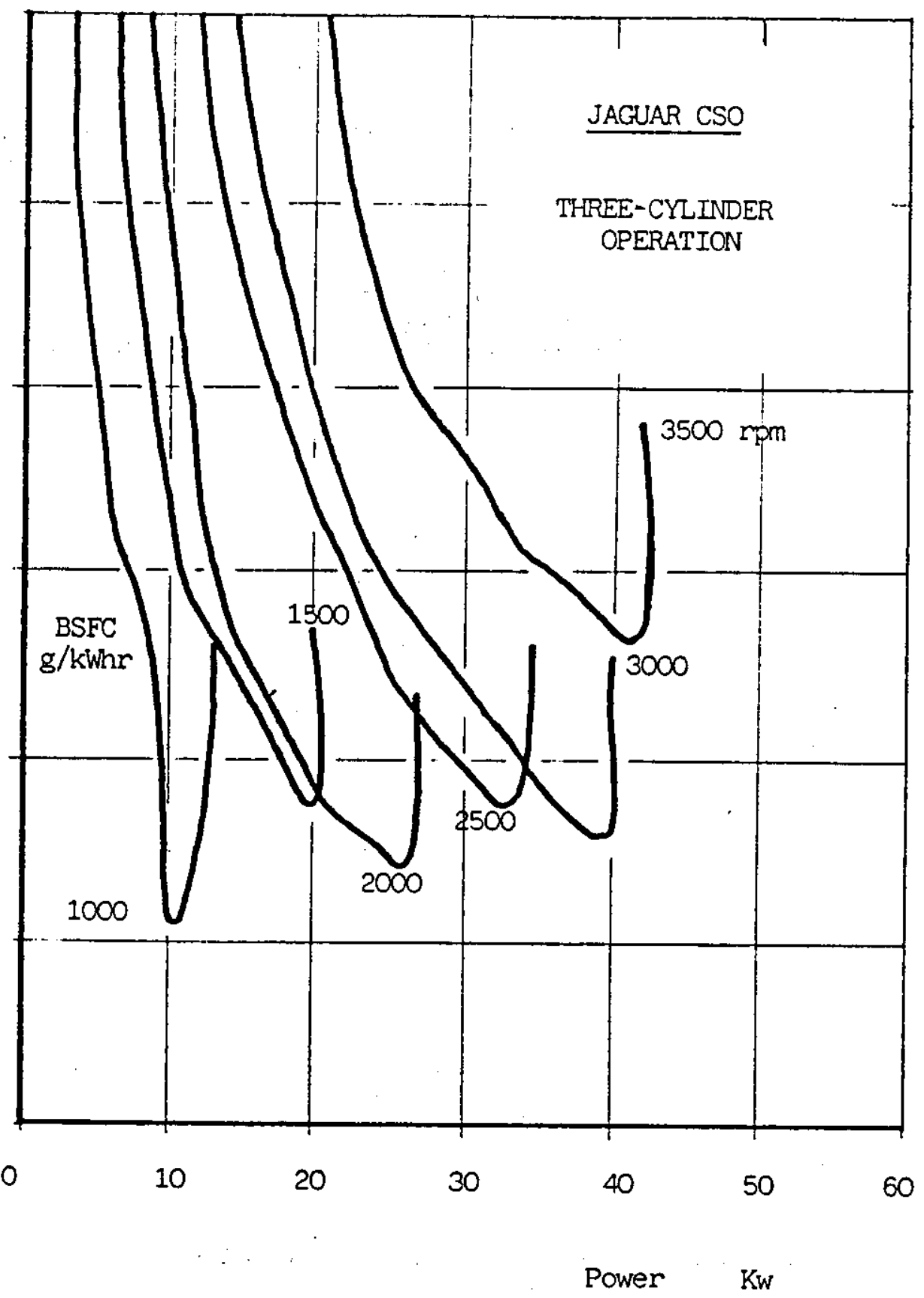

Fig: 33. Fuel Consumption Loops 


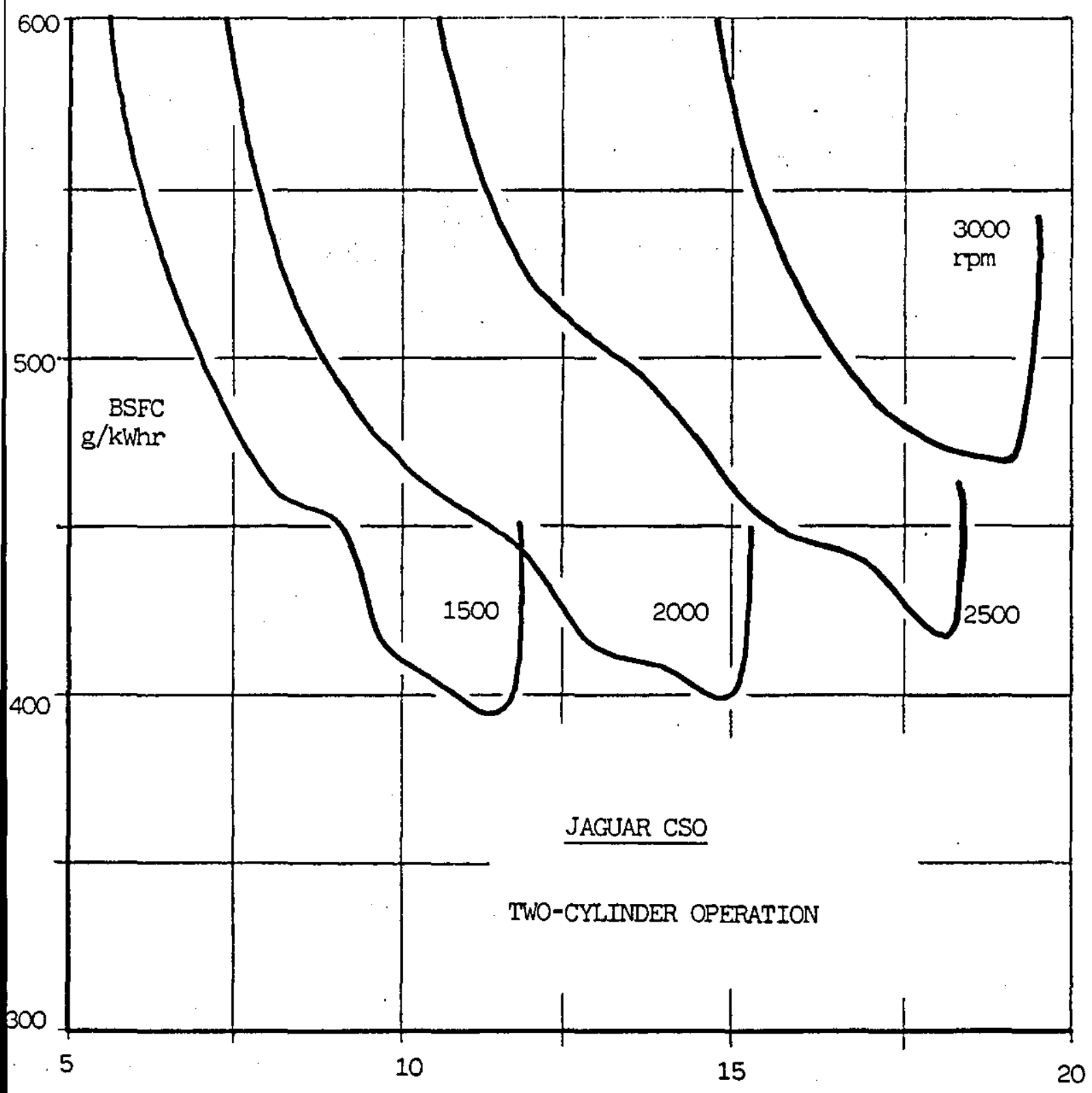

Power KW

Fig: 34. Fuel Consumption Curves 


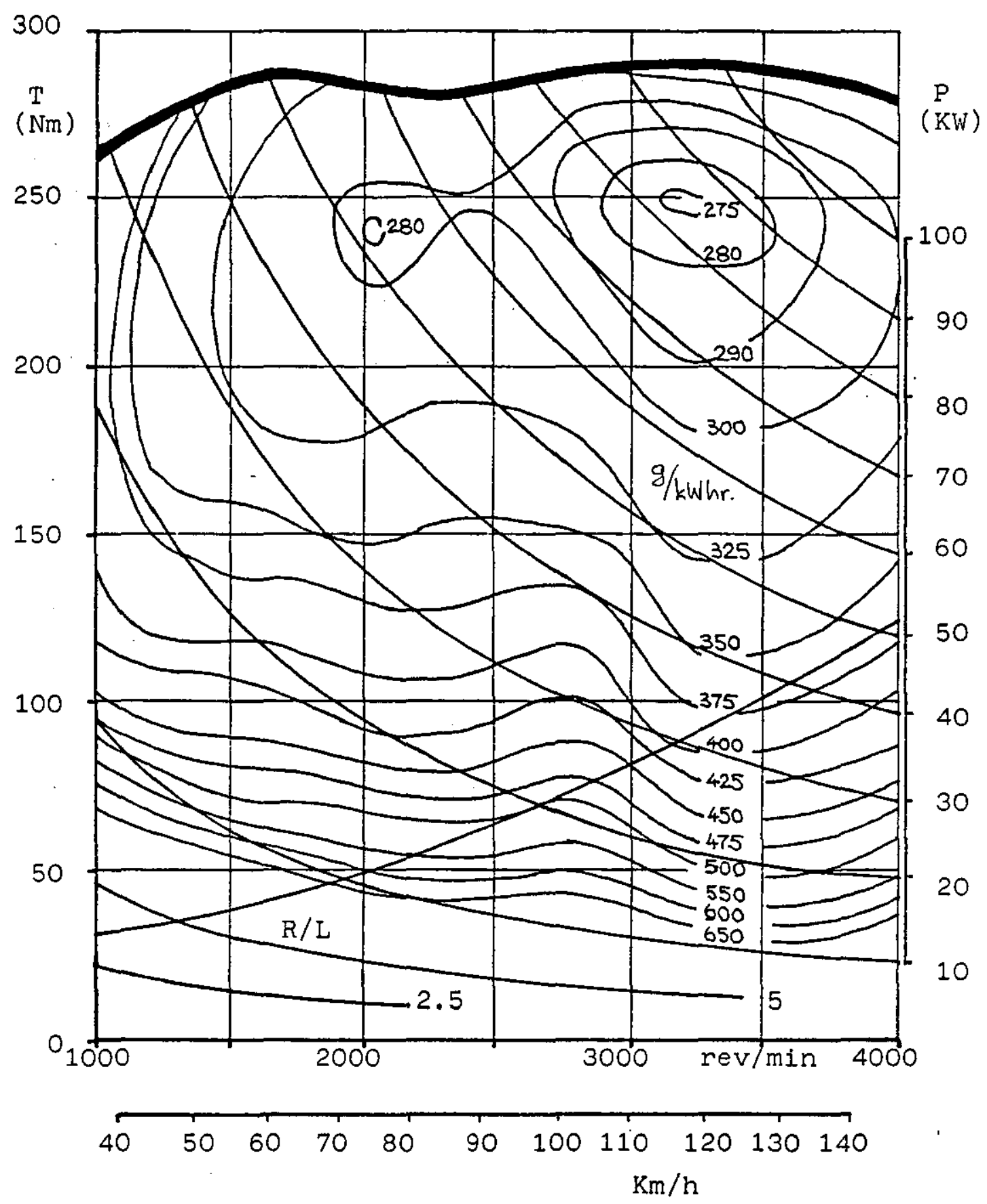

Fig 35. JAG 4.2L: Six-cylinder Engine Performance Map. 


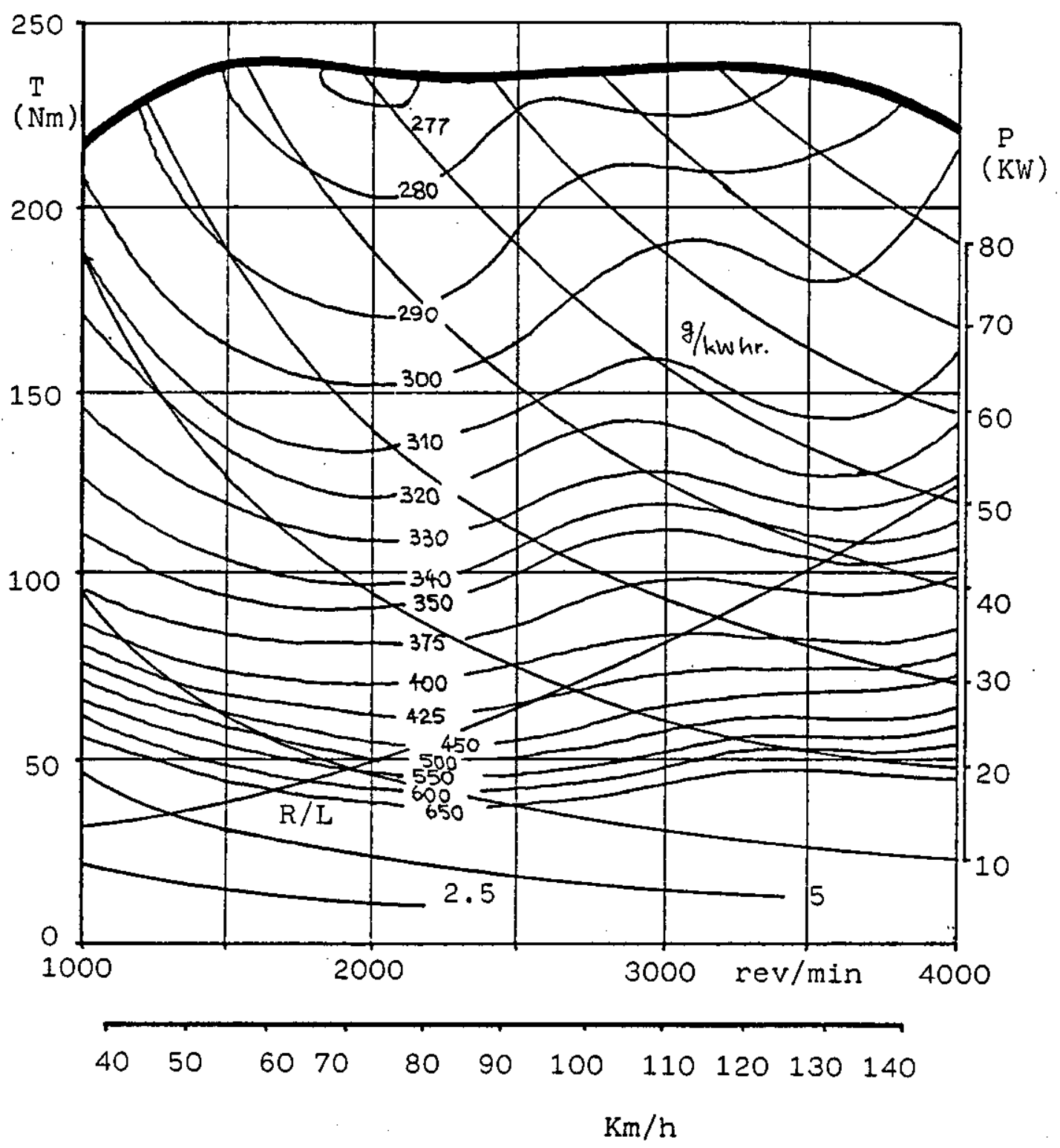

Fig36.JAG 4.2L: Five-cyl. Engine Performance Map. 


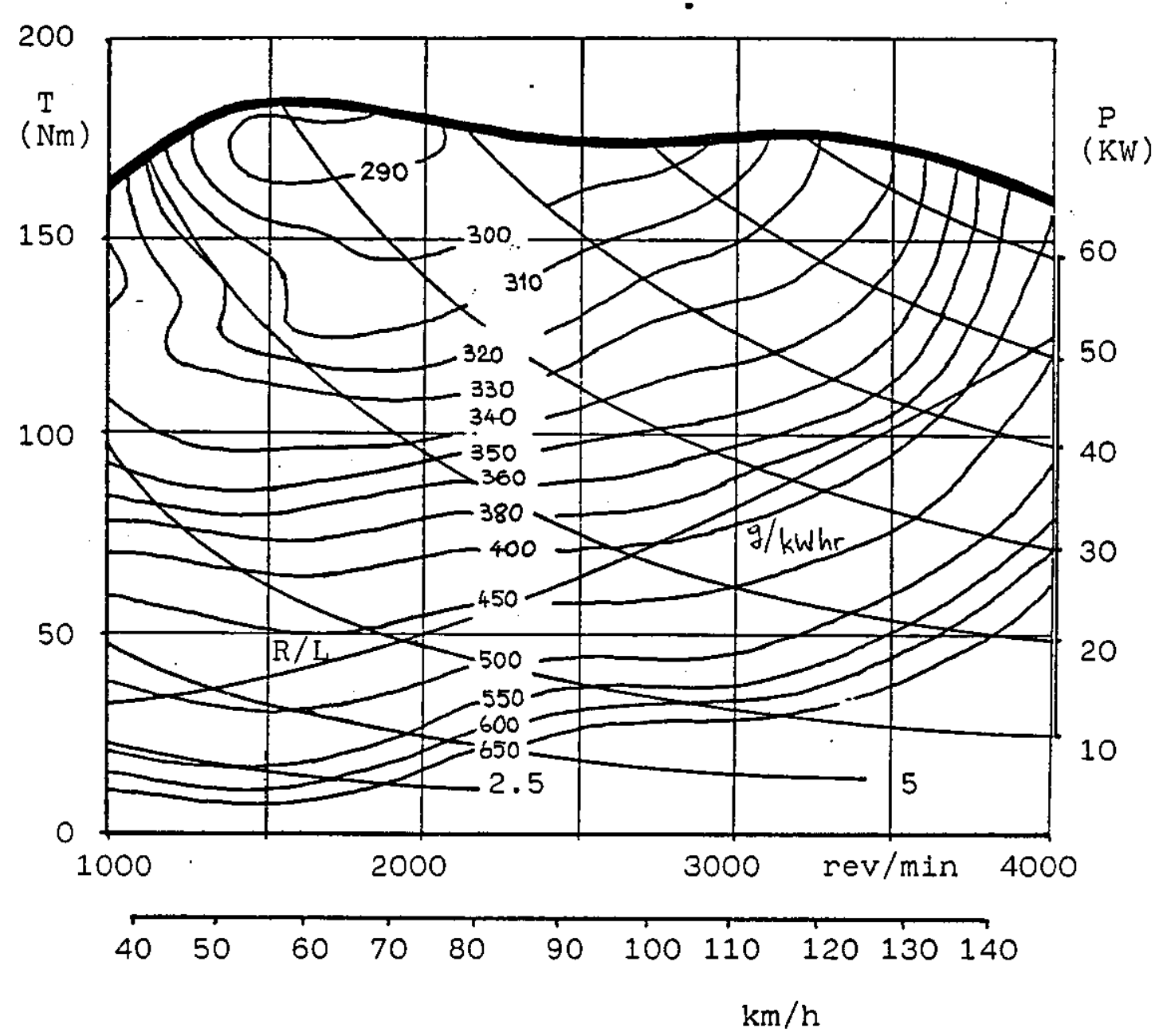

Fig37. JAG 4.2L: Four-cyl. Engine Performance Map. 
Fig 38, JAG 4.2L: Three-cyl Engine Performance Map
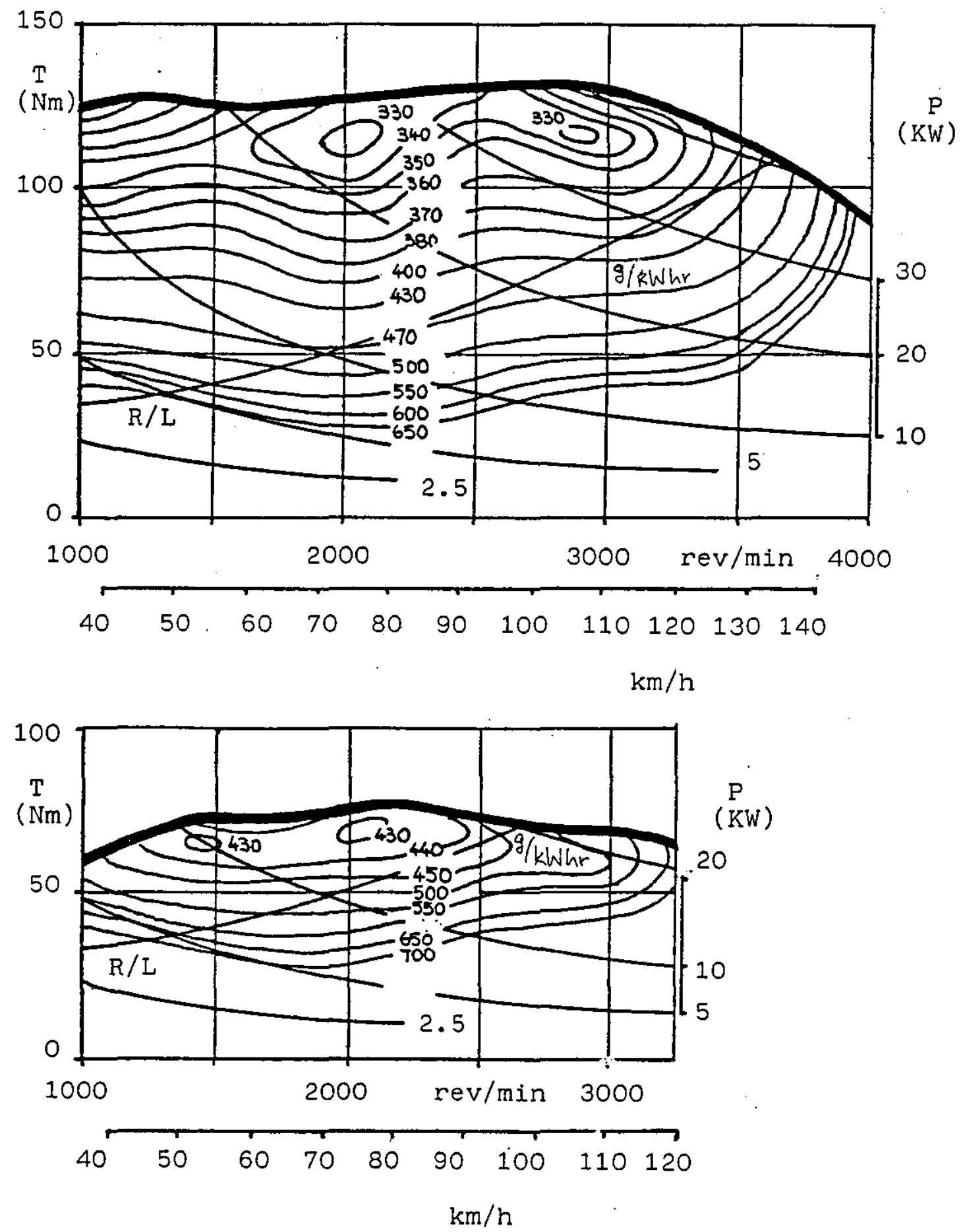

Fig 39. JAG 4.2L: Two-cyl Engine Performance Map 
\& FUEL ECONOMY GAIN

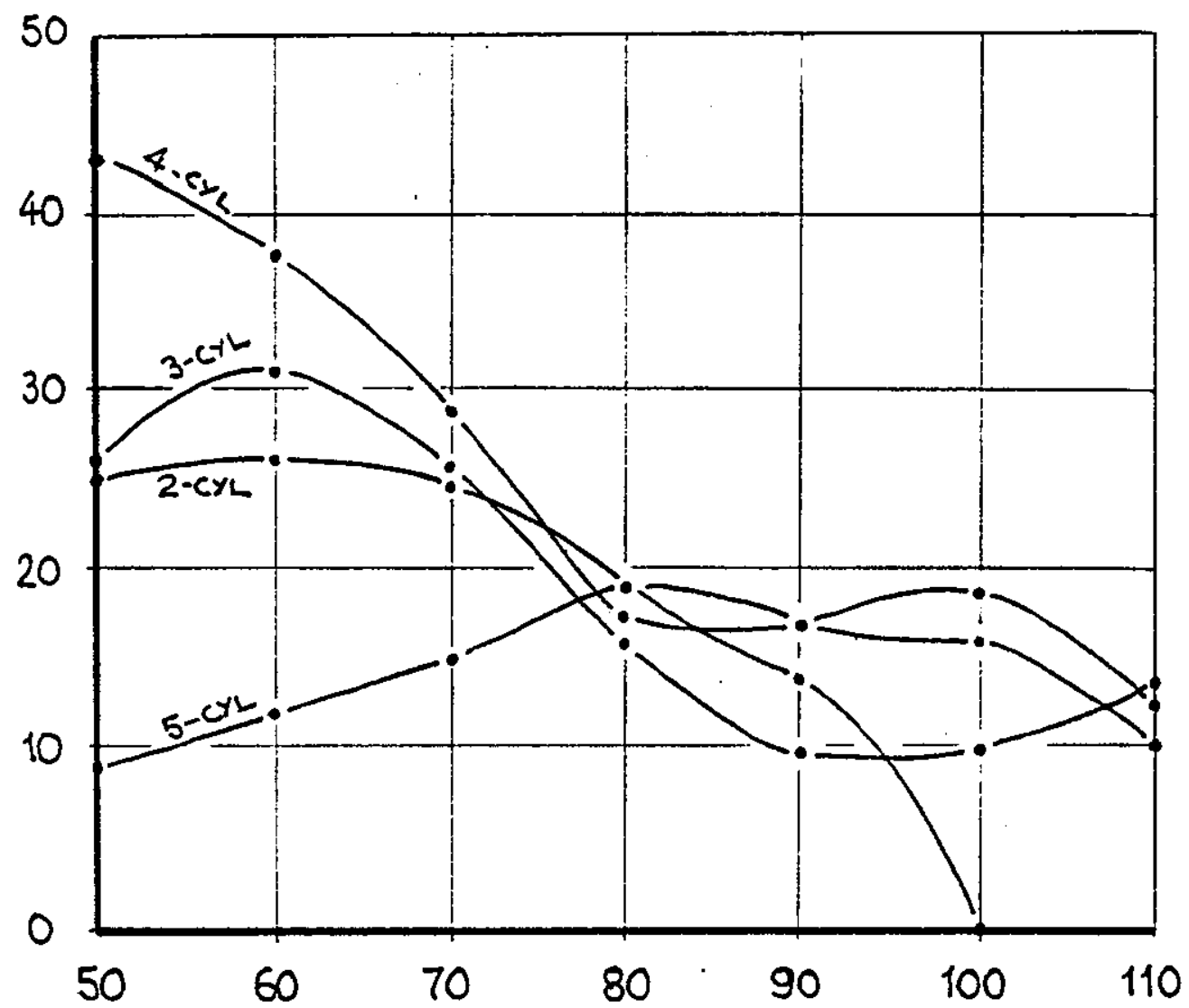

VEHICLE SPEED $\mathrm{km} / \mathrm{hr}$

Fig 40. Constant speed Fuel Economy Gains at Vehicle Road Loads in Direct 4 th Gear Ratio. 


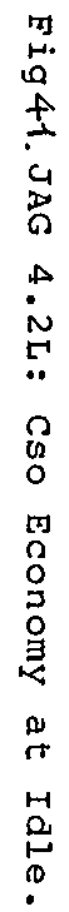

$\%$ ECONOMY GAIN

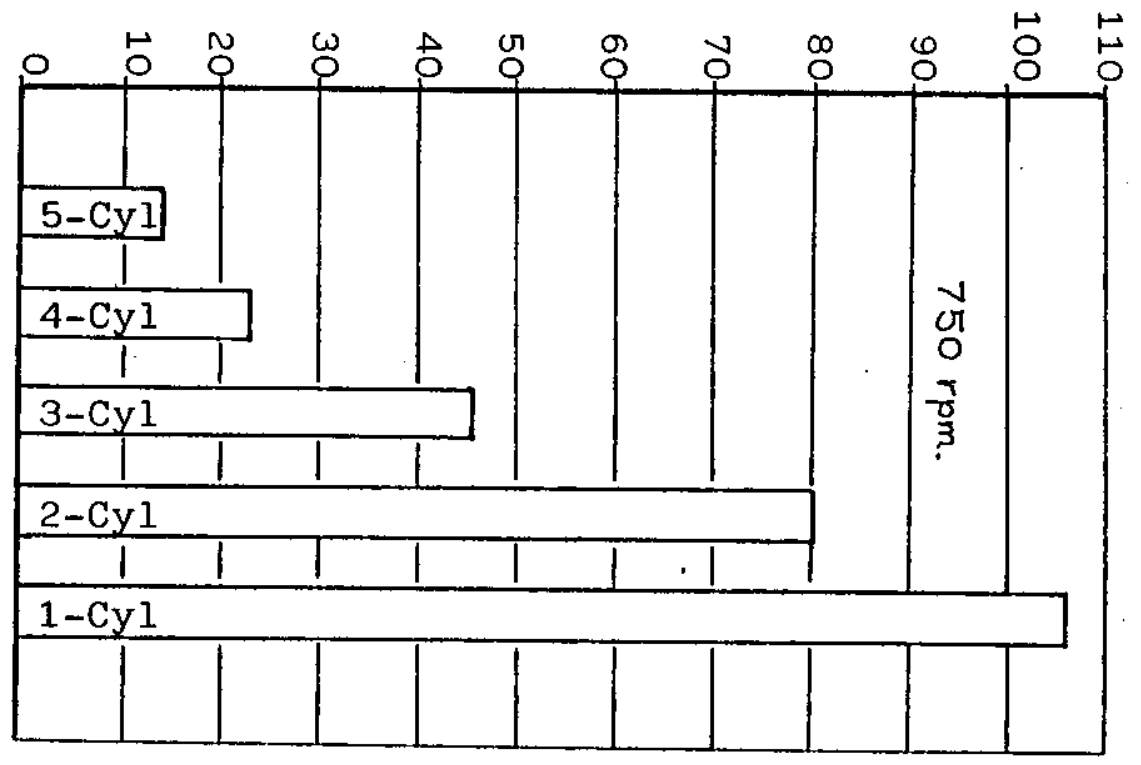




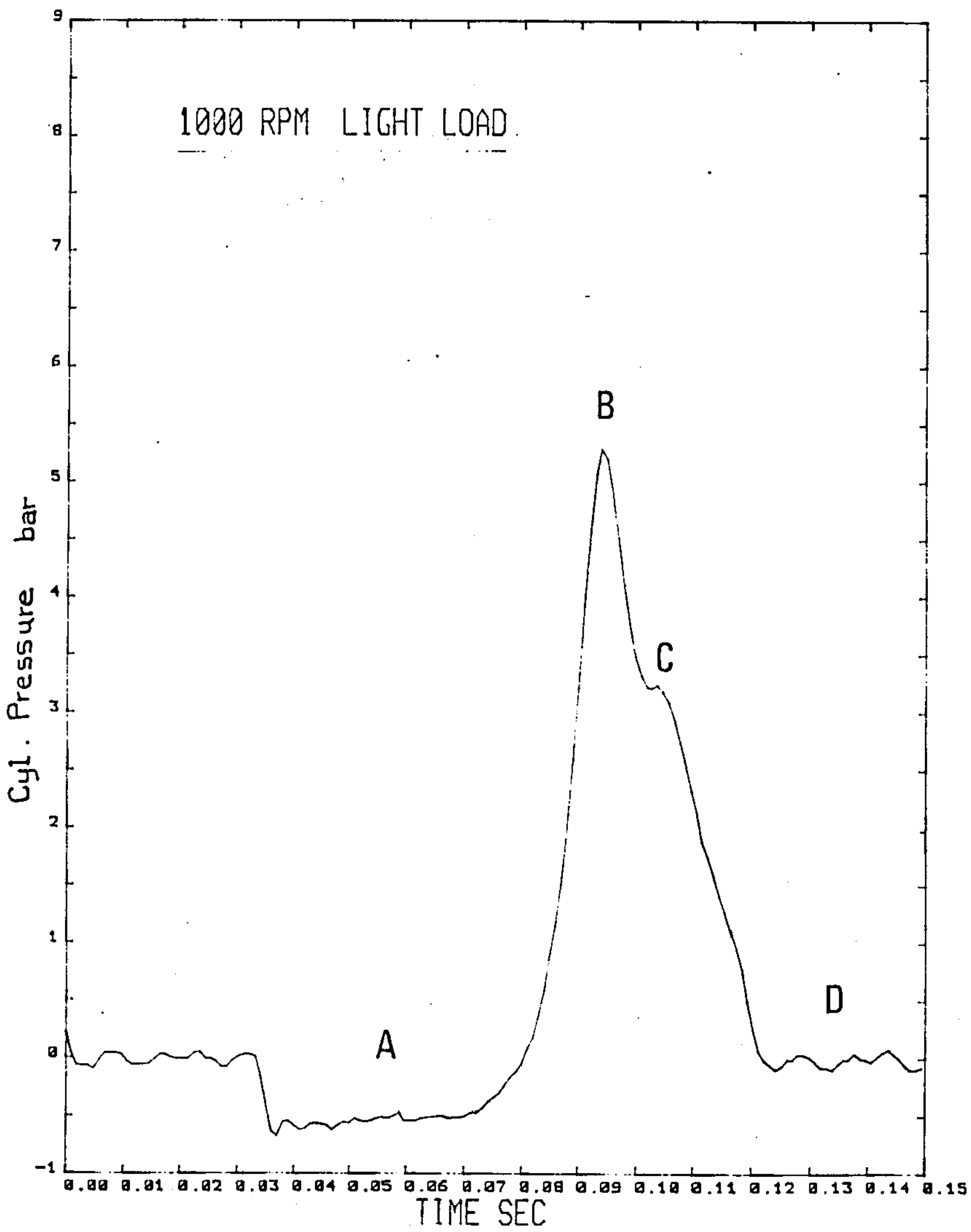

Fig 42 Single Cycle Cylinder Pressure Diagram - 1. 


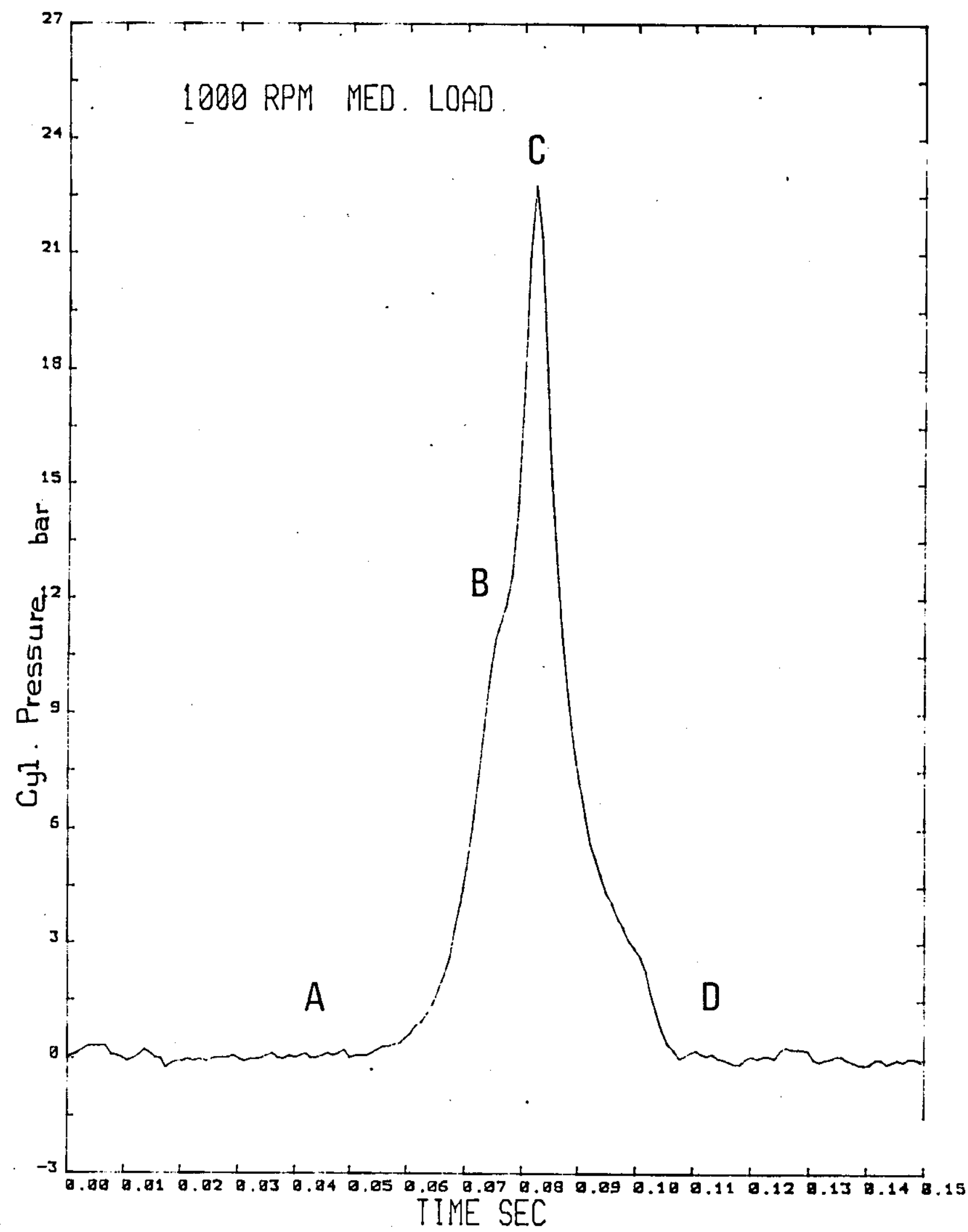

Fig 43 Single Cycle Cylinder Pressure Diagram - 2. 


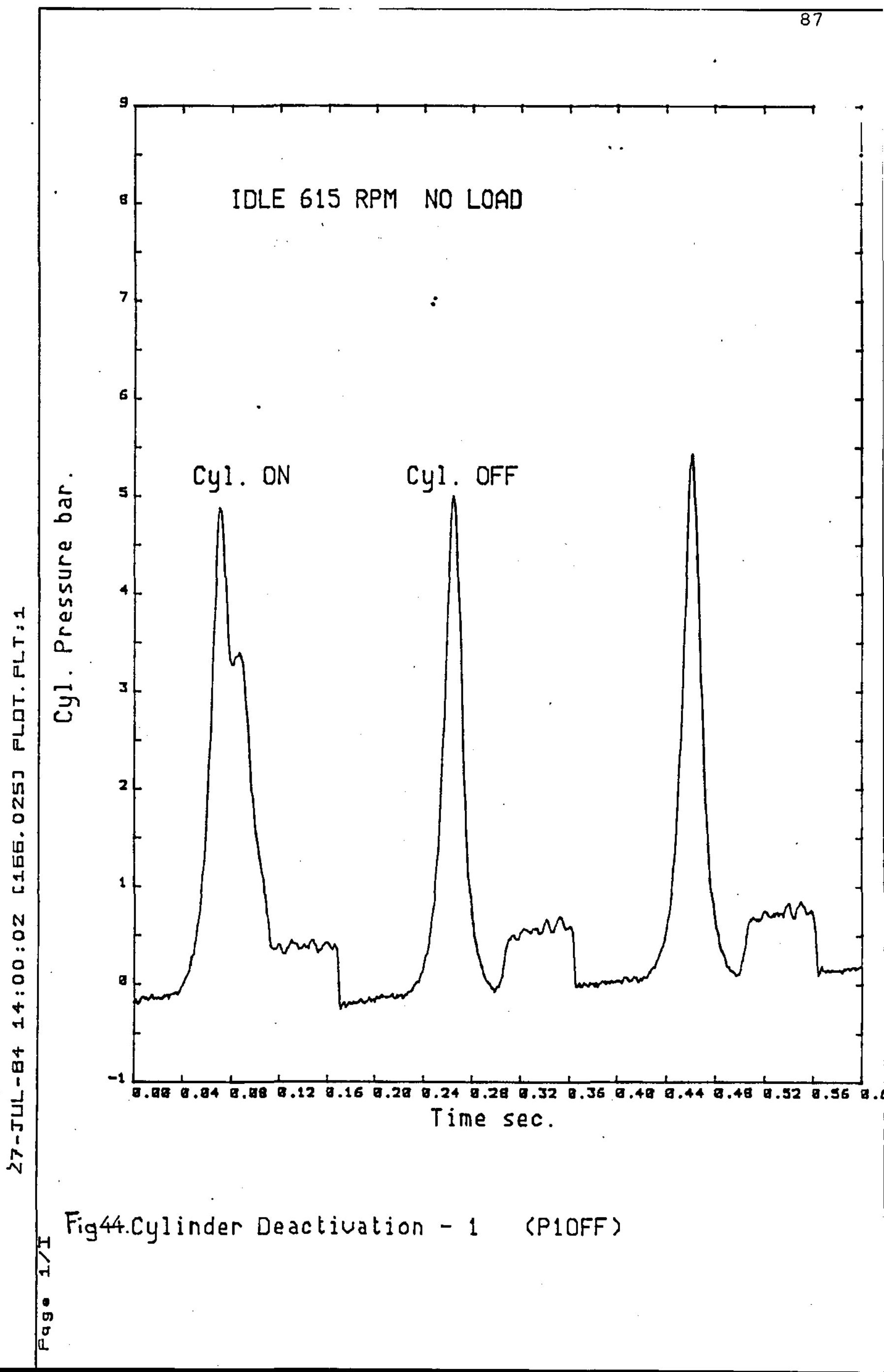




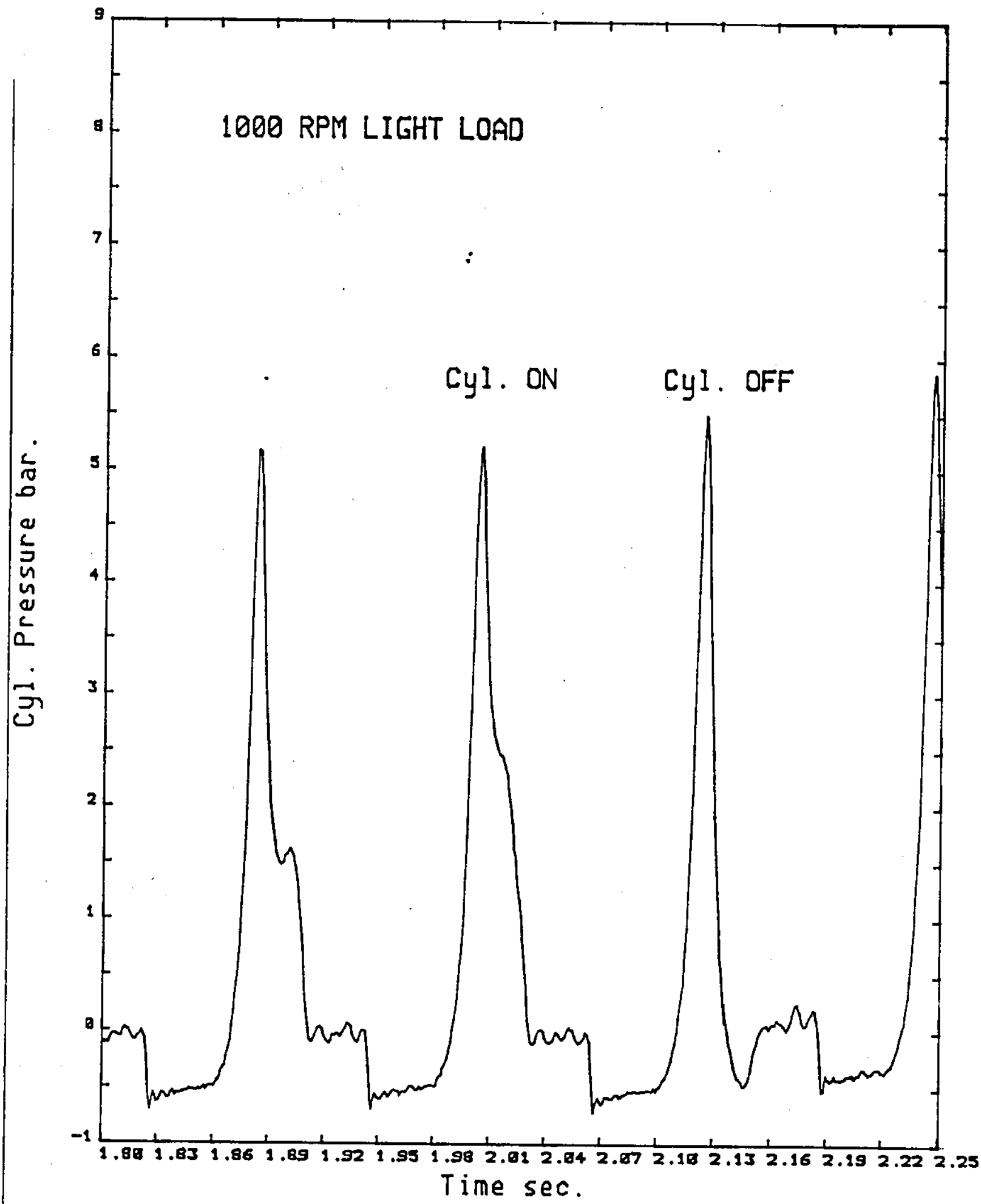

Fig45.Cylinder Deactivation - 2 (P2OFF) 


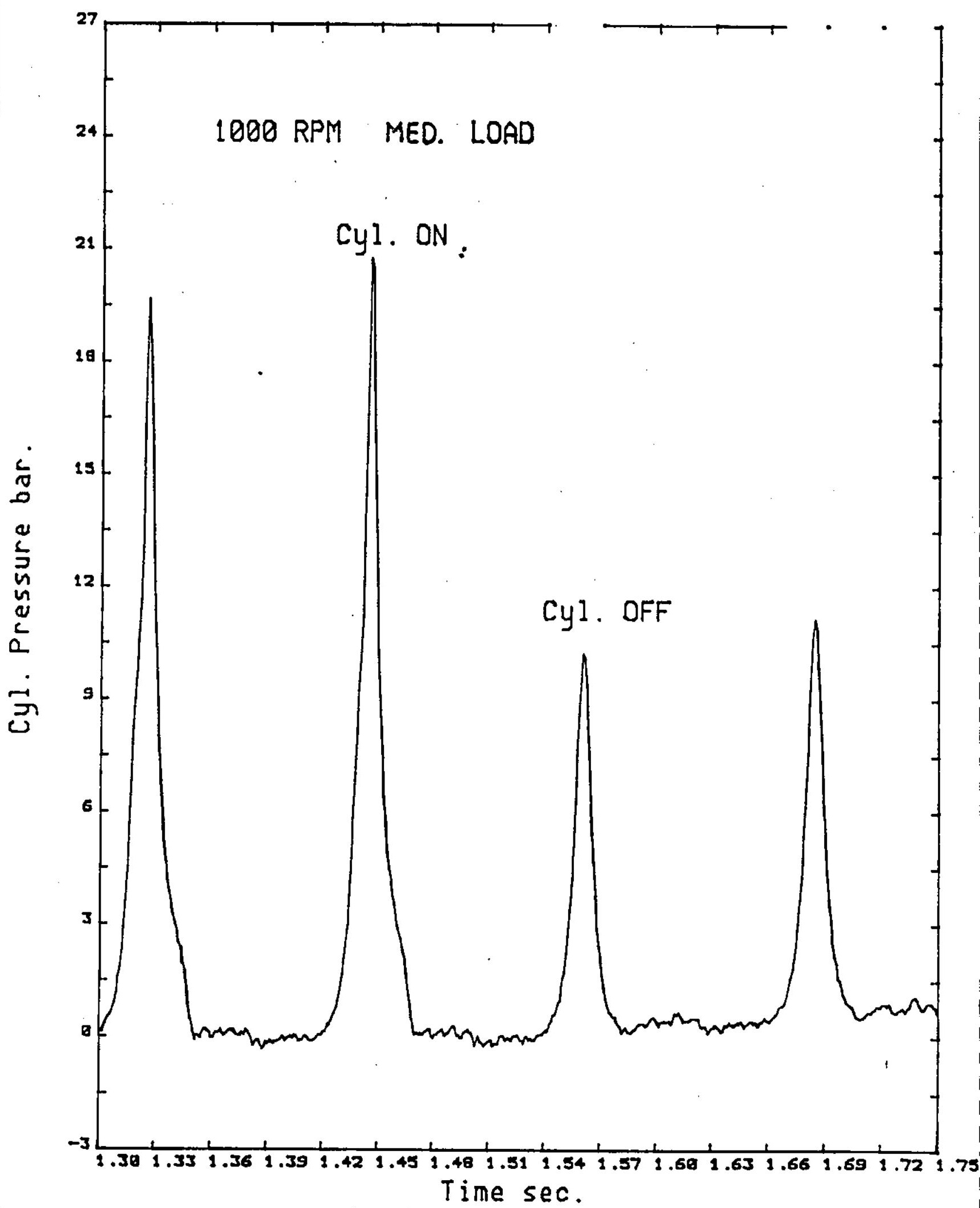

Fig46. Cylinder Deactivation - 3 (P3OFF) 


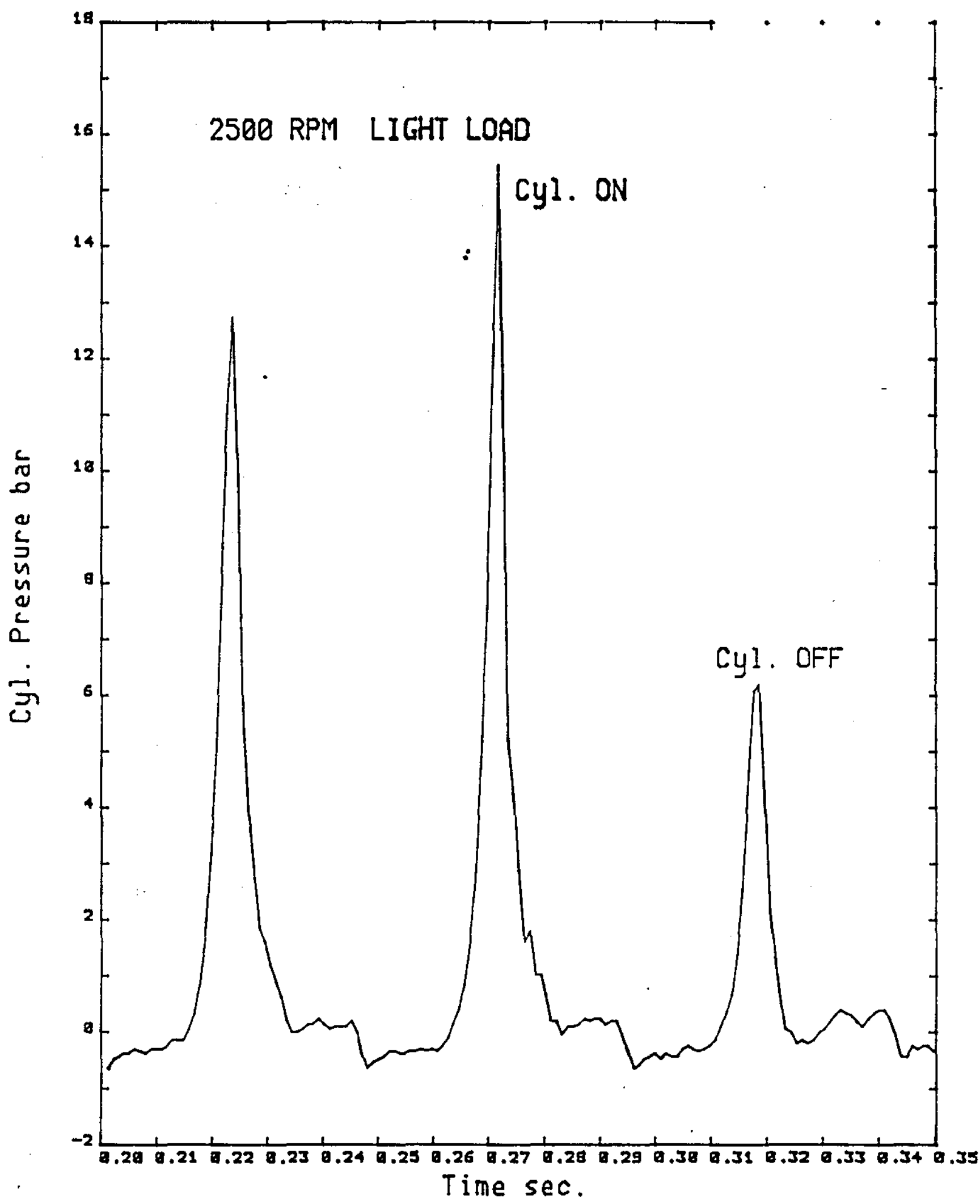

Fig47. Cylinder Deactivation - 4 (P4OFF) 


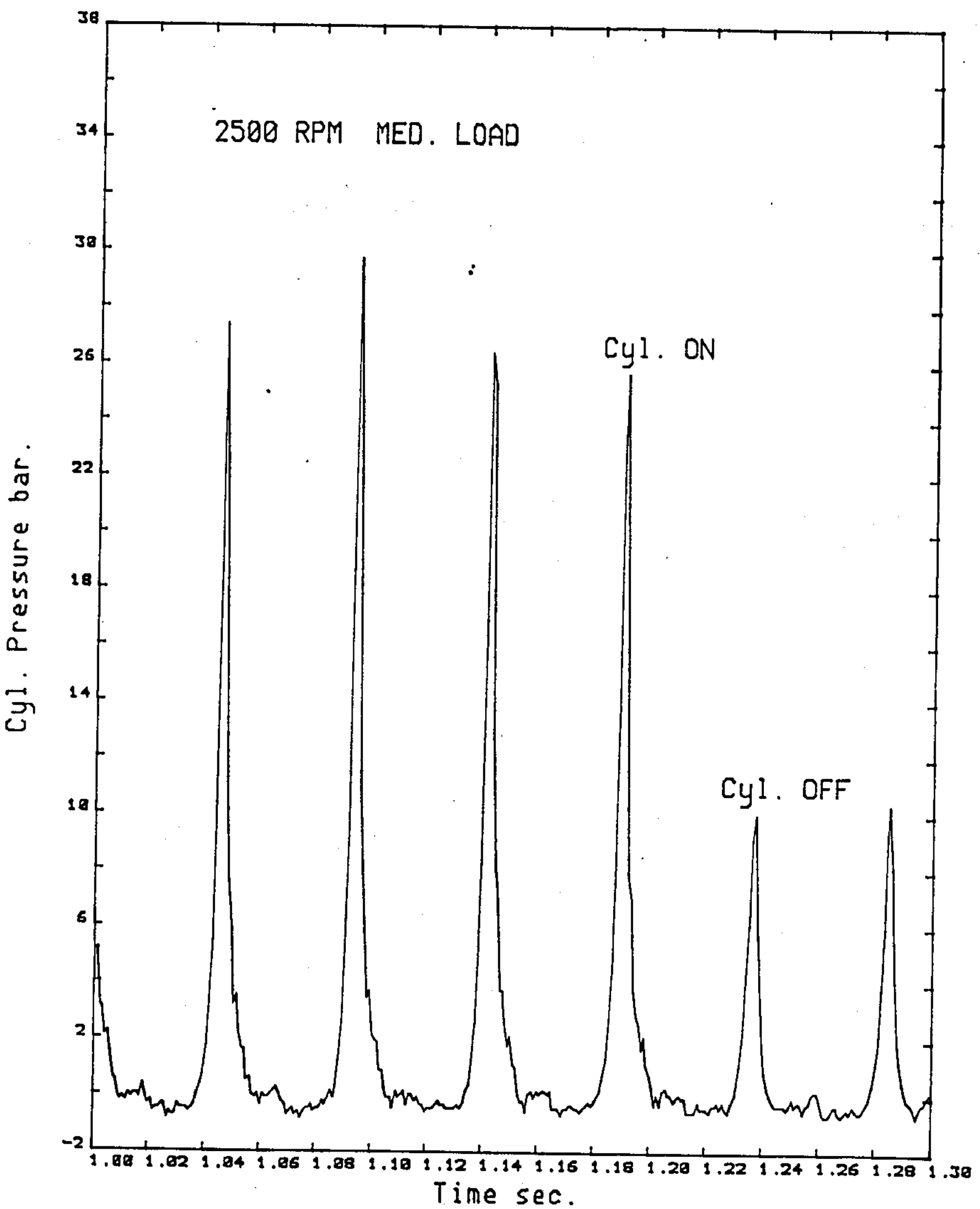

${ }_{H}$ Fig48. Cylinder Deactivation - 5 (P5OFF) in 


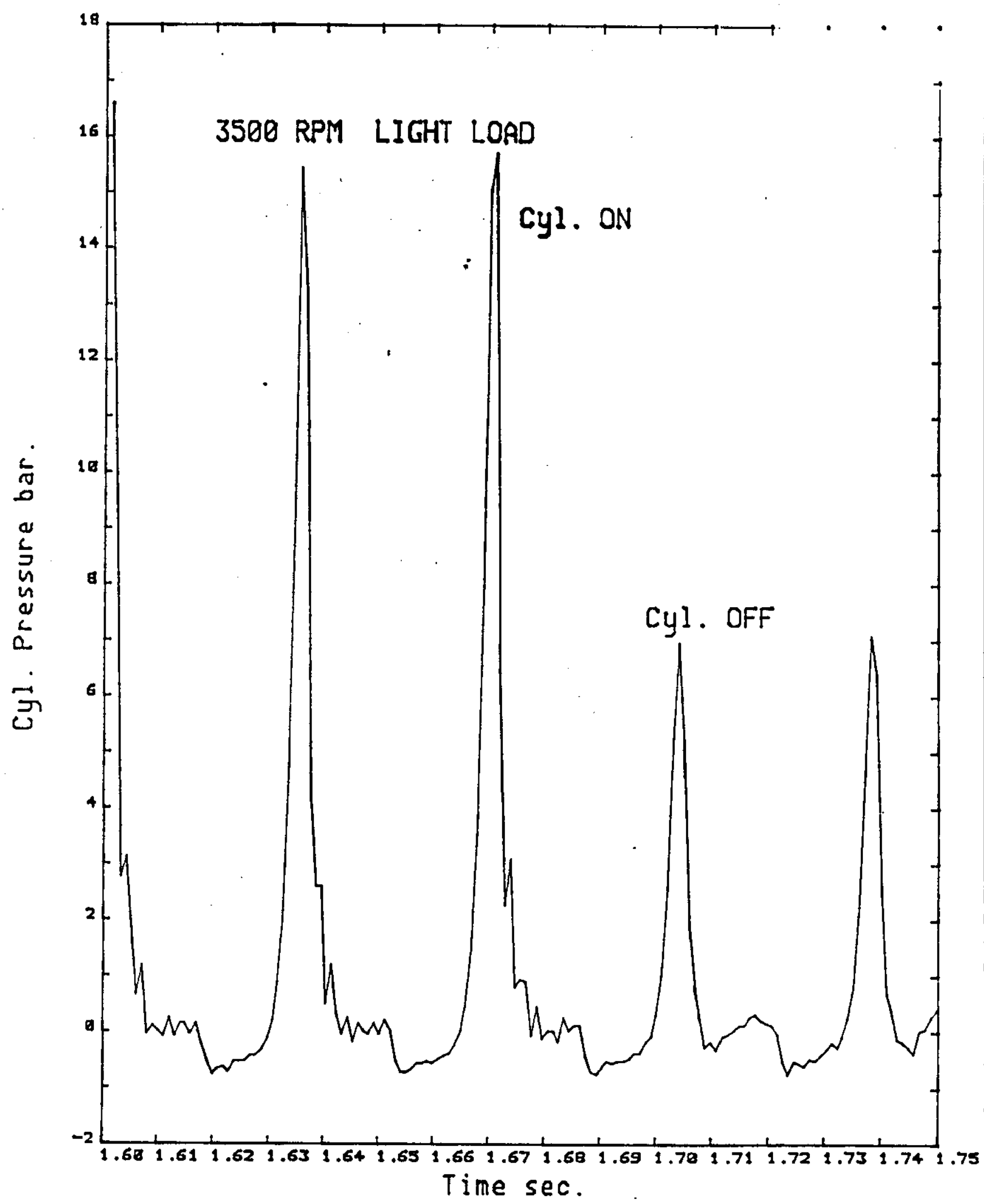

${ }_{H}$ Fig49. Cylinder Deactivation - 6 (P60FF) $H$
10
0
0
0
0 


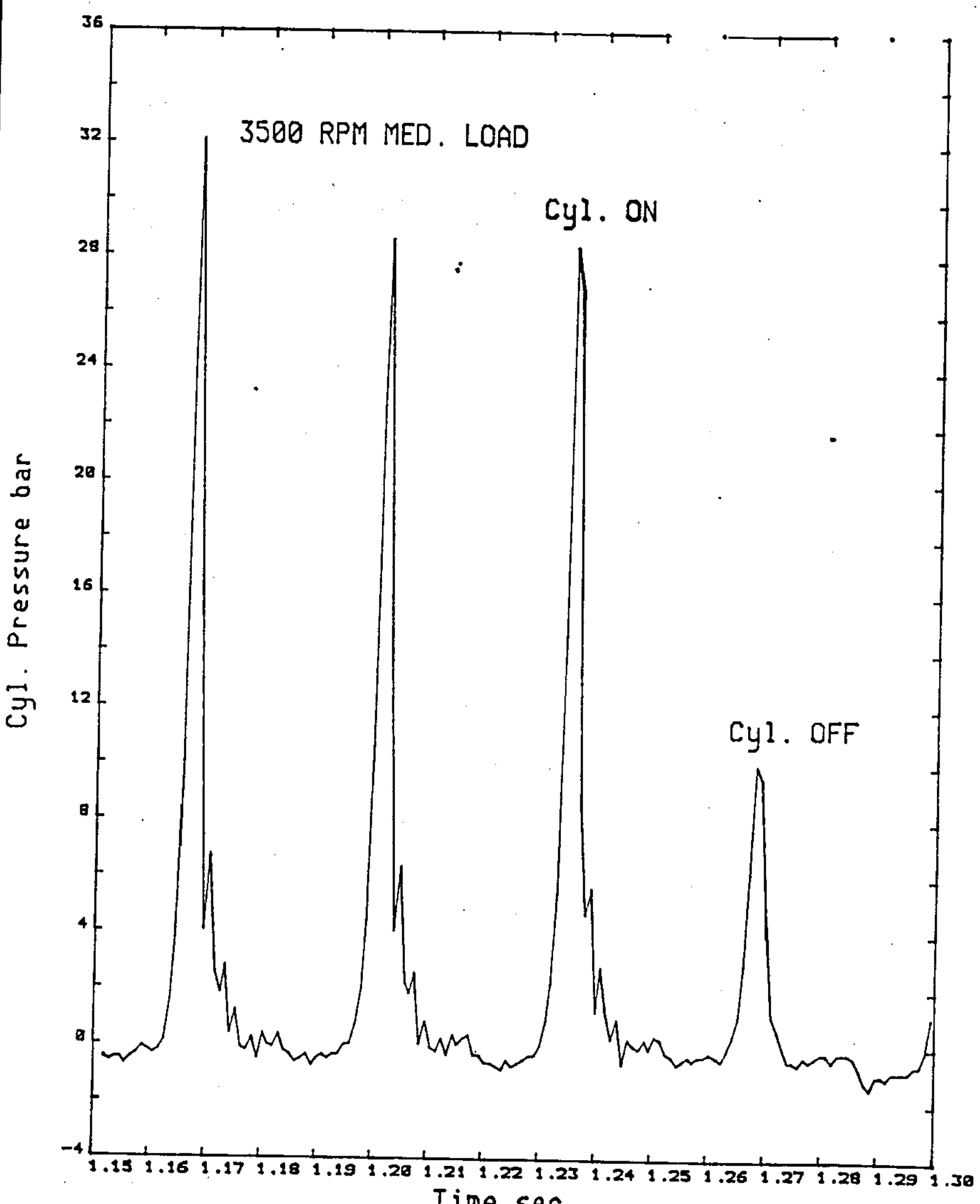

Time sec.

Fig50. Cylinder Deactivation -7 (P7OFF) 


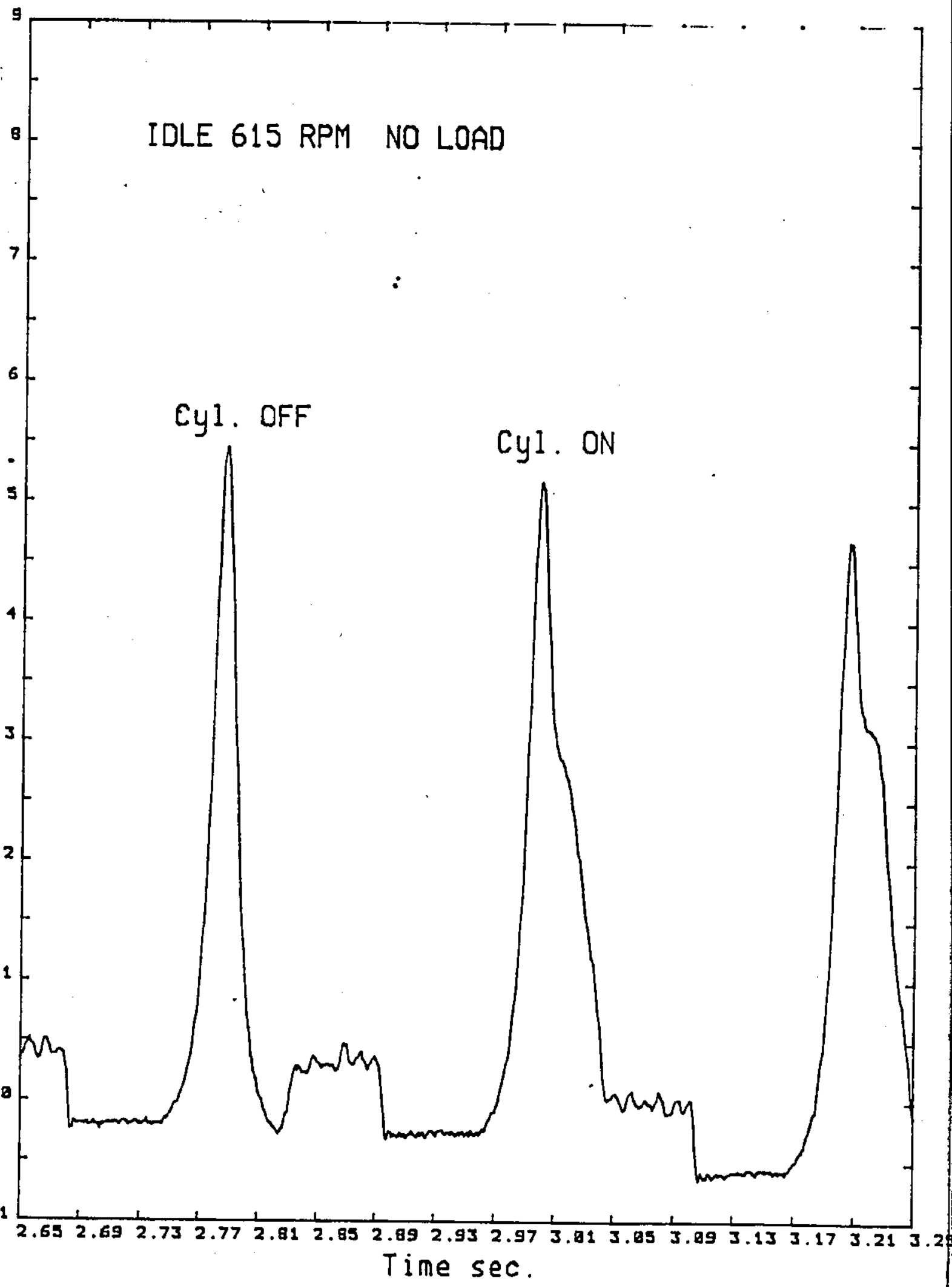

Fig51.Cylinder Reactivation - 1 (PION) 


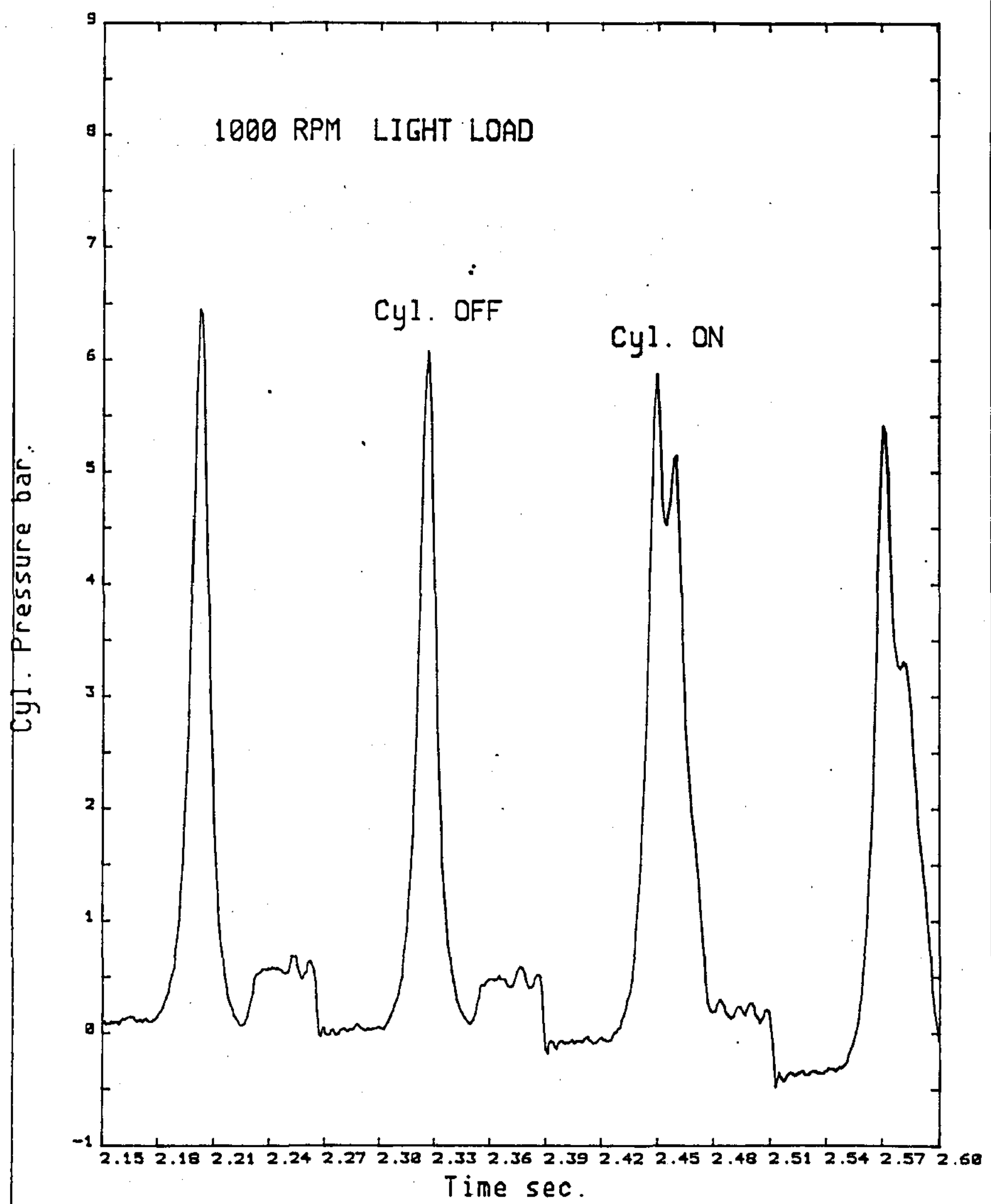

Fig52.Cylinder Reactivation - 2 (P2ON) 


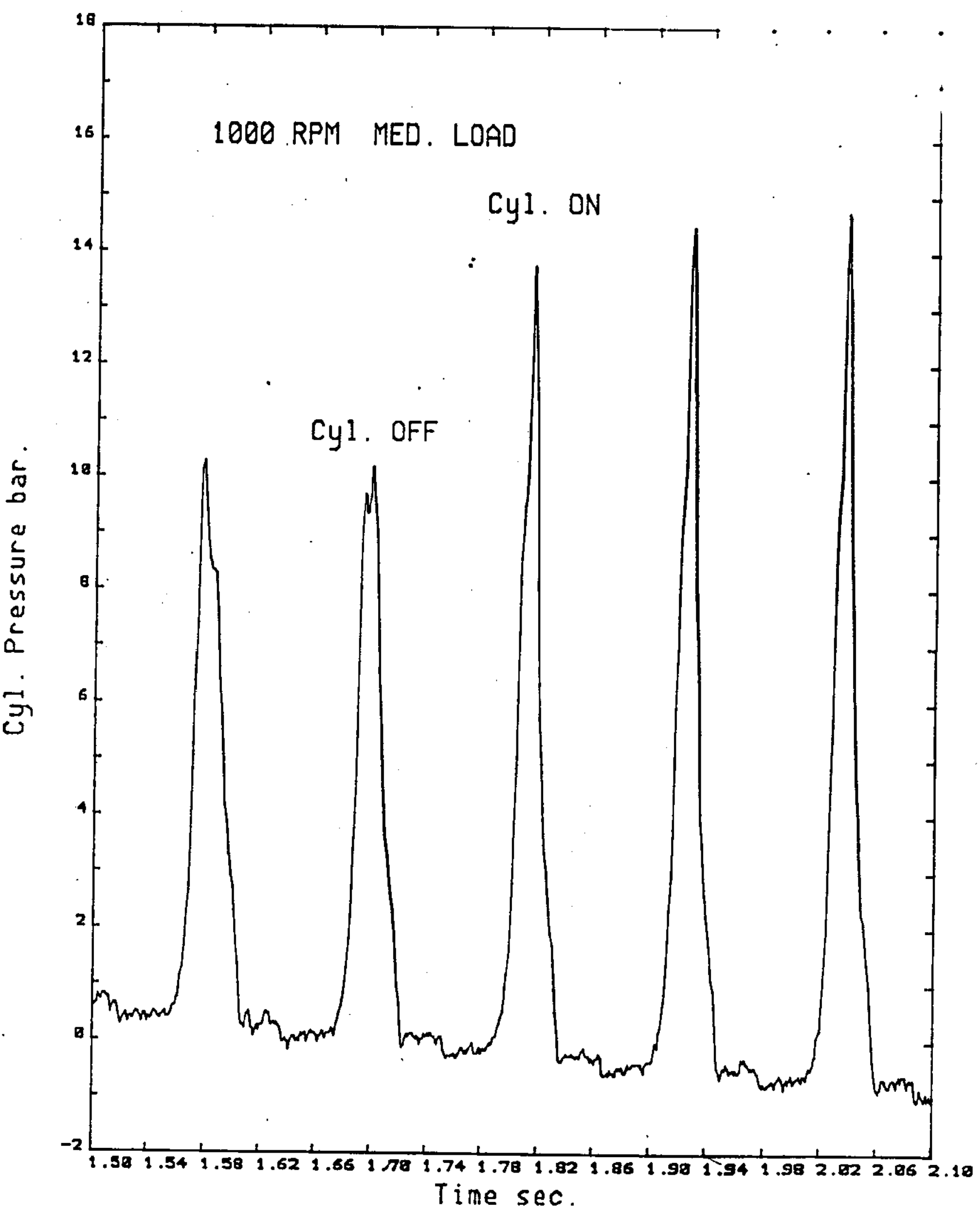

Fig 53. Cylinder Reactivation - 3 (P3ON) 


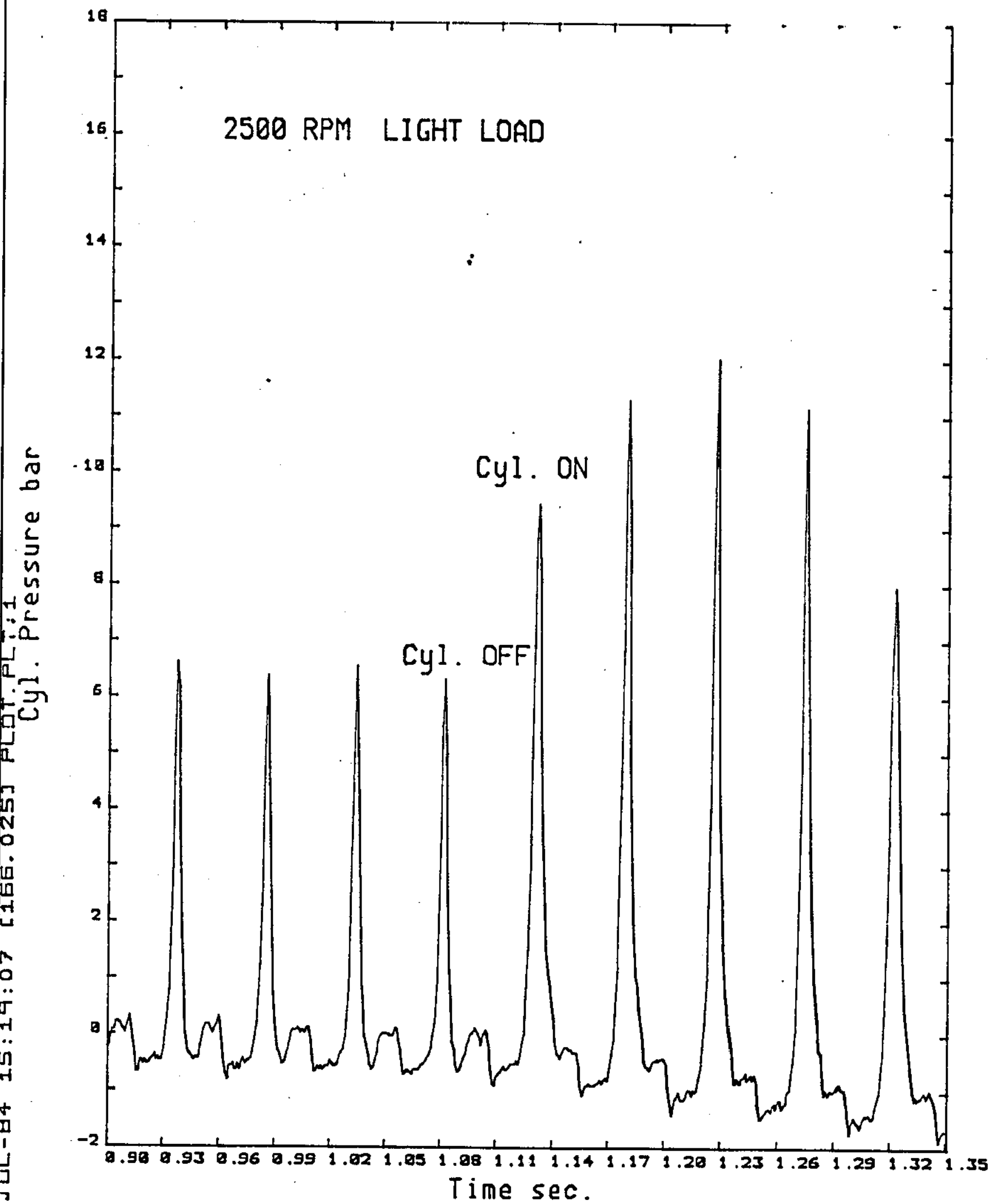

Fig54. Cylinder Reactivation - 4 (P4ON)

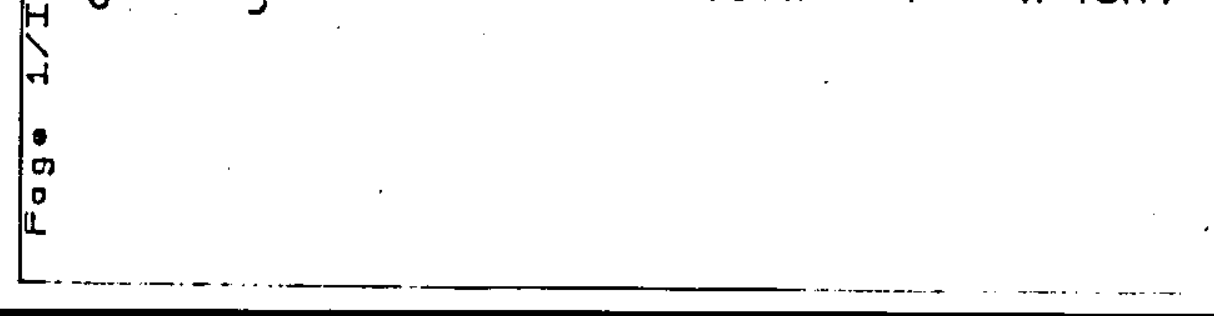




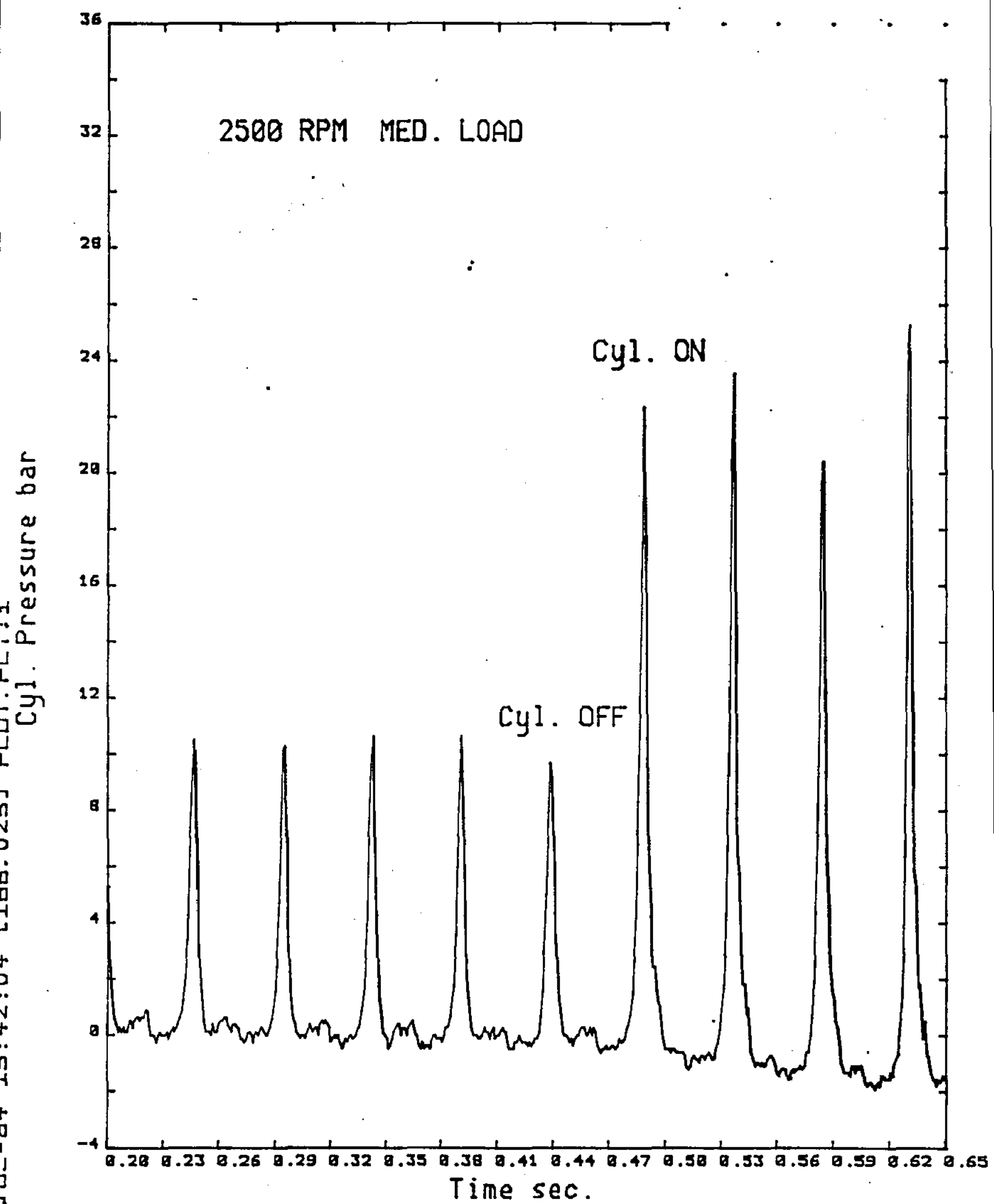

Fig55. Cylinder Reactivation - 5 (P5ON). 


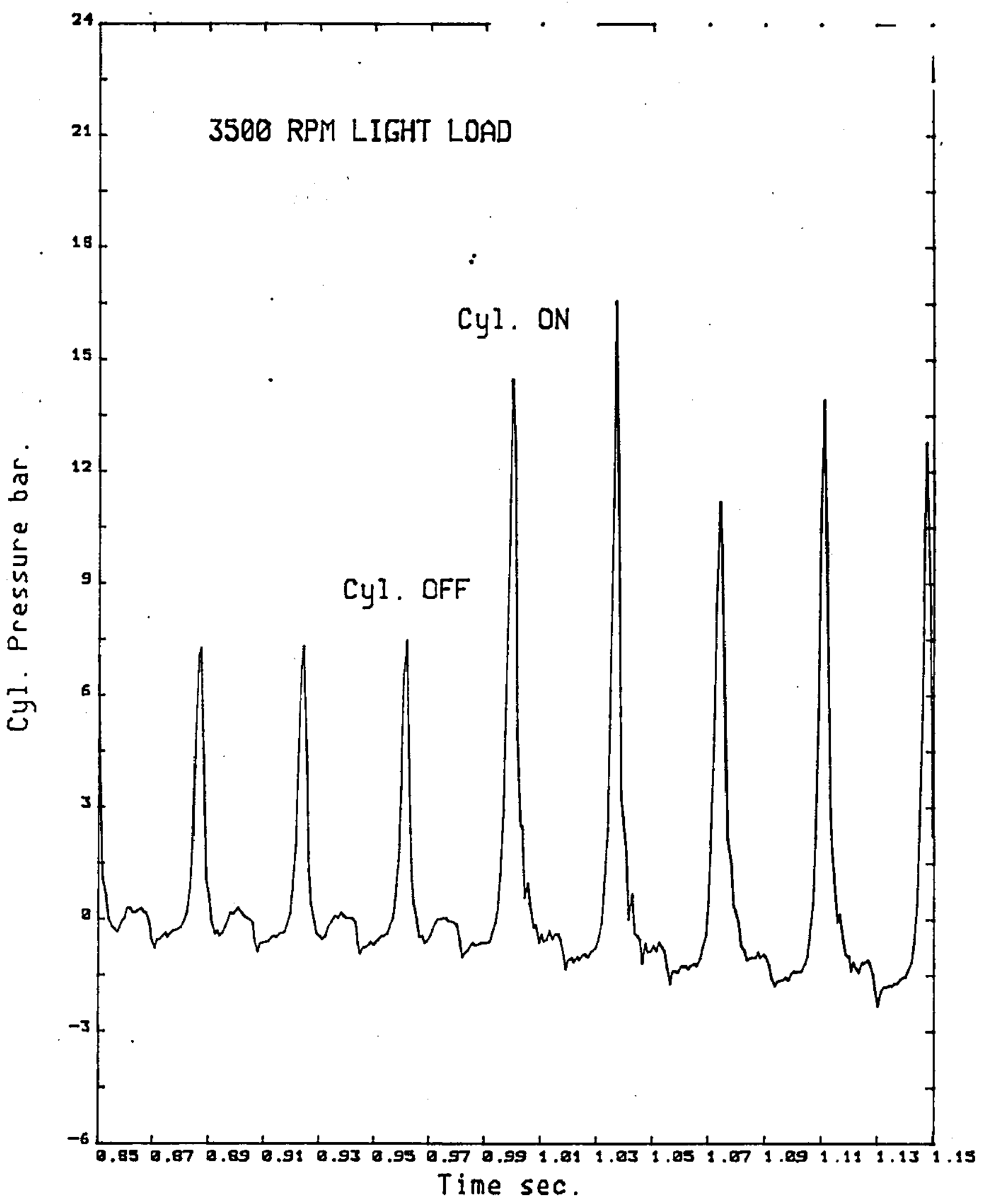

Fig56. Cylinder Reactivation - 6 (PGON) 


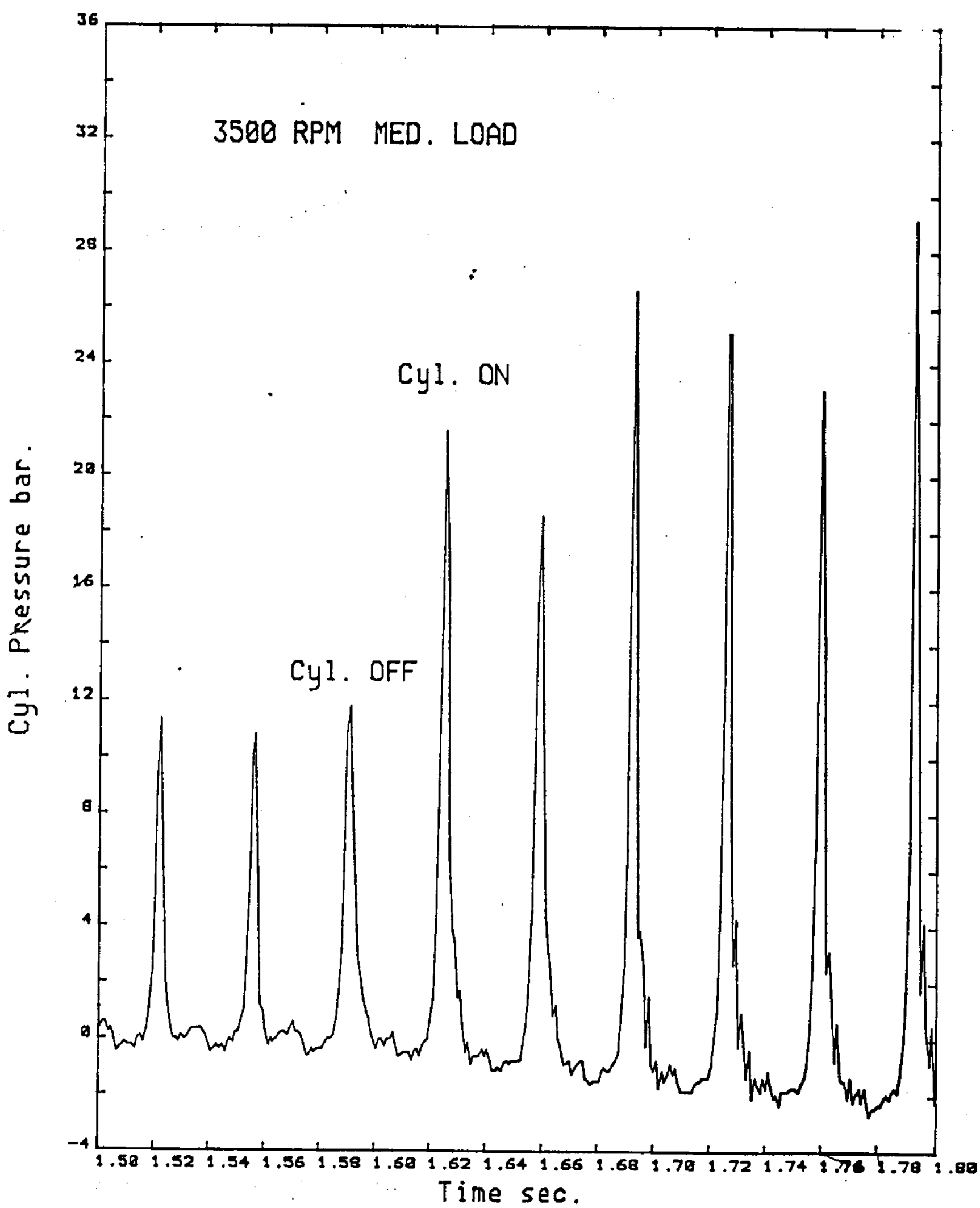

Fig57. Cylinder Reactivation - 7 (P7ON)

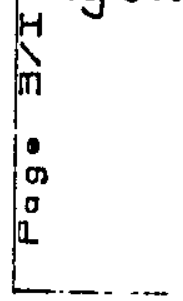


A.S.D GRAPH@ $95 \mathrm{kph}$.
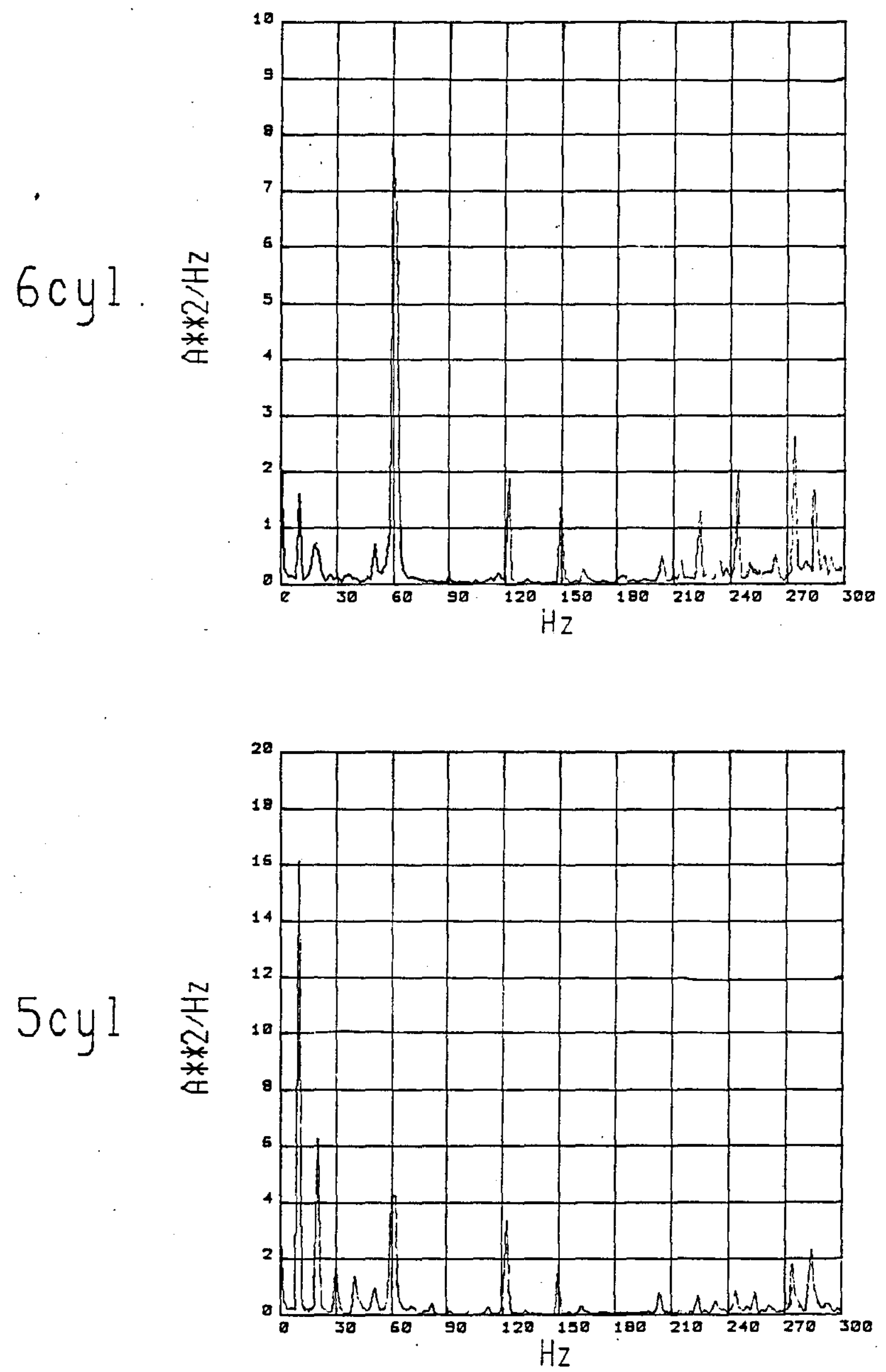

Figure 58 
A.5.D GRAPH @ $45 \mathrm{kph}$.
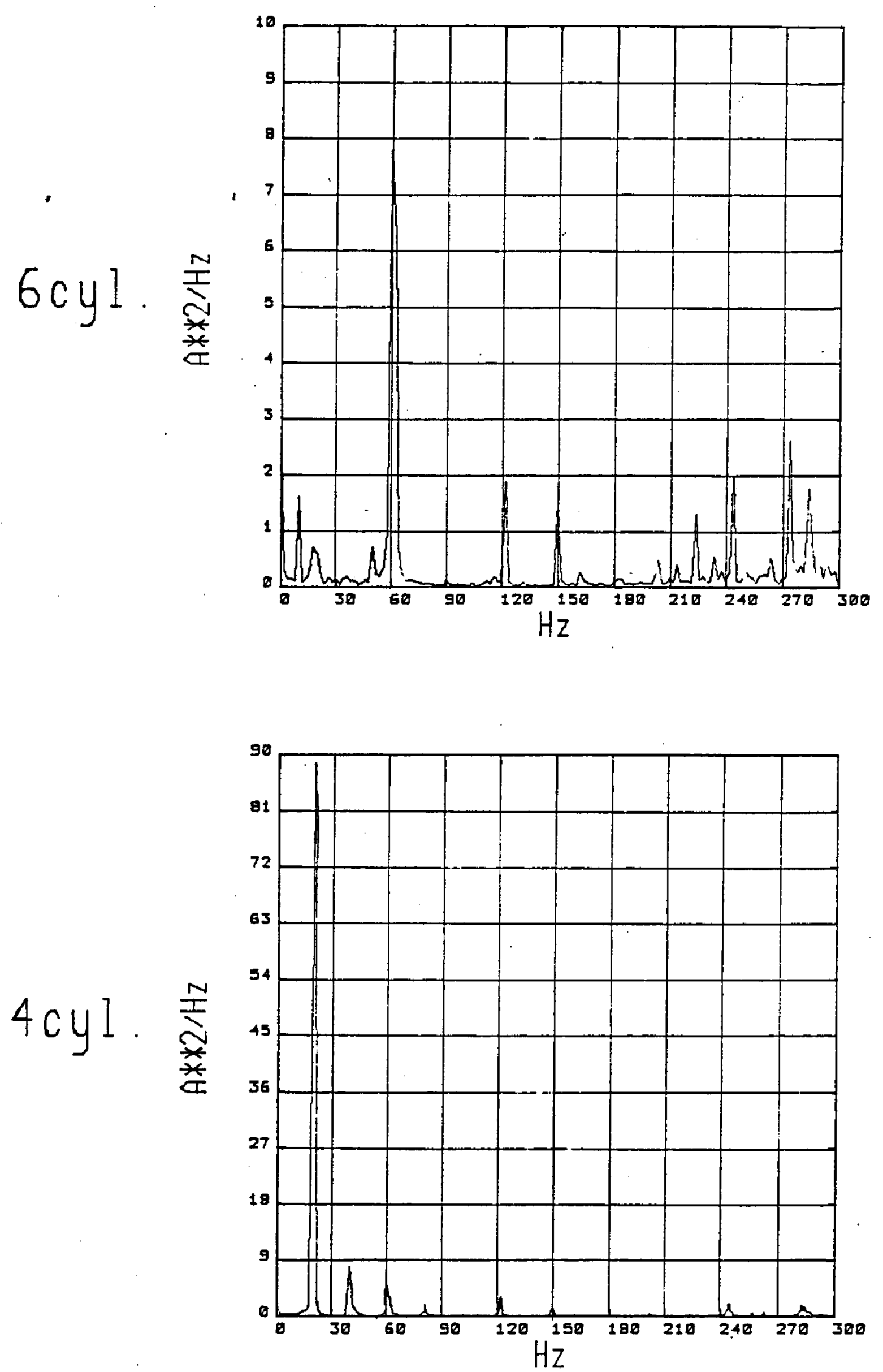

Figure 59 
A.S.D GRAPH @ $45 \mathrm{kph}$.
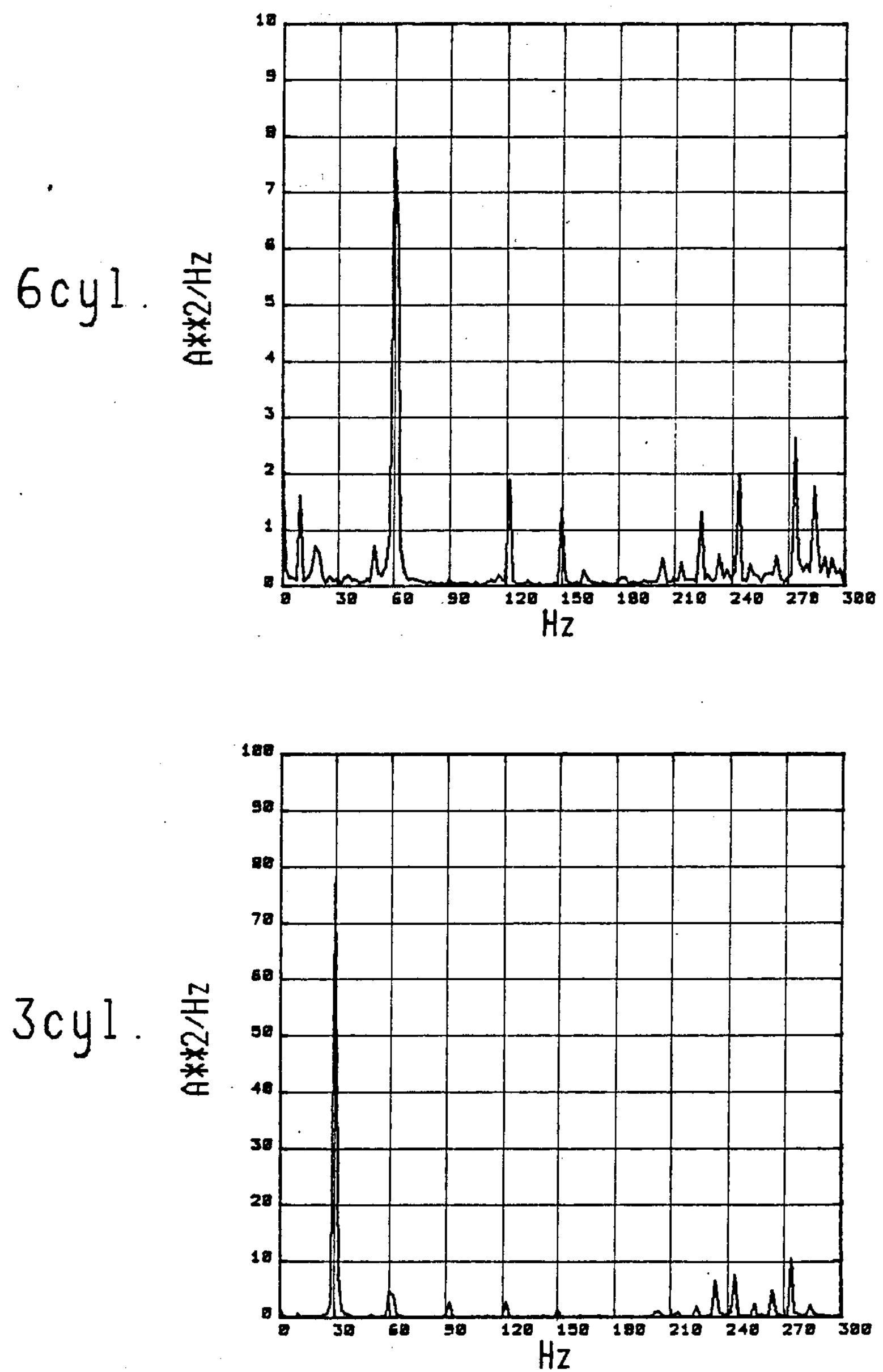

Figure 60 
A.S.D GRAPH @ $45 \mathrm{kph}$.
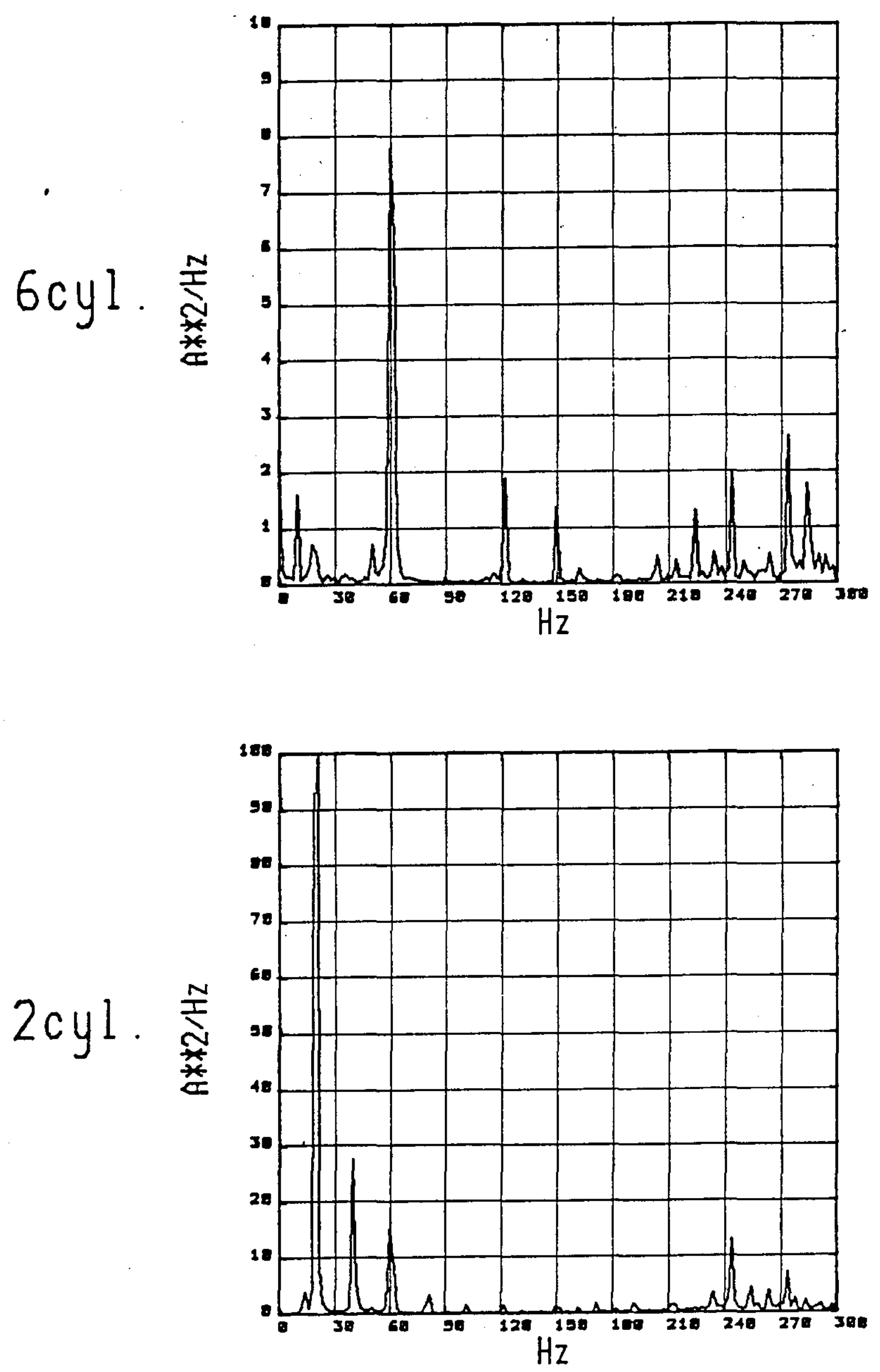

Figure 61 
A.S.D GRAPH @ $80 \mathrm{kph}$.
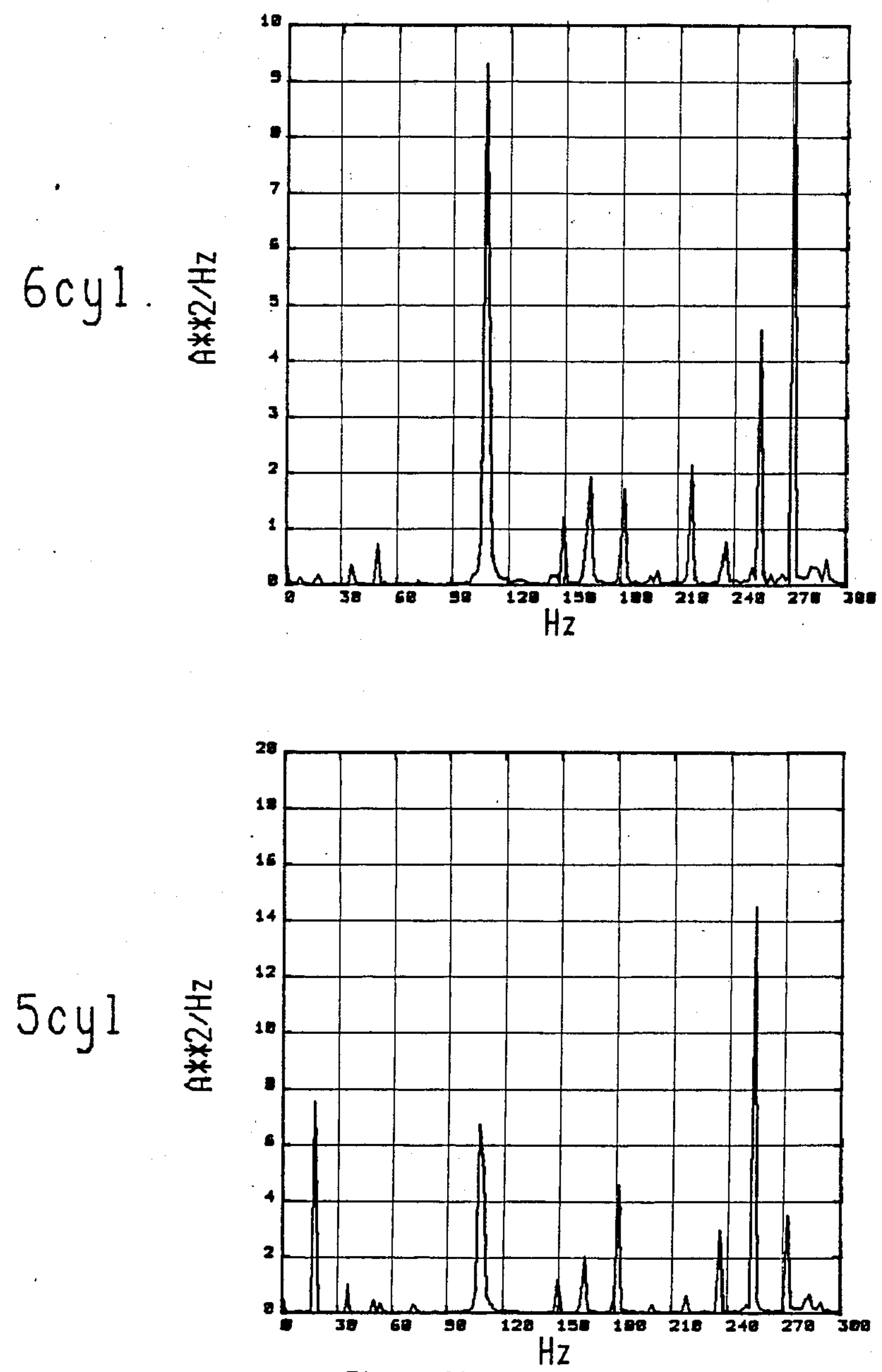

Figure 62 
A.S.D CRAPH @ $80 \mathrm{kph}$.
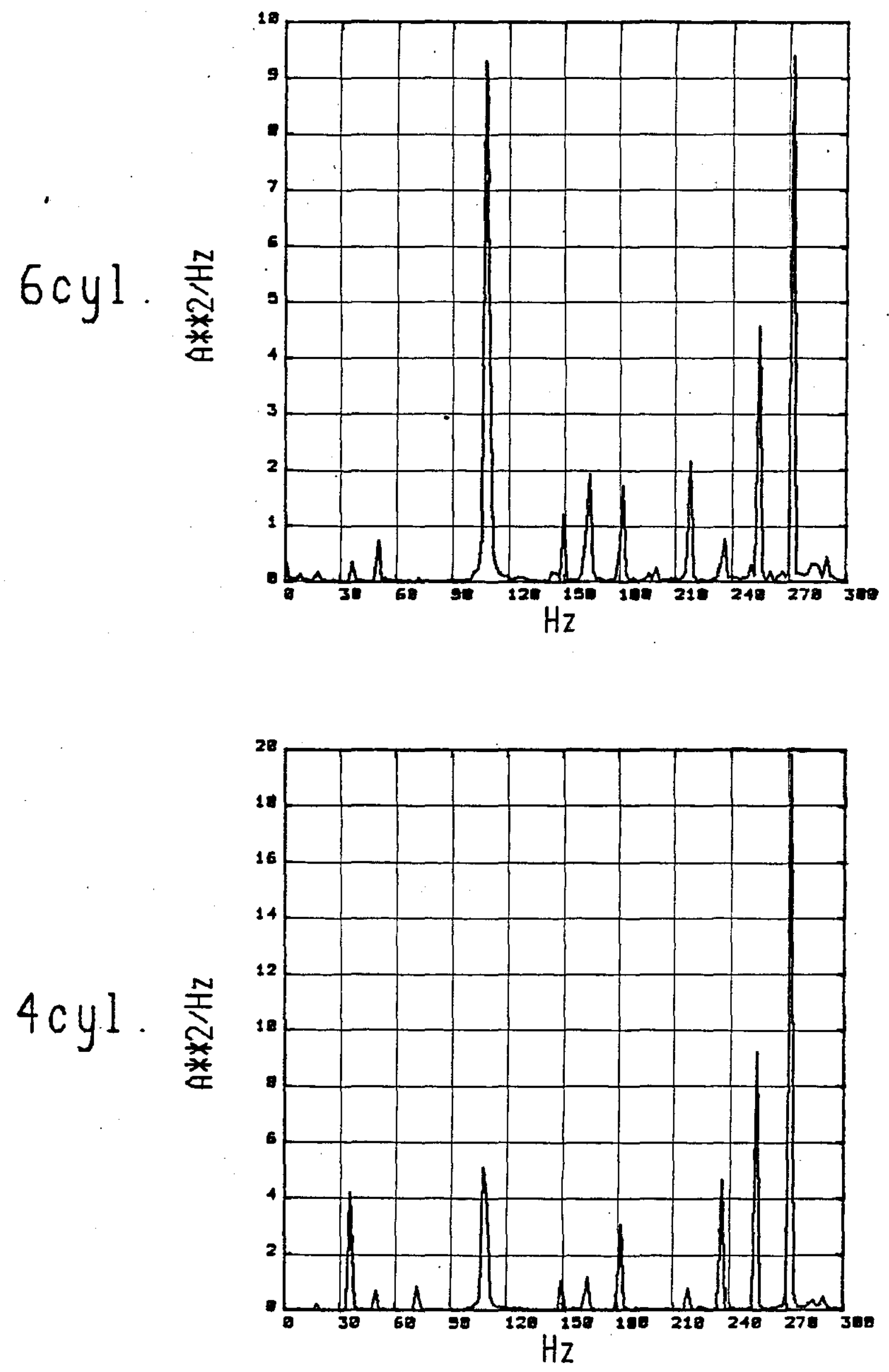
A.S.D.GRAPH @ $80 \mathrm{kph}$.
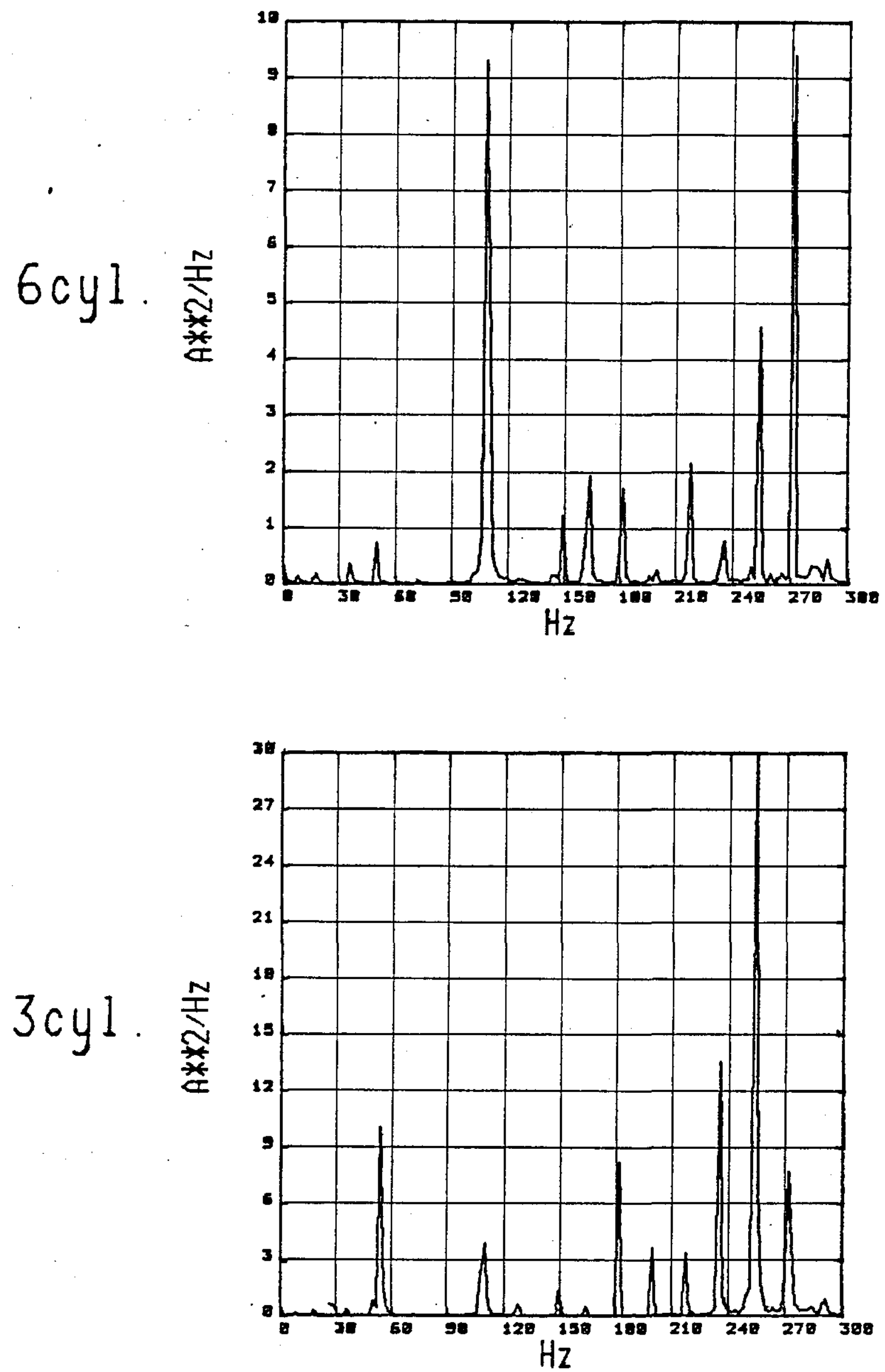

Figure 64 
A.S.D GRAPH @ $80 \mathrm{kph}$.
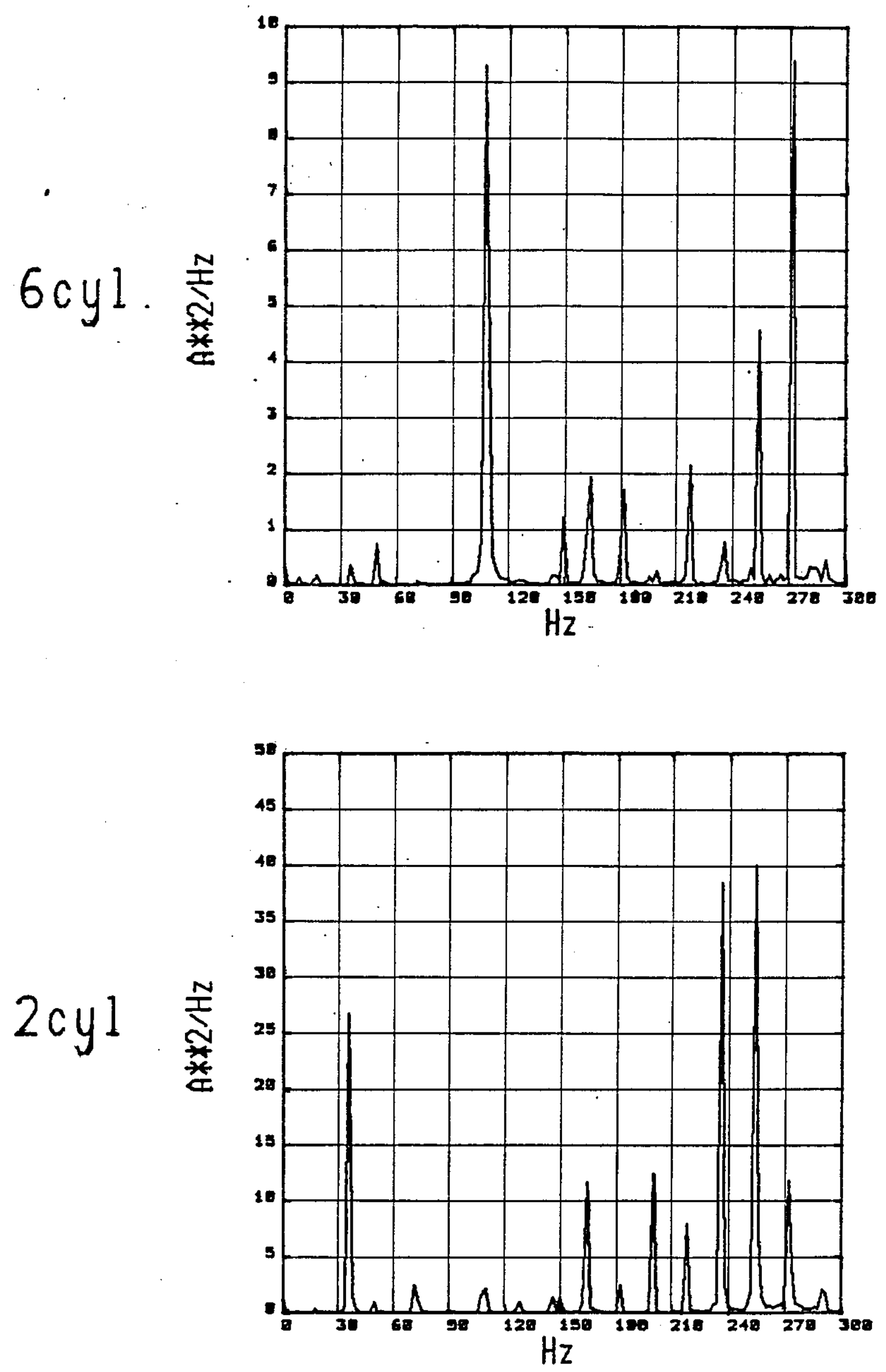

Figure 65 


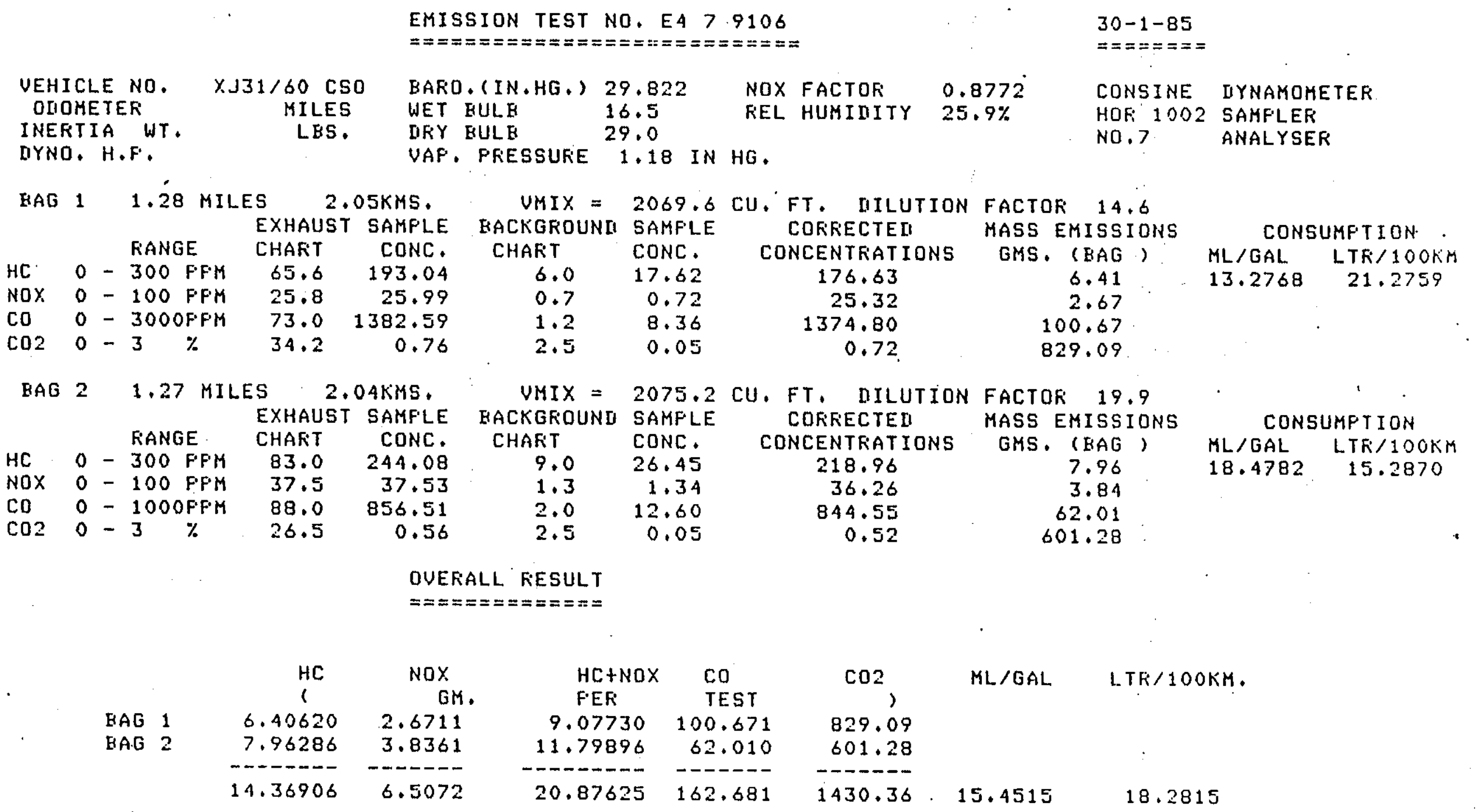

Fig 66. Emission Results from HOT EURO 04 test:

Bag 1: 6 cylinders, Bag 2: 3,4 cylinder active 


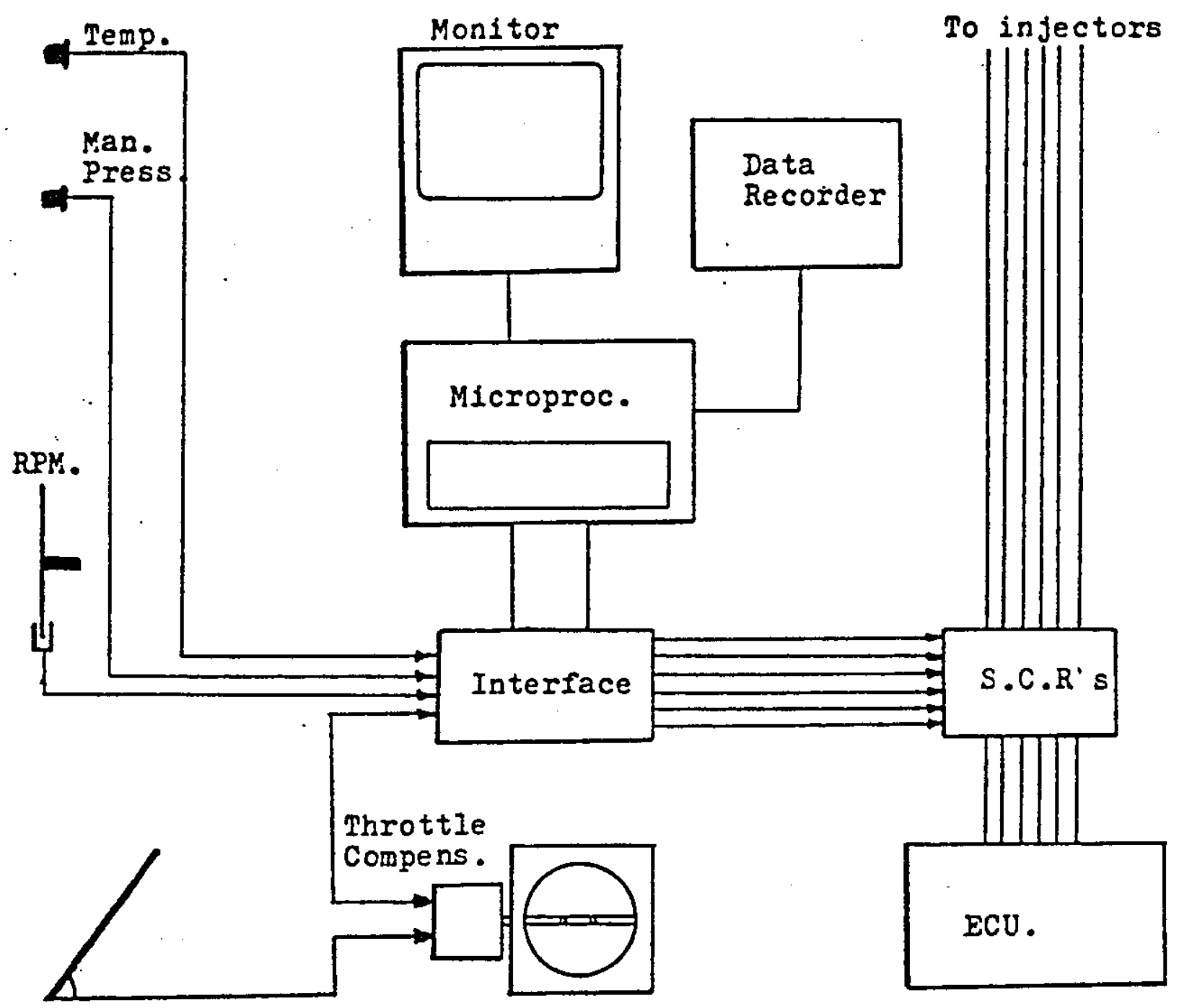

Accel. Pedal

Throttle Valve

Fig 67, Stage 2. Microprocessor-based Cso 


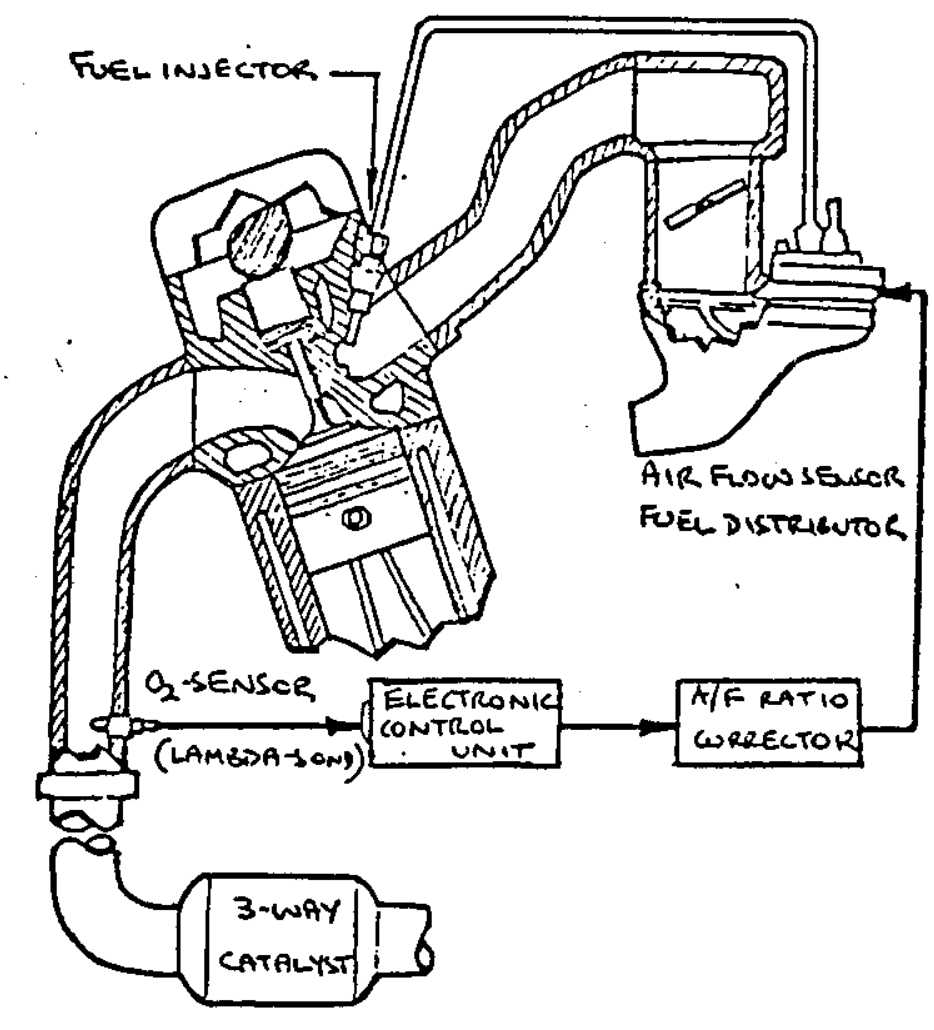

Fig 68 Oxygen Sensor Feedback System.

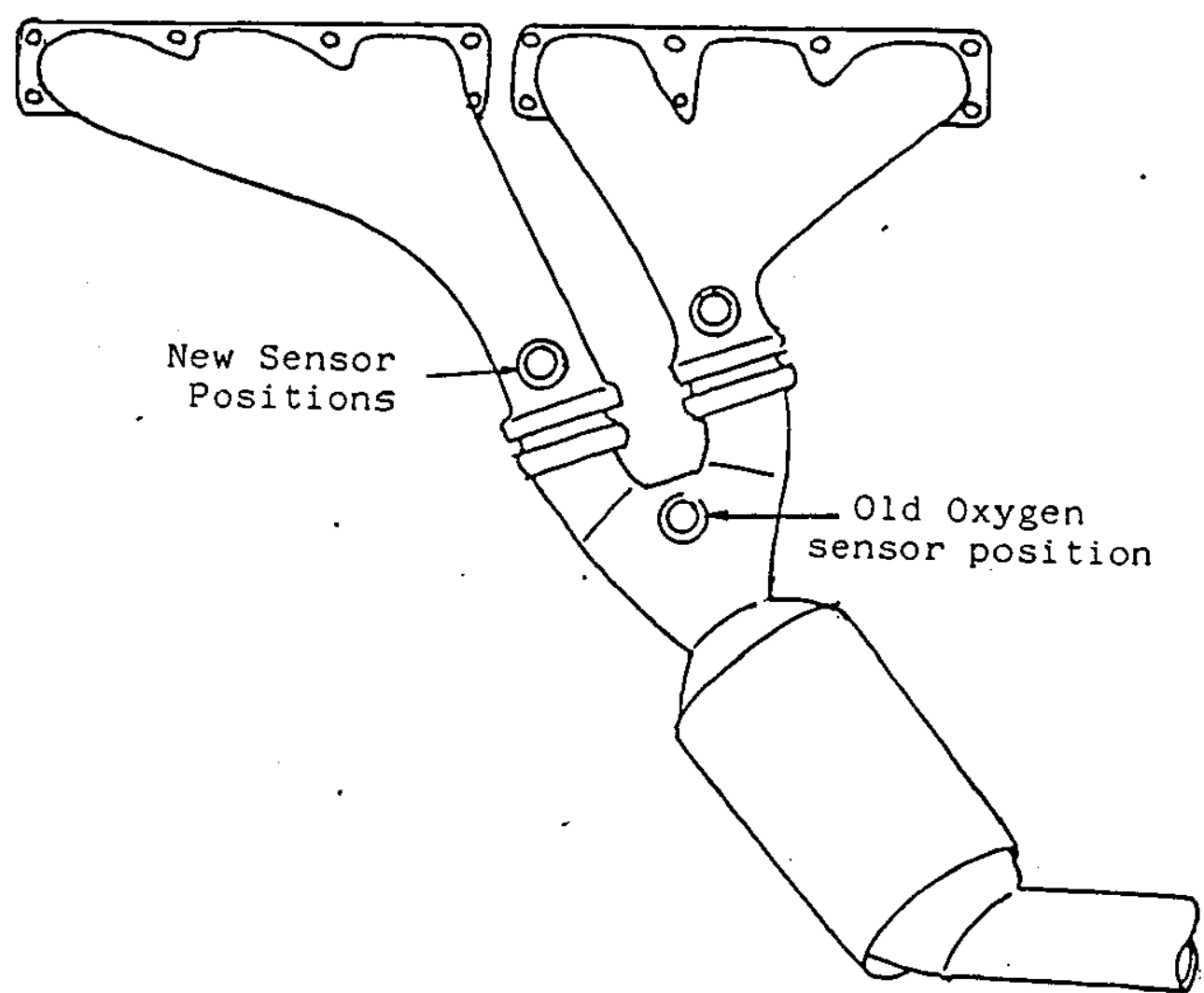

Fig 69 4.2xK Downpipe Catalyst Modofication with CSo. 
APPENDICES 
Formulae for calculating the performance characteristics of an engine(22):

(i) Brake power output $P=\frac{W \times N}{K_{1}}$

where:

$$
\begin{aligned}
& W=\text { Brake Load (Ibs.) } \\
& \mathrm{N}=\text { Engine Speed }(\mathrm{rpm}) \\
& \mathrm{K}_{1}=\text { Brake Constant }=400 \text { for bhp } \\
& =536.41 \text { for } \mathrm{kW}
\end{aligned}
$$

(ii) Torque output $T=W \times K_{2}$

where: $\quad K_{2}=$ Constant $\quad=13.13$ for lbft

$=17.802$ for $\mathrm{Nm}$

(iii) Brake mean effective pressure (BMEP)

$$
\operatorname{BMEP}=\mathrm{W} \times \frac{K_{3}}{\mathrm{n}}
$$$$
\text { where: } \begin{aligned}
\mathrm{K}_{3} & =\text { Constant } \\
& =317477 \text { for } \mathrm{N} / \mathrm{m}^{2} \\
\mathrm{n} & =46.046 \text { for } \mathrm{psi}
\end{aligned}
$$

(iv) Brake specific fuel consumption (BSFC)

$$
\mathrm{BSFC}=\frac{134280}{\mathrm{P} \times \mathrm{t}} \mathrm{g} / \mathrm{kW} \mathrm{hr} \text {. }
$$

$$
\text { where: } \quad \begin{aligned}
t & =\text { Time for Consumption of } \\
& 50 \mathrm{ml} \text { of Fuel, in sec. } \\
P & =\text { Brake Power, in } \mathrm{kw}
\end{aligned}
$$

or

$$
\mathrm{BSFC}=\frac{296}{\mathrm{p} \times \mathrm{t}} \quad \text { lbs / bhp hr. }
$$

where: $P=$ Brake Power, in bhp

Correction Factor:

$$
C=\frac{29.92}{\mathrm{BR}} \times \sqrt{\frac{460+\mathrm{TP}}{520}}
$$

where: $\quad T P=$ Air Inlet Temperature, in deg $F$ $\mathrm{BR}=$ Atmospheric Pressure, in ins. Hg 


\section{Auto Spectral Density}

The Auto Spectral Density of a signal is the mean square value of the signal distributed as a function of frequency. In common with other densities derived from sampled data, it is a discrete quantity having the dimensions of Units ${ }^{2} / \mathrm{Hz}$. The overall mean square value therefore, is given by the sum of all the individual frequency components.

The mean square value, $\bar{x}^{2}$, of a signal $x(t)$, over a finite time $T$ is given by

$$
\bar{x}^{2}=\frac{1}{T} \int_{0}^{T} x^{2}(t) d t .
$$

Similarly, the mean square value may be represented as a distribution over frequency, giving the spectral Density function $G_{x x}(f)$, where

$$
\bar{x}^{2}=\int_{0}^{\infty} G_{x x}(f) d f .
$$

This formula leads to one method of estimating the spectral Density function by filtering the signal between two frequencies, $f_{1}$ and $f_{2}$, and forming the mean square level of the output.

Hence,

$$
\bar{x}^{2}\left(f_{1}, f_{2}\right)=\int_{f_{1}}^{f_{2}} G_{x x}(f) d f .
$$

An estimate of $G$ (f) can therefore be given by

$$
\hat{G}_{x x}\left(f_{1}\right)=\frac{\bar{x}^{2}\left(f_{1}, f_{2}\right)}{f_{1}-f_{2}}
$$

This method of estimation shows that a A.S.D. has dimensions of Units ${ }^{2} / \mathrm{Hz}$, and that the method of estimating the S. D. function may be considered a filtering operation. 
This section contains a paper written by Dr. G. G. Lucas, Mr. J. Hughes and the author, for the XX FISITA Congress held in Vienna on 6-11 May 1984, titled "The Application of a Microprocessor to engine cylinder disablement" and based on work covered in this Thesis. 


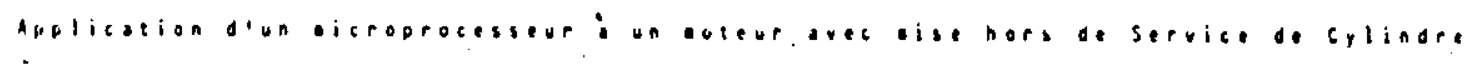

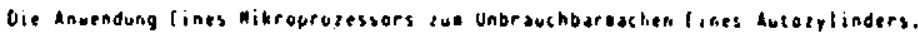

I.f.. lucas. L. Hugies and h. Manias.

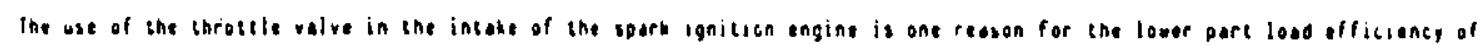
this engine ohen coepared with the coupression ignition engine. ine need for the throttle walve can be avoided by the disableaent of incividual bylinders.

A aicroprocessor is being used to operate on the fuel injection to the inlet ports as atans to disable the cylinders. Je is being prograned such that the cylinders disabled. cycle by cycle, can be varied in order to keep all ene cylinders hot and to ainieise the aptitude of the vibracions of the pover unit on its sountings. Further. the nuaber of cylinders disabled. crcle by crele. can be voried in order to provide. fine control of engine pouer output.

the control systes is cescribed and the results of the experieencal test eork are presented. The paper also cantains the theoretical adelling of the dynasics of the poser unit on its ecuntengs excited by the range of forcing lorques oapected froe en engine witl disabled cylunders. A bis degree of freedoe codel is being used.

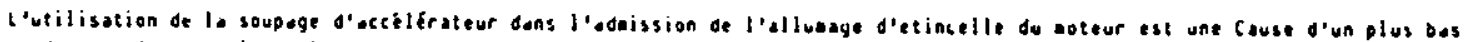

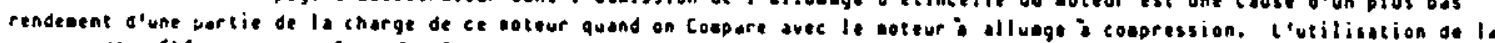

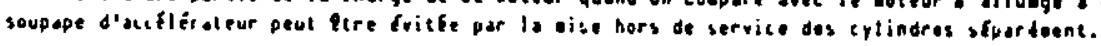

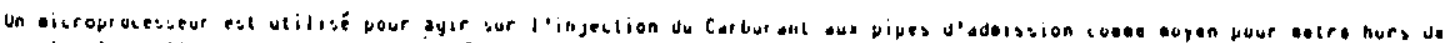
service les cylindes. Il est prograené de belle eaniere que les sylindres eis hors de service, eycle eprts cyele, peuvent

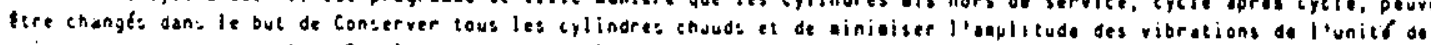
puissance sur ses supports. De plus noebre des cylindres ais hors de service, evcle spris cycle, peut Itre. thangl pour fournir un Control fin do la puissance de sortie du eoteur. Oans le docueent le systeme de control ast de'cris el les

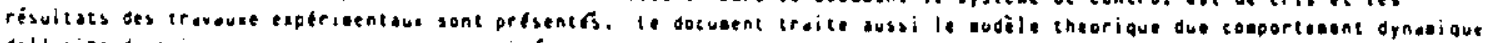

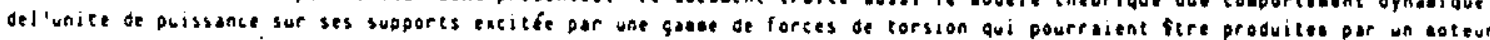
aver cylindres us hors se service. Un nodele J sin $(6)$ degrés se liberté est utilsé.

liner der Grüne tir die geringere iadefanigkeit dieses hotors io vergleich eit ded der des noporessionseosors ist der Gebrauch der Orosselhlappe ährend aer Aufnahee der lÿndung des verbrennungsootors. Oas Bedïrinis für eine Orosselihlappe karn durch das Unbraubbarasihen der eincelnen lylinder verhindere verden.

lin mikroprozessor eird veruendet, ue die orennstoffeinspeiczung in die tinlabnäfen laufen at lassen, und dadursh obe iylinder

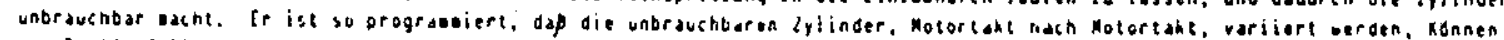

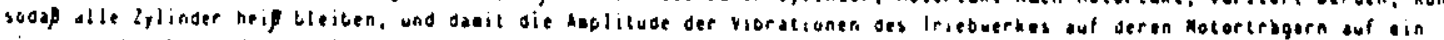

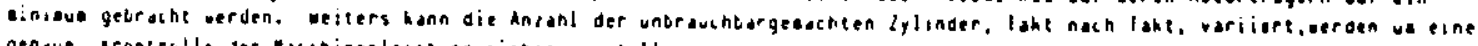
genave kronirulle jer haschinenlelstung sicher cu blellen.

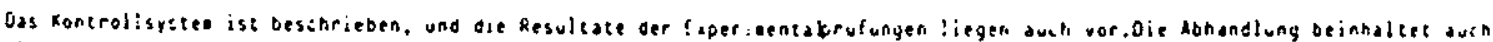

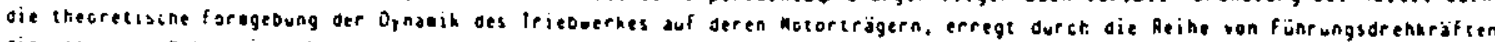

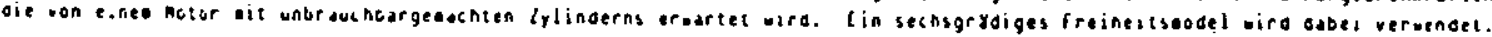




\section{ABSTRACI}

The use of the throttle value in the intake of the spark ignjtion engine is one reason for the lover part load efficiency of this engine when conared with the cgepress. ion ignition engine. The need for the throttie valve can be aroiced by the disatienent of indivioual cylinders.

A eicroprocessor is being used to operate on the fuel injection to the inlet ports as a weans to disable the cylinders. It is being prograned such that the cylinders disatied, cycle by cycle, can be varied in order to keep a) the cylinders hot and to ainiaise the aaplitilude of the vibrations of the pover unit on its ecuntings. Further, the nunder of cylinders disabled. cycle by cycle, can be varied in order te provite fine contrcl of engine pover output.

The controi systed is sescribed and the results of the exoeribental test roek are presentec. The paper alsc contains the theoretical lodelling of the dynatics of the pouer unit on its ecuntings excited by the range of foreing torques expected froe an engine vith disabled cylinders. A six degree of freedos sodel is being used.

\section{INTROOUCTION}

The usual. wethod of contralling the pover output of the spark ignition engine is by throttling the iniake. This has the effect of increasing the purping losses and the prooortion of energy to the coolant at lov load. These engines therefore, when installed in passenger vehisles, spenc the ujority of their lives operating at a relatively low efficiency.

One vay of increasing the econoey range of the outticylinder S.l. engine is to allow the engine to operate on fever cylinjers at part-load. The increase in thro:t!e angle raquired to coepensate for the reduction in pouer has the effect of "detheottling" the active cylinders, increasing the voluctic efficiency ard decreasing the brahe specific fuel consuation.

Several systeas have teen developed to selectively deac:ibate cy!inders by several onufacturers in the past. [aton Corporation (1) developed an electro-uethanica! syste: unich could disable the injet and eanaus: vaives, incereasing fuel ecorichy by up to 252 when "oriving" ane 2 ? at idie. Bates, Oasdall and stith (2) show that vo enjirt using this value disating systes could operate on any nin: : of cylinders. They reporied fue! econos, gains of ui to : witheu: cegeating everall pertogance. Caicier-gena hi j. (6) developed electronically controlled sysieas erating 21 . 6.6 cperation aith fuel savings of up to 662 cr. the $i c t$ sy: it Ford (5) showed that v 6 engine could be selit, effective! into two three-cyinder engines vith separate intake systeas. affording a fuel econony of $20 z$ on the $5 C$ cycle, with reasonate ncise,vibration anc harshress levels. Sott hifa Aoneo (6) anc Mitsubisti (7) have developed four-cylinicer engines capaole of operating on two cylinde-s, the feraer using fuel cut off and the facility to switch active anc itead'

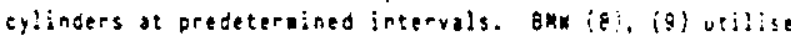
hot extaust gases diverted into three deactivated cylinoens of their six-cylinder engines. in order te keeg these iy!je. ders wart. The systen has achieved a $25 \%$ eccrisen gain cree the furciean urtan sycle. Watanabe and Fubu:ani (is) foss also that six-cylinder engine vibration covit be reduces a: id!e with theer-cycle operation.

These investigations have, to date, adocted a rather consert ative approach to engine cylinoer disatieber:. Nanufaiture-s have beer content to disable three cylinders of a sil iy:irseetsine or, as in the cast of Alsa poseo, is sisatie in cy!inciers of a four cylinder engine. The reasis for tits $\vdots$ s siojie; if a number of cylinoers other than na:f ihe :a:a: nuaber in the engine is disatlec the vibration of athersto becoses unaccestatle.

The use of a broptocessor to disatle cylince-s, eitiner tor oferation on the fuel injection syster or on the ralve gad. provides the possibility of any disablement sequerce :a :t uses. The nutater of cylinzers disated, cycle-oy-cyile, ar, ajse be varied te provide a fine contrel of iceer oves:.

In this paoer, the effects of cylinder cisaticoent on the perforance ap of the engine and on engise vis-a:ion are shoun. A six oegree of freedow odel of the engine vitoatisy or its counts is also discussed with a rieo is it use in

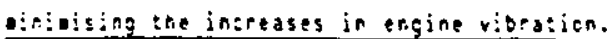

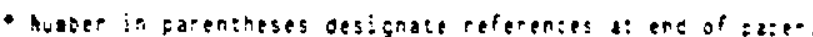




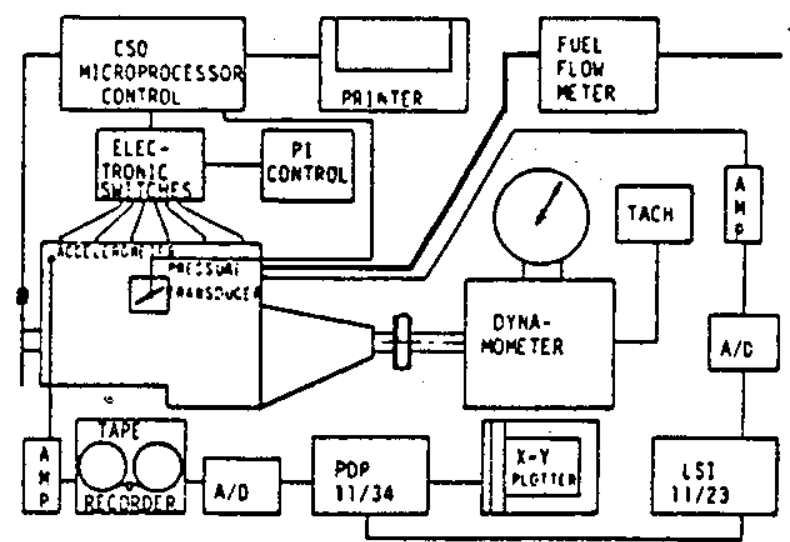

\section{IEST EOUIPHENT}

The engine use for this investigation was a jaguar xke it cylinder iwin everhead caushaft engine, equipied with BEsch L-Jetronit electonic fuel injection systea, the latter being an air-fion based systea. The engine specification is listed in table 1, and the layout of the equipoent used is shoun in Fig.l.

Table 1 - General specification of Test Pouer Unit

Jagcar XKG 4.2L Low Conpression engine

No. of cylincers $t$ in line

Fuel!ing

Coneressiar ez:is

Bosch l-jetronic

7.8:1

Rated Pewer Ou:Eut

$153 \mathrm{kH}$ e 5C0O rpa

Fated lorgue Quiput

321 NE $\& 350$ rPA

The engine was bounted on a test bed having an eddy current dytangeter, equipped with speed control. The special engine instrusentation consisted of a kistler pressure transducer convunitating with the engine contustion chater and $0 . J$. Birchell acceleetacter counted on the outside of the head. A sloited fise was mounted on the crankstaft foruard ef the engine fuiley te provide a t.d.c. incicator. A labarato:y standard ase recerder was used to record the acceleroueter output. The sigeal being then passed ihrougr anti-aijsing filters and an arologue/digital converter into the Departuen:'s PDF li/j6 conputer.

\section{The disabiesent control systee}

Engine cylincer disablecent was achieved by switching off the cu-rent suas!y to the fuel injectors. No atteant was ace to operate on the rather conac:ly designed twin overhead canstiat valve gear systeo. Electronic Osto-couflet SCR's were nocniet in the leacs between the noreal contecl systen, wich was not notified, and the individual injectors. These SCR's weet operated, through a suitable interface, by an ln:e! 8ces based aicroprocessor development systel. Fig. 2 shews the systes sehenatically. The slotted dis: nousted on the canhstaft culley in conjunction with an octo-suttch festces the in:evot sigral to the itroprocessor.

ire disasteaer: Fogran used as daia a series of to tit
FlGUAR 2. OISABLSMSKI CONTROL SYS:TY

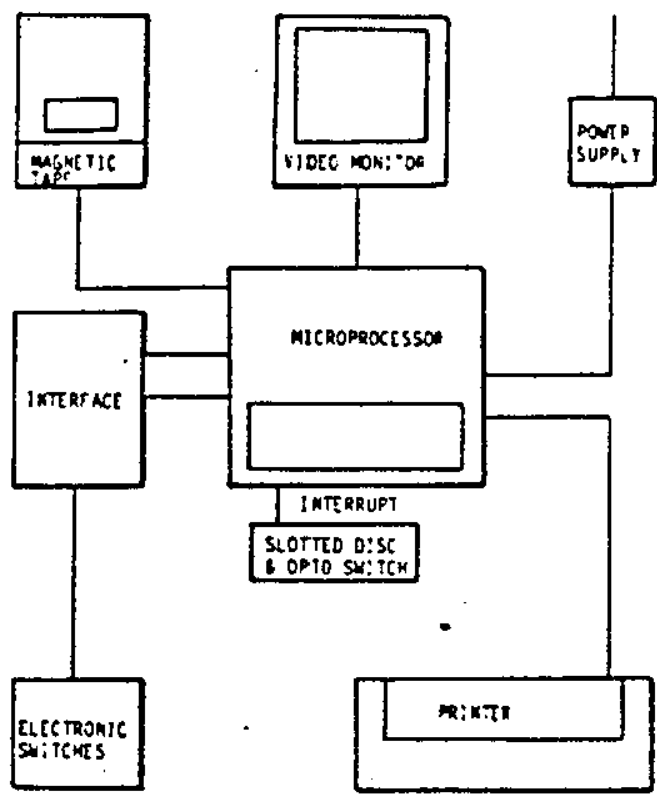

binary nuabers, the six least significar: ti:s of each acing used to operate the SCR's. Any nuater :f engine therasdynatis cycles, vithin the capacity of the nicrocosputer's nevory, could be accomodated in the sezuenze. The seejes at binary nuobers was teruinated by a rou ef ze:os, signifyin a return to the start of the series anc a resed: of the sticers. In this canner, any castination of the nos:t of cy! inje-s disat:ec cycle by cycle and any nuevet if i, ies in tie secuence could be provided.

Such an arrangevent is versatile anc ictal for cesear: purposes. The softuare arrangenent of arazicai. amosustion systev will be, of necessity, nuch sore conelex. soge iasz of the factors which a practical systen ail tare to accomsitate are siver in Apcendix 1.

\section{Discussion of Engine Test Results}

The ruger of eylinders disabled was wajec foce cre $t::_{0}$.

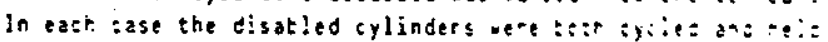
fixec. he difference in power output c* bel screntitic uas

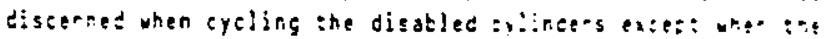

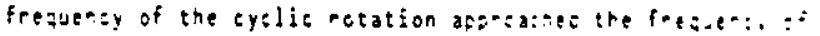

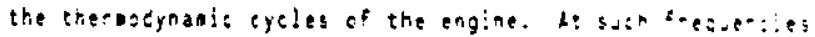
the oeactivated cylinders tended to fire scias araity, particularly at low loads, due to the presense of fuel va:ter in the anifold.

In the tests the speed. load and number ch cyilnters firirs

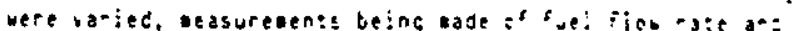
vibration. The perforkance mass eere bictiec frou inese al:a and arzear as figure 3 . A cursory glante ot a feo peiris along a tyoical load line drawn shous that it is in the areas of steev gradient of the specific fue! ions ar:isa cortican that the benefies of cylinder disatienent lie. Is nign!lar: the econoey gains figures 4 and 5 have tepe pasuipe. Trese show the reduction in fuel consueption as a cersenisse :"

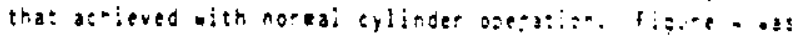

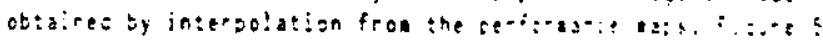

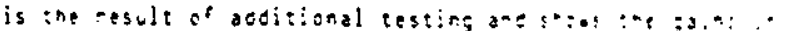

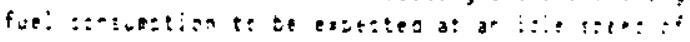


F!SUPE 3. TNGINE PERE OPMANCE MAPS.

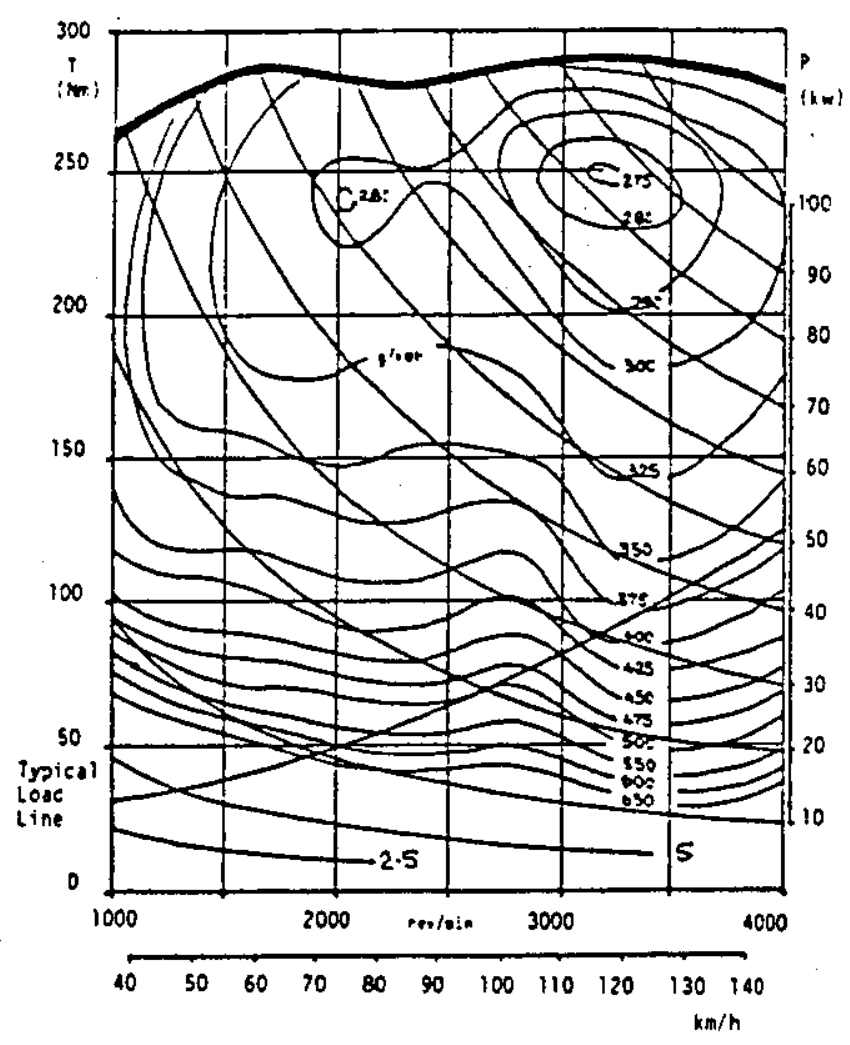

Figure 3a. 6 fyl. Firing.

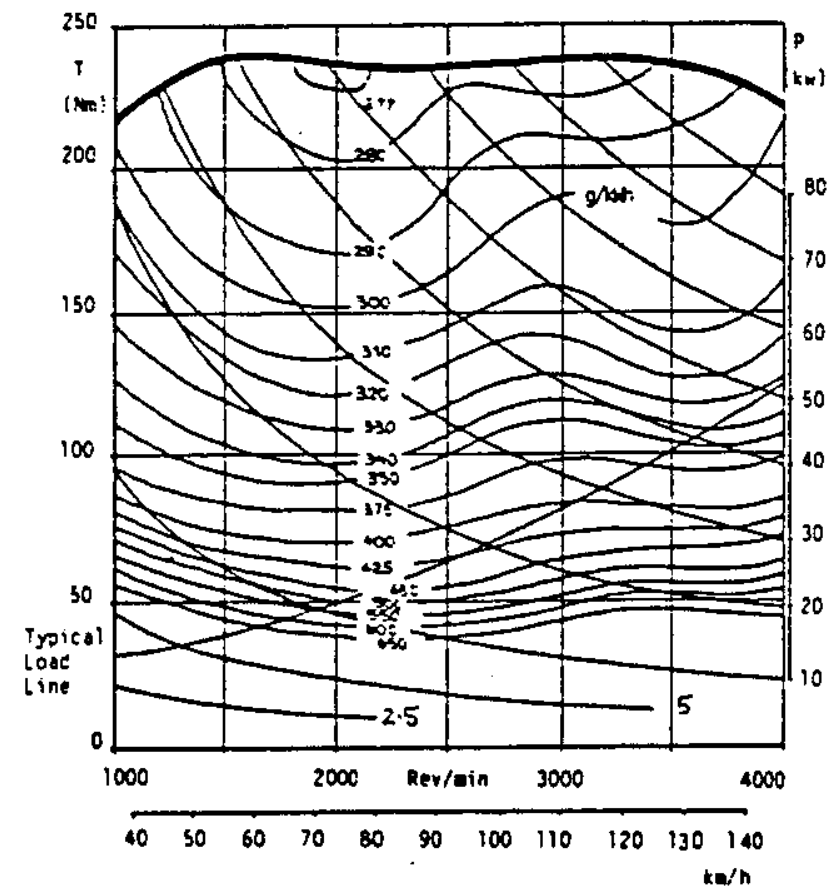

figure 3b. 5 cyl. Firing.

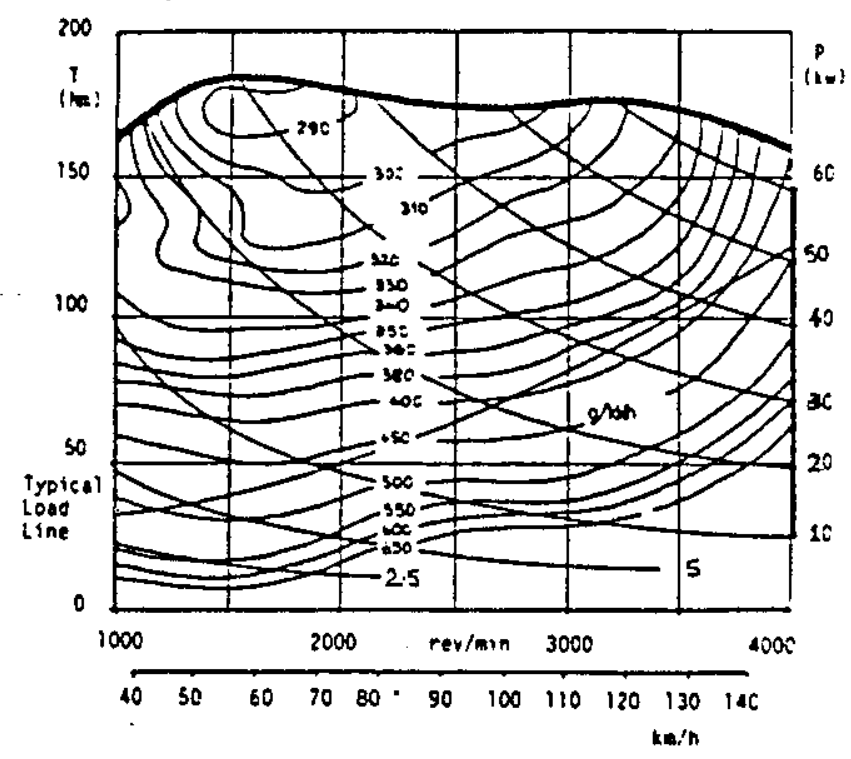

Figure 3e. "Cyl. Firing.

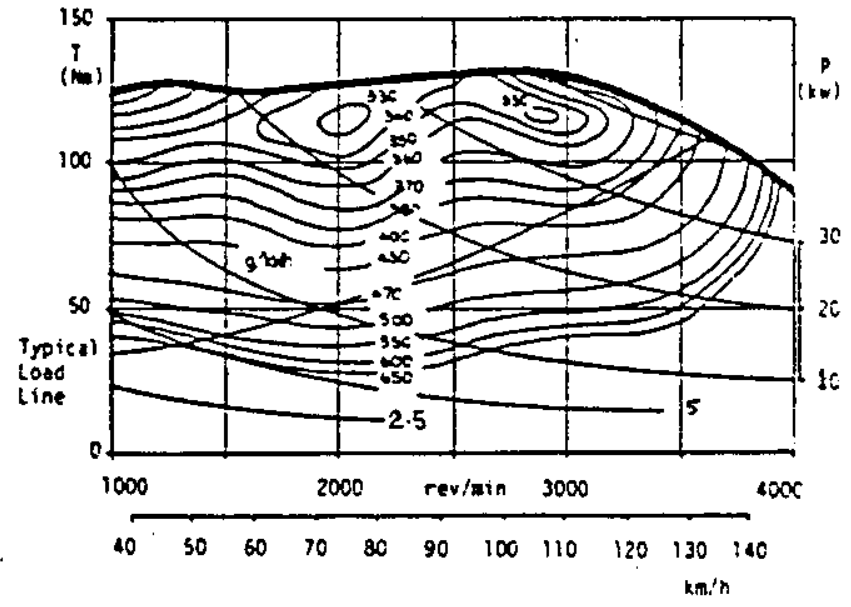

Figure. 3d. 3 Cyl. Firing.

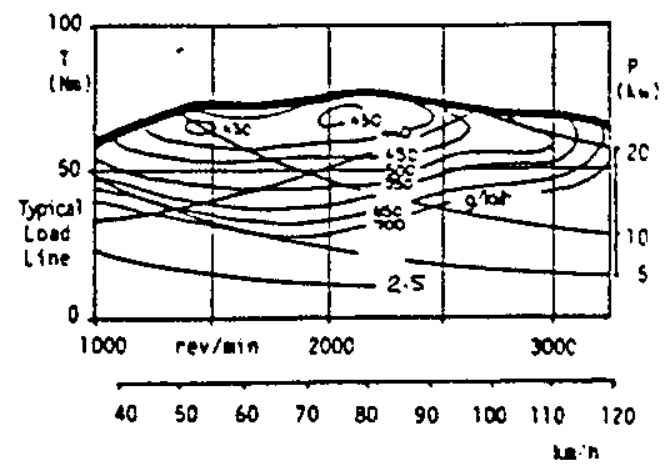

figure ze. 2 cyl. firing. 
750 rev/oin.

HIGURE 4. CORSTAMT SPEEO EEONOMY GAINS

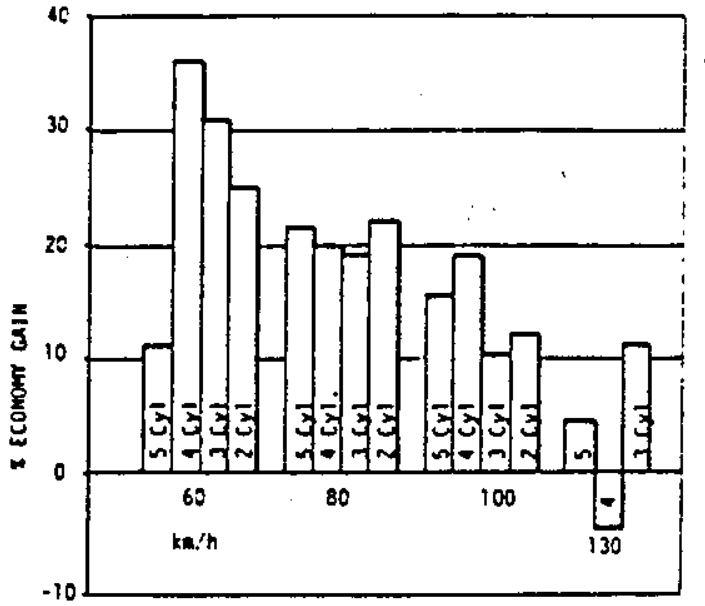

PIGUFE 5. ECONENY GAIN AT JDLE

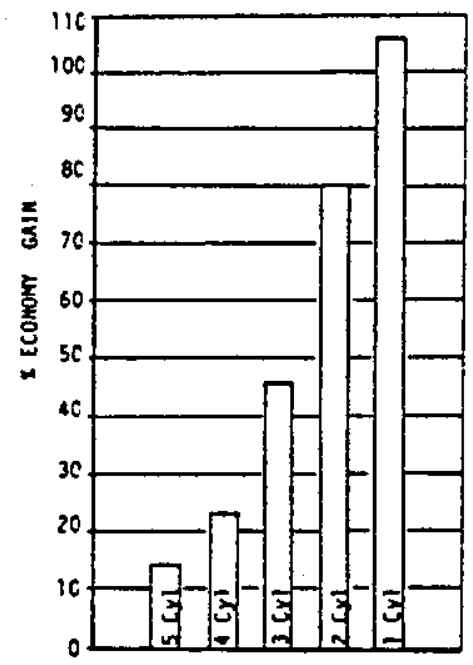

Given that the relative inertial and frictional losses increase with the number of deactivated cylinders the advantages of engire cylinder disablewent decrease with increases in speed. This is snour. in figure 4. Maxieun benefit is obtaines when cylinders are deactwated at idle. However if are than three cylinders are disabled the engine vibration becoses unaccepeatle. This situation could be iapecres by increasing the icle speed. Hoce that at 1000 rev/ain w: $:$ h cylinders firing the ieprovecent in fuel consunption would still be around $58 x$.

frov the liaited nsuber of test results obtained so far it can be corfiraed that engine cylinder disableaent can provide the very vorthuhile reductions in brake specific fuel consuaption expettec froe an untheottled engine at low loas operation.

Such an iavlecentation of engine cylinder disableaent, were any nuazer of $c$ ! incers can be disabled. does nevever introfuse frotleas with engine vibetion. Figure 5 a sheus the calsulated toroue outfut trace froe asix cylinder engine utin all eylinders at:ive. Tre following five

figures stiow what happens to the tergue outpul is cylinders are progressively disabied. These diageans were generateo

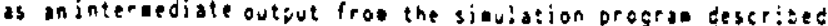
in Appendin 2. They shou hav low fresancy oulsations are introduced both into the drive! ine :orse ane ihe engine vibration. The increase in torque fju:tuation as crlinders are oisatled can also be seen. This gives rise to the increase in vibration experienced during engine cylinder dis. ableeent.

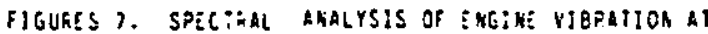
1200 rev/rin

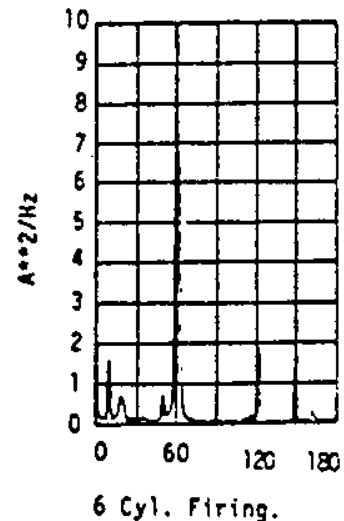

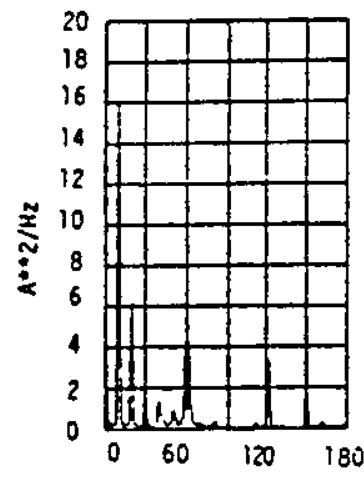

$5 C_{y}$. Firing.

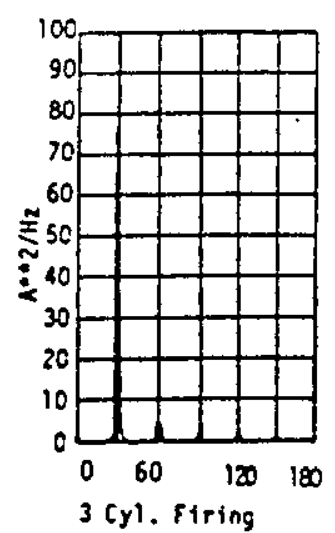

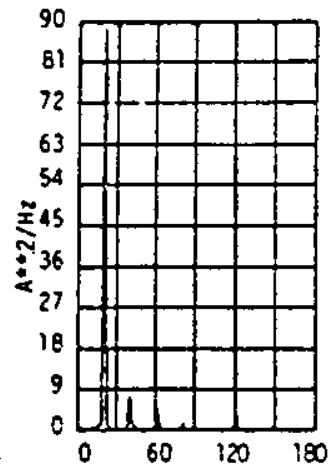

4 Cyl. Firing

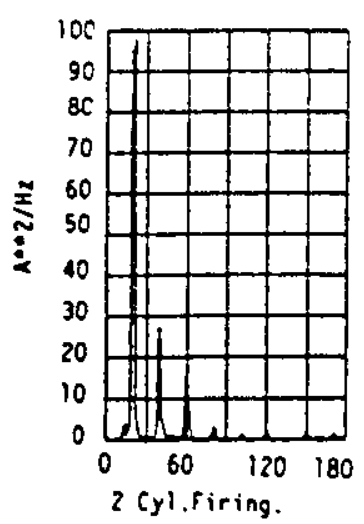




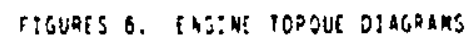

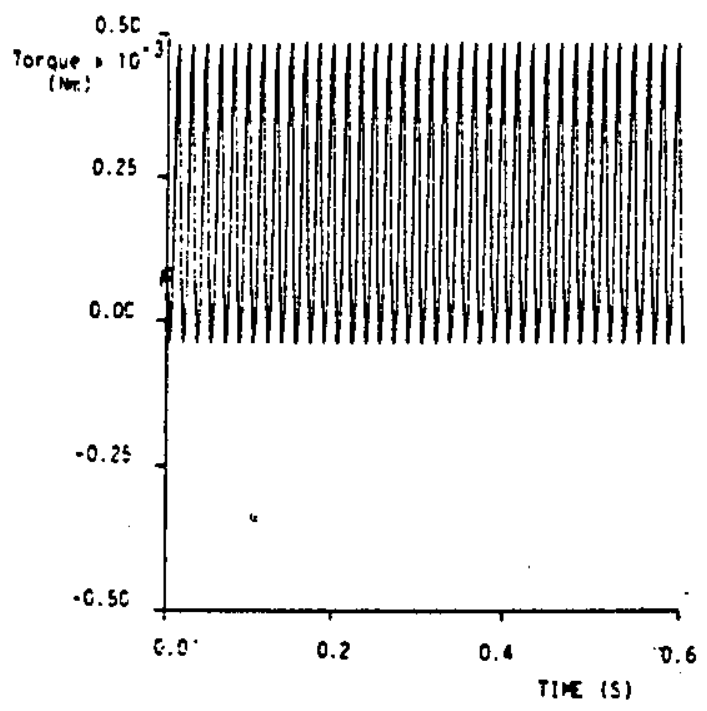

Figure 6a. $f$ iyl. Firing
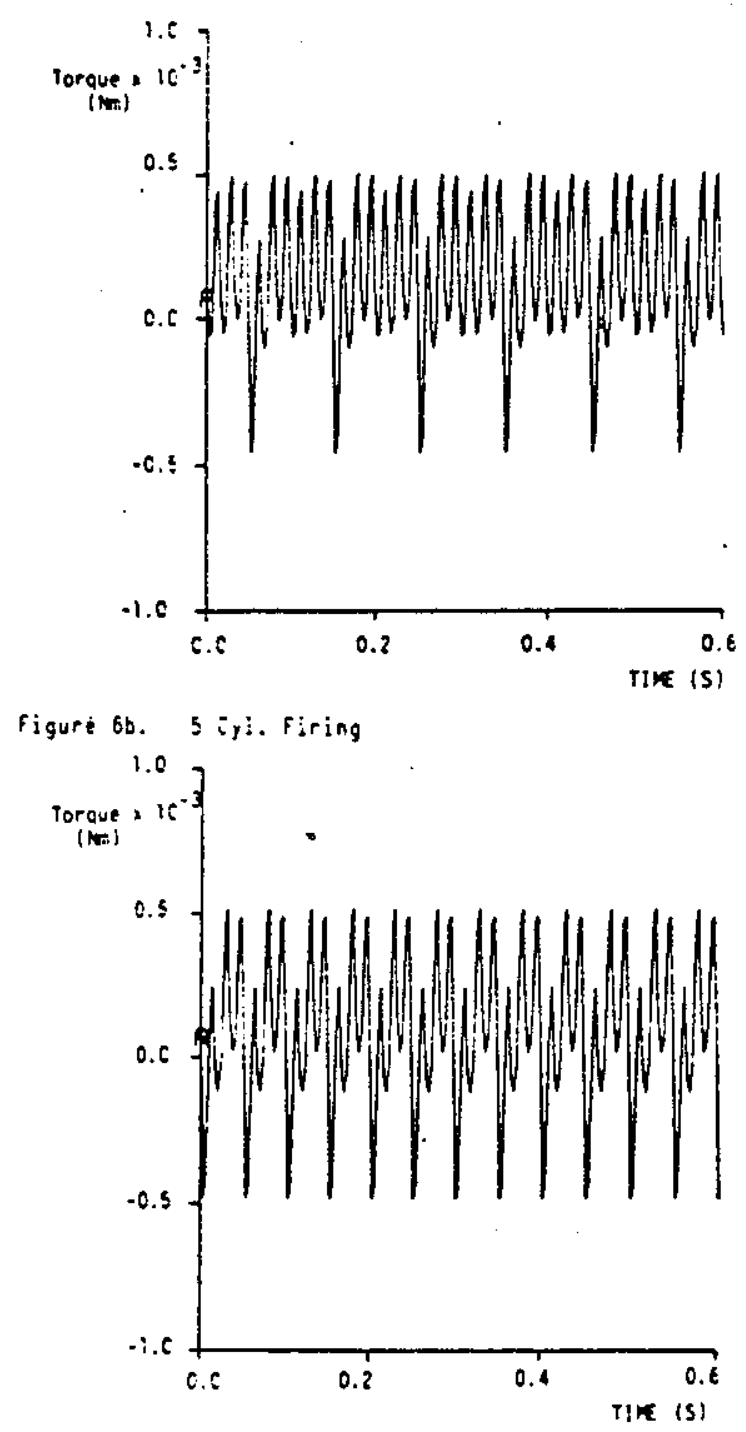

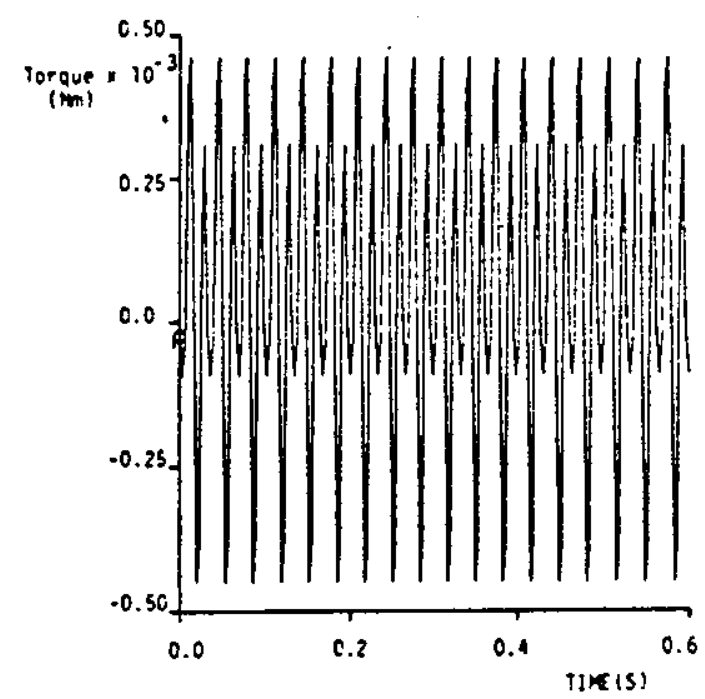

Figure ed. ICyl. Firing

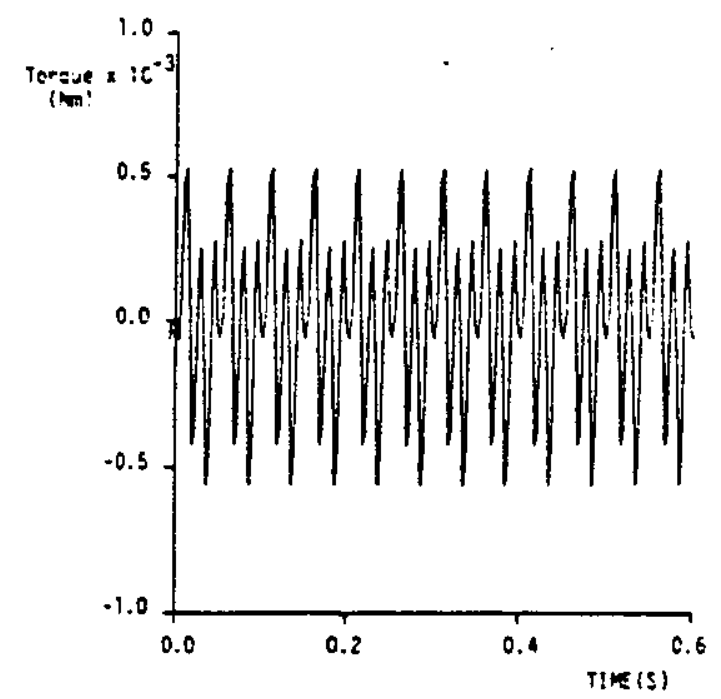

Figute te. z Cyl. Firing

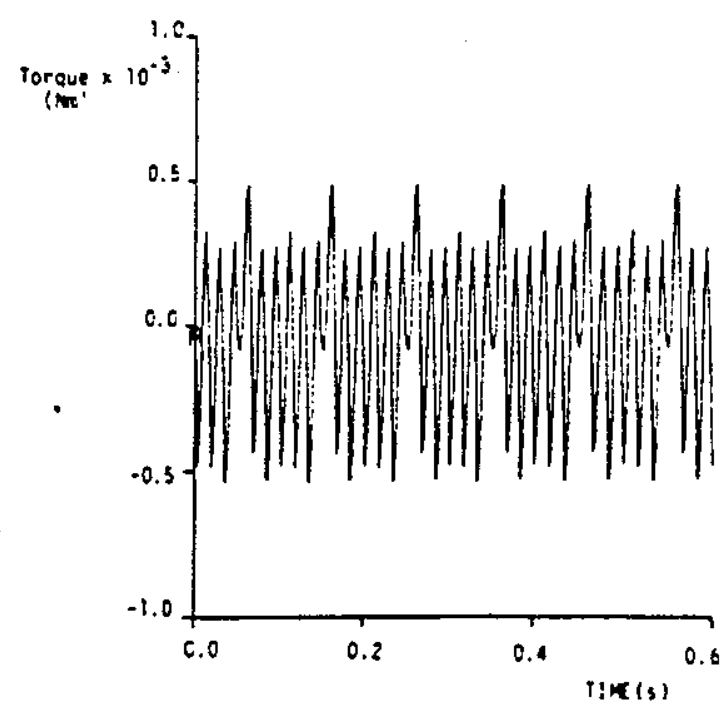

pigure to. i cyl. Firing 
APP[nล̄]X 1.

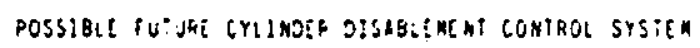

A dicroprocessor based cy!inter disatienent syster sust actively in:e-fere vith the engine anagenent syater. ihis -akes such a syste particula-ly attractive on engines using electronic fuel in jestion ane ignition since interfacing between the ius controi systees does not call for the use of additiond: electro-aestani:a! untes then fue! cut-off is used to prosite cylincer deactivation.

For such a systen to be effective in terns of obtaining near axinur fue: econony gains, a ninioun number of inputs is envisagec. Ptiese are

\section{Engine tesserature}

Engine speec

Load desand

The engine sesperature input is expested to be required in order that ail cylinders are used guring the wars-us period. Wher the engine reaches its noral operating terierature cylinder deactivation can ther :aine place, the ruster of active cylincees. and their orser, deterained by the ciner two variaties: engine sated ane load demand.

It is expestes shat, in a pra::isa! systen, the thre:tle valve vill silll be resuired, if only to cater for the warn up period. The coveser: of the accelerator pedal therefore will provioe a pasttior signal to the eicroprocessor. systeth. This, in cenjuntition a!th the engine inputs, will cause the -icroprocessor to point to a particular cylinder disabling sequense ane pos:tion tie theo:ile value suitably by reans of a stepaer acior.

One can envisage further conplications when autouatic transissions ans other soon!stica:es electronic control sysiens are used.

APPENDIX 2

Dynatic Mosel

In order te irflewent an engine sylinder disableaent systen as describec, unere any number of cylinders could be otactivated it is necessary to have a realistic athesa: ical codel of the engine vibrating on its nounts. Such a metel would enat: different cisatesent sequences to be $i r$ iec and the etietis on engite vibration neted.

The equations necessar, :e des:-ise the sotion of the engine are outlines beiou. Fig. 8 shens a flouchart of the progra which was ecjec in a continuous systens simulatior language. Outast aay be eitier torace,acceleration, veiosity or displacement. The azt-ix teaz:ions of motion to cesseribe the free vibration of a rigid asd ocunted on $n$ isciators is given by sosllen (1I) as:

0
0
0
$\operatorname{lnk}$
0
0

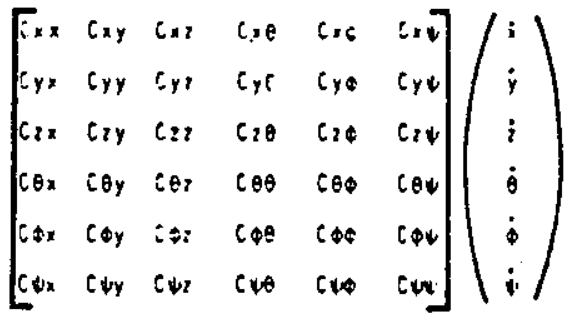

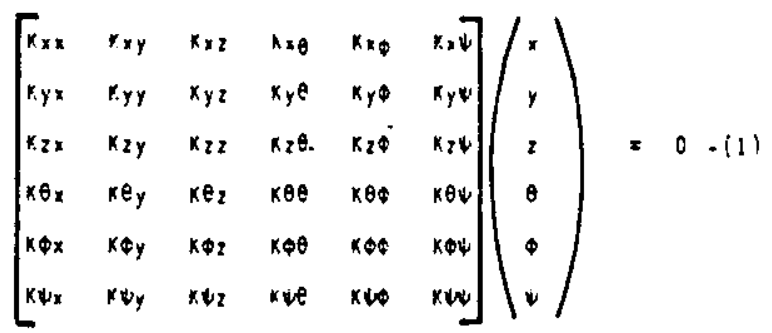

where is the mass of the engine and gearoox asseat? with all accessories fitted, ilj are the princisal poerts of ineritia,rij andij are the retarding forces about the principal axes due to all juclator elenents per unit cisplacerent/velosity. in his caper saollen cevelops the necessary equatices te relate the indiviousl isolator properties to the glota! stiffness and daping matrices ateve Translational and rotational stiffnesses and facing ay be incorprated in the isolator unit. It is necessary only to be able to write the radius and transforation atrices for each isolator.

The forces acting on the engine are shoun in figure 9. Jiven that ve have a six cylinder engine then that engine is in prieary and secondary balance. It is therefore possiole to neglect $F i$ and $k$, the out of balance forces anc oner:s. Ir:s leaves the inertia anc gas forque given by $s h$ gley ane Uicker (12) as:

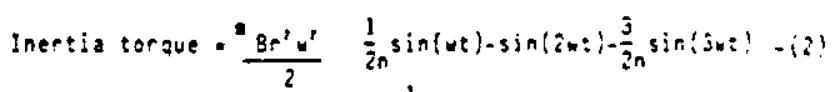
Gas torque $=f \operatorname{grsin}(x t) ! \cdot \frac{1}{n} \cos (u t)$

where ${ }_{a}$ is the equivalent reciprocating wass, whe rotational frequency, r the crank throw, n. L ir uherelis the con-rod lengtin and $\mathrm{g}$ the gas force.

The dynacosezer loas wa be taken as beingecul :o : "e vean torque output fros the engine. Hense the ialal tomase aci:ig on the engine is:

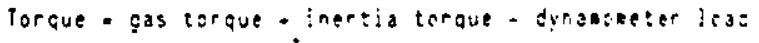

This torque acts abou: the cranshiaft axis se the forsing function for equation! is:

\section{[4] $|i|$}

where $[A]$ is the $3 \times 3$ teansfaration oatrin necessar, i: describe the torque vector $(i)$ in a co-orsinate systes coincident with the peinipal axes of the engine. le spoulo be noted the force ve:tor is zero. 
Figure $E$ ivithi VIgEATION SIMULATION PRQGRAM FIONCHAR:

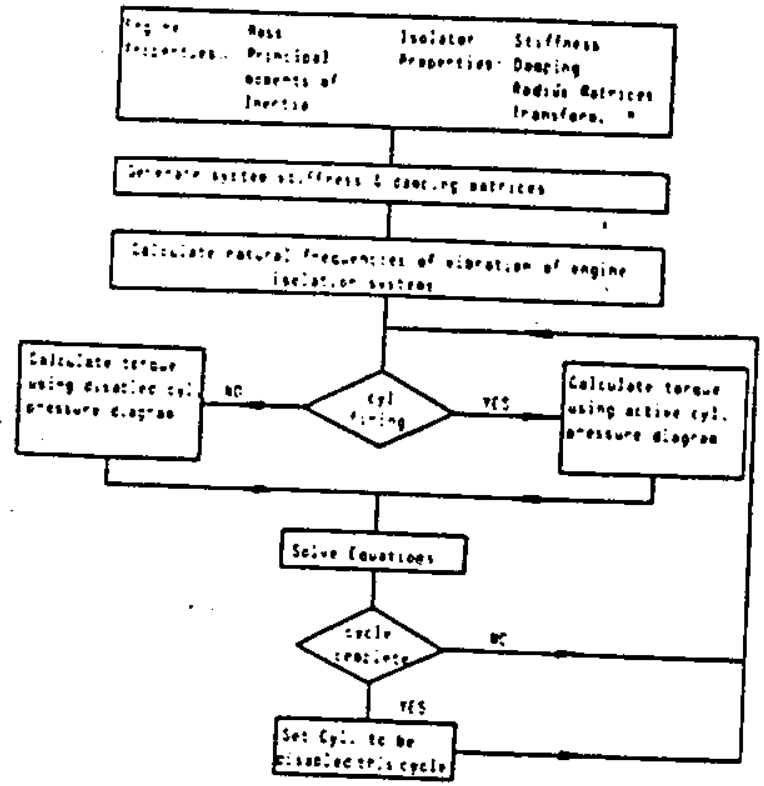

- Egute 9 fors:s acTING ON THE ENGINE

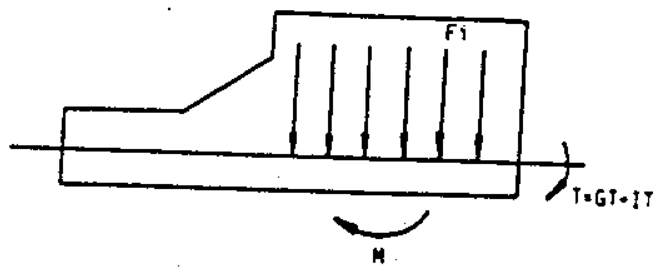

LFF:NG:

Solution of the Equations of Motion

In orcer tha: the equations detailed in Appendix 2 way be sevecit is resessary to deterwine certain properties of the engine ans atarbox asseably and also to cellect certain das froe the engine. of ast int also to cellect certain gravity, oriecengine. Of nost interest are the centre of covents of ireraion of the principal axes and the principal the eylinder oress. It will also be necessary to represent wrich this inessure diagra cathenatically. The seans by with this infiration was obtained ill now be discussed.

If a rigie bes, is suspencet frop a single point it will atoot ar ceiesiation such that its cente of gravity will lie on a line ecaun through that point and nornal to be ground. The engine can therefore be suspended fron three different fiir:s in turn, the relevant lines being const-acted on engine drauings. The centre of gravity then
A eptetedy. suscended as in Fig.le and allowed to oseill. ate tith free anguiar vibration, vill have $i$ is suspensior einieum.

Given that we have a reasonate idea of the position of the axes we can suspend the engine as shown in 8 ig. 10 . The slider can ther be wed to acjus: the position about which the engine rotates. Figure 11 sheus the results The whict is then rotated through 900 and the processults. The eng:-e loeates the pasition of one and the process repeated. in: one further acasurement to axis. It is necessary to abte systee. Using the sant to locate the orthogonal axes fropeach orincipal ame equipuent the engine is suspendec of inertia calculated.

It is possible to represent any waveforn by a series of si.e waves of differing aoplitude and ohese,i.e. a fourier sesiet.

Cylinder pressure fron number 1 cylinder is logged via a Kisiler pressure transducer and charge anplifier. The sigra: is passed through an $4 / 0$ and storec in a $15111 / 23$ aicroare averaged in the tSi the da:a logging syster. Resui:s variation, 100 cycles has been sollected it is transferrec taken, Once the da:a PDF computer. Initiation of enerec by a direst line to $t$. indieater in the fortion of the ca:a logging is by a 100 mounted on the crankshaft. slo:ies sisc and opto suitech either $T O C$ or 360 anshaft. Sigral conditioning enables point in the ercle before $T D C$ to be chosen as the start ana'ysis on the daza to POF conplier is used to run an $F F$ : ana:ysis on the dasa to give resuits of the form.

$$
2 A \cos (2 \pi+t+B)
$$

whe:e $A$ is half the anolitude of the sine wave, $f$ its frequency and $B$ its phose angle.

On running the siaciation progras tie appropriate value fe. the cylinder pressure is obtained by suaring these sine was. The shase angle is aultiolied by $n \pi / 3$ where $n$ is the cylirse. nuater $(0-5)$ for correct handing of the firing interval between eranks. 
FigURE 10. EOJ:EMENT IO DETERMJNE IHE LOCAIIOK OF IME PE: $X_{:}:$PA: AXES.

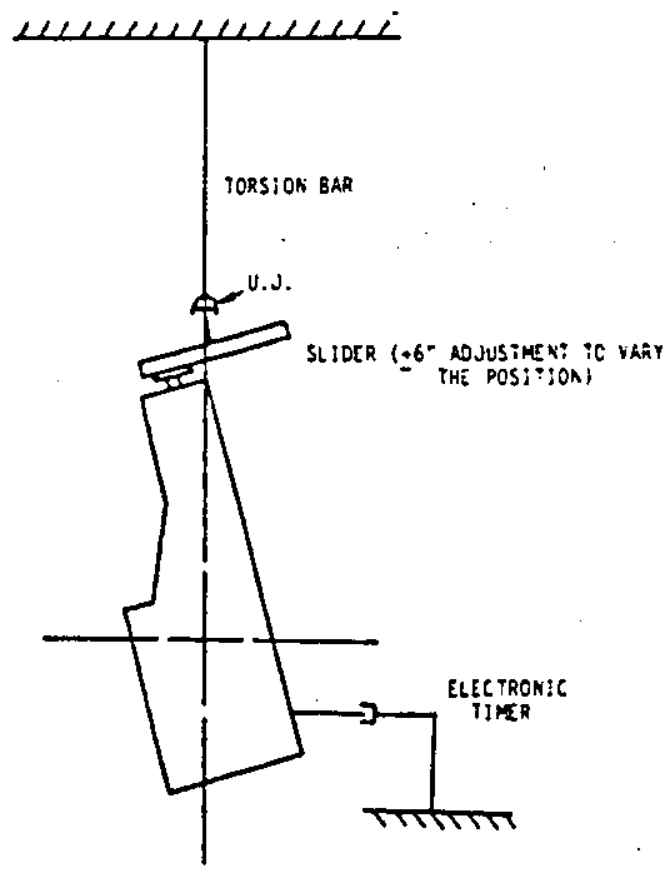

BIGURE 11. PERIODIC ITHC OF ANGULAR VIBRATION ABOUI CHGINE ixis.

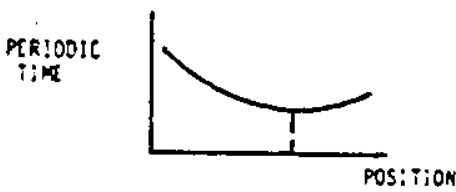

FIGURE 12. CYIJHOER PRESSURE DATA LOGGIHG INSTRUAENTATION.

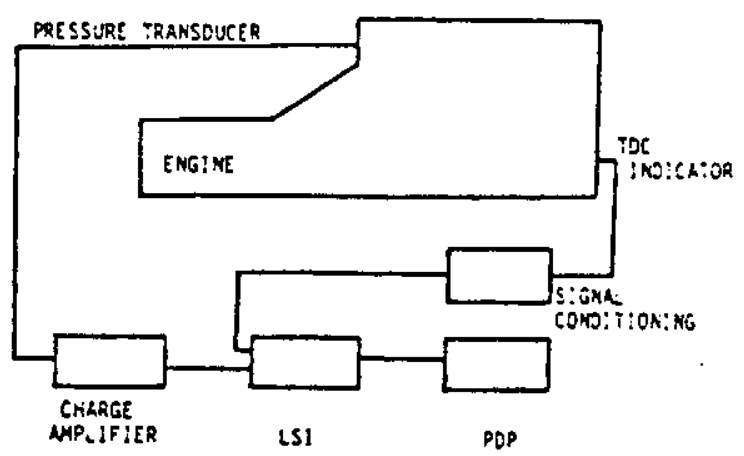


Bosch L-Jetronic Fuel Injection - Principle of Operation

The L-Jetronic is a pulsed fuel injection system employing electronic control. The controlling parameters, representing the fuel requirements of the engine, are sensed by transducers and relayed in the form of low-current signals to the electronic control unit which then calculates the optimum opening times for the injectors. The injectors are operated electromechanically, and inject fuel under pressure onto the inlet valves of the engine.

The main control parameters for the determination of the injection pulse duration are the quantity of air entering the engine, and engine speed.

\section{Operation:}

Figures 1 and 2 show the main components of the injection system and their relevant positions on the engine respectively, and described in Table 1. An electrically driven pump delivers the fuel through a filter and provides the pressure. This pressure is controlled by the pressure regulator so that there is a constant pressure difference between the fuel pressure and the inlet manifold. This is achieved by connecting the inlet manifold to the spring chamber of the pressure regulator, thus making the fuel delivery of the injectors dependent only on the injector pulse duration.

The pump delivers more fuel than the engine requires at maximum power, the excess fuel being returned to the tank by the pressure regulator.

The inlet air flows from the air filter via the air meter and the throttle valve, into the plenum chamber and then to each cylinder through inlet tracts. There is one fuel injector for each of the cylinders, and this is sited near the inlet valve, for driveability and emissions reasons resulting from precise fuel delivery to each cylinder. However, as a consequence, when starting the engine at low ambient temperature the injected fuel has little chance of mixing with the incoming air and vapourising due to the short distance to the cylinder. Thus, a further injector, giving particularly good fuel atomisation, the 'cold start' injector is fitted in the plenum chamber and activated during low-temperature starts.

The injected fuel quantity is determined from measurements of inlet air quantity and engine speed. The air fuel diagram, shown in Figure 3 , illustrates the relationship.

The air drawn in by the engine works on restricting flap in the air meter, and a flap angle A, corresponding to a particular air 
The engine vitration during the lests as logect and onalysed using the Degarivent's For cosucer eunning a proprietary software pachage. The engine siete us 1200 rev/ain or 10 thernodynabis eysies/second. It is frequenty of 10 Hz is therefore the funcamental frequen:y of engine vibration at that speed. The salient resulis of the spectral analysis are shown in Fig.7 and are suaratised in lable?

lable 2. Doojran frequensies iazid rev/oin

No. of Cyl.Active

Couirar: frequencies $\left(\mathrm{Hz}_{z}\right)$

$\begin{array}{ll}6 & 60 \\ 5 & 10 \\ 6 & 20 \\ 3 & 30 \\ 2 & 20\end{array}$

These freouencies should be studiec in conjunction with the torque fiagrass. figure 6 . The ditinant frequency of engine vibration is ine sane as the lsoes: frequency of torque pulsations introsuced by the disa: :enent of cylinders.

This is the ajo- disadrantage of engine cylinder cisablewent systems are the reason why or:y linjtec use has been wade of thes te cate. $0: 5$ at ling ialf the tc:al nurber of engine cylinders nas been saveres cefause it intrcouces torque and vibra:ion frequencies of half those experienced under nornal ofezation. Any other number of deactivated cylinders introcices louer frecues:ies.

Two apprcaches oy be eaployed to iniaize this increase in vibration. A cyclic disatiesent sequence could te adopted to inisise the vibration or the engine isolation systen redesigned. If a cyclic disablesun: sequence is favoured we are lieites t: running on $8,6, t_{\text {or }} 2$ cylinders, with either 5 or l cyidider operation inere is insufficient scope to optiajz: the disatlexen: sequence. At $3200 \mathrm{rev} / \mathrm{nin}$ with 5 cylinde? static operation :et doninan: frequency of vibration is : $9 H_{z}$. Any cyeling of the cylinders introduces lowee fequency seaponeris of vibration. With 4.2 or 2 cylinoer operation there is uch greater scope for optiaizing the sequence. To this end a utheatical ocdel of the engine has been derelopec. This is described in appendix 2 and enables the vibra:ion of the engine to be investigated for different disatlenent sequences. Appendix 3 detajls how the orientation of the principal ares. principal secents of inertia and rezeesentation of the cylinder oressure wavefore mere oz:alned. Randoc gisablesent of cylingers could be thet but this could iead to an increase in engine vibration t.e to the transient vibration introcused.

Redesign of the engine isolation systen ejther by thoosing an isolater unit with nore aperoz-iate properties or by relozating the isolator positiots to achieve a greater degree of cotion decoupling vould coviously reduce the transtission of ine vibration.

\section{Conclusions}

The results of our investigations show the potential of engine cylincer tisableaent in pritijing rery worthwile fuel savings. To earinise its asortages the systet should offer the possis:iity of disab!iry any nuater of cylinders and of disat!ing oifferent nubbers st cyilinders or eifferent therocynasis igits. The ease a : whigh fuel shst off ay be ac:onolished and the fact that the overall perform. ance of the rehicle renains unaffected, abes such, systea comercially attractive.

Engine vitration and, to a lesser extent. eissions have preventec suct an inolesentation to date. A final solution to this protien of engine vibration is expecied to incoris. orate cy:lit disablement sequences, a re-designed engine isolatior systea and. pertaps, increased fiyaheel inerial the tatier to reduce torque and sceed fluctioations in the driveline.

\section{Acknowiecjeasnts}

The Authars vish to acknculedge the helo and encourageatent affordec by the Science and Engineering Research Council. Jaguar Cars ltd., and their colleagues in the Department of Iransport Technology. Loughborough University of Technology.

\section{REFERENE:S}

1. Givens, L.."A Hew Aporoach to Variable Disoiacenent", Au:eotive Engineteing. Vol.85, No,5, pe30-3: 11977$)$.

2. Bates, 6.,Desdall, J.H. and Srith. O.h., "variable Cisplazement by Engine value Control", SAC 706145 (19)

3. Abthicff, J., Schuster, M.D. and wollerhaupt, $\therefore$. , "Ér Mecorenbonzede ajt Zyllinderabstra!tung wne seine Verterachsreduziefungen", Motortechrisshe Zeissshrift, Juiy/hugust 1980 (NIRh trans!ation Nc.53/80) 11980 ).

6. "Cylinder cut-off for OHC $\checkmark-8$ ". Autooctive ingineering. Vol.88, Ho.1, peto (1980).

5. Stejek,0. and Bet:oeley, 0., "The Ford $3 \times 6$ ingine Progera". Proceedings International Symosiua on Autorstive Technology 6 Auconation (15A1A), Cologne, 15-z3 Sepisuber, 1983, dol11-128 (1983).

6. "Oual-Mode engine al terristes paired cylinders".

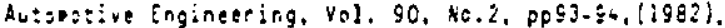

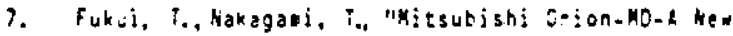
Variab!e Disolacenen: [ngine", SAE ke. E310:7 \{1983\}.

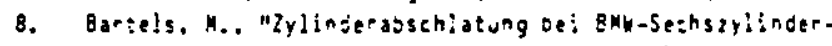
acsoren", Motorortechnische Zejtschrift. July'August 198:. po 285-290 (19E!).

9. "Siaglified dual-node engine near production". Alecontive Engireering, Vol.89, No.7, pa80-8: issi).

10. Wa:anabe, E., and Fukutani, 1., "Cy! inder Cotgif of 6-stroke Cycle Ingines at Part-load and Idle", SAE Ho.820156 (1982).

11. Socllen. L.E. "Gerieralisec Matrir Me:rod fo- ine Desion ans dnalysis of bieration - Isolation Systels". journa! of the Acoustical Society of Anericd, Val. t.. NC.1 PF!:3-204 (1966;.

12. Shigley. J.E. and bither. J.R., "Thes: of

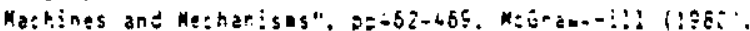


flow $Q$ is obtained. A potentiometer operated by the restricting flap converts this angular position A to a voltage $U$, with the relationship between voltage $U$ and airflow $Q$ per unit time being reciprocal. In the control unit this voltage is divided by the engine speed to give air quantity per stroke, $q$, and hence the fuel injection pulse duration, $t$.

$$
\text { i.e. } \begin{aligned}
t & \propto q \\
\text { or } t & \propto \frac{Q}{n} \quad \text { where } n=\text { engine speed } \\
t \times n & \propto Q
\end{aligned}
$$

The speed information is given in the form of the time interval between consecutive ignition sparks. The pulses generated in the control unit energise the injectors so that by the above relationship the injected fuel quantity, qi, depends on air flow and engine speed as:

$$
\text { qi } \propto \mathrm{t} \propto \mathrm{q} \propto Q / \mathrm{n}
$$

The fuel injectors are connected in parallel and thus activated simultaneously, but at different phases of the thermodynamic cycle for the individual cylinders. In order to reduce this timing discrepancy one half of the required fuel quantity is injected for each engine revolution. Consequently, injection pulses are triggered directly from the ignition low-tension circuit, and in the case of the Jaguar 6-cylinder engine each injection pulse is triggered every third ignition spark.

Additional Controls

When cold starting and during subsequent running, the engine requires a greatly enriched mixture. During cranking, the enrichment is provided by the cold start injector if the engine temperature is below a fixed value, set by the thermo-time switch which also limits the energisation period according to temperature, to prevent possible flooding of the engine.

During the warm up phase the enrichment is controlled by the water temperature probe (thermistor), located in the engine coolant. During cold starting and running, a greater air flow is required to maintain idle speed, in addition to the enriched air/fuel mixture. This additional air is controlled by the extra-air valve, whose variable aperture is changed by means of a bi-metal strip according to the temperature of an electrically heated coil.

Idle and full-load running conditions are further optimised by the use of a throttle-controlled switch, and an adjustable bypass on the air flow meter permitting further trimming of the 
mixture at low air flow conditions such as idle. An additional mixture adjustment is provided by a temperature sensor mounted in the air inlet mainstream, to compensate for variations in air density due to ambient and under-bonnet temperatures.

The purpose of the electronic control unit (ECU), is to supply impulses of specifically defined length to the electromagnetic injection valves. Figure 4 shows a functional block diagram of the unit.

The injection control multivibrators are triggered twice per camshaft revolution by the pulse shaper and frequency divider integrated circuit. This shapes the low-tension pulses and divides the frequency of these pulses by 3 (6-cylinder engine), producing two trigger pulses per camshaft revolution. The output $t^{\prime}$ from the division multivibrator is a pulse time equal to approximately half the injection duration, which is lengthened by a multiplication factor $k$ by the multiplier stage of the ECU. The factor $\mathrm{K}$ is approximately 2 for a hot running engine, but is increased for idle, full-load, cold running, starting and so on, so that the injector pulse time $t$ is:

$$
t \propto k \times t^{\prime}
$$

In addition, the multiplier stage adds a time $t$ " to $t$ to compensate for the 'dead' time of the injectors, which varies with battery voltage, so that the final injection time $T$ is produced:

$$
T=t+t^{\prime \prime}
$$

The Bosch L-Jetronic fuel injection system is widely used in the form described above on current mass-production passenger vehicles, and is particularly suited to the application of Cylinder Disablement, as described in the Thesis. 
TABLE 1. BOSCH FUEL INJECTION - MAIN COMPONENTS

(FIG 1. AND 2.)

1. Air Meter

2. Extra Air Valve

3. Main Injector

4. Cold Start Injector

5. Fuel Pressure Regulator

6. Fuel Rail

7. Throttle Switch

8. Idle Air Adjustment (and Overrun Valve)

9. Coolant Temperature Sensor

10. Ignition Coil

11. Thermotime Switch

12. Double Relay

13. Electronic Control Unit (ECU)

14. Idle Mixture Adjustment

15. Fuel Pump

16. Fuel Tanks

17. Fuel Filter

18. Oxygen Sensor

19. Air Inlet Temperature Sensor

20. Battery 


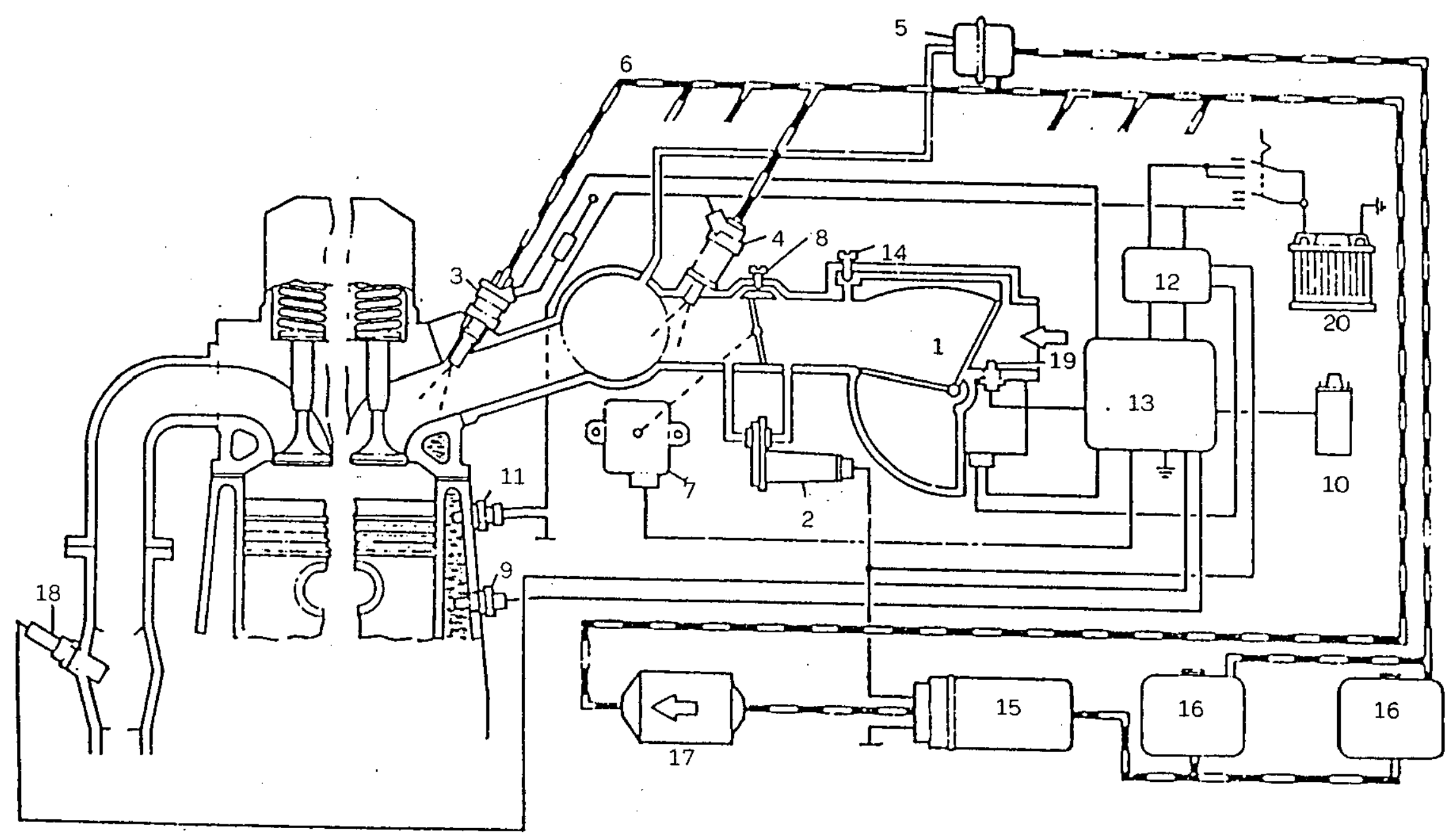

Fig 1. Bosch ' $L$ ' Jetronic Fuel Injection System 
Fig 2.

Jaguar 4.2 litre XK Six

Cylinder Engine and Location of Main Elect. Fuel Injection Components

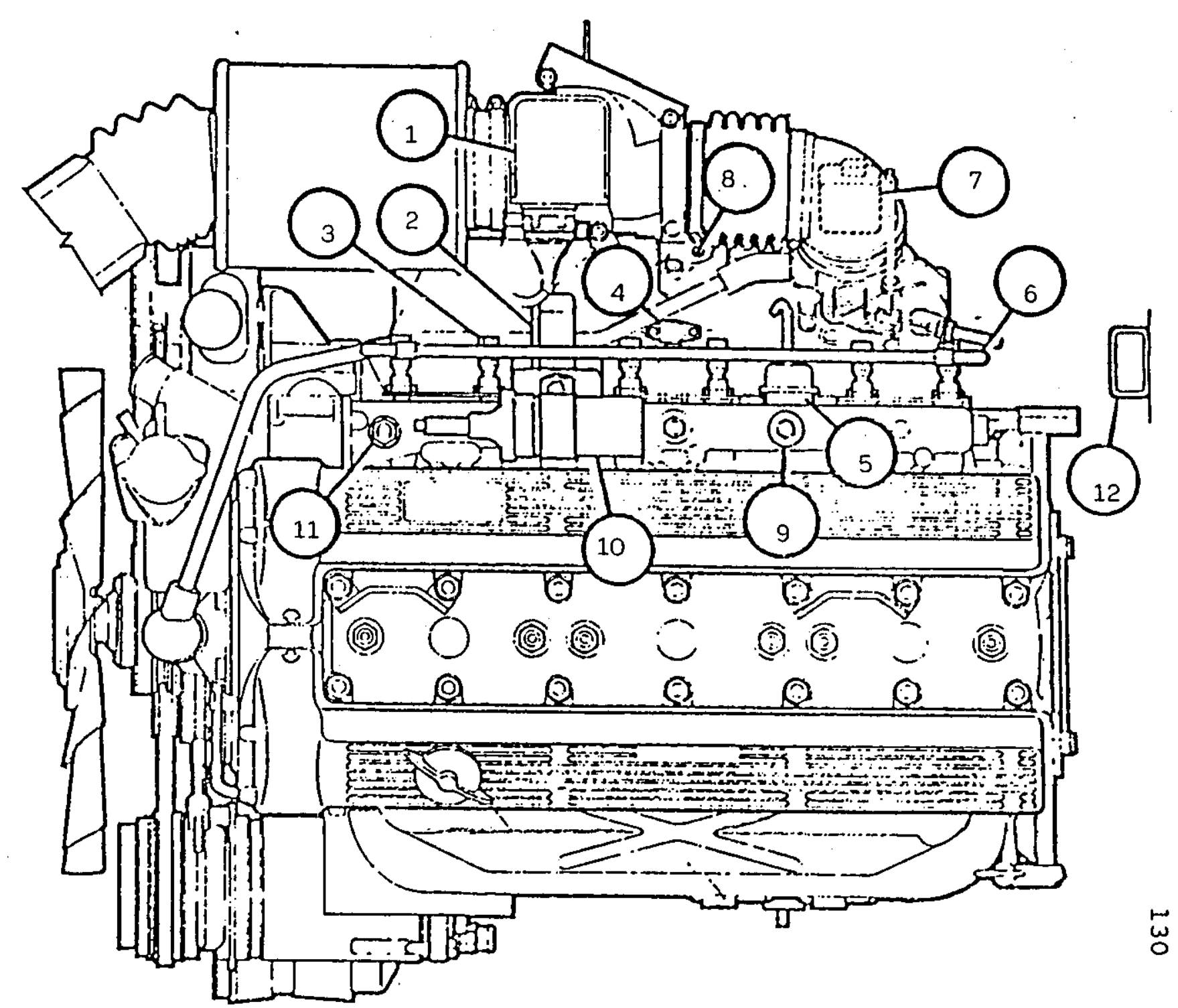




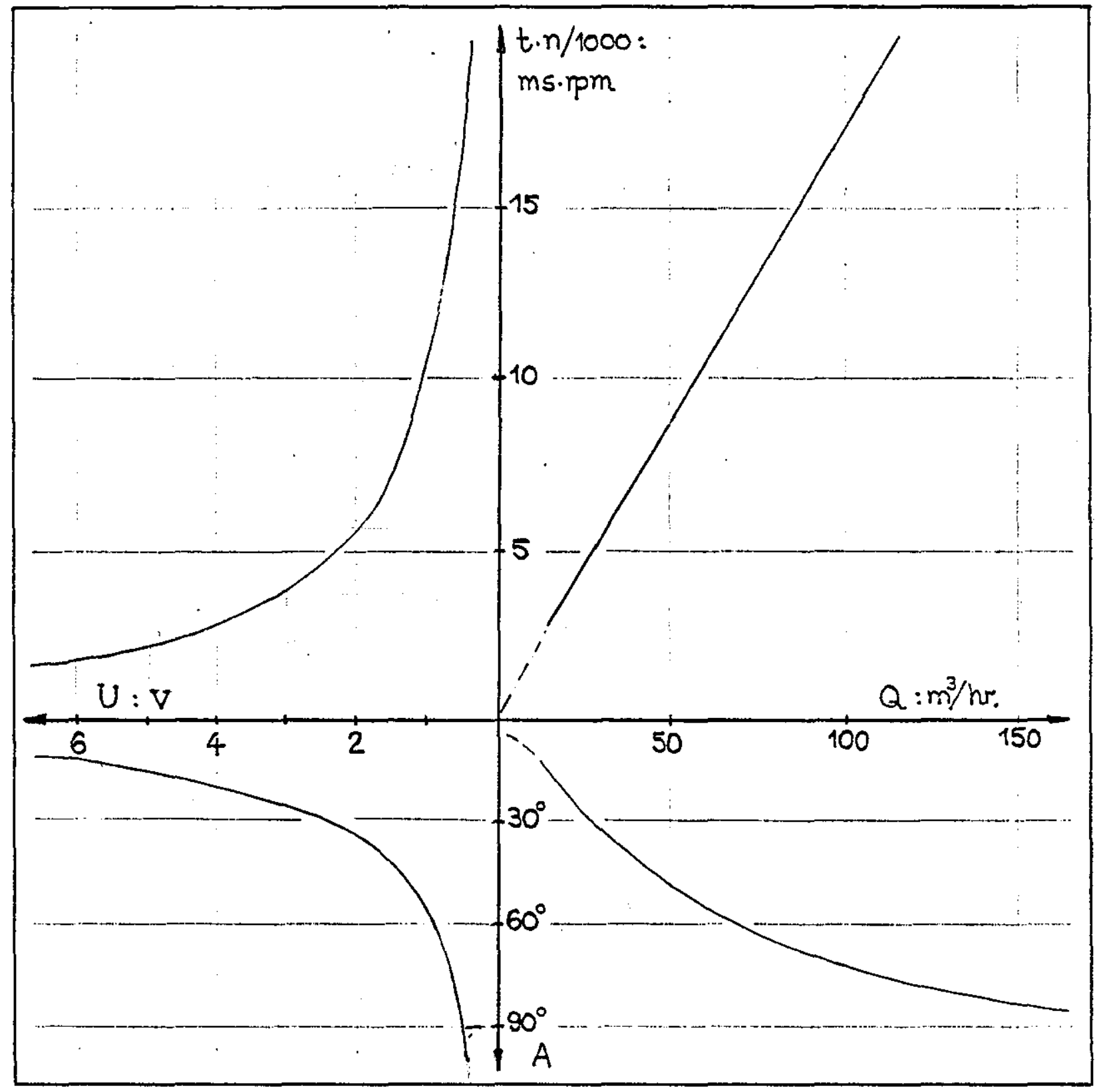

Fig 3 Bosch L-Jetronic Air Flow Diagram. 


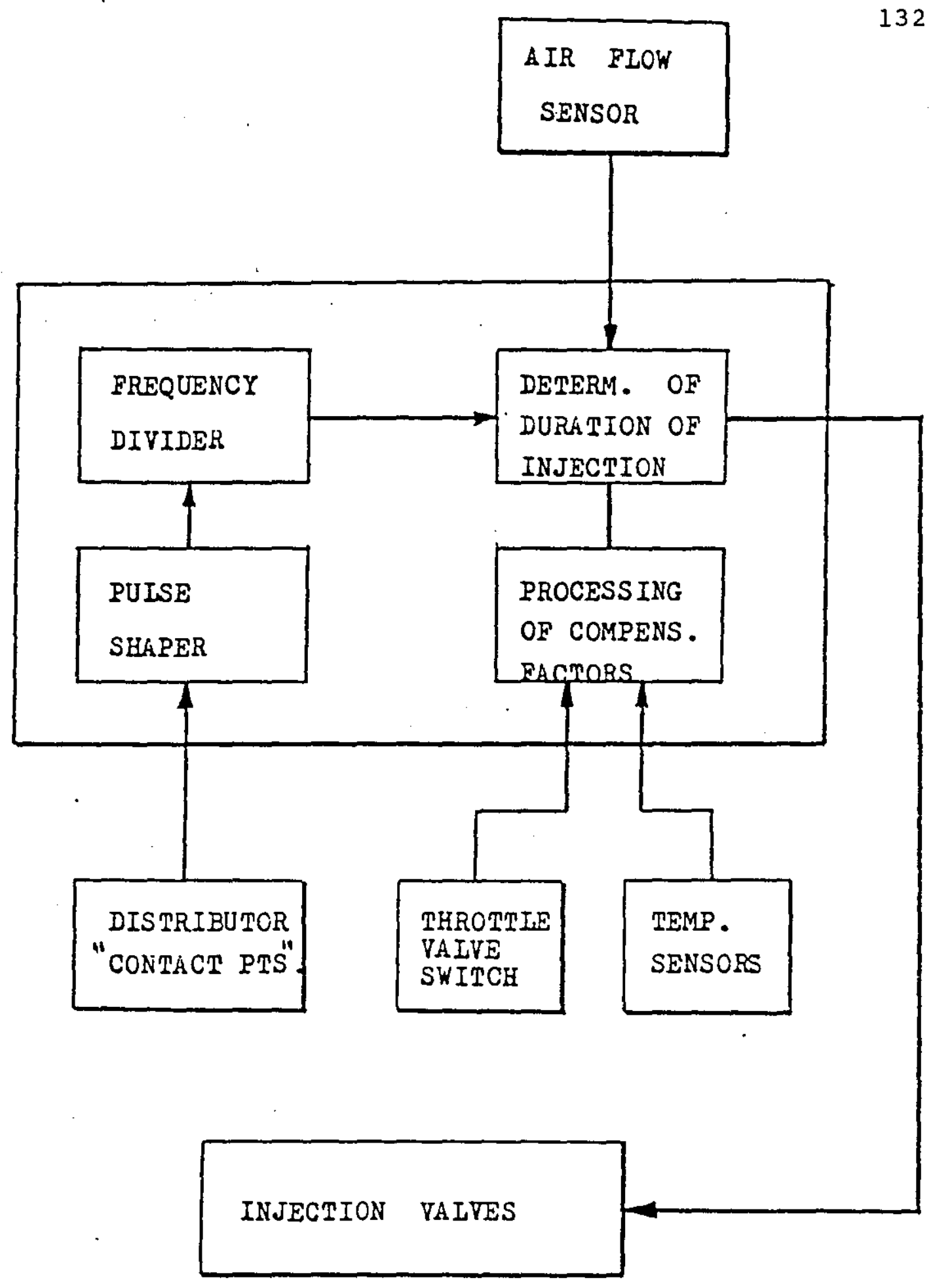

Fig 4 Electronic Control Unit Function - Block Diagram 
APPENDIX IV

Data Sheets

This appendix contains copies of the product specification Sheets relating to the microprocessor system CPU, a Toshiba TMP8085A chip, and the main interface board chip, a Am8155/Am8156 RAM and I/O device shown in Figures 1 and 2 respectively. 


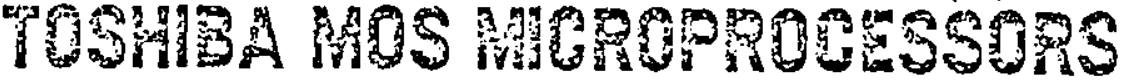

SINGLE CHIP MICROPROCESSOR

PANNEL SILICON GATE MOS

\section{GENERAL DESCRIPTION}

The TMP808SA is a new generation, complete 8 bit parallel central processing unit (CPU). Its instruc. tion set is $100 \%$ software compatible with the TMP. 9080A (8080A) microorocessor, and it is designed to - improve the present 9080 's performance by higher system speed. lis high level of system integration allows a minimum system of ihree IC's: TMPEO8EA

\section{FEATƯRES}

- 100\% Sotiware Comoatible with TMPg080A

- $1.3 \mu$ s instruction Crcie

- Single +5V Power Supply

- On-Chio Clock Generator (with External Crystal or RC Ne(work)

- On-Chio System Controller: Advanced Cycle status information avaiiab!e for Larģe System Control

\section{TMP8085AP}

(CPU), TMP8155P/TMPS15EP (RAMI) and TMPS755 AC (EPROM)/TMP825EP (ROM). The TMPSOESA uses a multiplexed data bus. The address is solit between the 3 bit adcress bus and the $B$ pit dato ous. The on-chip address istches of TMPgi5JP/TMP. 8156P/TMP8755AC/TMPS355P memory produc:s allow 3 direct intertace with TMP3085A.

- 4 Veciored Interrupts 10 re is Non-maskabie)

Plus an TMF9080A compatible interrupt

- Decimal, Binary and Dousle Precision Arithmetic

- Serial In/Serial Out Port

- Direct Addressing Capability to ôK Bytes of Mernory

- Compazibis with Iniel's $8085 A$

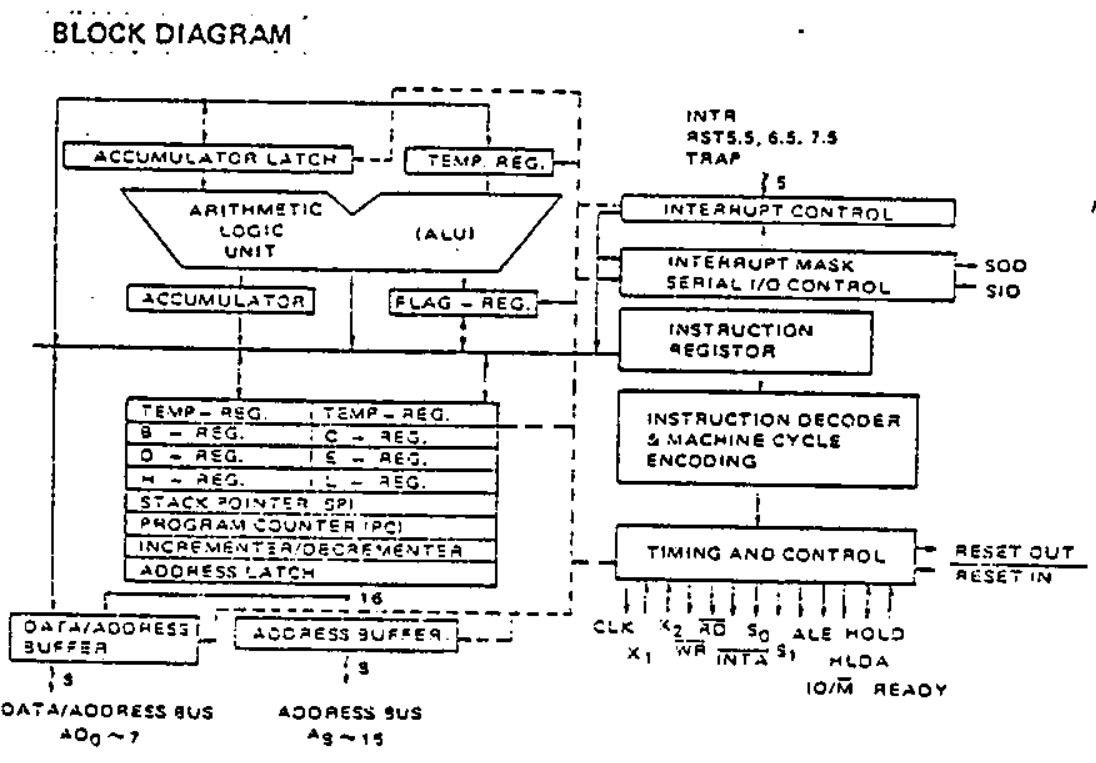

PIN CONNECTION. (TOP VIEW)

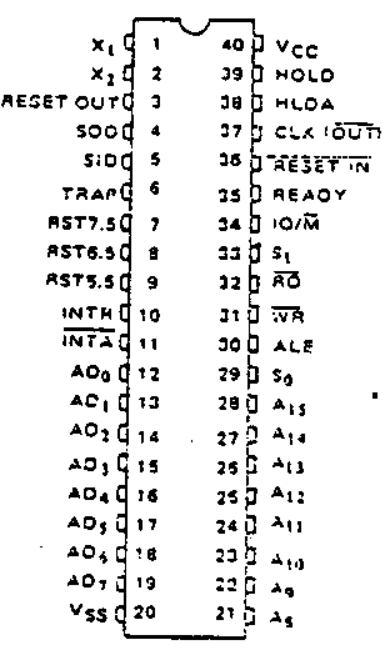

Fij. 1. TMPgogsa Functiond Black Diagram

Fig. 2. Thipgossa Pinout Oimpram

\section{Fig 1 TOSHIBA TMP8085AP Central Processing Unit Data Sheet}




\section{PIN NAME AND PIN DESCRIPTION}

$X_{1}, X_{2}$ (input)

Crystal, LC. or RC network are connected to $X_{1}$ and $X_{2}$ to drive the internal closing generator. $X_{1}$ and $X_{2}$ can aiso be driven from an externaily derived frequency source. The input frequency is divided by 2 to give the processor's internal operating frequency.

\section{CLK (Output)}

Clock output for use as a system clock. The poriced of CLK is twice the $x_{1}, x_{2}$ input period.

\section{$\overline{\text { RESET IN (Inoui) }}$}

The RESET Input intiaiizes the processor by ctearing the program counter, instruction register, SOD latch. Interrupt Enable flip-flop and HLDA flip-ilop. The address and data buses and the control lines are 3-sta:ed during RESET and because of the asyn chronous nature of $R E S E T$, the processor's internal registers and flags may be alterend oy RESET with unpredictate resultis. RESET IN is a Schmiti. triggered input, allowing connection to an RC network for power on RESET celay. The TMPSOESA is held in the reset conzition as iong as $\overline{\text { AESET IN }}$ is applied.

\section{RESET OUT (OUTPUT)}

The RESET OUT signai indicates that the TMP. 2085A is teing reset. it can be wised as a sysiem reset. It is synchronized to :he processor clock and lasts an integral number of clock periojs.

\section{SOD (Output)}

Serial output data ine. The output $S O 0$ is set or reset as specified by the SiM instruction.

\section{SID (Input)}

Serial input data tine. The data on this line is load. ed into accumulator bit 7 wherever a RIM insiruction is executed.

\section{INTR (InDUt)}

INTERRUPT REQUEST signai provices a mechanism icr excernai zsuces : mocity the instruction fiow of the program in frogress. It is sampled only during the next is ine iast sock crcte $2 i$ an instruc. tion and during Holc and tialt stätes. If it :s resery. nized. the processor will complere the execution of the surrent insiruction, aric then the program Count. ef (PC) will be inhibited from incrementirg and dil INTA will te issued. During this cvcle a RESTART or CALL instruction can be inserted to jump to the interrupt service routine. The INTA is enabied and disabied oy software. It is disablec by RESET and immediataly after an interriot is accepted.

\section{INTA (Output)}

INTERRLPT ACKNOWLEDGE: Occurs in tesponse to an Interrupt inout and indicates that the processor will be ready for an interrupt instruction on the data bus. It is used instean of land hass the same timing as) $\overline{\mathrm{HO}}$ during the instruction $\mathrm{cycie}$ after on INTR is uccepied.

\section{RST 5.5}

RST 6.5$\}$ (1nputs)

RST 7.5

RESTART INTEPRUPTS: These enrge ir.puts heve the same timing as INTR exceot they cause in internal RESTART to be automatically inserted These interrups have a higher priority than INTR. The prioricy of these interrupts is ordered 35 snown Table 1. They may be individually masked out using the SiM instruction.

TRAP (Inout)

Trap interrupi is a nonmaskaola RESTAĒT inter. rupt. It is sompled ot the same ilme as INTA or BS? 5.5 - 7.5. It is unartected by any rask or incer:uv! Enable. It has the highesi priority of any intarlifit

$A D_{0}-A D_{7}$ (Incut/Outcut. 3-state!

Lower 8 bits of the memory adcress (or liO 34 . dressi appear on the bus during tite tirst dock sycre (T) state) of a machine cycte. It men tecomes the data bus during the secone and thirc cleck oycles.

\section{$A_{6}-A_{5}$ (Output. 3-siate)}

The masi significant 8 bits of the memory acdras or the 3 bits of the i/O acciess. 3.jiated curing Hoid and tiali modes and during fase

\section{Fig 1 (cont'd)}


So. $S_{1}$ and $1 O / \bar{M}$ (Ou:put) Wachine cycie status:

$\begin{array}{cccl}I O / \bar{M} & S_{1} & \text { So } & \text { Status } \\ 0 & 1 & 1 & \text { Opcode fetch } \\ 0 & 1 & 0 & \text { Memory read } \\ 0 & 0 & 1 & \text { Memory write } \\ 1 & 1 & 0 & 1 / 0 \text { read } \\ 1 & 0 & 1 & 1 / 0 \text { write } \\ 1 & 1 & 1 & \text { Interrupt Acknowiedge } \\ \text { TS } & 0 & 0 & \text { Halt } \\ \text { TS } & X & X & \text { Hold } \\ \text { TS } & X & X & \text { Reset }\end{array}$

Note: $T S=3$-state (high impecance)

$x=$ unspecified

\section{ALE (Output)}

Address Latch Enable: It occiss during the firs: clock state of a machine cycie and enables the address to be latched into the on-chip latch of peripheral chips. The falling edge oi ALE can be used to strcte the status information. ALE is never 3-state.

\section{WR (Output. 3-state)}

WRite control: A low ievel.on $\overline{W R}$ indicates the data on the Data Bus is to te written into the se!ected memory or 1/O location. Data is set up at the trailling eoge of WR. it is 3-stated ruing Hold and Halt modas and during RESET.

\section{$\overline{R D}$ (Ourpue, 3-state)}

READ conirol. A low tevel on $\overline{P O}$ incicates the selected memory or $1 / 0$ cevice to ce read and that the Data bus is available for the cata transier, 3. siated during Hoid and Halt modes and during RE. SET.

\section{- READY (Inout)}

When READY is aosent iOOWl, indicating that the exierral cperation is not complate. the processor wil! enter the Watt siate. It will wait an iniegral numicer of clock cycles for REAOY to go high cefora com. pleting the read or write cycle.

\section{HOLD (Inout)}

The Hold input gtlows an extarnat signal to sut.se the processor to eilinquisi: control over the aocress bus and the data bus. 'When Hold goes active. tre processsor completes its iur:int operzilon. activatas the HLDA outplit, and Juts the Aadress. Oata, AO.
$\overline{W R}$, and $1 O / \bar{M}$ lines into their high-impedance state. Internal processing can continue. The Holding device can then utilize the adtress and data buses without interference. The processor can regain the bus only after the Hold is removed.

\section{HLDA (Output)}

The Hold Acknowledge output signal is a response to a Hold input. It incicates that the processor has received the HOLO request and it will relinquish the bus in the next cycle. HLCA goes low after the Hoid request is moved. The processor takes the ous one half slock cycle af ter HDLA goes low.

vec

+5 volt supply

VSS

\section{Ground Reierence}

\section{FUNCTIONAL DESCRIPTION}

The TMP8085A is a complete 8-bit parallel central processor. Its vasic clock sceed is $3 \mathrm{MH} 2$. Also it is designed to fit into a minimum system of three IC's: The CPU (TMPQCESA), a RAVI 1/O (TMP8I5JP of TMP8156P), and a ROM or EPROM 1/O chip (TMP. $8355 \mathrm{P}$ or TNPP 75EACl.

The TMPQC85A is provided with iniernal Z-bit registers and 16.bii regisiers. The TMP8085A has eight addressable 8-but registers: Six of ihem can te seed either as 3 -0it ragistars or as i6-bic regis:er pulrs In addition to the reguster pairs. She TMPSOSEA corl. tains two more 16.0it registers. The TMF8085A register set is as tollows:

- The accumulator (A Register) is the centre of ait the accumulater instructions. which include aritr. metic. lcogic. load and store. and 1/O insiructions.

- The program scuncer (FC) always poinis :o : ine memory location of the next insirliction io be executed.

- General - purpose ranisters 8C. DE, and HL may be usad as 3 chit regisiars or as throe 16 thit regisiers. interchangezoly, depending on the insirtistion beng veriormed.

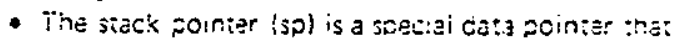
ahays p.jinis to the jtack too thext al:st:30te stack actresst

- The tiag register contains five one.tit i! jgs. zacn at

\section{Fig 1 (cont'd)}


which records processor status information and may also control processor operation.

The five flags in the TMPROREA CPU are shown below:

\begin{tabular}{l} 
(MSa) \\
\hline \begin{tabular}{|l|l|l|l|l|l|l|l|}
\hline 07 & $O_{6}$ & $0_{5}$ & $0_{4}$ & $0_{3}$ & $0_{2}$ & $0_{1}$ & $0_{0}$ \\
\hline$S$ & 2 & & $A C$ & & 9 & & $C$ \\
\hline
\end{tabular}
\end{tabular}

- The carry flag $(C)$ is set and reset by arithmetic operations. An addition operation that results in an overflow out of the high-crder bit of the accu. mulator sets the carry flag. The carry flag also acis as a "borrow" tlag for suburace instruction.

- The auxiliary carry flag (AC) indicaces overflow out of bit 3 of the accumulator in the same way that $C$ flag indicates overflow ou: of bit 7 . This flag is commonly used in $\mathrm{SCO}$ arithmetic.

- The sign flag $(S)$ is set to the condition of the most significant (MSa) bit of the accumulater tollowing the execution of arithmetic or logic instructions.

- The zero flag $(Z)$ is set if the result generated by certain instructions is zero.

The zero fizg is cleared if the result is not zero.

- The parity flag (P) is jet to $t$ if the parity inumioer of l-bitsl of the accumulator is even. If odd, it is cleared.

In the TMPSOS5A microprocessor contains the functions of clock genuration. system bus control. and in:errupt priority selection, in addition to execu. tion of the instivction set. The TivipsC85A uses 3 multiplexed Dain bus. The address is split between the higher 8-bit Address Bus and the lower 8.0it Address/Data Bus. During the first $T$ state $\left(T_{1}\right.$ ciock cyciel of a macinine cyc!e the lower orcer address is sent out on the Address/Data Bus. These lower $\beta$ bits may be latched externaliy by the Address Lateh Enadie signal (ALE). During the rost of the rachine cycle the data tus is uses tor memory or $1 / 0$ cata.

\section{INTERRUPT AND SERIAL I/O}

The TivlPSCBSA has 5 interrupt incurs: INTR. RST 5.5. AST 6.5. RST 7.5 and TRAP. INTR is

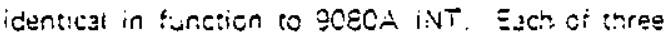
RESTART nouis 5.j. c.j. 7 J nas a croyrammaoie masK. TRAP is 2150 a RESTART interrupt bu: $t$ is non.maskable.

The trree ลEวT AลT interngois czuse the internal execution of RESTART if the interrupts are enablid and if the interrupt mask is not set. The nonmusik. able TAAP causes internal execution independent of the state of the interrupt enable or masks.

There are two different types of insurs in the re. start interrupts. RST 3.5 and RST 65 are high level. sensitive like INTR and are recognized with the same timing as INTR. RST 7.5 which is rising edge-sensitive

For RST 7.5, only a.pulse is required to set an internal tlip tloo which generates the interiust request. The RST 7.5 request flip flop remains set until the request is serviced. Then it is reset automatically This flip llop may also be reset by using the SIMt insiruction or oy issuing a RESE IN to the Tinit' 8085A. The RST 7.5 internat flip floo will be set iv a pulse on the AST 7.5 pin even wher the RST 7.5 interrupt is masked oute.

The interrupis are arranged in a fixed priority that cetermines which interrupt is to be recognized if more than one is sending: TRAP highest priority. RST 7.5, RST 6.5. RST 5.5, INTR-icwest priority. This priority scineme does not take into account th. priority of a routine :hat was siarted by a highe. priority interrupt. RST 5.5 can interrupt a RST 7.5 routine if the interrufts were reerabled cetore the end of the AST 7.5 routine.

The TRAP interrudt is useful for cotastropis: errors such as power faiture or ous error. It is no: affected by anv flag or mask. The TAAP inoui is both edge and level sensitive. The TRAP inpul must go hign and remain high until it is acknowlecged. It will not be recognized again unitl it goes low. thun high açaın. This avoicts any fáse triggertng due to noise or logic glitches.

The TRAP interrupt is special in inst it dissoles interrupts, but oreserves the previous interrupt enable stasus. Performing the tirst GIM instruction follow. ing a TRAP interruot zilows you io setermine wheth. er incertupts were enabled or cissabled oricr to the TRAP. Ail sutsequent RIM Instruction provide current interrupt enable siatus. Períorming a Riv instruction iolicwing INTR. or AST $\bar{\Xi} .75$ wi! provice cur:ent interruot enabie siatus, ruveailng :nat inierrupts are disaded.

The serial 1/0 system is also contro!lec sy ins =1, and SIM insirluctions. SIO is reac oy alivl. and Slivl sets tre SCD Jata.

\section{Fig 1 (cont'd)}


Teble 1. Inturvot Priority, Autrant Addros, and Sensitivity

\begin{tabular}{|c|c|c|c|c|c|c|}
\hline Name & & Pricrity & 1 & $\begin{array}{l}\text { Address Branchied :o } \\
\text { When Interruct Oce:urs }\end{array}$ & i & Type Trigger \\
\hline TRAP & : & 1 & $!$ & 24 (Hex.) & 1 & Rising toge and high level until samcied. \\
\hline RST 7.5 & 1 & 2 & $\vdots$ & $3 C($ Hex.) & 1 & Risıng ecge latched. \\
\hline RST 6.5 & 1 & 3 & 1 & 34 (Hex) & 1 & High level innil samsled. \\
\hline RST 5.5 & 1 & 4 & $i$ & $2 C$ (Hex.) & $i$ & High lent untit sampied. \\
\hline INTR & $i$ & 5 & 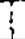 & See Note $(2)$ & 1 & High tevel until sampted. \\
\hline
\end{tabular}

Notes: (1) The orocessor oushes the PC on the stack beicre tranching to the indicated acdrass

(2) The address oranened so decends on ine instruction crovided to the TMPSCS5A when the interrupe is acknowledged.

\section{BASIC TIMING}

The execution or each instruction by the TMP. $8085 \mathrm{~A}$ consists of a sequence of from one to five machine sycles, and sach machine cycle sonsisis of a minimum of from three to six clock cycles. Most machine cycles consist of three $T$ siates, lcycles of the CLK output) with the excepion of opcode ferch. which normaily has either four or six $T$ stares lunless WAIT or HOLD siates are forced by the receipt of REAOY or HOLD incuitl. Any T state must ve one of ten possible siates, shown in Table 3 .

At the beginning of syery ndchine cycle. the TMP. 8085A sends out ihree startus signais (1O $i \overline{\mathrm{M}}: \mathrm{S}_{1}$. So) that define what tyoe of machine cycle is about to ake place. The TMP8085A also sends out a 16-0it address at the beginning of every machine cycie to identify the faricular memory location or $1 / 0$ port. that the macinine cycle apolies to.

The special ining signal, AODRESS LATCH EN.ABLE (ALE), is used as a strobe to sample the lower B.bits of address on the ADO. AD, ines. ALE is present during $T_{1}$ of every machine svcle. Contiol

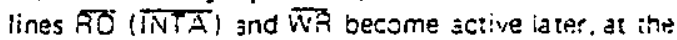
time when the iransier of data is to iake place.

Figure 3 shows an instruction tercin, memory resd and 1/O write c/cle las would occur juring processing of the OUT instructiont.

Table 2. TMPBOE5A Machime Cyete Chare

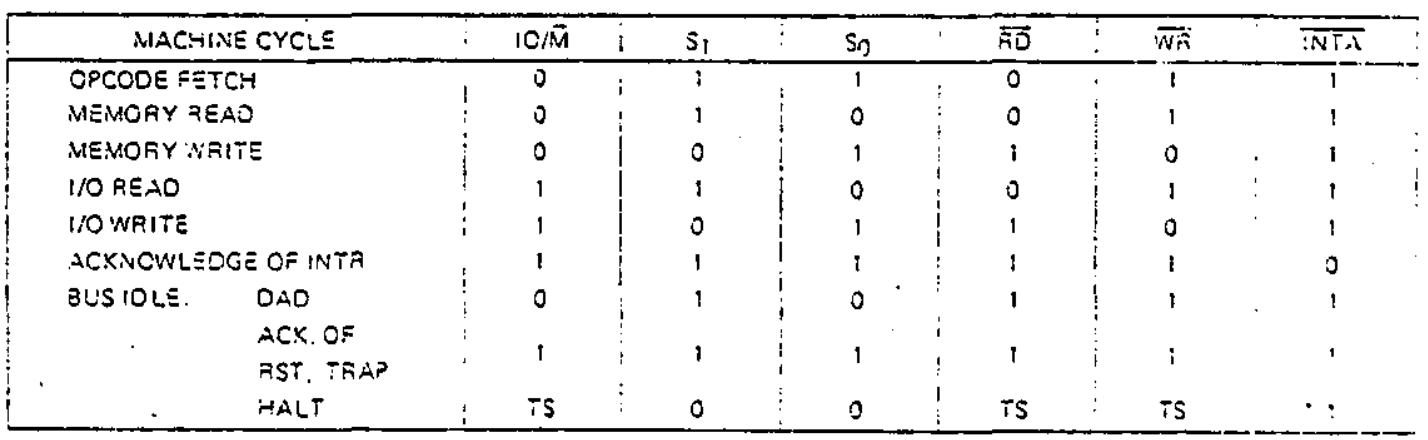

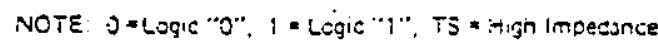


Table 3. TMP8OB5A Mechina Stote Chart

\begin{tabular}{|c|c|c|c|c|c|c|c|c|c|}
\hline MACHINE STATE & Si. So & $10 i \bar{M}$ & $A_{g}-A_{15}$ & $A C_{0}-A D_{7}$ & $\overline{\mathrm{AD}}, \overline{W A}$ & ; & INTE & 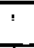 & ALE: \\
\hline$T_{1}$ & $x$ & $x$ & $x$ & $x$ & 1 & 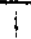 & 1 & 1 & $1^{\circ}$ \\
\hline$T_{2}$ & $x$ & $x$ & $x$ & $x$ & $x$ & 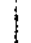 & $x$ & . & 0 \\
\hline$T_{\text {Walt }}$ & $x$ & 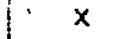 & $x$ & $x$ & $x$ & 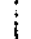 & $x$ & i & 0 \\
\hline$T_{3}$ & $x$ & $x$ & $x$ & $x$ & $x$ & & $x$ & & 0 \\
\hline$T_{4}$ & 1 & Ot & $x$ & TS & 1 & & 1 & & 0 \\
\hline$T_{3}$. & 1 & ot & $x$ & TS & 1 & & $t$ & ! & 0 \\
\hline$\cdot T_{6}$ & 1 & ot & $x$ & TS & 1 & 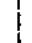 & 1 & 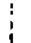 & 0 \\
\hline$T_{\text {RESET }}$ & $x$ & TS & TS & TS & TS & 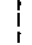 & 1 & & 0 \\
\hline ThALT & 0 & TS & TS & TS & TS & 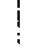 & 1 & $i$ & 0 \\
\hline THOLO & $x$ & TS & TS & TS & TS & $i$ & 1 & 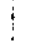 & 0 \\
\hline
\end{tabular}

NOTES. (1) $O=$ Logic " $O$ ". $1=$ Logic " $1 "$ ". is = Higin Incedance. $X=$ Unspecitied

(2). "ALE not generated durimy 2ne and $3 r d$ mschine sycles of $D A D$ insiruction

(3) $+10 / \bar{M}-1$ during $T_{4}-T_{6}$ of iNA machine cyete

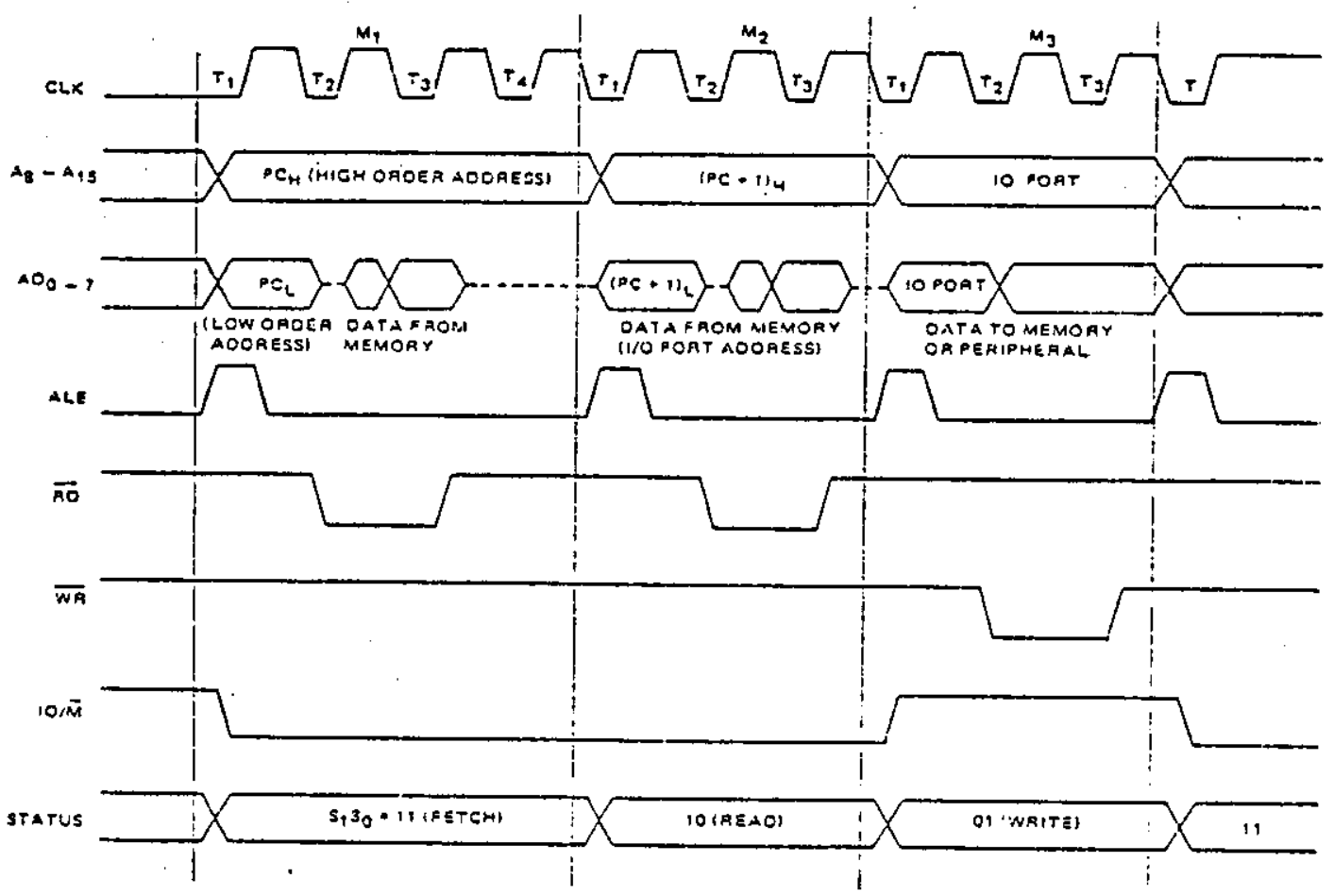

Fig 1 (cont'd) 


\section{DRIVING THE $X I$ AND $\times 2$ INPUTS}

You may drive the clock inputs of the TMPg085A with a crystal, an LC tuned eircuit, an RC neiwork or an external clock source. The driving frequency must be at leas: $1 \mathrm{MHz}$, and must be twice the cesired internal clock irsquency.

\section{A. Quartz Crystal Clock Driver}

If a crystal used, it must hove the following characteristics.

- Paraliel resonance at iwice the clock frequency assired

- CS (shunt cacacitance) $\leqq 7 P F$

- RS (equivalent shunt resisiance) $\leqq 75$ Ohms

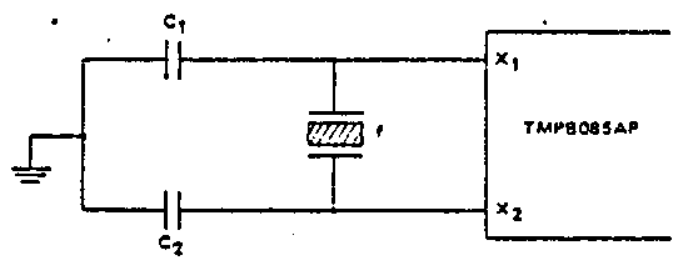

Note a value of the external capocitors $C_{1}$ and $C_{2}$ between $x_{1}, x_{2}$ and ground. In case of the crystal frequency above $4 \mathrm{MHz}$, it is recommended that you cticose a valtue of $10 \mathrm{pF}$ for $\mathrm{C}_{1}$ and $\mathrm{C}_{2}$ and less than $4 \mathrm{MHH}, 20$ of capacitors are recom. menced.

\section{B. LC Turned Circuit Clock Driver}

A parallei-resonani LC circuit may be used as the frequency-detarming network for the TMP. 8085A, providing that it has a frequency tolerance of Less than 10\%. The components are chosen from the iormula.

$$
i=\frac{1}{2 \pi \sqrt{L\left(C_{\text {ext }}+\bar{C}_{\text {int }}\right)}}
$$

The use of an LC circuit is noc reccmmended ior irequencies hıgner tnan acproximuteiy $5 \mathrm{MHz}$

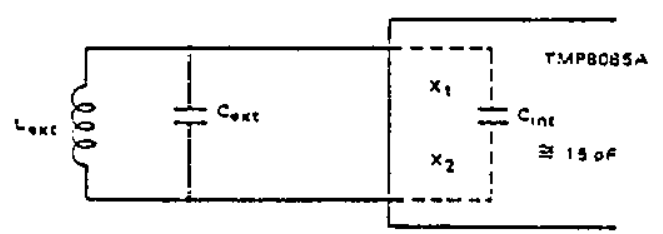

\section{RC Circuit Clock Driver}

An RC circuit may be used as the frequency Cetermining network for the TMPS085A if main. taining a precise clock frequency is of no impor. tance. Variations in the on-chip timing generation can cause a wide variation in frequency when using AC circuit. The oriving irequency generated by the circuit shown is approximately $3 \mathrm{MHz}$. It is not recommended that frequencies greatly higher or lower than this be attempied.

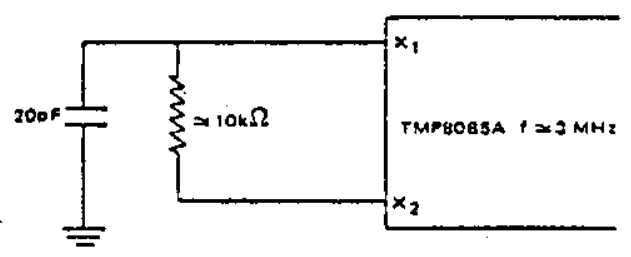

D. External Clock Driver Circuit

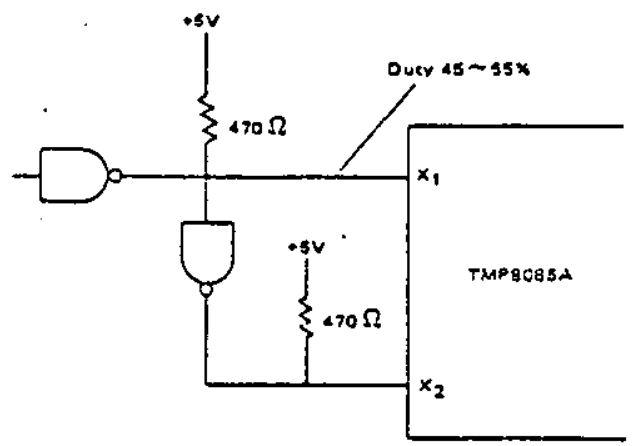

\section{POWER ON AND $\overline{R E S E T ~ I N ~}$}

The TWPPCE5A is no: guaranieed :0 work until 10 ms arter $V_{C C}$ ractines $4.75 \mathrm{~V}$. It is suggested inat RESET IN be kept low during this period.

Note that the $10 \mathrm{~ms}$ cerivd cces no: incluce : he time it takes for the power iucoly :o eezch its $4.75 \mathrm{~V}$ level.

\section{Fig 1 (cont'd)}




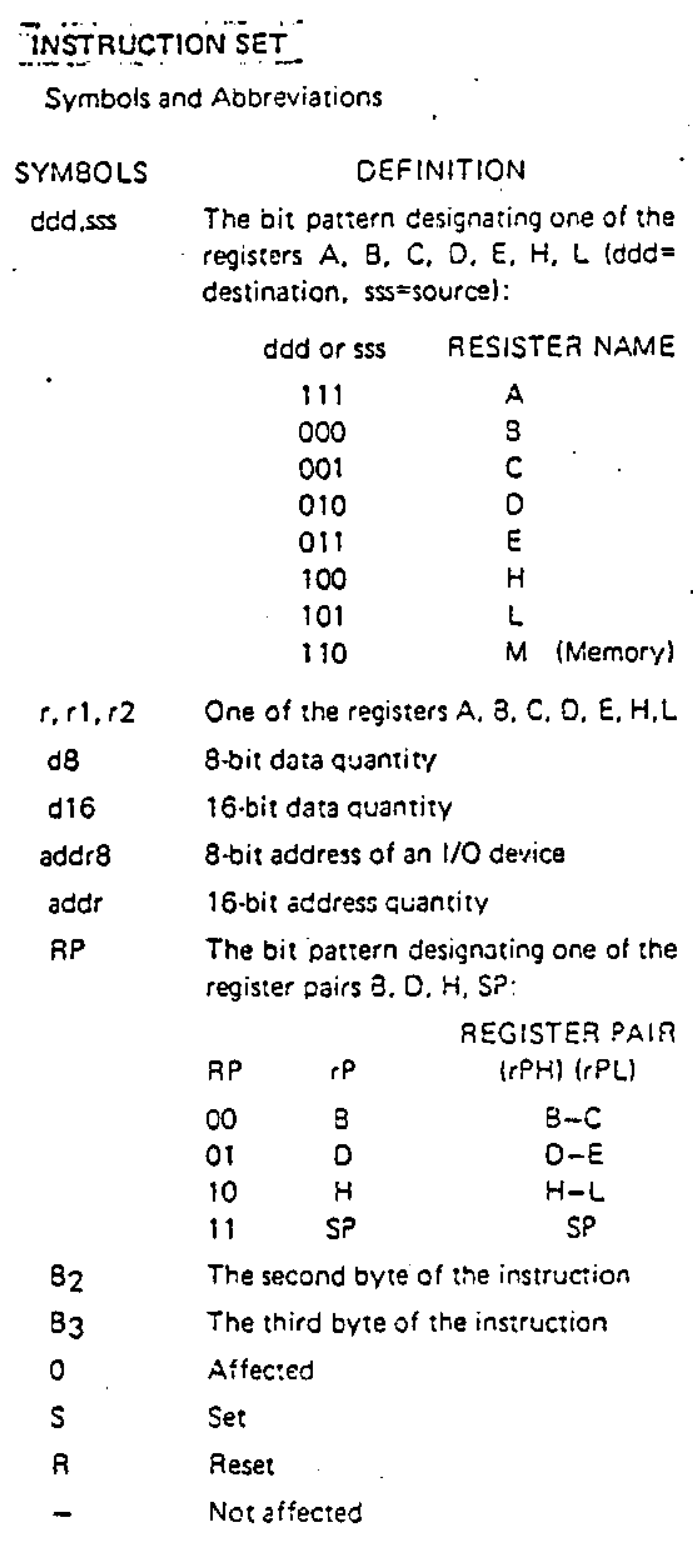

\section{Fig 1 (cont'd)}




\section{Data Transfer'}

\begin{tabular}{|c|c|c|c|c|c|c|c|c|c|c|c|c|c|c|c|c|c|}
\hline \multirow{2}{*}{ Mnemonic } & \multicolumn{9}{|c|}{ Instruction Code } & \multirow{2}{*}{ Oceration } & \multirow{2}{*}{ 8yres } & \multirow{2}{*}{ States } & \multicolumn{5}{|c|}{ Fläy } \\
\hline & 07 & 06 & Cs & 04 & 03 & 02 & 01 & 0 & & & & & $c$ & 2 & 5 & & $A C$ \\
\hline MOV $+1 . r 2$ & 0 & 1 & $a$ & d & $d$ & 5 & s & & s & $(r))-(r 2)$ & 1 & 4 & - & .- & & - & - \\
\hline MOV M, r & 0 & 1 & 1 & 1 & 0 & s & s & $s$ & s & {$[(H)(L))-(r)$} & 1 & 7 & - & - & - & - & - \\
\hline MOV P. M & 0 & 1 & 10 & $d$ & $d$ & 1 & 1 & 0 & 0 & $(r)-(\{H)(L)]$ & 1 & 7 & - & - & - & - & - \\
\hline MVI r,d8 & 0 & 10 & 0 & $\frac{d}{8}$ & d. & 1 & 1 & 0 & 0 & $(n)-(3-1)$ & 2 & $\begin{array}{l}7 \\
\end{array}$ & - & - & & & - \\
\hline MVI M.dB & 0 & 10 & 1 & $\frac{1}{3}$ & $\frac{0}{2}$ & 1 & 1 & 0 & & {$[(H)(U)]-\left(B_{2}\right)$} & 2 & 10 & - & & & - & - \\
\hline LDA addr & 0 & 0 & 1 & \begin{tabular}{|c|}
1 \\
8 \\
8
\end{tabular} & & 0 & $i$ & 0 & & $(A)-\left(\left(B_{3}\right)\left(B_{2}\right)\right]$ & 3 & 13 & & - & - & - & - \\
\hline LDAX 8 & 0 & 0 & 0 & 0 & 1 & 0 & 1 & 0 & & $(A)-(i 3)(C) \mid$ & 1 & 7 & - & - & - & - & - \\
\hline LDAX 0 & 0 & 0 & 0 & 1 & 1 & 0 & 1 & & 0 & $(A)-[(D)(E)]$ & 1 & 7 & - & - & - & - & - \\
\hline LHCO addr & 0 & 0 & 1 & 0 & & 0 & 1 & 0 & 0. & $\begin{array}{l}(L)-\left\{\left(B_{3}\right)\left(B_{2}\right)\right\} \\
(H)-\left\{\left(B_{3}\right)\left(B_{2}\right)+1\right\}\end{array}$ & 3 & 16 & - & - & - & - & - \\
\hline$L X \mid H, d 16$ & 0 & 0 & 1 & $\frac{0}{0 !}$ & & 0 & 0 & 1 & 1 & $\begin{array}{l}(H)-\left(B_{3}\right) \\
(L)-\left(B_{2}\right)\end{array}$ & 3 & 10. & & - & - & $-\vdots$ & - \\
\hline$L \times 10.016$ & 0 & 0 & 0 & $\frac{1}{8}$ & & 0 & 0 & & 1 & $\begin{array}{l}(D)-\left(B_{3}\right) \\
(E)-\left(B_{2}\right)\end{array}$ & 3 & 10 & - & - & - & - & \\
\hline$L x \mid B . d 16$ & 0 & 0 & 0 & $\begin{array}{r}01 \\
8 \\
8\end{array}$ & & 0 & 0 & & : & $\begin{array}{l}(8)-\left(B_{3}\right) \\
\left.(C)-\mid B_{2}\right)\end{array}$ & 3 & 10 & & - & - & - & - \\
\hline LXI SP. $\$ 10$ & 0 & 0 & 1 & \begin{tabular}{|l|}
1 \\
8 \\
\end{tabular} & 0 & 0 & 0 & 1 & 1 & $\begin{array}{l}\left(S P_{H}-\left(B_{3}\right)\right. \\
(S P)_{L}-\left(B_{3}\right)\end{array}$ & 3 & 10 & - & - & - & & \\
\hline SHLO addr & 0 & 0 & 1 & \begin{tabular}{|l|}
0 \\
8 \\
8
\end{tabular} & & 0 & $i$ & & 0 & $\begin{array}{l}\left(\left(3_{3}\right)\left(B_{2}\right) 1-(L)\right. \\
\left(\left(B_{3}\right)\left(B_{2}\right)+1\right]-(H)\end{array}$ & 3 & 16 & & - & & - & $=$ \\
\hline STA addr & 0 & 0 & 1 & $\begin{array}{l}11 \\
8 \\
6\end{array}$ & 10 & 0 & 1 & 0 & 0 & $\left\{\left(B_{3}\right)(8, H)+\{A\}\right.$ & 3 & 13 & & - & - & - & \\
\hline $\operatorname{sTAx} 8$ & 0 & : 0 & 10 & 0 & 0 & 0 & 1 & 0 & 0 & $(B)(C))-(A)$ & 1 & 7 & - & $\sim$ & - & - & - \\
\hline STAX 0 & 0 & 0 & 0 & 1 & 0 & 0 & 1 & 3 & $?$ & $(|D| !(E))-(A)$ & 1 & 7 & - & - & - & - & - \\
\hline SPHL & 1 & 1 & 1 & 1 & 1 & 0 & 0 & 1 & 1 & $(S P)-(H)(L)$ & 1 & 6 & - & - & - & - & - \\
\hline$x C .4 G$ & 1 & 1 & 1 & 0 & 1 & 0 & $i$ & $:$ & $?$ & $\begin{array}{l}(H)-(D) \\
(L)-(E)\end{array}$ & 1 & 4 & & - & - & - & - \\
\hline XTHL & 1 & 1 & 1 & 0 & 0 & 0 & 1 & $i$ & & $\begin{array}{l}(L)-\{(S P) ! \\
(H)-((S P)+i i\end{array}$ & 1 & 16 & & & & & - \\
\hline IN actors & 1 & 1 & 0 & $\frac{1}{3}$ & 1 & 0 & 1 & 1 & & (A) - (da) & 2 & 10 & - & - & & & - \\
\hline OUT adcro & 1 & 1 & 0 & 11 & & 0 & 1 & $i$ & & (cata) - (A) & 2 & 10 & - & - & - & - & - \\
\hline
\end{tabular}

Fig 1 (cont'd) 


\section{Branch}

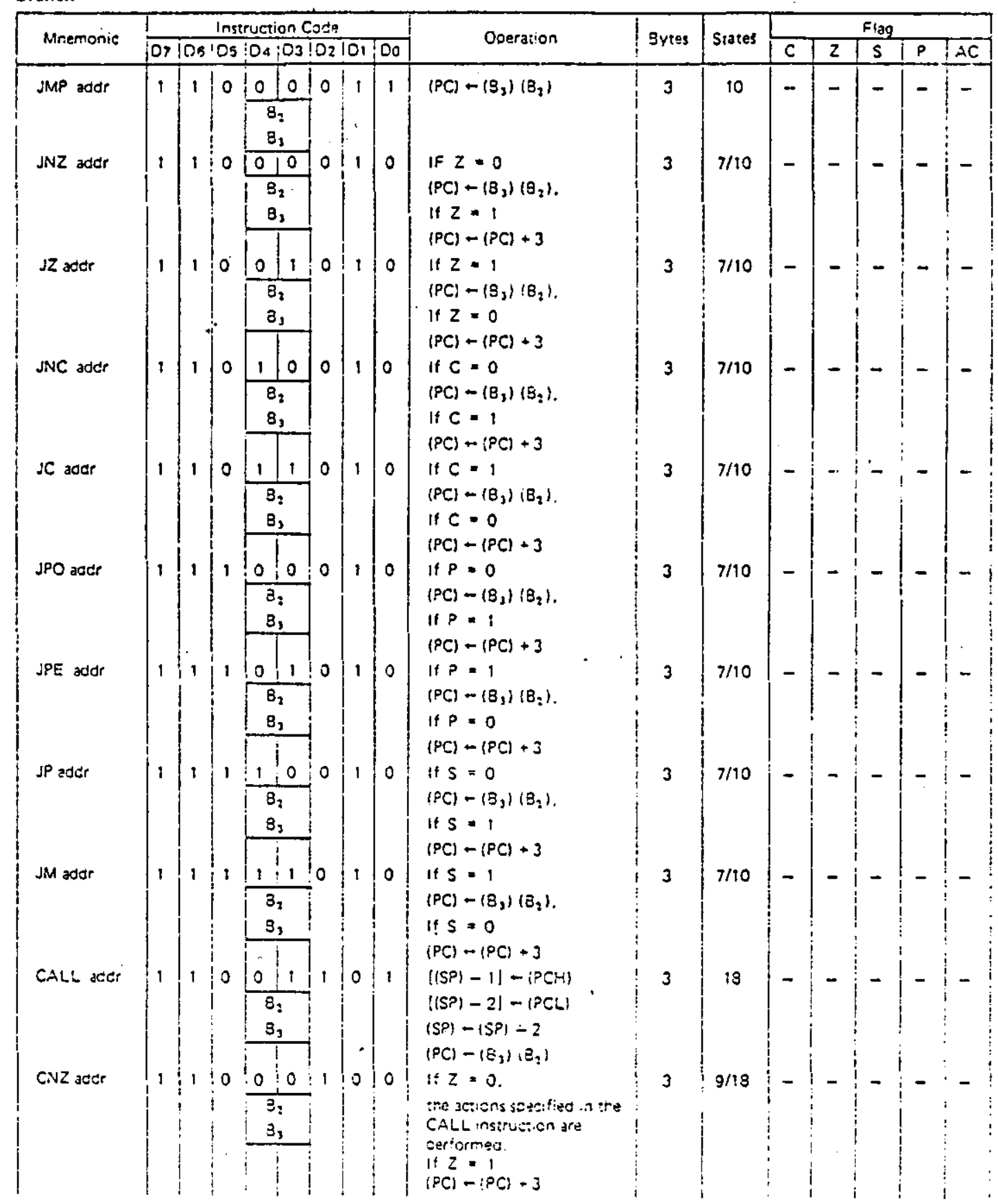

Fig l (cont'd) 


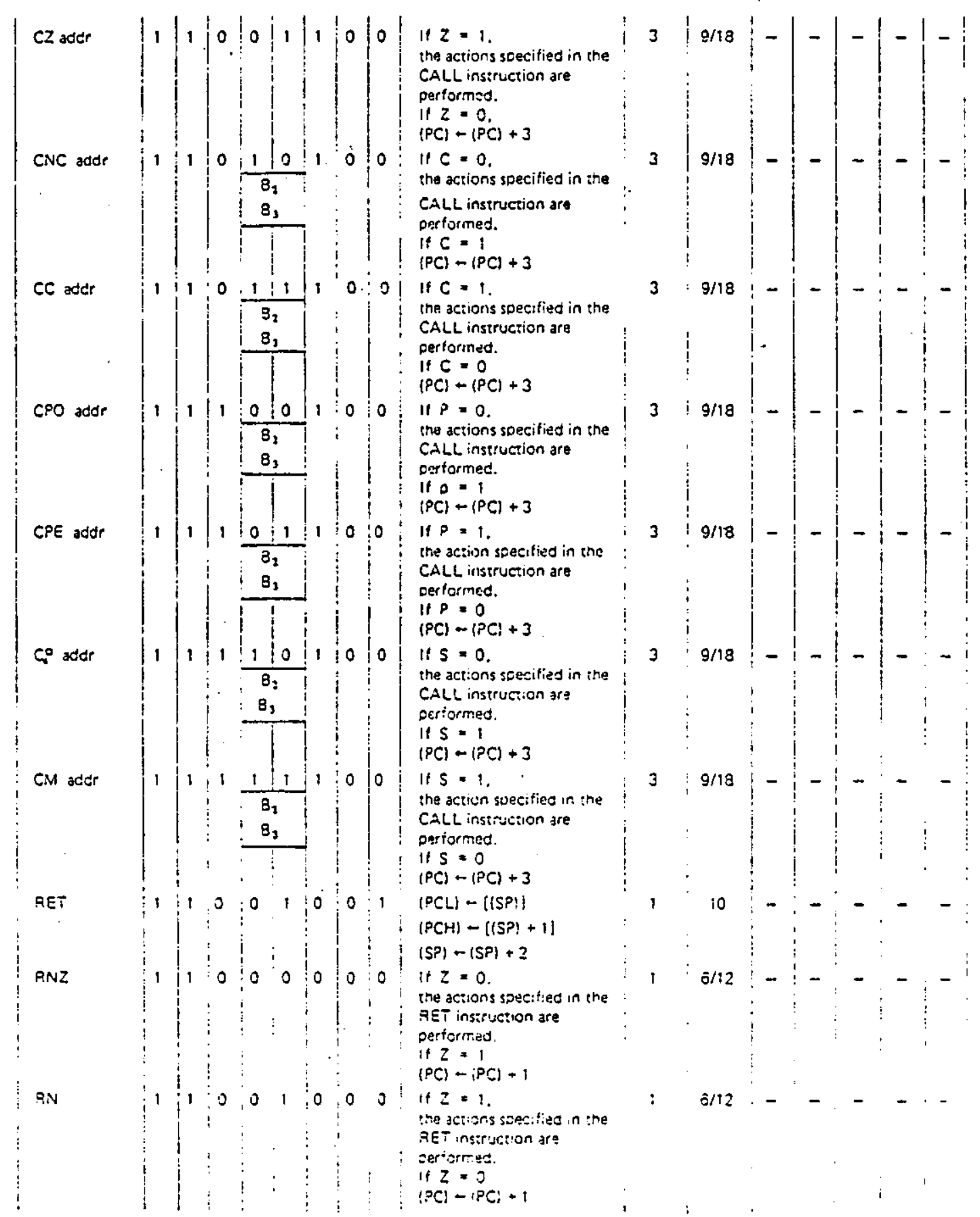

\section{Fig 1 (cont'd)}




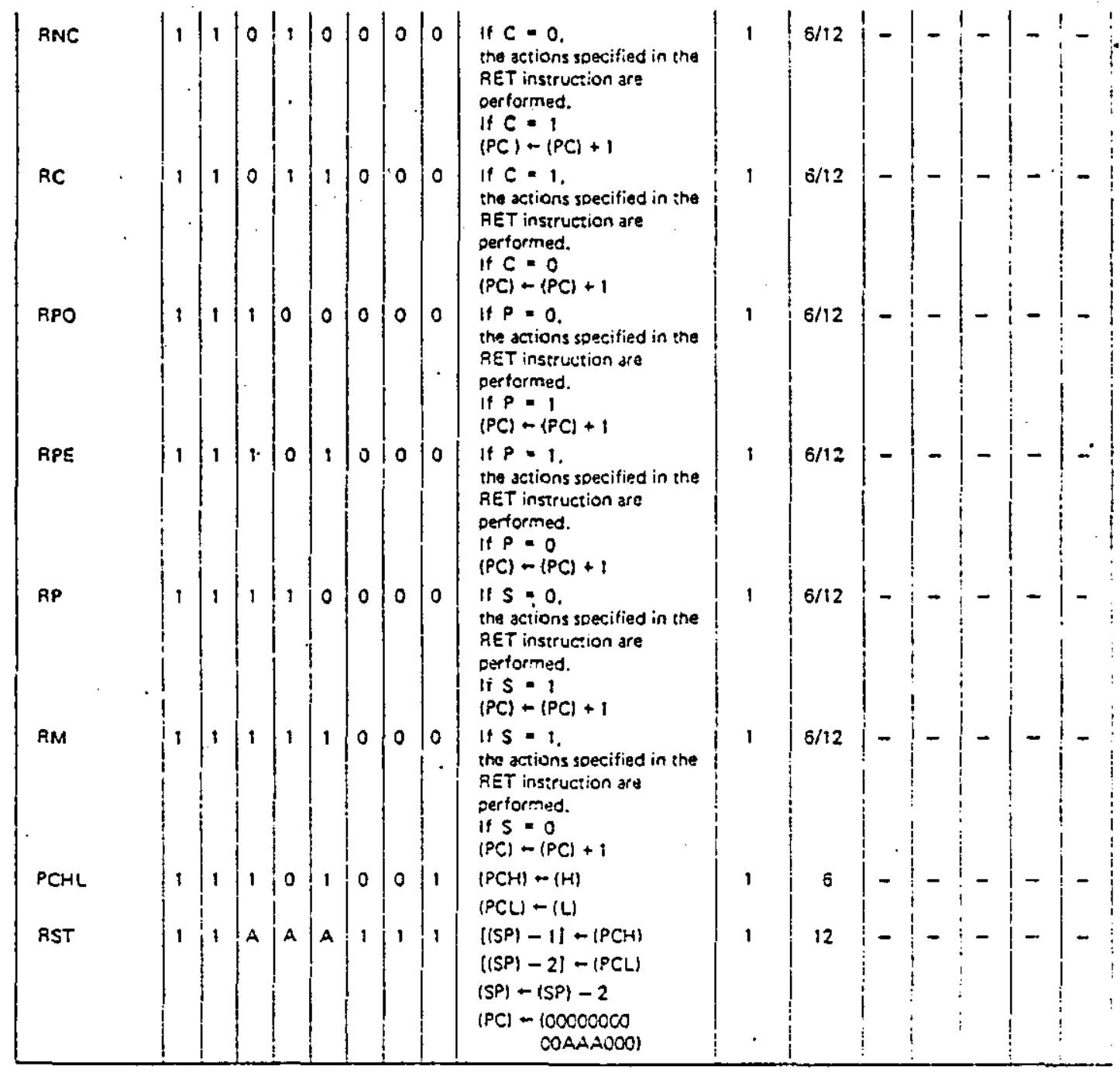

Fig 1 (cont'd) 


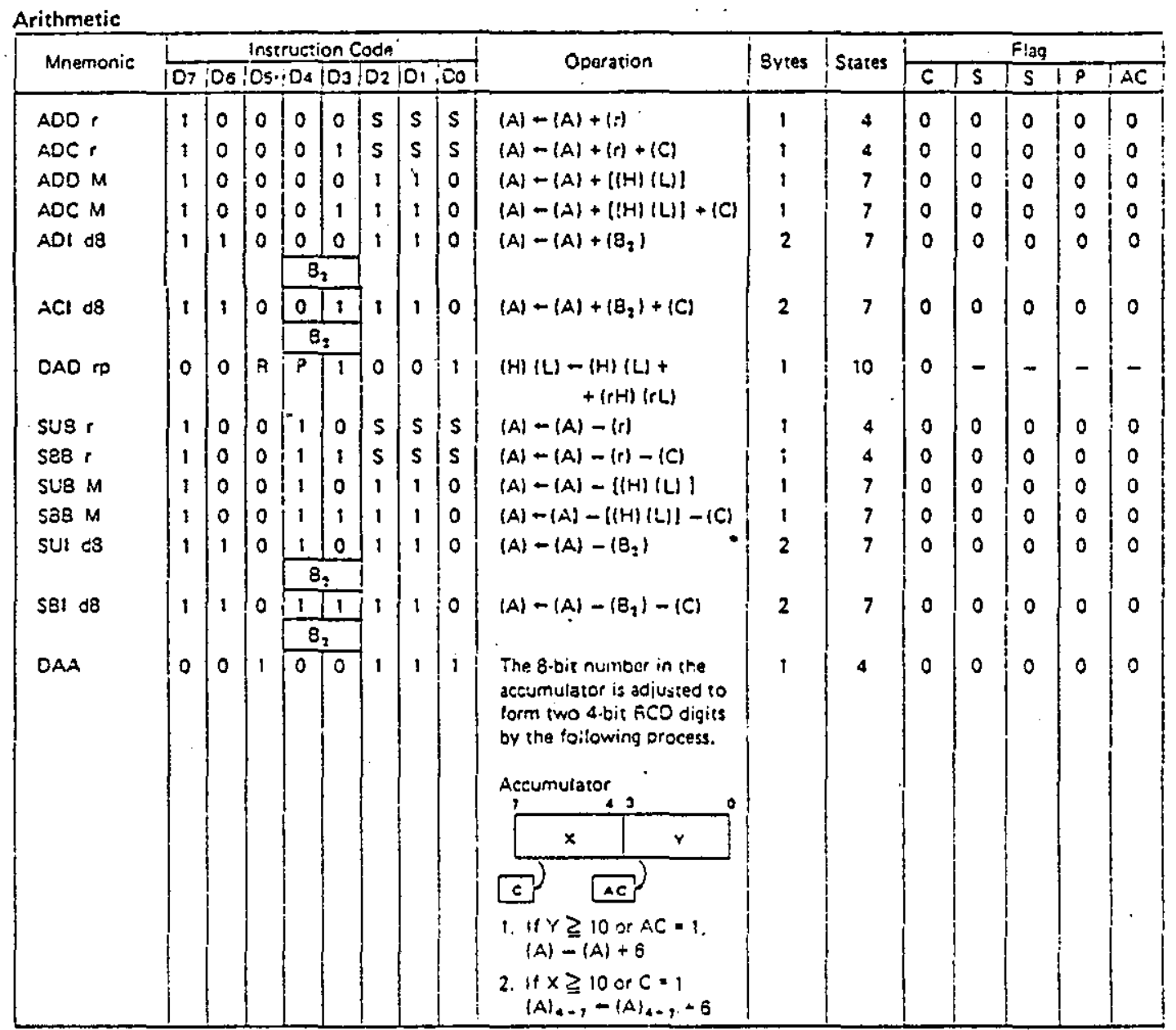

\section{Fig 1 (cont'd)}


Logical Instruction

\begin{tabular}{|c|c|c|c|c|c|c|c|c|c|c|c|c|c|c|c|c|c|c|}
\hline \multirow{2}{*}{ Mnemonic } & \multicolumn{9}{|c|}{ Insiruction Code } & \multirow{2}{*}{ Operation } & \multirow{2}{*}{ Bytes } & \multirow{2}{*}{ Stotgs } & \multicolumn{6}{|c|}{ Ftag } \\
\hline & 07 & $D 6$ & To5 & 04 & 03 & $\mathrm{C}_{2}$ & 0 & 10 & & & & & C & & $z$ & 5 & $\underline{P}$ & $A C$ \\
\hline ANA $r$ & 1 & 0 & $i$ & 0 & 0 & $s$ & $\mathrm{~s}$ & 3 & $\mathbf{s}$ & $(A)-(A) \wedge(f)$ & 1 & 4 & 8 & i & 0 & 0 & 0 & s \\
\hline ANAM & 1 & 0 & 1 & 0 & 0 & 1 & 1 & 1 & 0 & $(A)-(A) \wedge[(H)(L)]$ & 1 & 7 & $A$ & & 0 & 0 & 0 & 5 \\
\hline ANI $d 8$ & 1. & 1 & 1 & $\frac{0}{8}$ & 0 & 1 & t & 18 & 0 & $(A)-\left(A i \wedge\left(B_{2}\right)\right.$ & 2 & 7 & : & & 0 & 0 & 0 & $s$ \\
\hline XRA, & 1 & 0 & $t$ & 0 & 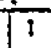 & s & $s$ & $s$ & $s$ & $(A)-(A) \forall(r)$ & 1 & 4 & $n$ & & 0 & 0 & 0 & ค \\
\hline XRA M & 1 & 0 & $t$ & 0 & 1 & $t$ & 1 & 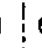 & 0 & $(A)-(A) \forall((H)(L))$ & 1 & 7 & : & & 0 & 0 & 0 & R \\
\hline XRI AS & 1 & 1 & 1 & 10 & $\frac{1}{3}$ & 1 & $i$ & 1 & 0 & $(A)-(A) \forall\left(B_{2}\right)$ & 2 & 7 & i $R$ & & 0 & 0 & 0 & a \\
\hline ORA, & 1 & 10 & 1 & 1 & 0 & $s$ & is & $i$ & $s$ & $(A)-(A) \vee(r)$ & 1 & 4 & $R$ & & 0 & 0 & 0 & 9 \\
\hline ORA M & 1 & 0 & 1 & 1 & 0 & 1 & 1 & 1 & 0 & $(A)-(A) \vee(I H)(L))$ & 1 & 7 & $\boldsymbol{F}$ & & 0 & 0 & 0 & 8 \\
\hline ORI A8 & 3 & 1 & $i$ & & $\frac{10}{3,}$ & 1 & 1 & 1 & 0 & $(A)-(A) \vee\left(B_{2}\right)$ & 2 & 7 & 8 & & 0 & 0 & 0 & $: 8$ \\
\hline CMP P & 1 & 0 & 1 & 1 & 1 & $S$ & s & 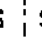 & $s$ & $(A)-(r)$ & 1 & 4 & 0 & & 0 & 0 & 0 & 0 \\
\hline CMP M & $i$ & 0 & 1 & 1 & 1 & 1 & 1 & $1 j$ & 0 & $(A)-((H)(L))$ & 1 & 7 & 0 & & 0 & 0 & 0 & 0 \\
\hline 69108 & 1 & 1 & 1 & $\frac{1}{e}$ & $\frac{1}{1}$ & 1 & 1 & 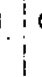 & & $(A)-\left\{B_{2}\right\}$ & 2 & 7 & 0 & & 0 & 0 & 0 & 0 \\
\hline CMA & 0 & 0 & 1 & 0 & 1 & 1 & 1 & 1 & 1 & $(A)=(\bar{A})$ & 1 & 4 & - & & - & - & - & - \\
\hline RLC & 0 & 0 & 0 & 0 & 0 & $i$ & 1 & 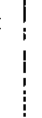 & 1 & $\begin{array}{l}\left(A_{n}+1\right)-\left(A_{n}\right) \\
\left(A_{0}\right)-\left(A_{n}\right) \\
(C)-\left(A_{1}\right)\end{array}$ & $\uparrow$ & 4 & 0 & & - & - & - & : \\
\hline RAC & 0 & 0 & 0 & 0 & 1 & $: 1$ & 1 & 1 & 1 & $\begin{array}{l}\left(A_{n}\right)-\left\{A_{n+1}\right\} \\
\left(A_{1}\right)-\left(A_{0}\right) \\
(C)-\left(A_{0}\right)\end{array}$ & 1 & 4 & 0 & & - & - & & $:-$ \\
\hline PAL & 0 & 0 & 0 & 1 & 0 & 11 & i & $\vdots$ & 1 & $\begin{array}{l}\left(A_{n+1}\right)-\left(A_{n}\right) \\
(C)-\left(A_{3}\right) \\
\left(A_{0}\right)-(C)\end{array}$ & 1 & 4 & 0 & & - & - & & $1-$ \\
\hline RAR & 0 & 0 & 0 & 1 & 1 & $\because$ & 1 & $1:$ & 1 & $\begin{array}{l}\left(A_{n}\right)-\left(A_{n+1}\right) \\
(C)-\left(A_{2}\right) \\
\left(A_{1}\right)-(C)\end{array}$ & 1 & 4 & 0 & & - & - & -- & - \\
\hline
\end{tabular}

Increment and Decrement

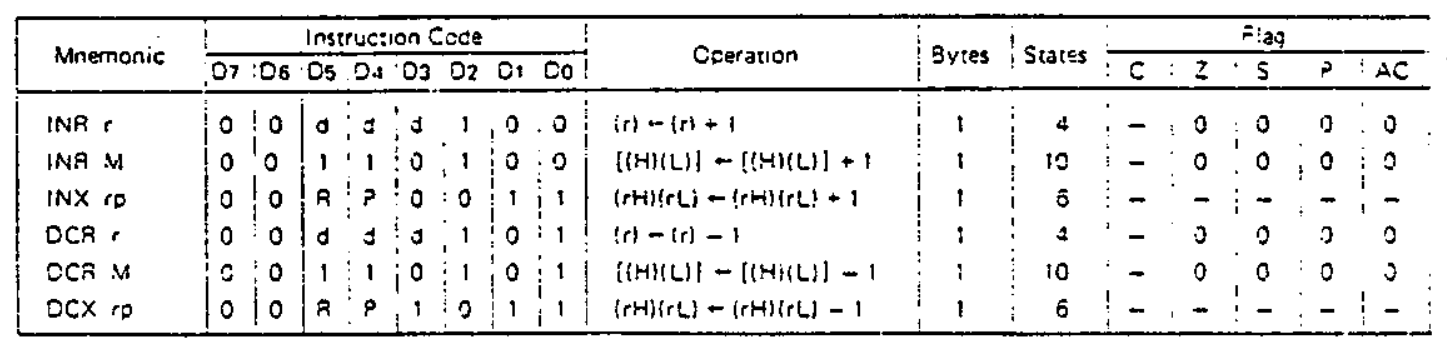

Fig 1 (cont'd) 
Stack

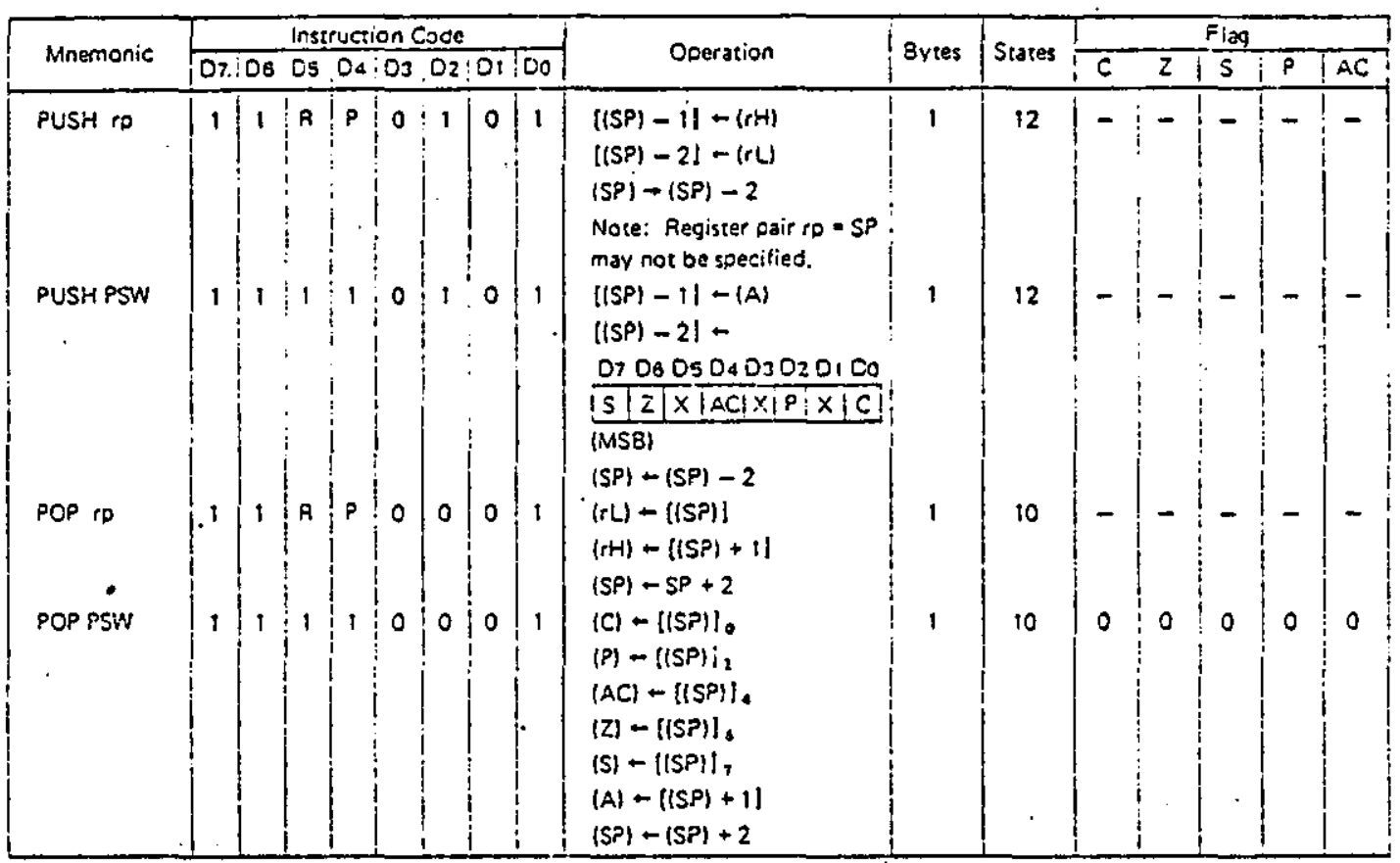

\section{Control}

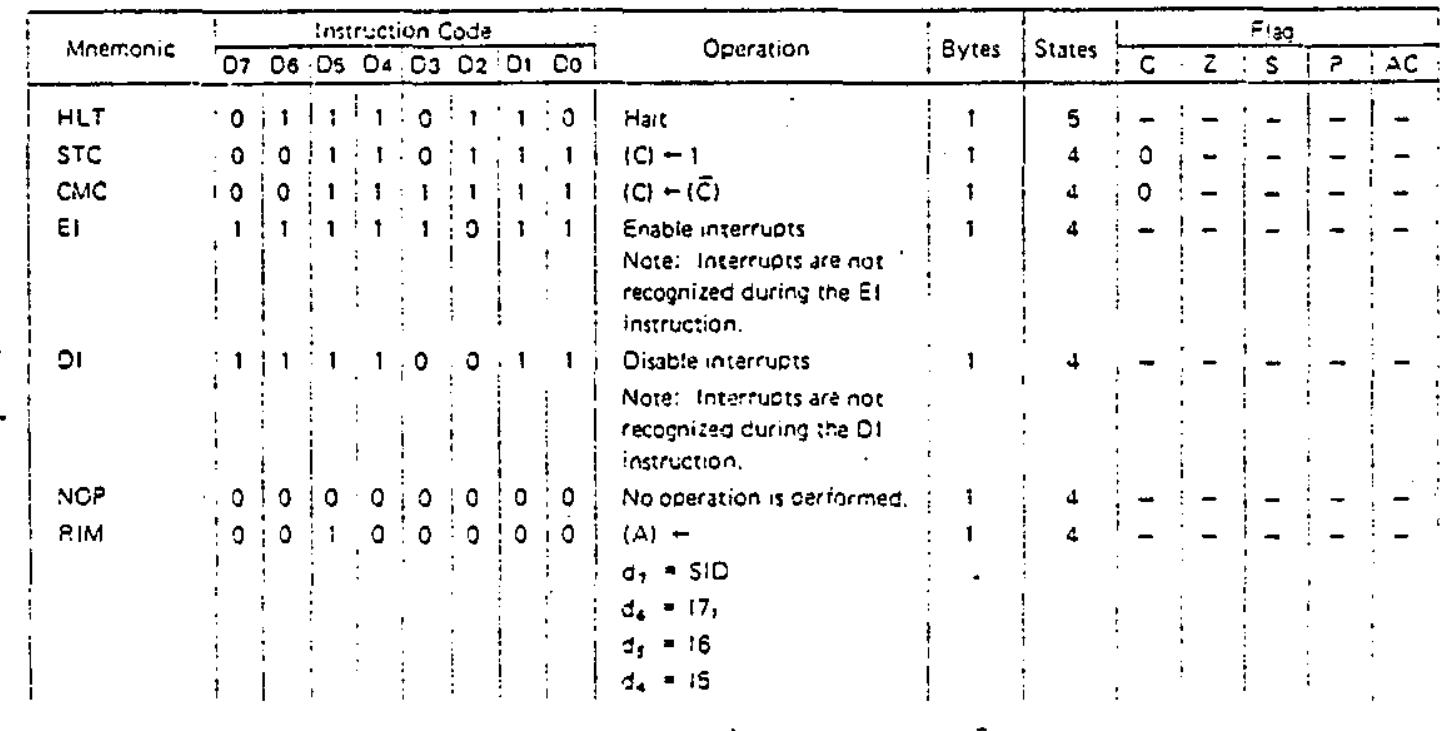

\section{Fig 1 (cont'd)}




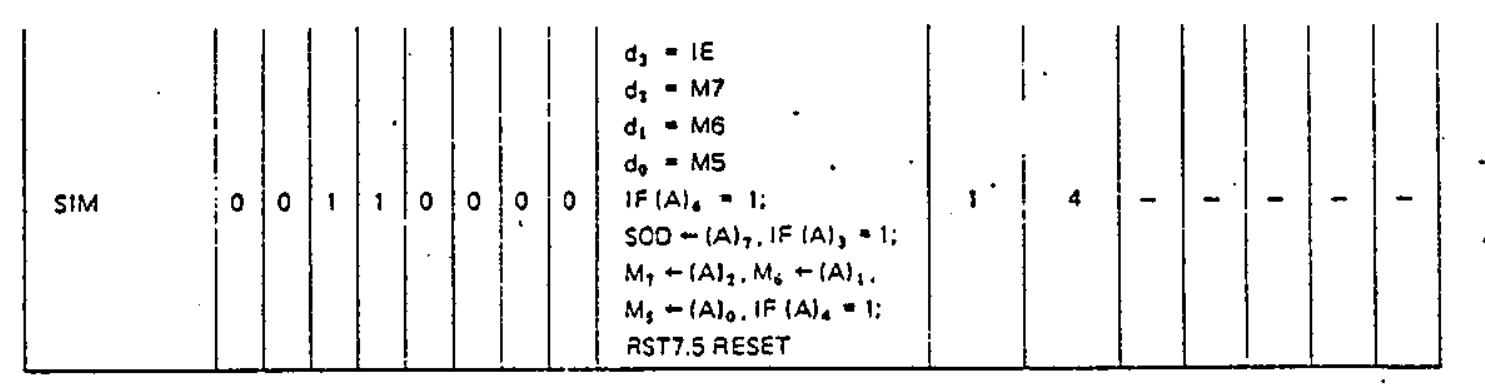

ABSOLUTE MAXIMUMM RATINGS

\begin{tabular}{|c|c|c|}
\hline Symbol & Item & Ratings" \\
\hline$v_{e c}$ & $V_{C c}$ Suooly Voltzge & $-0.5 \mathrm{~V}$ to $7.0 \mathrm{~V}$ \\
\hline$P_{0}$ & Povmer Dissication & $1.3 \mathrm{~W}$ \\
\hline$T_{\text {solder }}$ & Solcering Tsm:cerature !Soldering Time 10 sec.) & $250^{\circ} \mathrm{C}$ \\
\hline$T_{\text {stg }}$ & Storage iemoeratury & $-55^{\circ} \mathrm{C}: 10 \quad 150^{\circ} \mathrm{C}$ \\
\hline$T_{\text {opr }}$ & Operat:ng Tamcerature & $0^{\circ} \mathrm{C}$ to $70^{\circ} \mathrm{C}$ \\
\hline
\end{tabular}

D.C. CHARACTERISTICS

'TA $=0^{\circ} \mathrm{C}$ 10 $70^{\circ} \mathrm{C}, \mathrm{V}=\mathrm{C}=5 \mathrm{~V} \pm 5 \%$

\begin{tabular}{|c|c|c|c|c|c|c|c|c|c|c|c|c|}
\hline Symbol & $i$ & Purameter & $\cdot$ & Test Cendutions & $!$ & Min. & $\mathrm{i}$ & Typ. & $!$ & Max. & 1 & Units \\
\hline$V_{12}$ & $i$ & inoul Low voltage & & & 1 & -0.5 & T & & $\bar{\vdots}$ & 0.8 & $i$ & V \\
\hline$V_{1 H}$ & : & inout Hiçn Voltaça & & & $\div$ & 2.0 & $\vdots$ & & 1 & $v_{\text {ce }}+0.5$ & & $V$ \\
\hline $\mathrm{VOL}$ & $i$ & Outpur Low Voitane & & $\mathrm{OOC}=2 \mathrm{~mA}$ & & & $!$ & & $i$ & 0.45 & $\bar{\vdots}$ & $\mathrm{v}$ \\
\hline$v_{\mathrm{OH}}$ & ! & Ouppue Hign V/sitige & & $V_{2 H}=-4 C O \mu \mathrm{A}$ & & 2.4 & 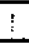 & & $\vdots$ & & $i$ & $\mathrm{v}$ \\
\hline ICC & 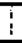 & Power Suboly Cirrent & $\because$ & & & & 1 & & & $i \overline{0}$ & 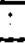 & nat \\
\hline$I_{12}$ & $\overline{!}$ & Inpu: Leakjge & & $v_{i N}=v_{c s}$ & $\vdots$ & & 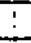 & & $!$ & \pm 10 & & $\mu A$ \\
\hline ILO & $\vdots$ & Output Liakas! & $\dot{\vdots}$ & $0.45 \leqq 0 U T \leqq V_{C S}$ & $\therefore$ & & $i$ & & $i$ & $=10$ & $i$ & A \\
\hline$V_{112}$ & 1 & Inour Low Level f SESET) & & & $!$ & -0.5 & $!$ & & $i$ & 0.8 & $i$ & 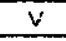 \\
\hline$V_{1 H A}$ & 1 & Inout Hign Lovel (FEJET! & $\vdots$ & & $!$ & 2.4 & ! & & & $v_{\text {ce }}+0.5$ & 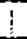 & $y$ \\
\hline$V_{H T}$ & I & Hysteres:S (AESET) & 1 & & $i$ & 0.25 & $\bar{i}$ & & & & $i$ & $v$ \\
\hline
\end{tabular}


A.C. CHARACTERISTICS

$T A=0^{\circ} \mathrm{C} 1070^{\circ} \mathrm{C} \cdot V_{C C}=5 V=5 \%, V_{S S}=O V$

\begin{tabular}{|c|c|c|c|c|c|c|c|c|}
\hline Symbol & Parameter & $\begin{array}{c}\text { Test } \\
\text { Conditions }\end{array}$ & Min. & Tyo. & & Max. & & Units \\
\hline cere & CLK Cyese Pariod & & 320 & $i$ & & 2000 & ! & ns \\
\hline$\overline{i c}$ & $\begin{aligned} \text { CLK Low Time } & - \text { Sianaard 150pF Loading } \\
& \text { - Liyntly Loated }[2]\end{aligned}$ & & $\begin{array}{r}80 \\
100\end{array}$ & $i$ & & - & & ns \\
\hline$\overline{t_{H}}$ & $\begin{aligned} \text { CLX Hign Time } & - \text { Standard 150pF Loading } \\
& - \text { Lightly Loaded } 21\end{aligned}$ & & $\begin{array}{l}120 \\
150\end{array}$ & $i$ & & & $i$ & ns \\
\hline$t, 4$ & CLK Fise and Fall Time. & & & & 1 & 30 & $\overline{:}$ & ns \\
\hline TXKR & $X_{1}$ Rising to CLK Fising & & 30 & 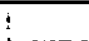 & ! & 120 & $\bar{\vdots}$ & ns \\
\hline $5 \times 2$ & $X_{1}$ gising to $C L X$ Falling & & -30 & $i$ & it & 150 & $!$ & ns \\
\hline iAC & $A_{B-i 5}$ Vatic :o Leading Ecga of Conirol (I) & & 270 & 1 & 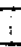 & & - & $n$ \\
\hline$t_{A C L}$ & $A_{0-7}$ Valid to Lascing Ecqe of Conirol & & 240 & & $!$ & & $i$ & ns \\
\hline$S_{A O}$ & A0-15 Valid : Valid Qara In & & & 1 & 1 & 575 & $\therefore$ & ns \\
\hline$t_{A F A}$ & 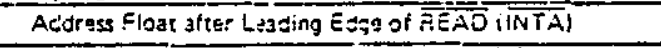 & & & 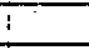 & $!$ & 0 & 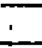 & ns \\
\hline tAL & $A_{8-15}$ Valid betore Trailing ë dge of $A L E$ (II) & & 115 & & 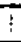 & & . & ns \\
\hline$T_{A L L}$ & A0-7 Valia beiore îrating ESGe of $A L E$ & & 90 & 1 & & & & ns \\
\hline$i_{A A Y}$ & AEAOY Vulid trem Aedraes Valid & & & 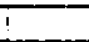 & . & 220 & 7 & ns \\
\hline iCA & Aisdress $\left(A_{3}-A_{1} 5\right)$ vilic aftar Control & & 120 & 1 & 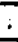 & & 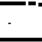 & ns \\
\hline tcc & 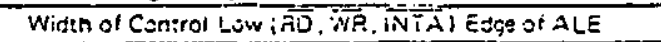 & & 400 & 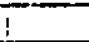 & 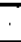 & & $:$ & ins \\
\hline CLL & Trailing Sdge of Control io Leating Edge of ALE & & 50 & I & 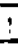 & & 1 & ns \\
\hline tow & Oata Vatid :o iratling E qu of white & & 420 & 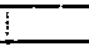 & $\dot{.}$ & & 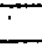 & $n$ \\
\hline imABE & HLOA to Bus Enable & & & $i$ & i & 210 & $!$ & as \\
\hline THABF & 8LS FloJ: atrar + tLCA & & & 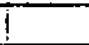 & 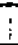 & 210 & $i$ & ns \\
\hline$t_{H A C X}$ & HLOA Valud :o Tratling Edge of CLK & & 110 & $i$ & $\frac{1}{!}$ & & $i$ & is \\
\hline (4بOH & HOLO Hold iime & & 0 & & 1 & & 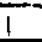 & ns \\
\hline TMOS & HOLO Secue Time to Trailing Sdye of CLK & & 170 & 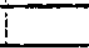 & $\overline{!}$ & & $:$ & $n_{3}$ \\
\hline inN & Níf Hola Time & & 0 & 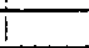 & $i$ & & $i$ & ns \\
\hline$i_{\text {INS }}$ & INTR. RST and TAAP Setuo Time to Falling EEge of CLK & & 100 & & - & & 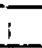 & ns \\
\hline$i \operatorname{lin}$ & 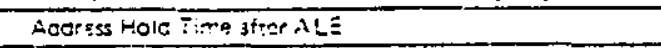 & & 100 & & & & 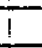 & ns \\
\hline BLC & 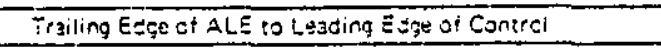 & & $130^{\circ}$ & & 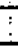 & & T & ns \\
\hline$t_{\text {Lex }}$ & $A L E$ Low ELring CLK Righ & & 100 & $\vdots$ & & & i & is \\
\hline Log & $\lambda_{-}$E:o Voice Gata curing Reac & & & & & $\Delta 50$ & I & ns \\
\hline iLow & $A L E$ :o Valid Oü:a during Wriso & & & & ז! & $2 \mathrm{CO}$ & $i$ & ns \\
\hline the & ALE Nic:n & & 140 & & $\dot{4}$ & & : & ns \\
\hline iLRY & ALE ro AEACY Siabte & & & & & $\$ 10$ & - & ns \\
\hline iAaE & 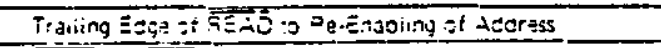 & & 150 & & $!$ & & & 75 \\
\hline tap & 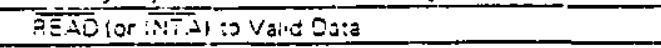 & & & U & & 300 & & is \\
\hline thy & 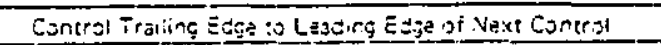 & & 400 & i & $!$ & & 5 & ns \\
\hline $\mathrm{C}_{\mathrm{ROH}}$ & 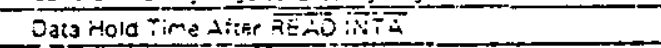 & & 0 & 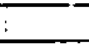 & & & $\therefore$ & $\therefore s$ \\
\hline TaYu & SEAOY Holl Time & & 0 & $\vdots$ & & & $\therefore$ & ns \\
\hline iRYs & 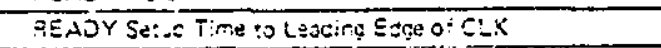 & & $1: 0$ & & & & & $\therefore 5$ \\
\hline$i_{w: O}$ & 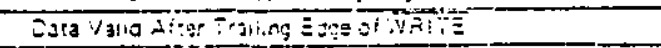 & & 100 & & & & & s \\
\hline (wot & 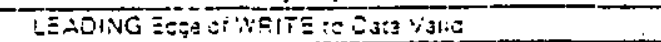 & & & & & \pm 0 & & is \\
\hline
\end{tabular}

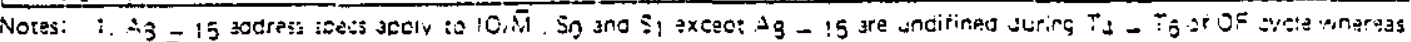
$10, \overline{N i}$. Sij. and $S_{i}$ zre itacie.

2. Lodcing edunvaient :c $\equiv 0$ or $+1 T L$ nowt

3. All timirgs arg Teasures 3t st:sur rertage

$v_{1}=0.8 \mathrm{v} . v_{H}=2.0 \mathrm{~V}$

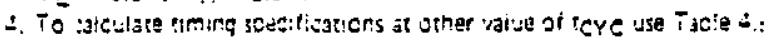

Fig 1 (cont'd) 
Table 4. Bus Timing Specifiestion \& \& TCYC Oependent

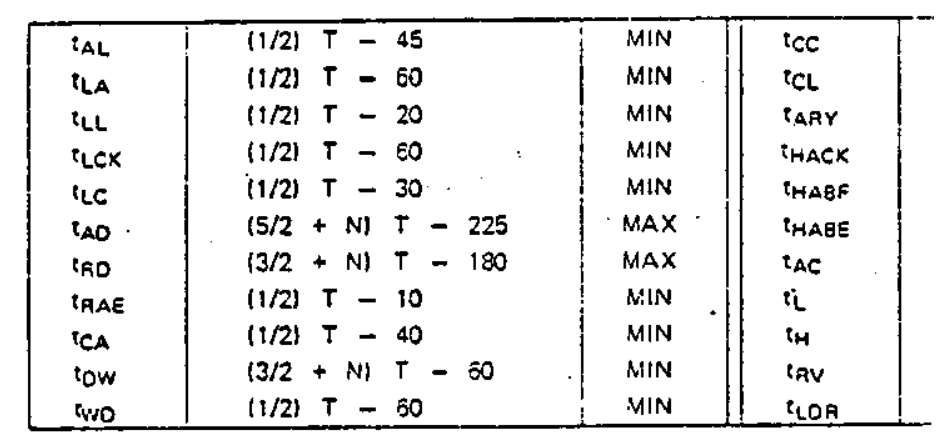

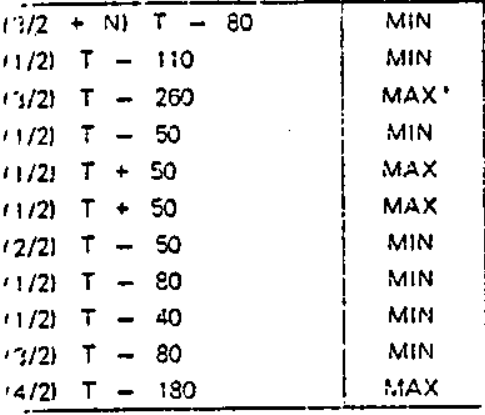

Note: $N$ is equal to the cosal WAIT siates.

$T=$ icre
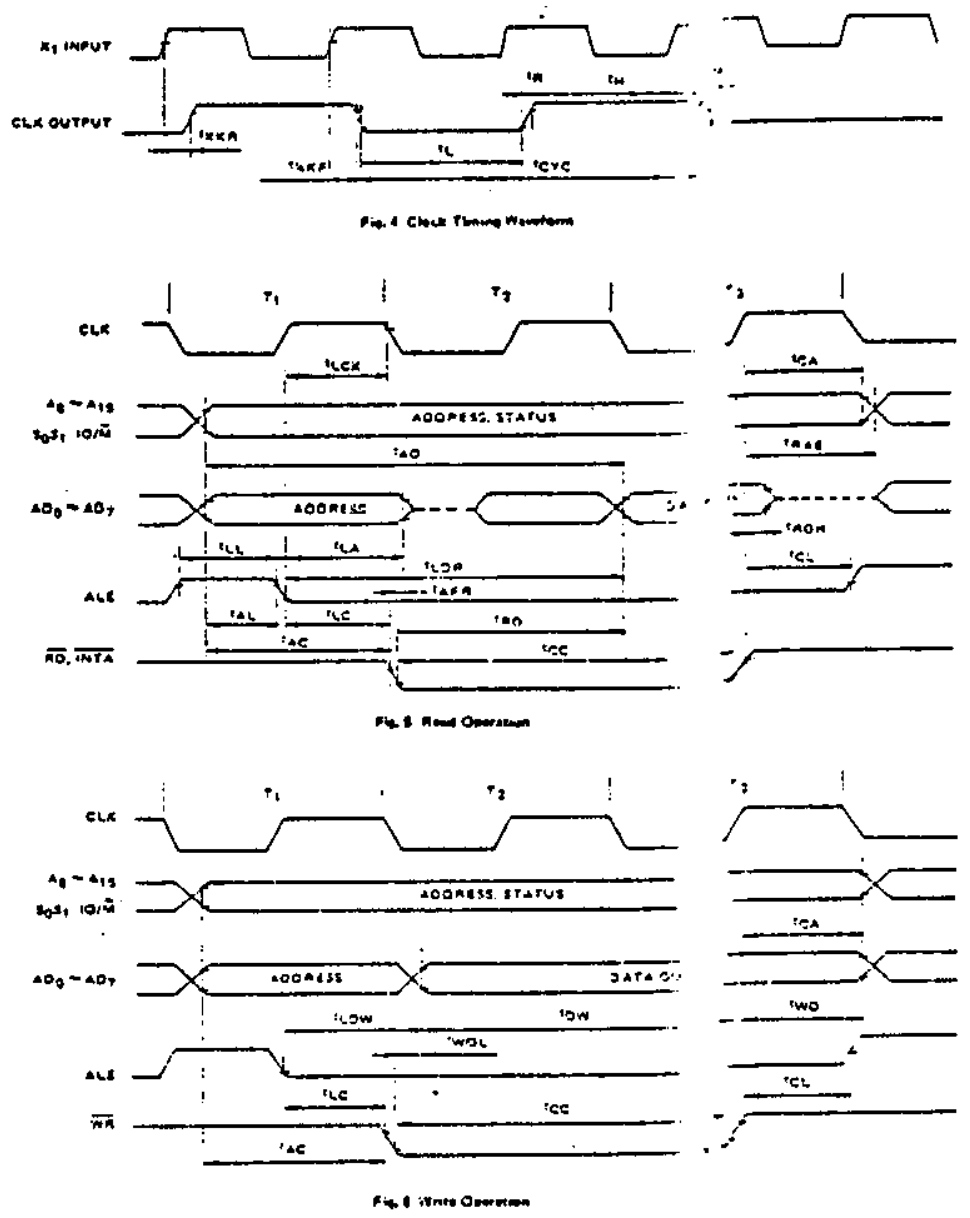

Fig 1 (cont'd) 


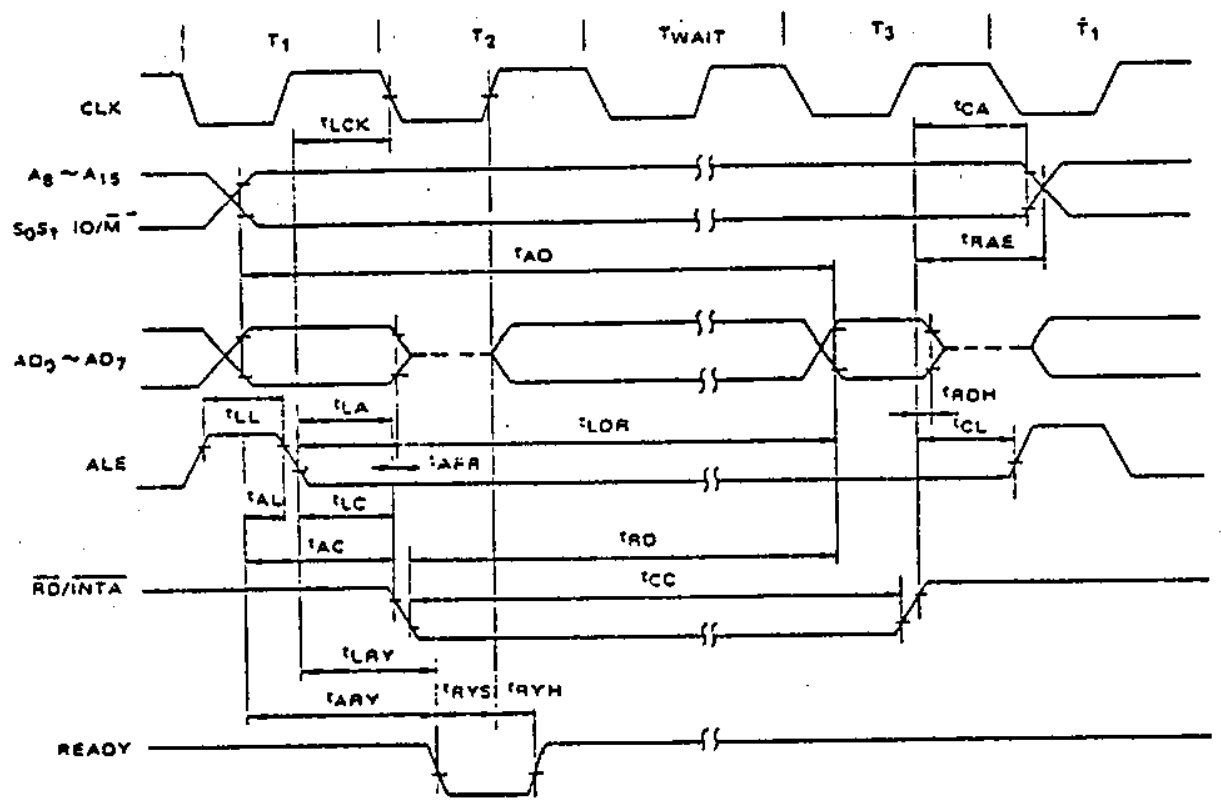

Fig. 7 Read Opuration with Wait Crele ITypieal

- Sama Rendr Timing Applies to Writo Oparacion

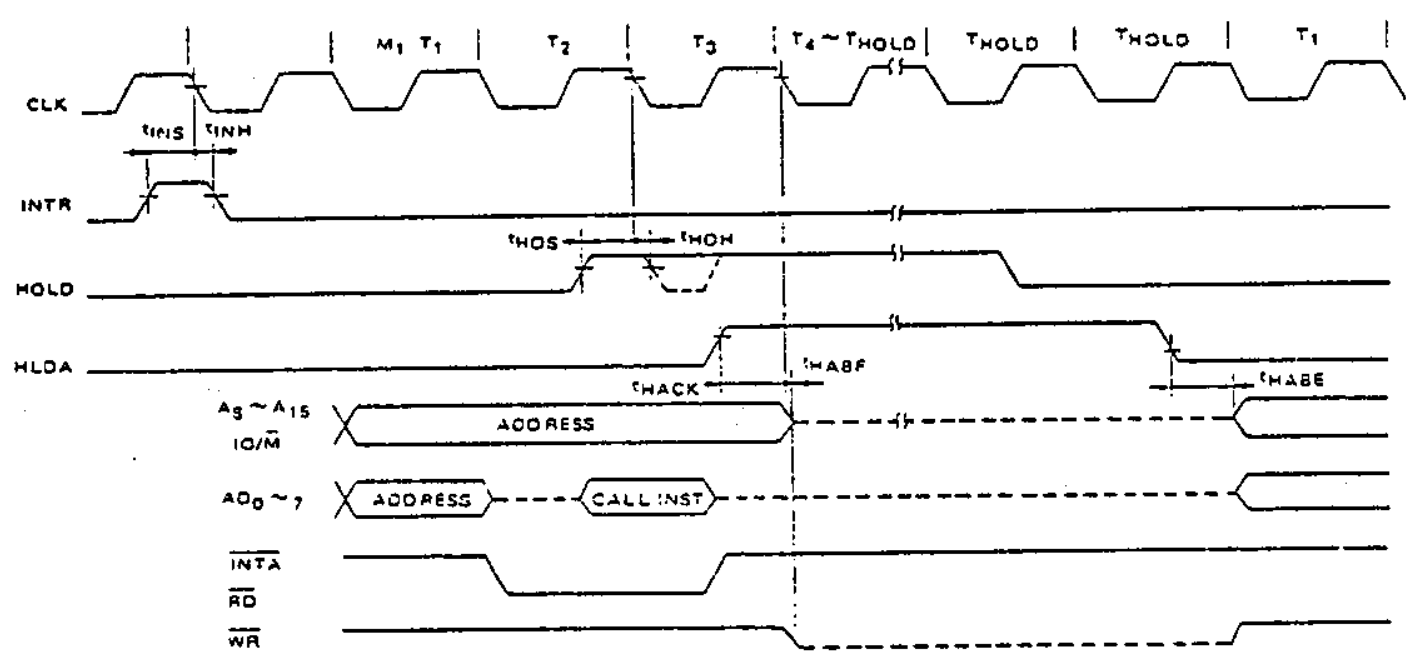

Fig. I Interrwot and Hold Timing

\section{Fig 1 (cont'd)}




\section{OUTLINE DRAWING}

10 Plos Plestic Peockezo

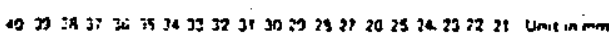

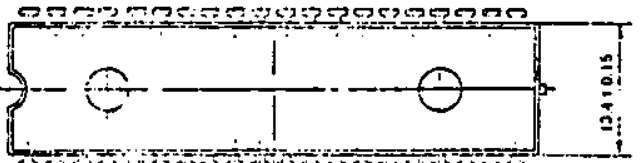

$12345: 1891011+2$ is is $151817: 9$ 19 20

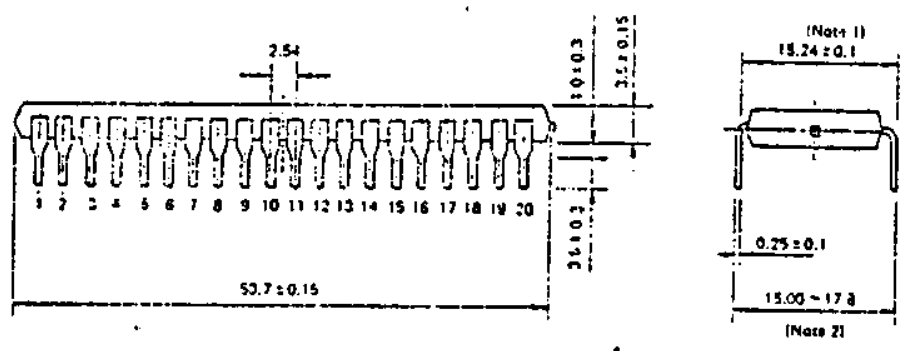

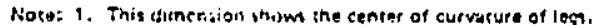

2. This dimansion thew so:ers of lezs.

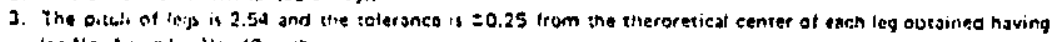
leq No. 1 ans legivo. 40 as the reterences.

\section{Fig 1 (cont'd)}




\section{Am8155/Am8156

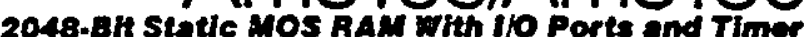 Advanced Mtero Devices}

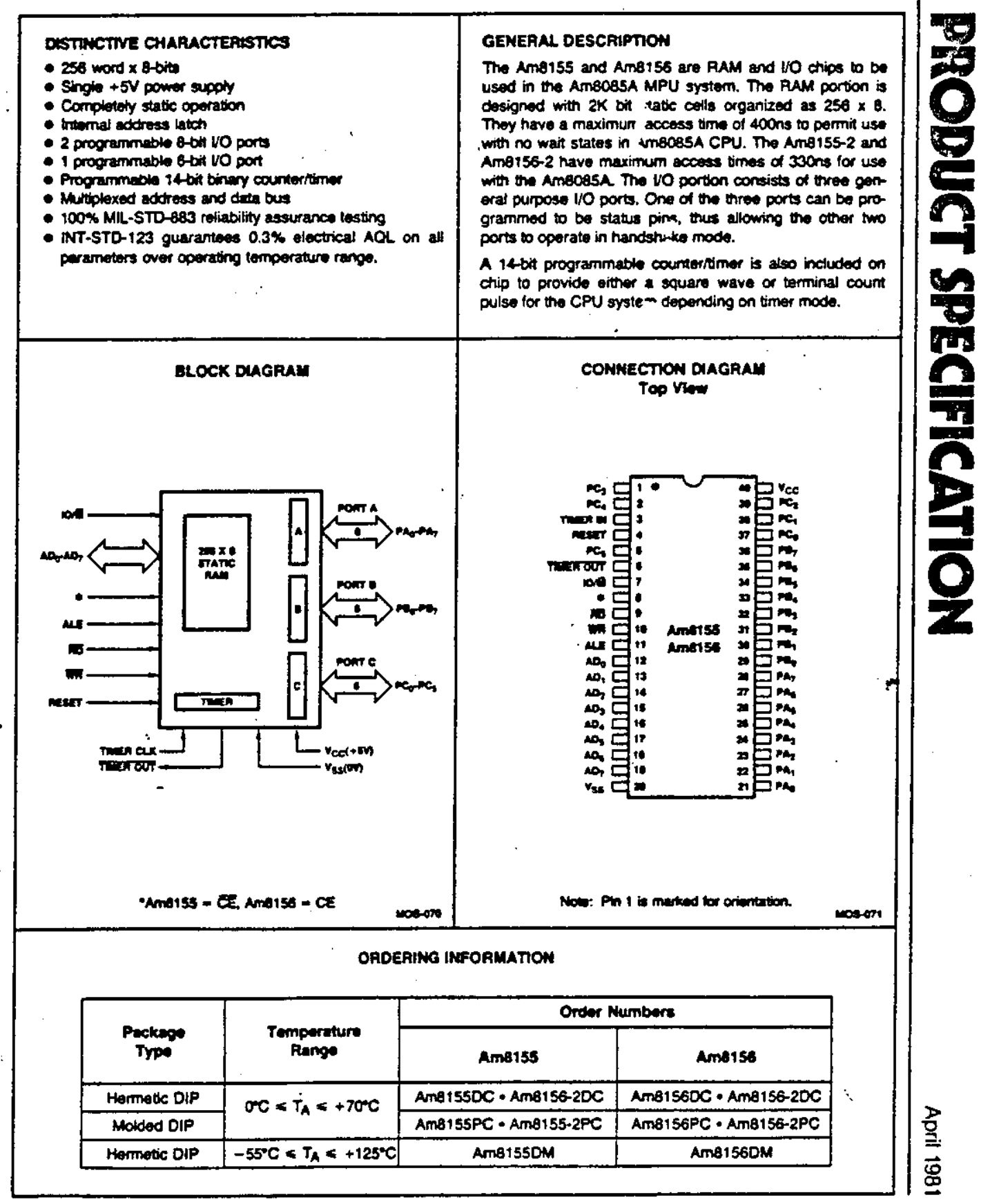

Fig2. Am8156 Interface Chip Data Sheet. 


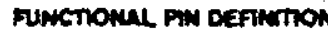

The following describes the huctions of at of the sme155t Ansise pins.

\section{RESET}

The Reser sions is o putse provided ty the Anecos of his tialize the system. houk high on this tho resets two chip and initializes the three vo ports to input mode. The width of RESET putes showid typically to s000ns. (Two AmecBSA dock oros times).

$\mathrm{AD}_{\mathrm{ANO}}$

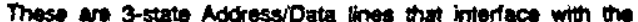
CPU kower 8-bit Address/Data Bus. The 8-bit address is Catchiod into the adoress latertion on the falling odge of the ALE. The address can be either tor the mernory section or the vo section depending on the polarity of the Kald input signel. The 8-ort data is either written into the chip or read from the chip depending on the status of WATE or READ input signal.

CE OR CE

Chip Enabla: On the Ame155, this pin is CE and is ACTIVE LOW. On Ams15s, this pin is CE and is ACTIVE HIGH.

\section{fis}

mput bow on this fine with the Chip Enable active enables the $A D_{4}$, buthers. If IOIM pin is low, the ANA content wh by read ard to the $A D$ bus. Otherwise the content of the selected VO port will be read to the $A D$ bus.

mit

hout low on this ine with the Chip Enable active causes the dits on the AD lines is be written to the PAM or VO ports cepencing on the polarity of lorin.

ALE

Adotress Latch Enablo: This control signal latches both the address on the $A D_{2}$, lines and the state of the Chip Enabie and $1 O M M$ into the chip at the falling eopo of ALE.

\section{$10 \vec{\pi}$}

10/ soloces the 10 a tigh

PAOPAY

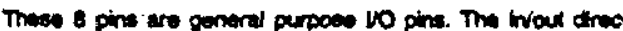
bon it solected by propremming the Command'Status Reogis

paspor

These 8 pins are general purpese vo pins. The invou drece tion is selected by programming the Command/Status Pegis. m.

$P \mathrm{Co}_{\mathrm{P}}$

These 6 pins can function as ather input port, output port, of as control signals for PA and PB. Programming is done through the CIS Register. When PCD.s are used as control signals, they will grovide the following:

$P C_{0}$ - A INTA (Pon A internut)

$P C_{n}$ - A BF (Port A Buthor tull)

$P C_{y}-\bar{A}$ STS (Pont A Strobe)

$P C_{3}$ - B WTR (Port B intempt)

$P C_{4}-8$ BF (Port B Buffior Fun)

$P C_{3}$ - BSTR (Pon a Strobo)

\section{TuEa a}

This the inped to the counter tirnor.

\section{IITEFOU?}

This pin is the timer outbut. This outout esen be either a square wave or a pulse dopencing on the binner mode.

$V_{\text {cc }}$

+5 voll supply.

$\mathbf{V}_{\mathbf{S S}}$

Ground reterence.

\section{MAXIMUN RATNNGS above which useful tife may be impaired}

\begin{tabular}{|c|c|}
\hline Storage Temperature & $-65^{\circ} \mathrm{C}+0+150^{\circ} \mathrm{C}$ \\
\hline Ambient Temporature Under Sias & $-55^{\circ} \mathrm{C} 10+125^{\circ} \mathrm{C}$ \\
\hline$V_{c c}$ with Respoct on $V_{s s}$ & $-0.5 \mathrm{~V}$ to $+7.0 \mathrm{~V}$ \\
\hline Ai Signel Volugges with Respect to $V_{S S}$ & $-0.5 \mathrm{~V} 10+7.0 \mathrm{~V}$ \\
\hline
\end{tabular}

Power Dissipation

$1.5 \%$

The products described by this specillestion inelude internal circuity desioned to protect inpent devices from dameging eceumulations of statc cherge. It is suggested, nevertheless, thet comventional precautions be observed during storage, handing and use in ordor is aveid exposure to excessive yoltages.

\section{CHARACTERISTICS}

\begin{tabular}{|c|c|c|c|c|c|c|}
\hline Peramotare & Duscrlotion & Tent Condtton: & min. & Tyen & $m_{n}$. & Unite \\
\hline$v_{12}$ & hat low volege & & -0.5 & & 0.6 & Voun \\
\hline$V_{1 K}$ & rout thon volesge & & 20 & & $v_{c c}+0.5$ & Volat \\
\hline$v_{\alpha}$ & Outou Low Volloge & $1 a-2 m a$ & & & 0.45 & \\
\hline$v_{\text {ow }}$ & Outout tion Vorters & bon $=-4004 n$ & 2.4 & & & vole \\
\hline 42 & hou Lavkege & $v_{1 m}-v_{C e}$ oo ov & & & \pm 10 & $m$ \\
\hline Lo & Outoul Leakege Cument & $0.45 \mathrm{~V}<v_{\text {out }}<v_{c c}$ & & & $=10$ & $m$ \\
\hline 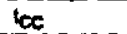 & $V_{c c}$ Supphy Curnert & & & & 180 & $m$ \\
\hline$h_{L}(C)$ & Chip Eneblu Leakeng Ansiss & $v_{1 N}=v_{C C} w_{0 V}$ & & $\begin{array}{l}+100 \\
-100\end{array}$ & & $m$ \\
\hline
\end{tabular}

"OC. $1.6 \mathrm{ma}$ for And $155 \mathrm{DM}$ and AMB 15BOM 
operatiNg RANGe

\begin{tabular}{|c|c|c|c|}
\hline Part number & Amblent Temperaturs & $v_{c e}$ & $v_{s e s}$ \\
\hline $\begin{array}{l}\text { Ams 155/Ams155-2 } \\
\text { Amb ISE/Ambise-2 }\end{array}$ & $\sigma c<T_{A} \approx+7 T_{C}$ & $+5.0 N \pm 5 \%$ & ov \\
\hline $\begin{array}{l}\text { Ambi5som } \\
\text { AmbisobiM }\end{array}$ & $-500 C+T_{A}<+1250$ & $+5.0 V=10 \%$ & ov \\
\hline
\end{tabular}

\section{AC CHARACTERISTICS}

Ame15s/Ame1s:

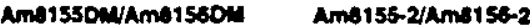

\begin{tabular}{|c|c|c|c|c|c|c|}
\hline Peremetars & Deveription & min & $\max$ & $\mathbf{m n}$ & Max & Unith \\
\hline the & Adoross vo Luen Settep Tme & 50 & & 30 & & nas \\
\hline u & Adcroses Hold TmK atwer Letch & $\mathbf{\infty 0}$ & & 30 & & $n$ \\
\hline he & Lach Io REAOWAITE Contol & 100 & & 40 & & n \\
\hline 40 & Valid Den ou Oelay trom REAO Comrol & & 170 & & $\$ 40$ & $n$ \\
\hline IND & 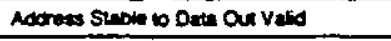 & & 400 & & 330 & $n$ \\
\hline 4 & Letach Enmole Woth & 100 & & 70 & & $m$ \\
\hline toro & Dete Bus Fom Aner READ & 0 & 100 & 0 & 80 & $\mathrm{mas}$ \\
\hline$a$ & RENOWFITE Contod D Larh Enoto & 20 & & to & & $n$ \\
\hline$\infty$ & AEADMAITE Control with & 250 & & 200 & & $m$ \\
\hline bow & Dats in io WRTIE Sotap Tim & 150 & & 100 & & ns \\
\hline 40 & Date in Hold Thus Aher WATTE & 0 & & 0 & & $m$ \\
\hline 4v & Aecovery Thro sermeen Controts & 300 & & 200 & & $n$ \\
\hline up & WAITE b Pon Qutpu & & 400 & & 300 & $n$ \\
\hline $\operatorname{lng}$ & Port inpun Senos Time & 70 & & 50 & & $n$ \\
\hline top & Port inpue Hold Tim & 50 & & 10 & & na \\
\hline tser & Strobe 10 Butler Fut & & 400 & & 300 & $n$ \\
\hline tss & Strobe wores & 200 & & 150 & & $m$ \\
\hline LeE & AEAD w Butier Emoty & & 400 & & 300 & $n$ \\
\hline $\operatorname{ts}$ & Strow to iNTR on & & 400 & & 300 & $n$ \\
\hline teat & REND to INTA OF & & 400 & & 300 & $n$ \\
\hline toss & Port Sotho Tirm to Strobs Swobs & 50 & & 0 & & $n$ \\
\hline ans & Port Hold Trme After Strobe & 120 & & 100 & & mes \\
\hline tsee & Stroben of Butter Empoy & & 400 & & 300 & $n$ \\
\hline mor & WFITE bo butien Ful & & 400 & & 300 & $m$ \\
\hline m & WATIE \& WTA ON & & 400 & & 300 & $n$ \\
\hline n & TREA WN DO TIMEA OUT LOW & & 400 & & 300 & $n$ \\
\hline Mn & 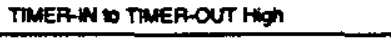 & & 400 & & 300 & $n$ \\
\hline HoE & Date Bus Enelos from REND Control & 10 & & 10 & & $n$ \\
\hline 1 & TIMEA-N LOW TIm & 80 & & 40 & & no \\
\hline 2 & 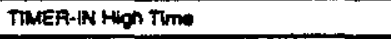 & 120 & & 70 & & no \\
\hline
\end{tabular}

Noin: Tout Concition; 150pf Lad.

Fig2. (Cont'd) 


\section{Operational OESCRIPTON}

The Ane155/8156 inctudes the following operational hotures:

- 2K Bit Static RuM organized as $256 \times 8$

- Two 8-bit VO ports (PA and PB) and on 6-bit vO port (PC)

- 14bin domn counier

The vo portion contains four registers (Commandrstatus,

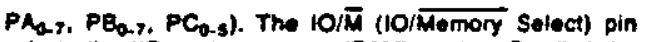
solects the VO or the mernory (RMM) portion. Ontailed de. scriptions of memory, 10 ports and time tunctions wile follow.

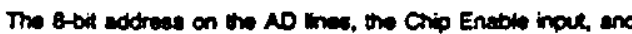

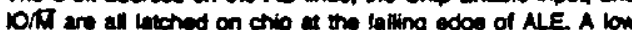
on the forth must be provided to select the memory section.

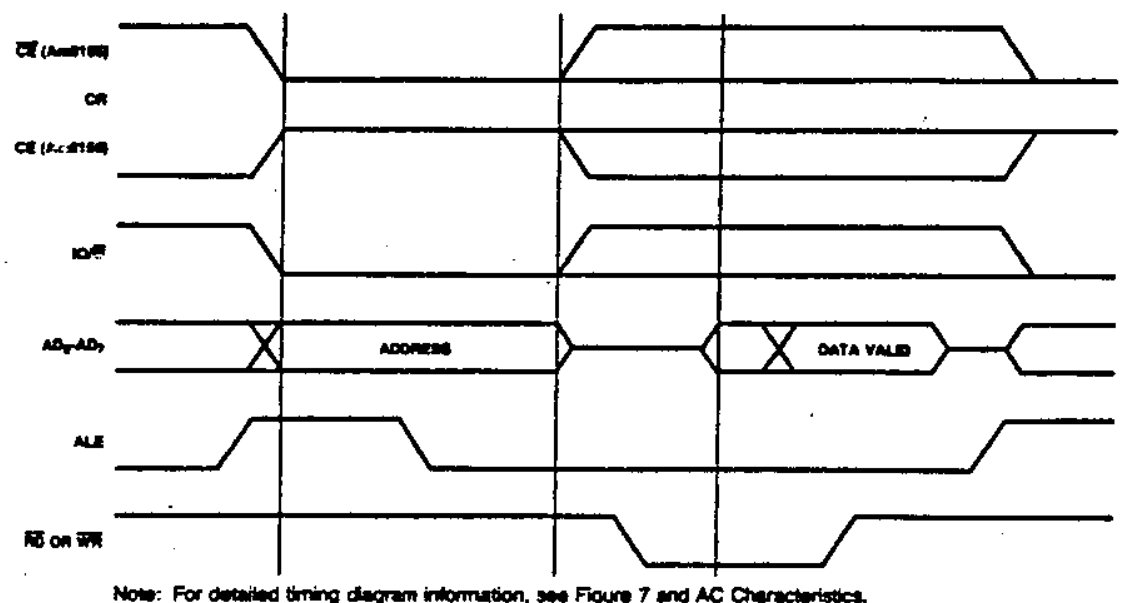

Fioure 1. Womory ReadWrtte Crate

\section{PROCRAMLAN OF the COMUANDISTATUS REGASTER}

The command register consists of eight latches, one for each bil Four bits (0-3) define the mode of the ports. Two bits (4-5) onable or disable the interrupe from port $C$ when it acts as control port, and the last two bits $(6-7)$ are for the timer.

The CIS register contents can be altered at any time by using the 1/O address $X \times \times \times \times \times 000$ during a WAITE operation. The meaning of each bit of the command byte is defined as follows:

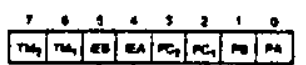

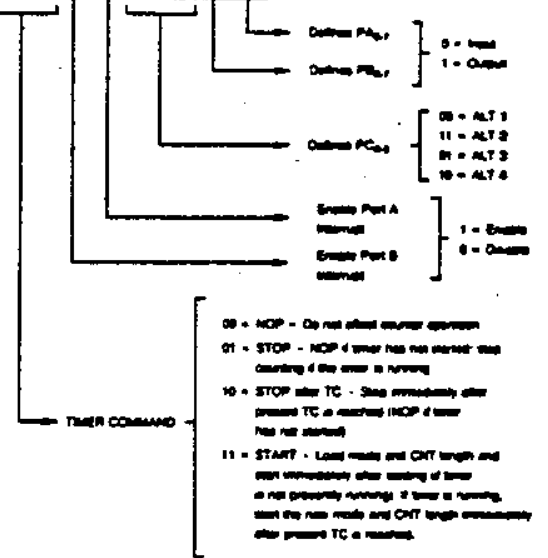

Flgure 2. Commendstutue Regloter Bn Acelgnment.

\section{READING THE COMHANOISTATUS REGISTER}

The status register consists of seven latches, one tor each bit: six (0-5) for the status of the ports and one (6) for the status of the timer.

The status of the timer and the reading the CIS Register (Address $X X X X \times(000$ ). Status word format is shown below:

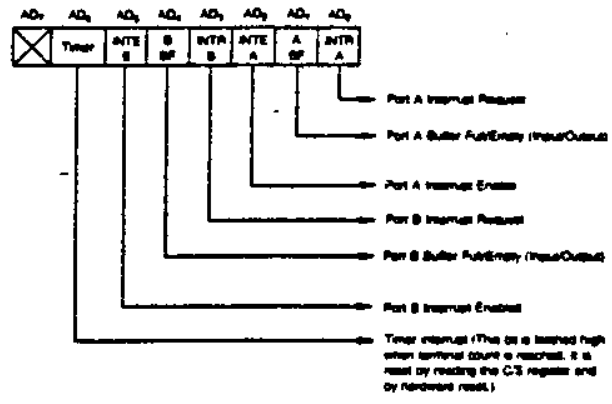

Figure 3. Command/stutu Anguter Stutue Word format. 
NPUTJOUTPUT SECTION

The VO section of the Am2155/B156 consists of fout rogister at cercrited below.

- Commendisatus Rogister (C/S) - This rogistor is assignod the edoress $X X X X X 000$. Tha C/S addreass serves the dual pupose.

When the CS register is seloctod during White operation L command is writuen into the comenand register. The con

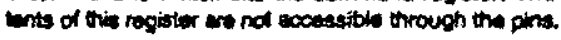

When the CIS $(\times \times \times \times \times \times 000)$ is solected during a READ oo -ration, the status intromation of the VO ports and the timer. become availabie on the $1 \mathrm{D}_{2}$, thros.

- PA Registor - This registes can to prosrammed to be - ither inow or octouk ports depending on the status of the contents of the C/S Plegister. Atso depending on the com mand, this port can coptrate in sither the basic moce or the strobed mode (see timing diegram). The wo pins assioned in relation to this rogister are PAa.r. The address of this rister is $X \times \times \times \times \times 001$.

- PQ Aogister - This register finctions the same as PA Peo ister. Tho l/O pins assigned are PQb.r. The adtress of this ropister is $x \times x \times x \times 010$.

- PC Aegister - This register thas the address $X X X X \times 011$ and contrains onty 8 be The 8 bits can to programmed to be wither inant ports, octpout ports of as control signals tor $P A$ and $P B$ by property programming the $A D_{2}$ and $A D_{3}$ bits of the cis rogister.

When $P C_{p a s}$ is ueed as a control port, 3 bita are assigned for Port $A$ and 3 for Part B. The first bit is an interrupt theat the Ambi5s sends oue the second is an output signar in dicating whather the turther is fult or emony, and the third is an input on to accopt a strobe for the strobed ingut mode. See Tabion 8 .

When the "C" port is procrammed to either ALT3 or ALTA, the control signals lor $P A$ and $P B$ are initalized as follows:

\begin{tabular}{|c|c|c|}
\hline Control & Inour Mosio & Output rode \\
\hline $\begin{array}{l}\text { BF } \\
\text { STIA } \\
\text { STE }\end{array}$ & $\begin{array}{l}\text { Low } \\
\text { Low } \\
\text { input Control }\end{array}$ & $\begin{array}{l}\text { Low } \\
\text { High } \\
\text { input Control }\end{array}$ \\
\hline
\end{tabular}

The sot and roset of INTM and BF with respect to STB, WA and FD tining is shown in Figure 8.

To summarize, the rogisters assignments aro:

\begin{tabular}{|c|c|c|c|}
\hline adtrous & Pinouts & Function: & $\begin{array}{c}\text { Ho. of } \\
\text { ons }\end{array}$ \\
\hline $\begin{array}{l}x \times x \times \times x 000 \\
x \times x \times x \times 01 \\
x \times x \times \times 010 \\
x \times x \times x 011\end{array}$ & $\mid \begin{array}{l}\text { mtemes } \\
P A_{0-7} \\
P B_{0-7} \\
P C_{0-5}\end{array}$ & 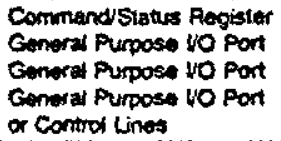 & $\begin{array}{l}8 \\
8 \\
8\end{array}$ \\
\hline
\end{tabular}

The following diagram shows how vO Ports $A$ and $B$ aro structures within the AmB155 and AmB156:

\section{Anbrss/Antrs:}

Ono bex at Pont A or Pont

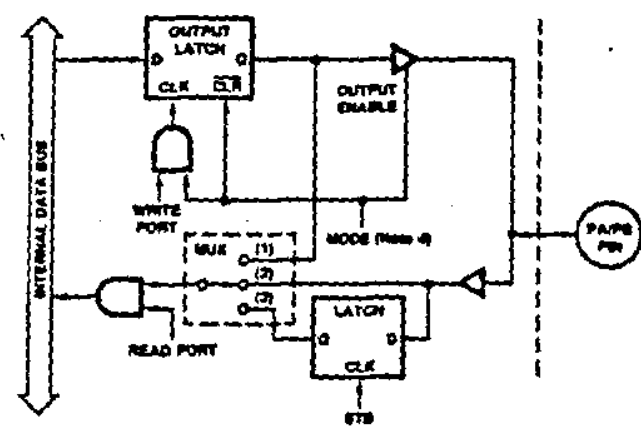

Nowe: 1. Outou Mbon

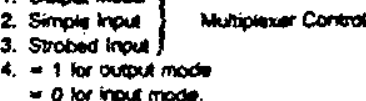

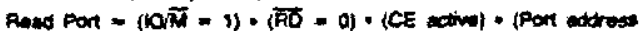
sexection

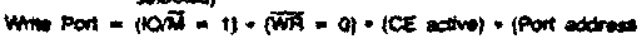
somection

Note in the diagram that when the UO ports are programmed to be output ports, the conterts of the outeut ports can stih be read by a READ operation when appropriately addressed.

Note aiso that the output latch is cleared when the port enters the input mode. The outrus lateh cannet be losded by writion to the part it the port is in the input mode. The result is that each time a port mode is changed trom input to oupurt the outout pins will go tow. When the Amsi55i8156 is RESET, to output latches are atl cleared and als 3 ports omror the hout mods.

When in the ALT 1 or ALT 2 modes. bits of Port C art structuted like the diagram above in the simple ingut or outou mode, respectivehy.

Poading from ant inper port with nothing comoctod to the pins will provide unpredictablo resuta.

Toble 1. Table of Pont Control Aasignment.

\begin{tabular}{|c|c|c|c|c|}
\hline Pin & Att 1 & ALT 2 & ALT 3 & ALT 4 \\
\hline $\begin{array}{l}P C 0 \\
P C 1 \\
P C 2 \\
P C 3 \\
P C 4 \\
P C 5\end{array}$ & $\begin{array}{l}\text { mout Port } \\
\text { mout Port } \\
\text { mput Port } \\
\text { mput Port } \\
\text { mout Pon } \\
\text { mput Port }\end{array}$ & $\begin{array}{l}\text { Outwus Port } \\
\text { Output Port } \\
\text { Output Port } \\
\text { Output Pors } \\
\text { Outwut Port } \\
\text { Outout Port }\end{array}$ & $\begin{array}{l}\text { A INTR (Port A interrupt) } \\
\text { A BF (Port A Butter Fulls } \\
\text { A STE (Port A Stroba) } \\
\text { Output Port } \\
\text { Output Port } \\
\text { Output Pont }\end{array}$ & 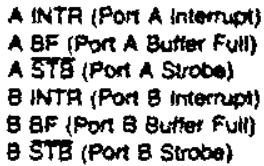 \\
\hline
\end{tabular}




\section{TMEA SECTION}

The timer is a 14bil down coumer that counts the timer inpurt putes and provides octer a square wave or pulse when torminsl coum (TC) is reschoct.

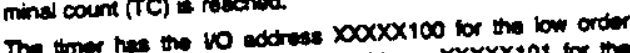
政 byte de vio rage of the rogister.

high ordor bye of the roginT LENCTH REG is beded

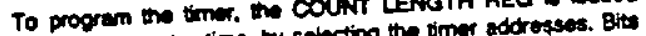

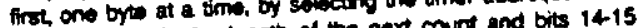
0.13 will specity the length of the noxt count and bits itits

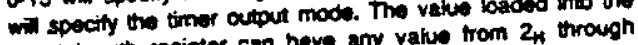

count length rogistor.

\section{There are tour modes to choose from:}

0 - Pusts out low during second hatt of count

1 - Square wave

2 - Single putse upon TC being raeched

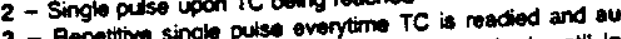
3 - Repertive single pulso ovor TC being reached, untit in

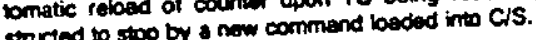

seructed to stop by a now cont Register contents are used to Bits 8-7 of Command/status Rogistor comouts aro usods to stent and stop-the countor. There

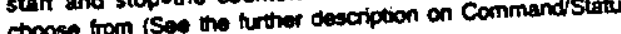
Register.).

\section{CST CSP NOP - Do not afroct counter operation.}

- STOP - NOP if timer has not started; stop - 1 counting the tirner is running.

10 STOP AFTER TC - Stop immediately ater STOP AFTEA TC - STOP in timer has not present TC started).

1 START - Losd mode and CNT length and start immediatoly after loading (if timer is start immediatoly attor loading is running. not presently running). In time length immestart the now mode and CNT lengt

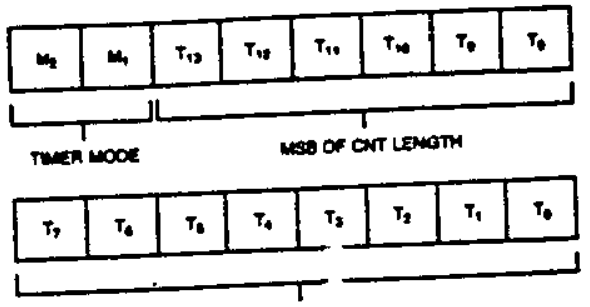

LSB OF CAT LEMGTH

Figure 4. Trine Formets

MQ and Mt define the timer mode as follows:

in v1

- 0 Puts out tow during second hall of coumt

1 Squere wave i. period of the square Square wave. i.e., tho poriod of ino square wave equals the count length prodram automatic roloed at tormingl courh.

- Sing pulse upon TC being reactiod.

1 . A Singlo pulse uponat, i.c. singlo pulse everytime 1 TC is reactiod.

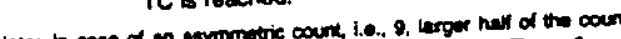

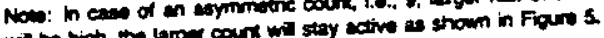

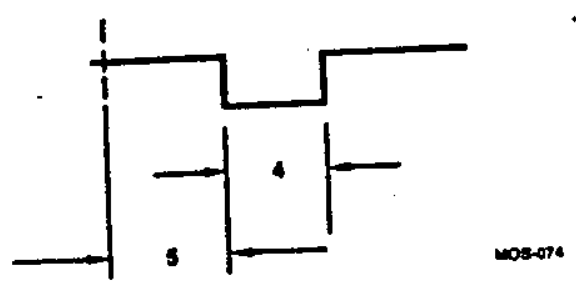

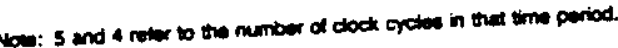

Figure 5. Aprmmetric Count

The coumter in the Amb155 is not initialized to amy particulas Tho coumter in tho Ambiss is not inithall occurs. but AESET mode or count when haroware RESET counting cannot begin for. does stop the counting. Therelore, cound is issued via the CIS lowing $R E S$

register.

Fig2. (Cont'd) 


\section{Universily of Tedmoligny}

From the ACCOMMODATION SECRETARY

EASTER VACATION ARRANGEMENTS 1986

BEGINNING OF VACATION

ALL STUDENTS ARE PERMITTED TO STAY IN THEIR PRESENT HALLS UNTIL 1300 HOURS ON SATURDAY, 22nd MARCH BUT FOR THE CONVENIENCE OF CLEANING YOU MUST VACATE YOUR ROOMS BY 1000 HOURS. KEYS TO YOUR ROOMS IN FALKNER/EGGINGTON COURTS AND WILLIAM MORRIS WILL BE AVAILABLE AFTER 1300 HOURS ON SATURDAY 22nd MARCH. KEYS WILL BE ISSUED AGAINST A DEPOSIT AND MUST BE RETURNED WHEN YOU LEAVE.

END OF VACATION

TERM RESTARTS ON 28th APRIL 1986. YOU MAY RETURN TO YOUR TERM TIME ACCOMMODATION ON SATURDAY 26 th APRIL.

ROOMS MUST BE CLEARED BY 0930 HOURS ON SATURDAY AND KEYS RETURNED BY 1000 HOURS ON SATURDAY, 26th APRIL.

YOU SHOULD ENSURE THAT YOUR ROOM IS LOCKED WHEN YOU LEAVE IT. 
WAVEFORMS

a. AESD CYCLE

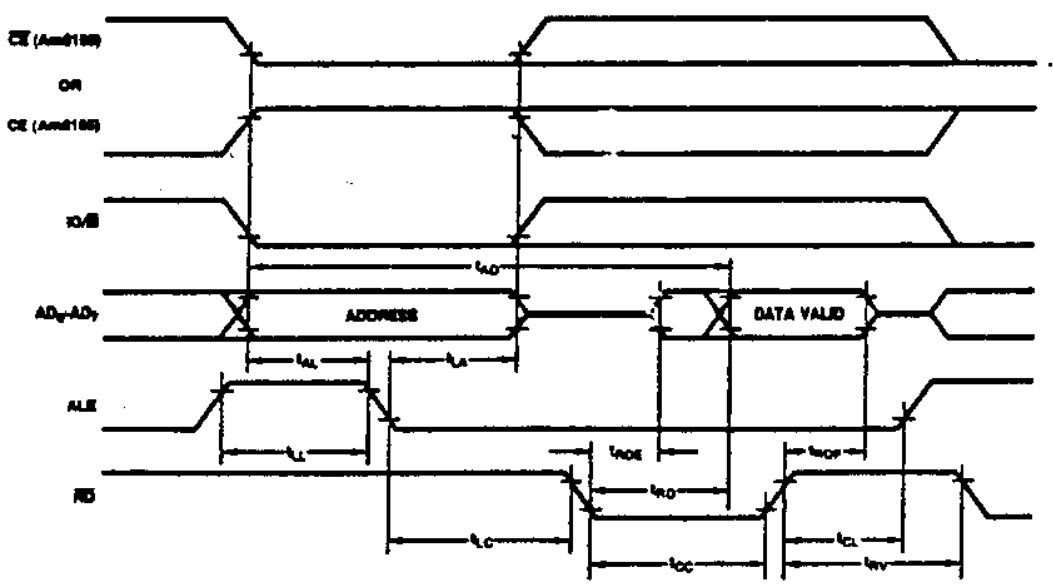

a. WRTE CYCLE

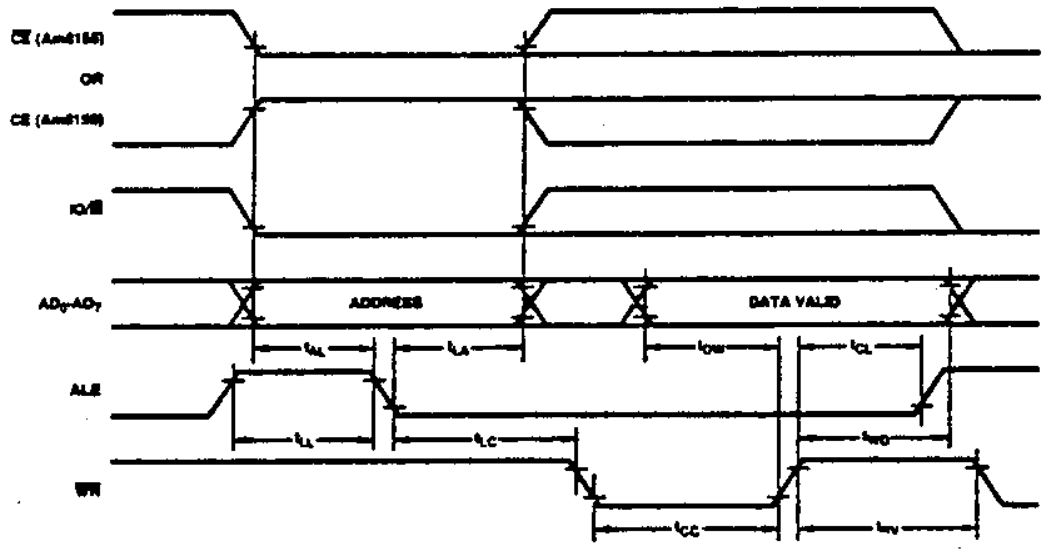

Flours 7. Ans15sbits Reedrwitu Tining Dlegrame.

Fig 2. (Cont'd) 


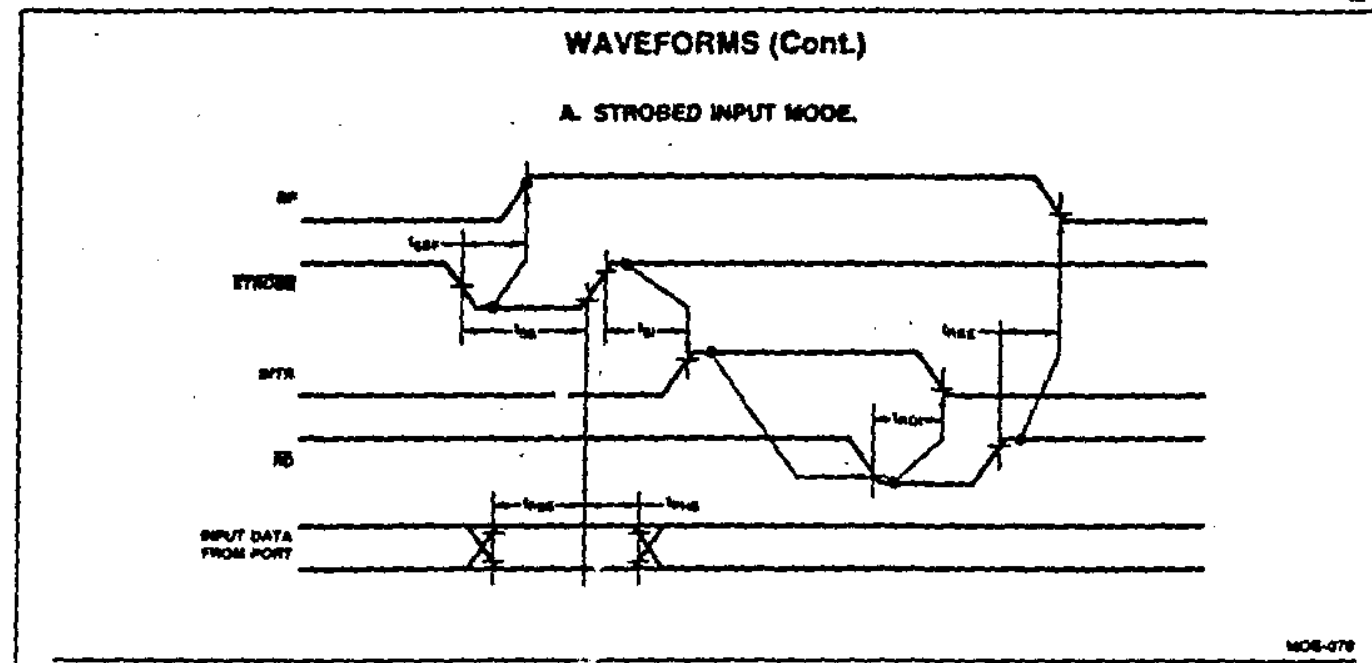

a. STAOEEO OUTPUT MODE.

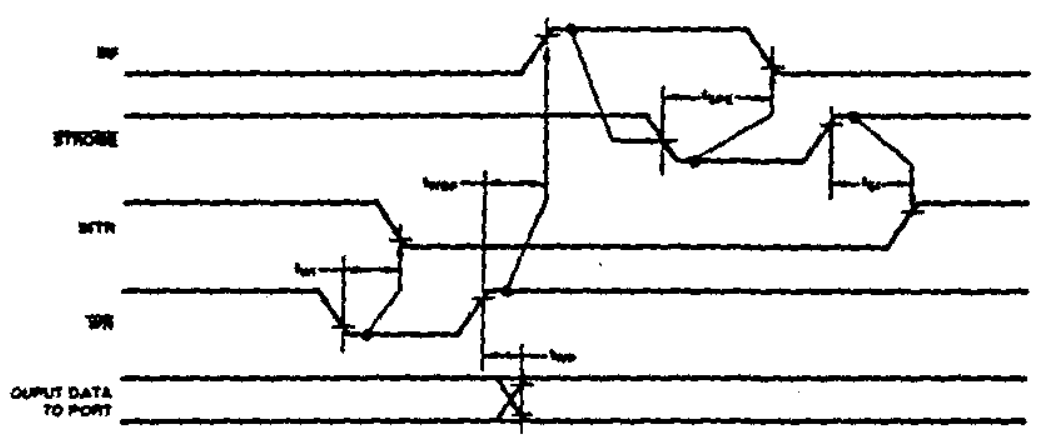

Figure a strobud vo thing

Dasic neut mooe

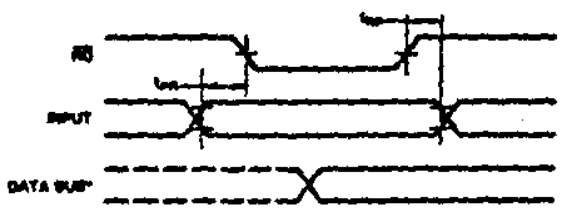

moneres
BAstc ourpur wode

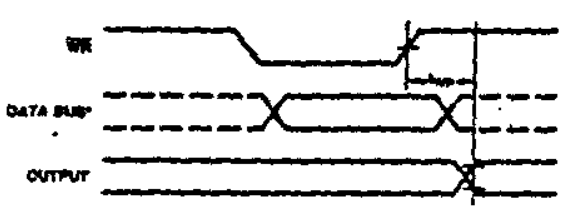

$\cos$

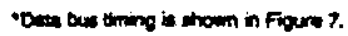

Prous a. Beak vo Jining Wavelorm.

Fig2. (Cont'd) 


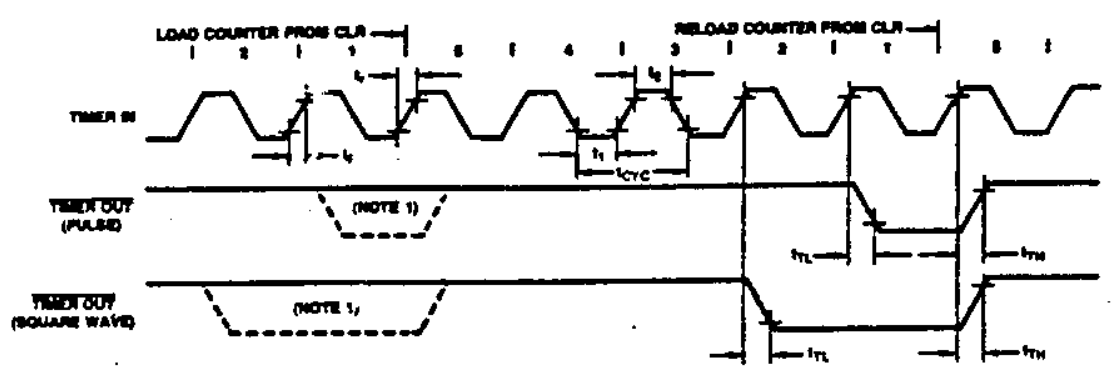

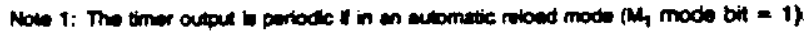

Figure 10. Nimer Outpet Wavelorm Countiown from 5 to 1.

Fig 2. (Cont'd) 
win Cards
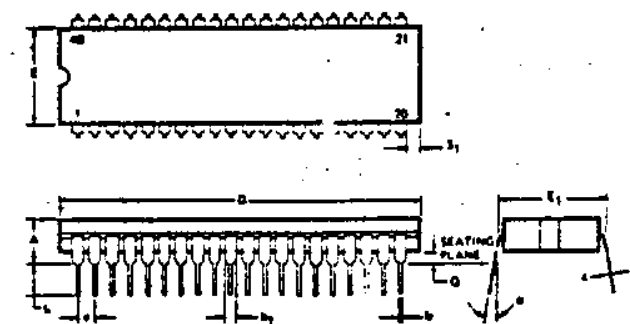

th

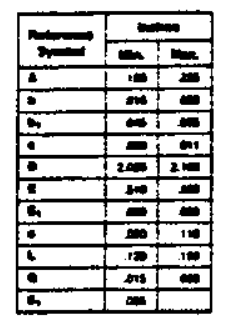

4apin Molded or
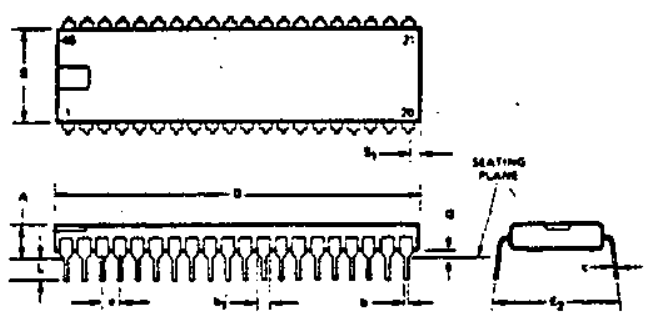

The International Standard of Guality guarantees these ejectrical AQ's on all parameters over the operating tempera ture range: $0.1 \%$ on MOS RAMS \& ROMs: $0.2 \%$ on Bipolar Loglc \& Interface; $0.3 \%$ on Linear, LS \& L Jogc \& other mernarles

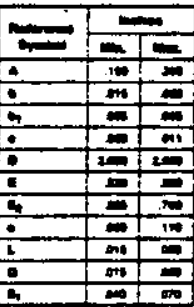

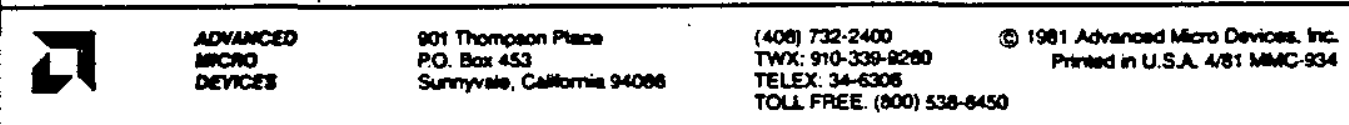

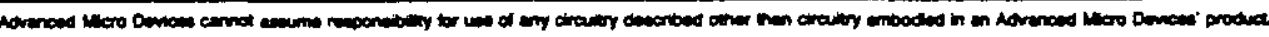

Fig 2. (Cont'd) 
The HEKTOR microprocessor software is based on the 8085 Assembly Language, the types of Instructions available with this language shown in Figure 1. The Instruction set is quite comprehensive, and is listed in Figure 2. The memory of the HEKTOR system contains $4 \mathrm{x}$ lk of Random Access Memory, which is allocated for the user read/write operations, the RAM addresses being at 3000-3FFF Hex. The remainder of the memory map is taken by the system software, as shown in Figure 3 .

The cSo program was written in assembler using the text buffer and Editor facilities of the system. The text was then translated into machine code using the system's RoM Assembler, a three-pass operation where, during the third and final pass the machine code is produced, and stored in the machine code buffer allocated in the free area of the memory, following the text buffer.

The assembled version of the cso program is shown in its memory-mapped form in Figure 4. In this form, the information given in the program listing includes the entry points for the system routines used, a complete list of which is given in Figure 5 .

Further to the description and flowchart of the cSo program given in Section 3, HEKTOR's Interrupt system, and in particular Interrupt RST7.5 with Vector address 2FOD/2FOE Hex. , Figure 6 , was used in conjunction with the signal output from the crankshaft-mounted opto-switch, via the interface, to initiate the output of CSo sequences to the S.C.R.'S.

The origin/Entry address of the program is $3 \mathrm{~A} 2 \mathrm{~F}$ Hex., that is the program, once loaded into the machine code buffer can be executed from the MONITOR status by entering:

$$
\text { G3A2F 〈CR }
$$

The operator then has the following choices:

(i) Input new cSo sequences, as described in section 3, by entering ' 1 ' or ' 0 '.

(ii) Display all CSo sequences, by entering ' $R$ ' .

(iii) Move the stack pointer to the top CSo sequence Table address, by entering ' $T$ '.

(iv) Enable the Interrupts, and hence output the sequences to the S.C.R.'s, by entering 'O'. 
The CSo sequences entered by the above method are stored in the user part of the memory, beginning at address :

$$
\text { DATA : } 3841 \mathrm{Hex} \text {. }
$$

The user memory, although expanded from standard by $0.256 \mathrm{~K}$ of RAM on the interface $8155 / 8156$ chip, it still needs further expansion in order to be able to use other Interrupts (RST5.5, RST6.5), to incorporate further refinements to the CSo system as has been discussed in section 5 . 
Daca Copy Group

MOV Copy data between register/memory and register/memory

MVI Copy operand data to register/memory

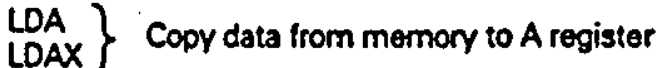

STA $\{$ STAX Copy data from A register to memory

LHLD Copy data from memory to HL register pair

SHLD Copy data from HL register pair to memory

LXI Copy operand data to register pair

XCHG Exchange data between HL and DE register pairs

XTHL Exchange data between $H !$ register pair and top of stack

Arithmetic Group

ADD Add register/memory contents to A register contents

ADI Add operand data to A register contents

ADC Add register/memory and Carry contents to A register contents

$\mathrm{ACl}$ Add operand data and Carry contents to A register contents

SUB Subtract register/memory contents from A register contents

SUt Subtract operand data from A register contents

SBB Subtract register/memory and Carry contents from A register contents

SBI Subtract operand data and Carry contents from A register contents

INR Increment register/memory contents by 1

DCR Decrement register/memory contents by 1

INX Increment register pair contents by 1

DCX Decrement register pair contents by 1

DAD Add register pair contents to $\mathrm{HL}$ register pair contents

DAA Adjust A register contents for $B C D$ result following addition

\section{Logical Group}

ANA Logical AND register/memory contents with A register contents

ANI Logical AND operand data with A register contents

ORA Logical OR register/memory contents with A register contents

ORI Logical OR operand data with A register contents
XRA

Logical EXCLUSIVE-OR register/memory 66 contents with A register contents

XRI Logical EXCLUSIVE-OR operand data with A register contents

CMP Compare register/memory contents with A register contents

CPI Compare operand data with A register contents

RLC Rotate A register contents lelt, and into Carry

RRC Rotate A register contents right, and into Cary

RAL Rotate A register and Carry contents left

RAR Rotate A register and Carry contents right

CMA Complement A register contents .

CMC Complement Carry contents

STC Set Carry contents to 1

Program Sequence Control Group

Jump if: Calt if: Return if: Condition is:

JC CC RC Carry (Carry=1)

JNC CNC RNC No Carry (Carry=0)

JZ CZ RZ ZeroRero=11

JNZ CNZ RNZ Not Zero (Zero=0)

JP $\quad$ CP RP $\quad$ Plus (Sign=0)

JM $\quad C M \quad R M \quad$ Minus (Sign=1)

JPE CPE RPE Parity even (Parity=1)

JPO CPO RPO Parity odd (Parity $=0)$

JMP CALL RET Unconditionally

PCHL Copy data from HL register pair to Program Counter

RST Call routine at restart address

Stack Operation Group

PUSH Push register pair contents onto the stack

POP POp top of stack data into register pair

SPHL Copy data from HL register pair to Stack Pointer

InputOutput Group

IN Copy data from $1 / O$ device to A register

OUT Copy data from A register to $/ / O$ device

Machine Control Group

El Enable interrupt system

DI Disable interrupt system

RIM Copy Interrupt Status data to A register

SIM Copy A register contents to interrupt Control

HLT Halt processor

NOP No operation 
MNEMONIC COOE TIME

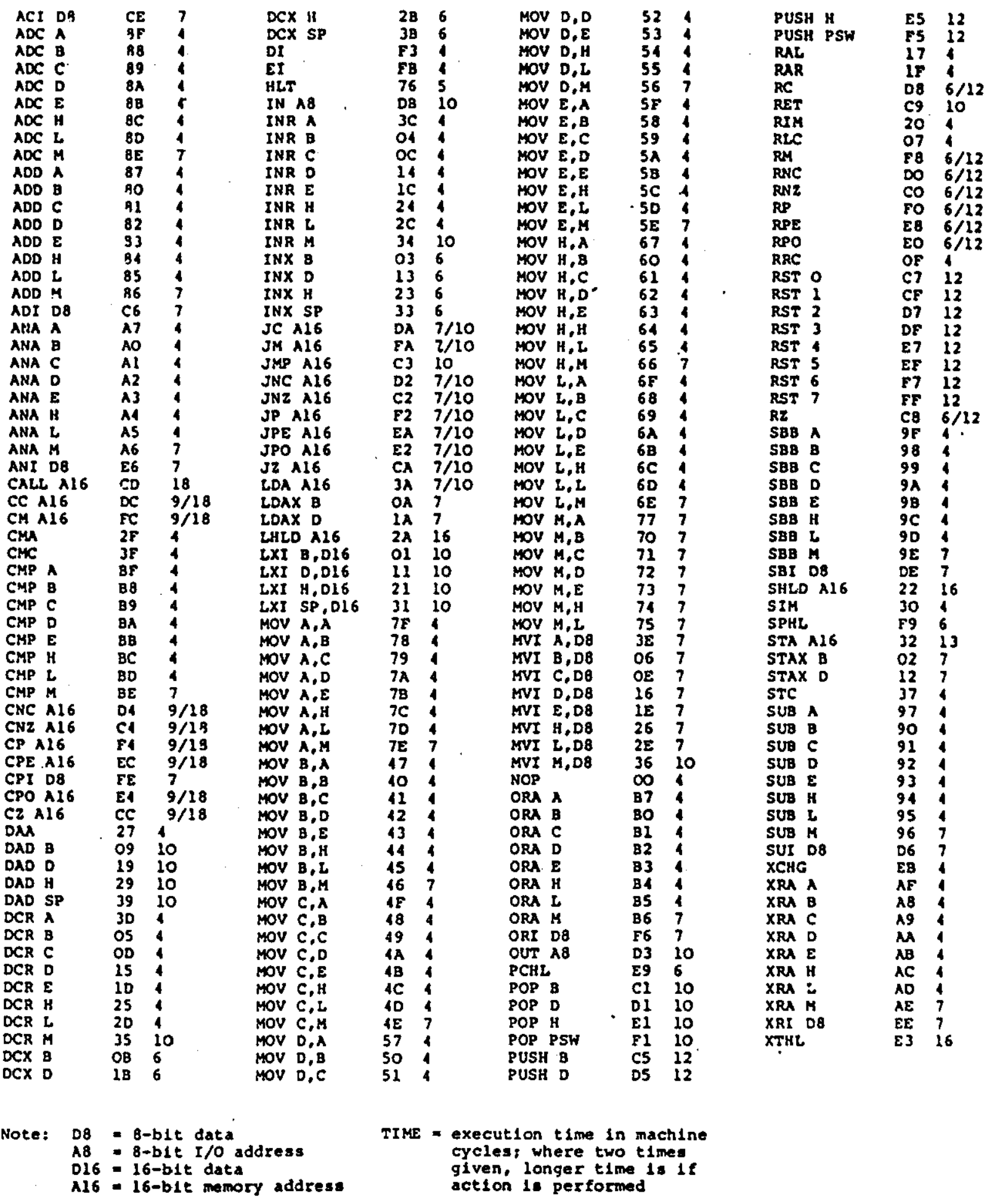




\begin{tabular}{|c|c|c|c|}
\hline $\begin{array}{l}\text { Hexadecimal } \\
\text { address }\end{array}$ & $\begin{array}{l}\text { Corresponding } \\
\text { physical device }\end{array}$ & $\begin{array}{l}\text { Principal usage } \\
\text { by system software }\end{array}$ & $\begin{array}{l}\text { Address range } \\
\text { used by sofwware }\end{array}$ \\
\hline 0000-1FFF & $2 \times 4 \mathrm{~K}$ ROM devices & $\begin{array}{l}\text { storage of system programs/ } \\
\text { routines }\end{array}$ & DO00-1FFF \\
\hline $2000-27 F F$ & none & none & none \\
\hline 2800-2BFF & TV output data port & TV interface & 2800 only \\
\hline $2 \mathrm{COO}-2 \mathrm{FFF}$ & 1/4K RAM in 8155 device & $\begin{array}{l}\text { workspace/stack for system } \\
\text { programs }\end{array}$ & $2 F 00-2 F F F$ \\
\hline 3000 - JFFF & $4 \times 1 K$ RAM devices & user read/write memory & 3000-3FFF \\
\hline $4000-7 F F F$ & (extemal 1/4K periph. board) & none & none \\
\hline 8000 - $9 F F F$ & \multicolumn{2}{|c|}{ same devices as for addresses 0000 to IFFF } & 0000 -1FFF \\
\hline$A 000-A 7 F F$ & none & none & none \\
\hline$A 800 \_A B F F$ & \multicolumn{2}{|c|}{ same devices as for addresses 2800 to $2 \mathrm{BFF}$} & 2800 only \\
\hline ACOO_AFFF & VO ports of 8155 device & keyboard. TV. cassette control & $A C 00-A C O 5$ \\
\hline B000-BFFF & \multicolumn{2}{|c|}{ same devices as for addresses 3000 to 3FFF } & 3000 -3FFF \\
\hline COOO_FFFF & none & none & none \\
\hline
\end{tabular}

Fig 3 HEKTOR Memory Map 


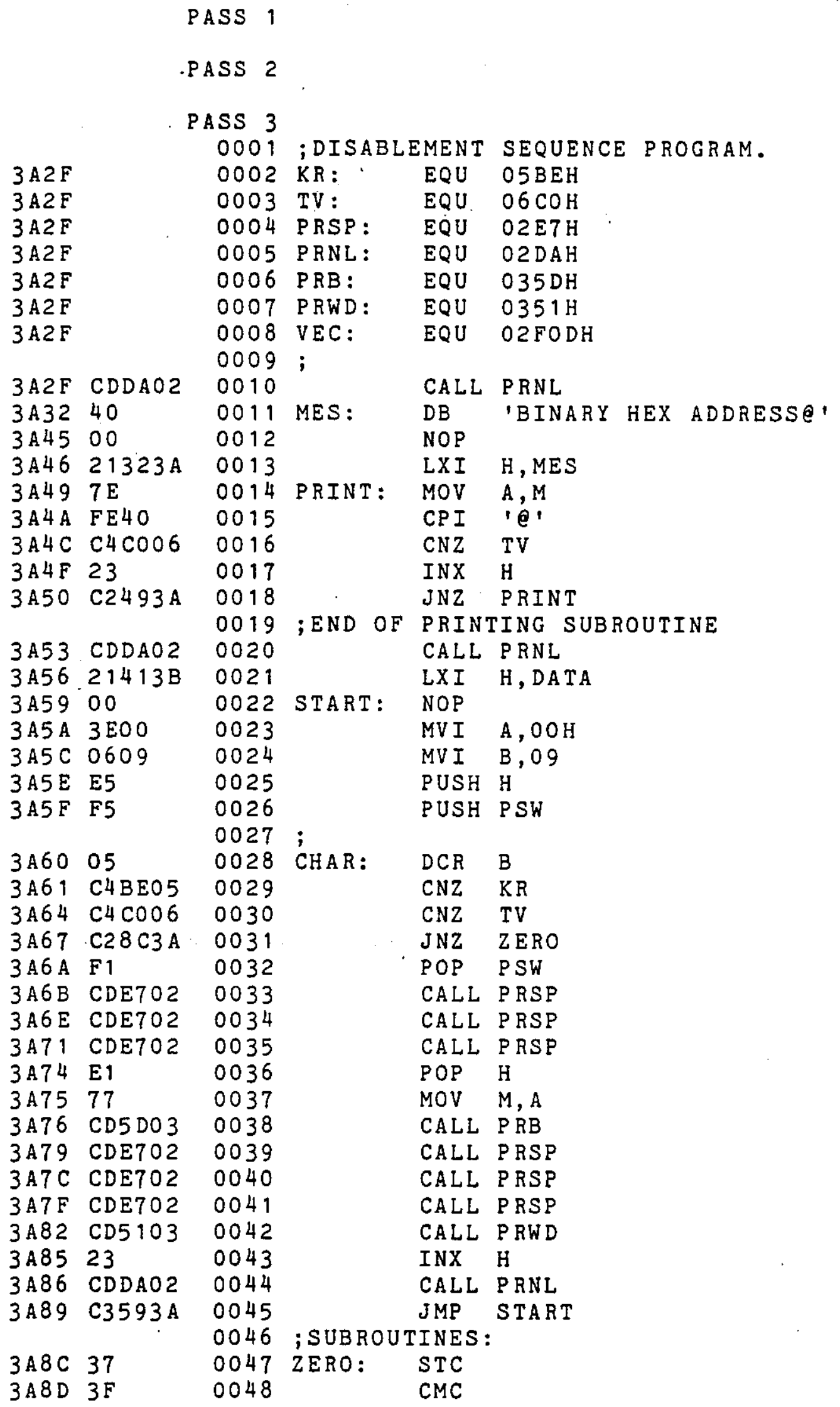




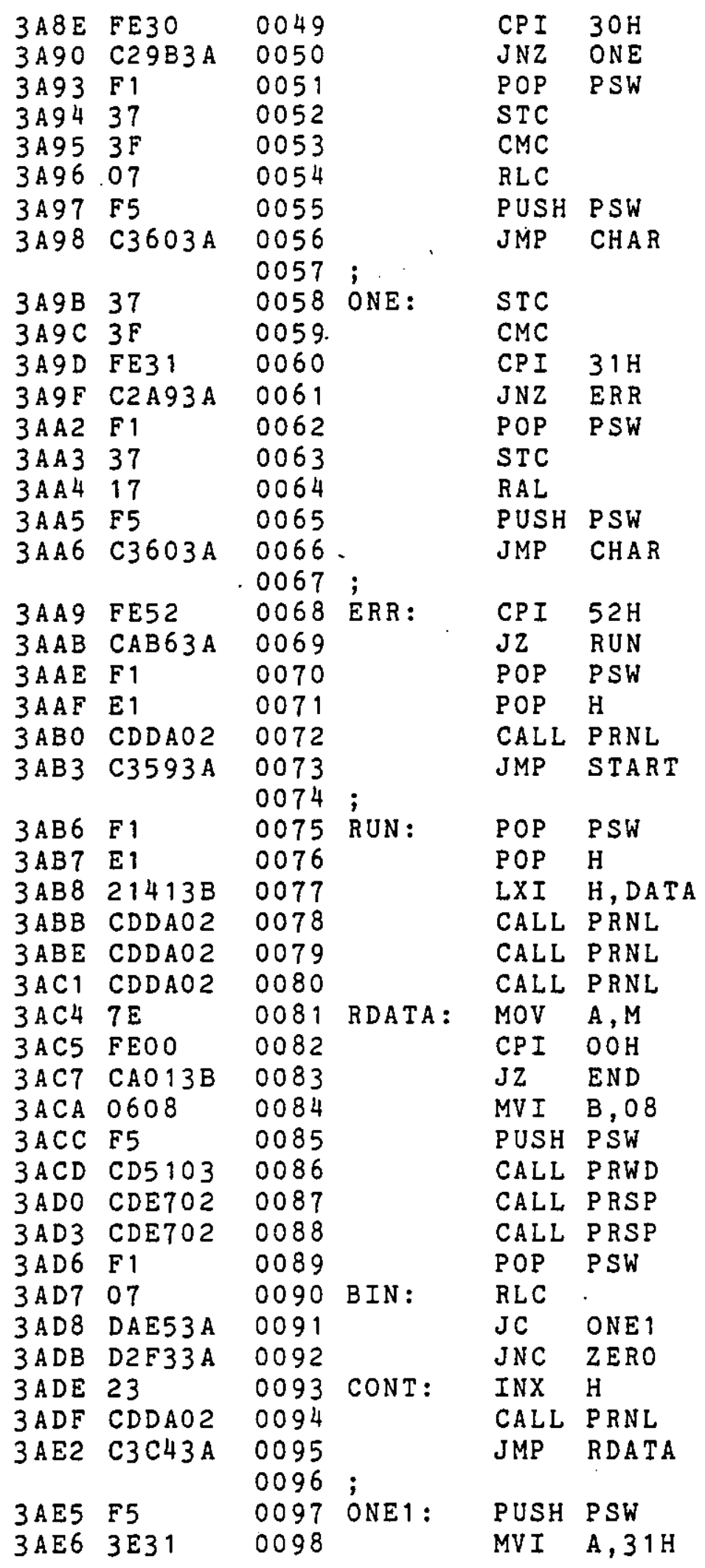




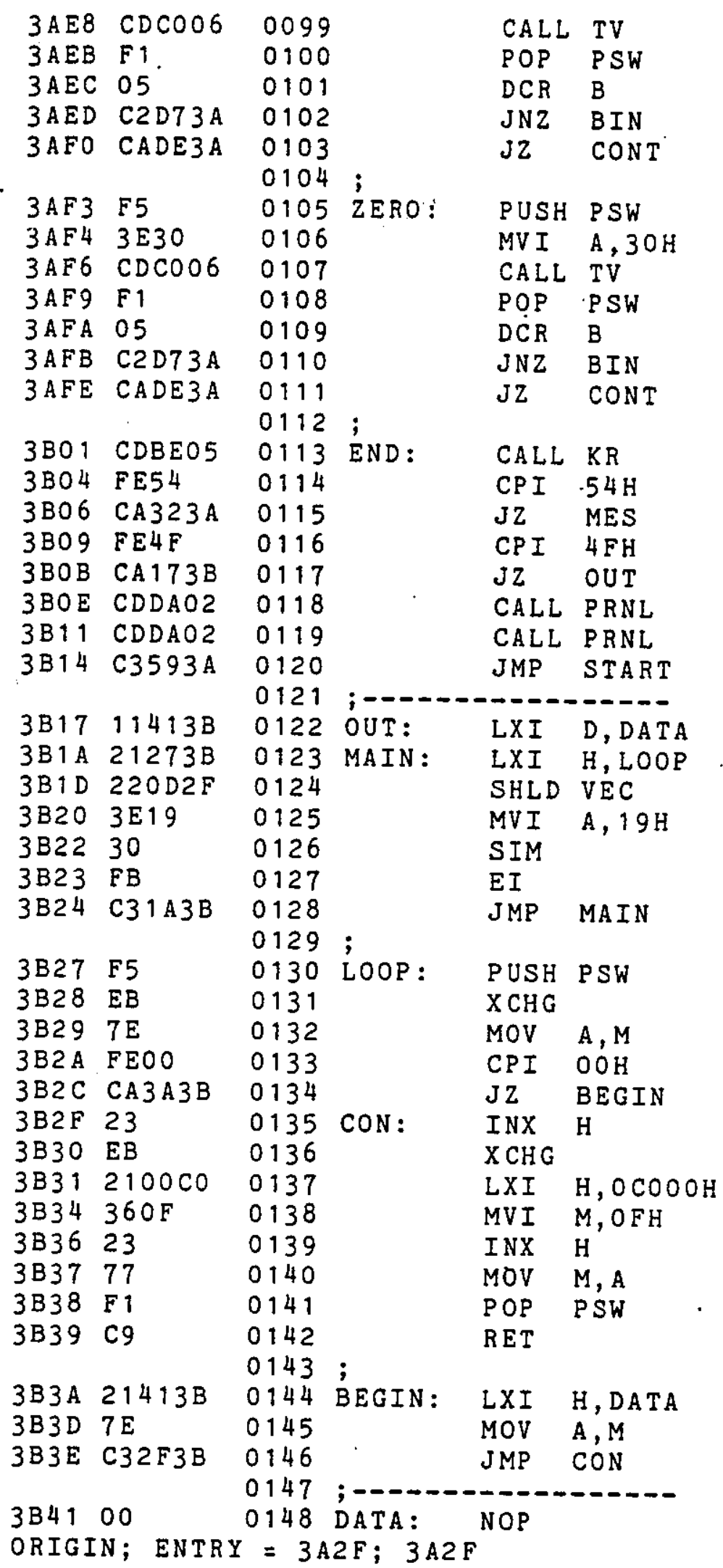




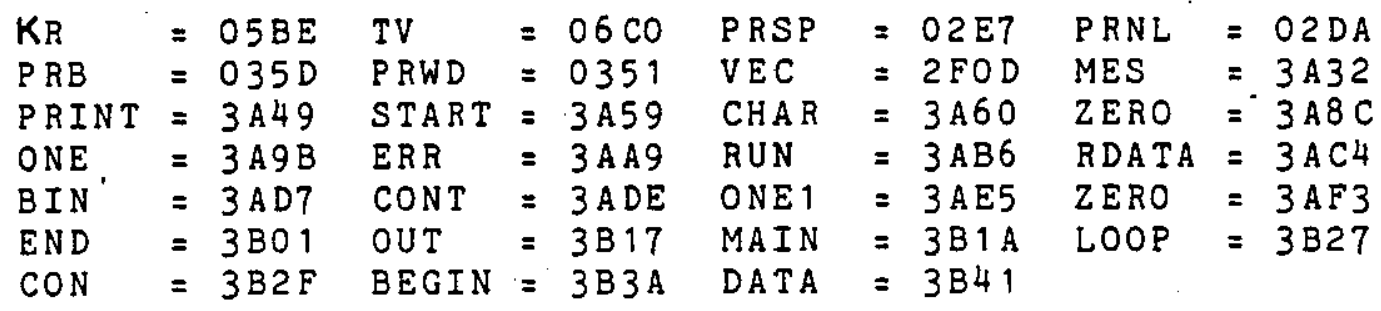




\begin{tabular}{|c|c|c|}
\hline Address & Name & Comment \\
\hline 0000 & MONC, & monitor 'cold" entry \\
\hline 0057 & MONW & monitor 'warm' entry \\
\hline 0201 & PRERR & displays error message \\
\hline 02DA & PRNL & new line on display \\
\hline 02E7 & PRSP & displays space \\
\hline 0302 & PRCOL & displays colon \\
\hline 030A & PRMES & displays string of characters \\
\hline 0347 . & PRWI & displays 4 hex digits. $H L=$ pointer \\
\hline 0351 & PRWD & $\begin{array}{l}\text { displays } 4 \text { hex digits, contents of } \\
\text { HL. }\end{array}$ \\
\hline 0359 & PRBI & displays 2 hex digits. $H L=$ pointer \\
\hline 0350 & PRB & displays 2 hex digits. contents of $A$ \\
\hline 0375 & CRS & saves data on cassette \\
\hline 0409 & CRL & loads/verifies data on cassette \\
\hline 049B & CRON & starts cassette motor \\
\hline $04 A 4$ & CROFF & stops cassette motor \\
\hline O4BB & KBUF & accepts line from keyboard \\
\hline O5BE & $\mathrm{KR}$ & accepts key from keyboard \\
\hline $062 E$ & KSTAT & tests if key pressed \\
\hline 0660 & KLUC & converts lower to upper case \\
\hline 0666 & KGRAF & converts to graphic code \\
\hline 0670 & sout & serial line output \\
\hline $06 \mathrm{CO}$ & TV & sends character to TV \\
\hline 0732 & DELAYI & short delay \\
\hline 073A & DELAY2 & long delay \\
\hline 0800 & EDITC & editor entry (cold) \\
\hline O8E4 & EDITW & editor entry (warm) \\
\hline 0016 & BCDSUB & BCD subtraction \\
\hline 0029 & BCDADD & $B C D$ addition \\
\hline ODAO & ASSEM & assembler entry \\
\hline 1816 & DMUL & binary multiplication \\
\hline 1831 & DDIV & binary division \\
\hline 1978 & TMS & tune machine (standard tune) \\
\hline 1986 & TMU & tune machine (user tune) \\
\hline IFFF & - & end of system ROM \\
\hline
\end{tabular}




\begin{tabular}{|c|c|c|c|c|c|}
\hline $\begin{array}{l}\text { Source of } \\
\text { Interrupt }\end{array}$ & Name & $\begin{array}{l}\text { ROM } \\
\text { Address }\end{array}$ & $\begin{array}{l}\text { Vector } \\
\text { Address }\end{array}$ & $\begin{array}{l}\text { Default } \\
\text { Handler } \\
\text { Address }\end{array}$ & Handler function \\
\hline $\begin{array}{l}\text { RESET } \\
\text { key }\end{array}$ & RSTO & 0000 & - & 0000 & Initialize system \\
\hline (program) & RST1 & 0008 & $\begin{array}{l}2 \mathrm{FO} 01 / \\
2 \mathrm{FO} 2\end{array}$ & 0000 & . \\
\hline (program) & RST2 & 0010 & $\begin{array}{l}\text { 2F01/ } \\
\text { 2F02 }\end{array}$ & 0000 & $\cdot$. \\
\hline (program) & RST3 & 0018 & $\begin{array}{l}\text { 2F01/ } \\
\text { 2F02 }\end{array}$ & 0000 & .. \\
\hline (program) & RST4 & 0020 & $\begin{array}{l}\text { 2FOMI } \\
2 \mathrm{FO2}\end{array}$ & 0000 & . \\
\hline (program) & RST5 & 0028 & $\begin{array}{l}2 \mathrm{FONI} \\
2 \mathrm{FO2}\end{array}$ & 0000 &. \\
\hline (program) & RST6 & 0030 & $\begin{array}{l}\text { 2FO1I } \\
\text { 2F02 }\end{array}$ & 0000 & .. \\
\hline $\begin{array}{l}\text { break } \\
\text { point }\end{array}$ & RSTT & 0038 & $\begin{array}{l}2 \mathrm{FOA} \\
2 \mathrm{FOB}\end{array}$ & O1ED & $\begin{array}{l}\text { Saves status. removes break point } \\
\text { exit to monitor }\end{array}$ \\
\hline timer & TRAP & 0024 & $\begin{array}{l}2 \mathrm{~F} 10 / \\
2 \mathrm{~F} 11\end{array}$ & 0206 & Saves status, exit to monitor \\
\hline BUSY & AST5.5 & $002 \mathrm{C}$ & $\begin{array}{l}\text { 2F04/ } \\
2 \text { F05 }\end{array}$ & 0000 & Initialize system \\
\hline $\begin{array}{l}\text { BREAK } \\
\text { key }\end{array}$ & RST6.5 & 0034 & $\begin{array}{l}2 F 07 I \\
2 F 08\end{array}$ & 0100 & Saves status, exit to monitor \\
\hline (ext) & - RST7.5 & $003 C$ & $\begin{array}{l}2 \mathrm{FOO} / \\
2 \mathrm{FOE}\end{array}$ & 0000 & Initialize system \\
\hline
\end{tabular}

Fig 6 HEKTOR Interrupt Sources, Vectors and Handlers. 
APPENDIX VI

Product specification

This appendix contains the product specification and calibration curve of the KISTLER pressure transducer used in monitoring cylinder pressures. 


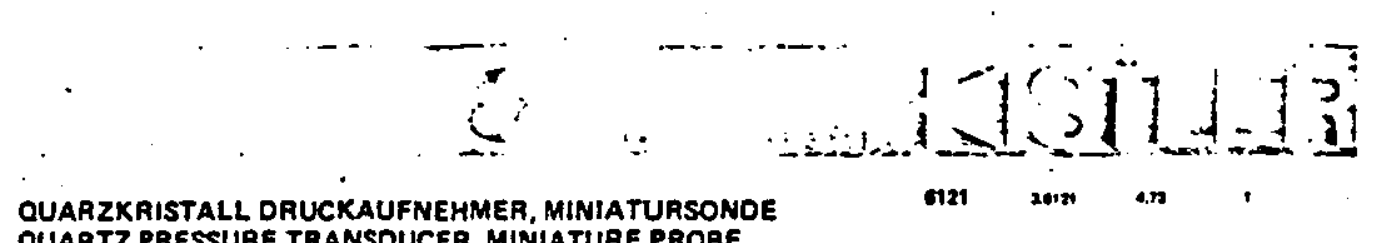
QUART? PRESSURE TRANSOUCER, MINIATURE PROBE

Miniatur Onuckaufnehmer für universelten Einsatz in Brennkrattmaschinen, Raketen, Explosionskammern usw. Arbeitet zu: trässig bei Umgebungstemperaturen bis $350^{\circ} \mathrm{C}$ und er ägt intermittierende Flammtem. peraturen bis $2560^{\circ} \mathrm{C}$.
Miniature pressure transducer for universal application on internal combustion engines, rockets. explosionchambers etc. Works reliably in ambient temperatures of up to $350^{\circ} \mathrm{C}$ and withstands intermittent flash temperatures of up to $2500^{\circ} \mathrm{C}$.
- Neues Polystable Ourakristallelememt

New Polystable ouarz element

Betriebstemperatur bis $350^{\circ} \mathrm{C}$. Normalerweise

- Keine Wasserkühlung nötig.

Operating temparature up to $350^{\circ} \mathrm{C}$. Normally no watercooling required.

Empfindlichkeit ändert sich weniger als $\pm 0,5 \%$

- im Bereich $100 . .300^{\circ} \mathrm{C}$.

Sensitivity varies less than $\pm 0,5 \%$ in the range $100 . .300^{\circ} \mathrm{C}$

- Unempfindlichkeit auf hohe Flammitemperaturen. Insensitive to high flash temperatures

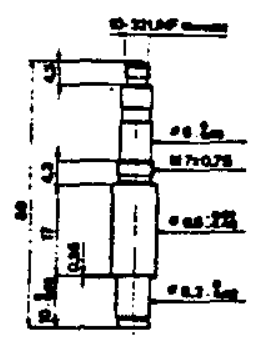

Typos 6121

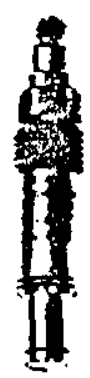

- Masseisolierte Austührung

Groundinsulated design

$$
-2 \text {. }
$$

Technische Daten

Technical data

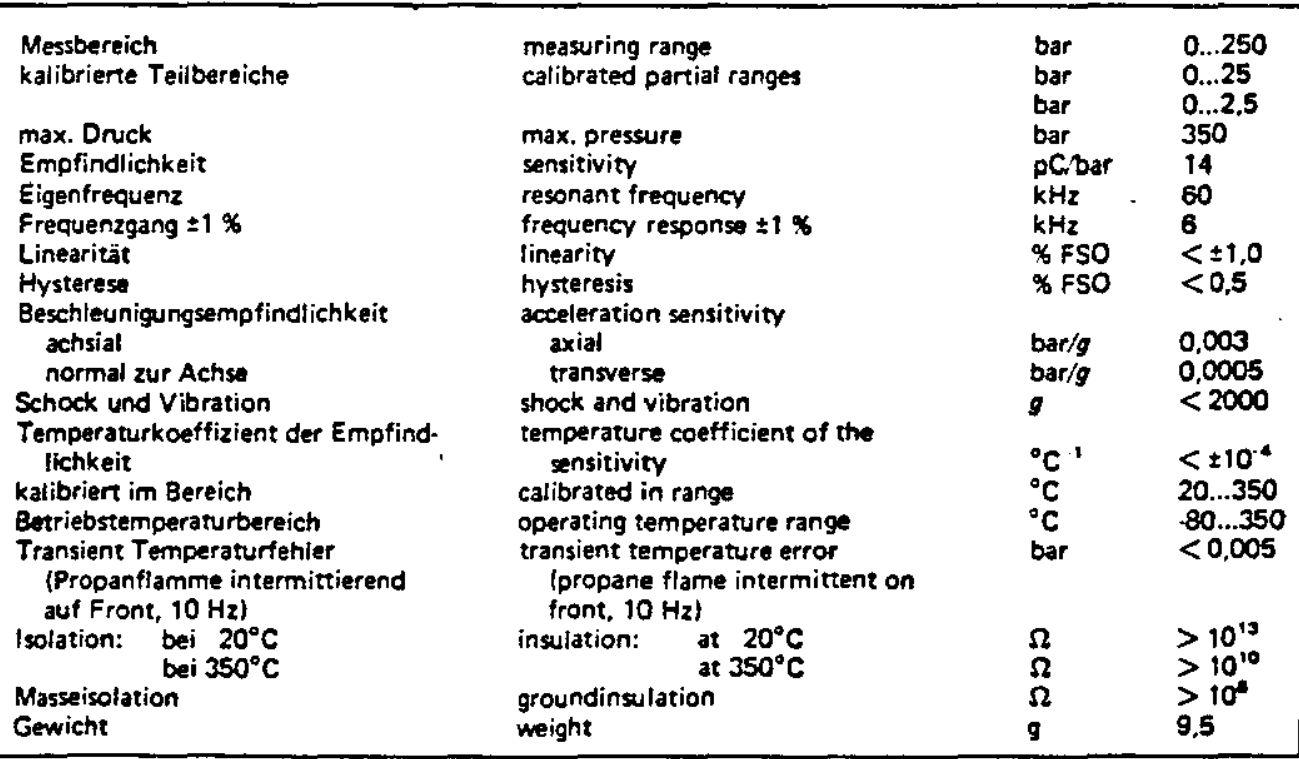

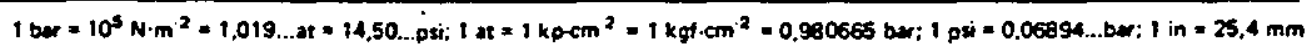

Polystable ${ }^{O}$ Quarzk ristallejemente sind international durch Patente geschüzt

Polystable 0 wartz elements are internotionally patented

Fig 1. KISTLER Pressure Transducer Data and Calibration Sheet. 


\section{ALLGEMEINE BESCHREIBUNG}

Des Polystable ${ }^{\circ}$ Quarzkristallelement, das Kernstück des Aufnehmers, ist das Ergebnis mehrjähriger Forchungsarbeiten und hat sich im praktischen Einsata bereits bewähr.

Polystable Q Quarkeristallelemente sind selbst bei hohen mechanischen Beanspruchungen und hohen

Temperaturen sicher gegen Zwillingsbildung und gewährleisten damit Stabilität. Zudem bleibt der piezoelektrische Koeffizient über einen Tempers. turbereich ron -80 bis $350^{\circ} \mathrm{C}$ innerhalb von $\pm 1,5 \%$. A: "nehmer mit Polystable(ब) Quarzkristallelementen $k c$. men daher universell eingesetzt werden und kom tran 2.B. im Motorenbau ohne Wasserkühlung aus, was einfache und zuverlässige Messungen ergibt.

Der Aufnehmer hat ein Gehäuse sus korrosionsfestem $\mathrm{CrNi}$.Stahl und ist dicht verschweisst. Ein keramisch isolier rer Stecker gewährleistet auch bei extremen Temperaturen die notwendige Isolation.

Die patentierte Doppelmembrane ist mit keramischer Frentplatte ausgerustet, wodurch das Messresultat auch durch hohe intermittierende Fiammtempera. turen nicht beeinflusst wird.
Einbsubeispiele

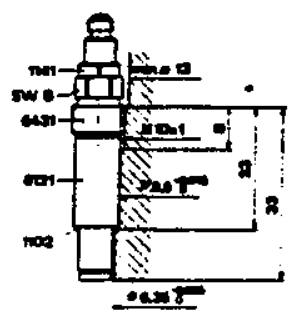

Tyon 6t2149

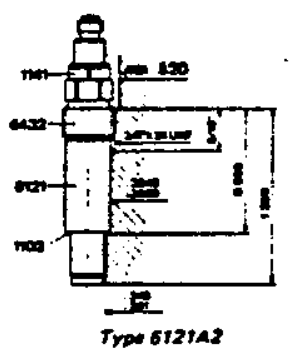

Stondwitiom. Dis Obormirfmuter kemn nech

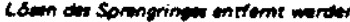

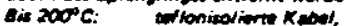

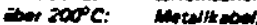

Sendurd form, the metainim me mer be imoned for toovening the circtio.

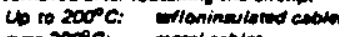
un 2000.

\section{GENERAL DESCRIPTION}

The Polystable Quarta Elemem, the heart of the transducer, is the result of years of research and has been extensively field tested.

Polystable ${ }^{\oplus}$ quarta elements we sofo apoinst twinning even under high mechanical loads and high temperatures and thus ussure stability.

In addition, the piezoelectric coefficiem remains within $\pm 1,5 \%$ over \& temperature rans from -80 to $350^{\circ} \mathrm{C}$

Transducers with Polystable quare etements therefore find universal applications ond do not require watercooling as e.g. on internal combustion engines, thus resulting in simpler and more reliable measurements.

The transducer has a housing of corrosion resistant $\mathrm{CrNi}$-steel and is welded tight. A connector with ceramic insulation maintains high insulation even under extreme temperatures.

The patented double diaphragm has a ceramic frontplate which keeps pressure measurements unaffected by high intermittent flash zemperatures.

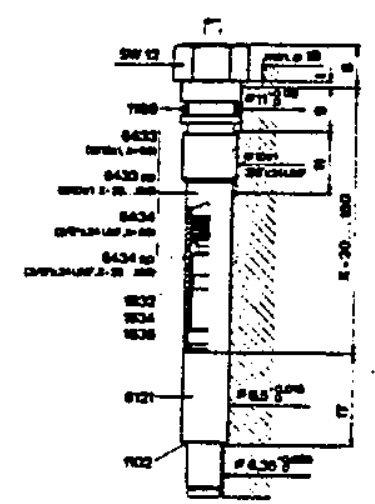

7 Troe 6430

wroxi

$=50 \mathrm{~mm}$

Troesess

$=210 \times 130 \mathrm{~mm}$

\section{Troposi3n}

$3 \% \times 24$ UNF

$x=50 \mathrm{~mm}$

Tros 603010

$=20.150 \mathrm{~mm}$

Sonduetom duren wituchroubaens oin

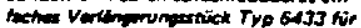

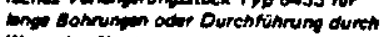

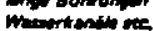

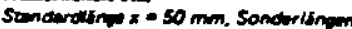
a 20. . 150 min kurstristip lioferae.

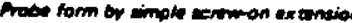

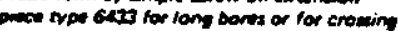
cooting dese it on mpine.

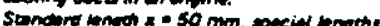

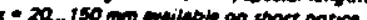

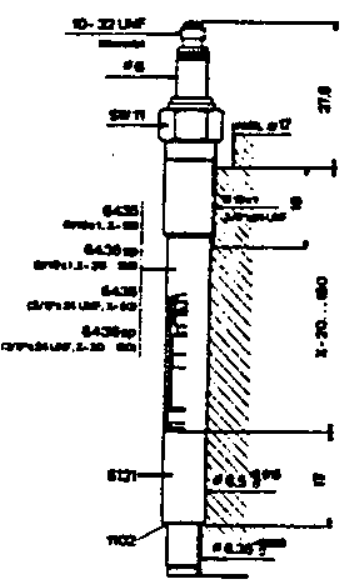

74000135

$x_{10 \times 10}$

Typososs

inde onseses

$410 \times 1$

$n=20.150 \mathrm{~m}$

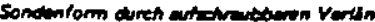

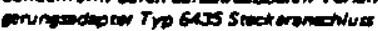
meinizoliont.

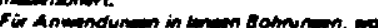

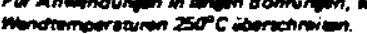

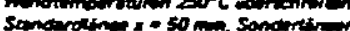

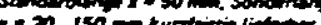

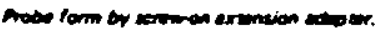

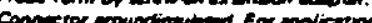

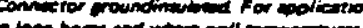
exenod $250^{\circ} \mathrm{C}$.

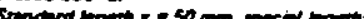

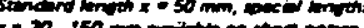

Fig 1. (Cont'd) 
Rempolatt

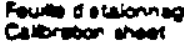

E

KISTLER

\begin{tabular}{|c|c|c|c|c|c|}
\hline \multicolumn{5}{|c|}{$\begin{array}{l}\text { Druckautnehmer } \\
\text { Capteur de pression } \\
\text { Prossure transolucer }\end{array}$} & \multirow{3}{*}{ 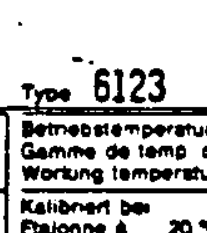 } \\
\hline 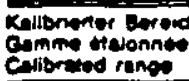 & [bar] & $0 . . .200$ & $0 . . . \infty$ & $0 . . .2$ & \\
\hline 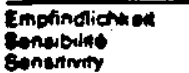 & [pc/barl & $-16,1$ & - 16,95 & $-18,2$ & \\
\hline 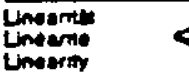 & $< \pm \$ F S O$ & 0,3 & 0,3 & 0,3 & $\begin{array}{l}x=10 \\
100 \\
100.0\end{array}$ \\
\hline
\end{tabular}

$\because 6123=156719$

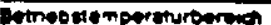

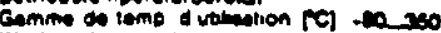

Wortung tomoermerure remes

Ketiomen bo

Eatonme $20^{\circ}$ by the Dare 4.8 .42

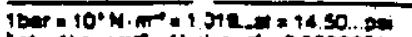

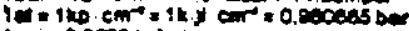

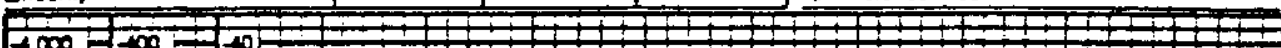

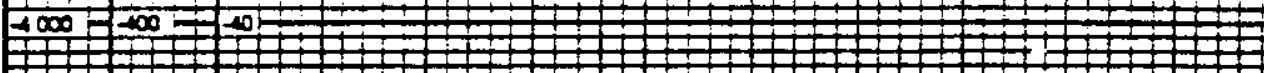

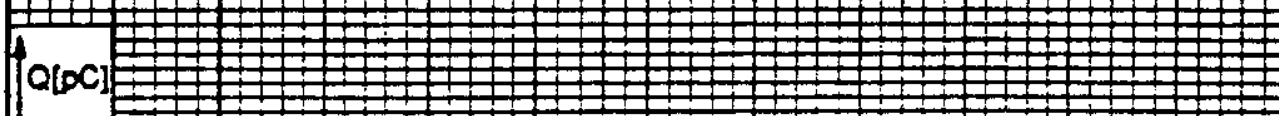

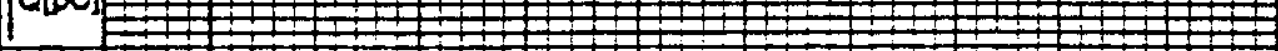

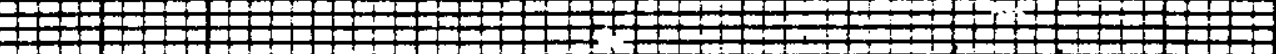

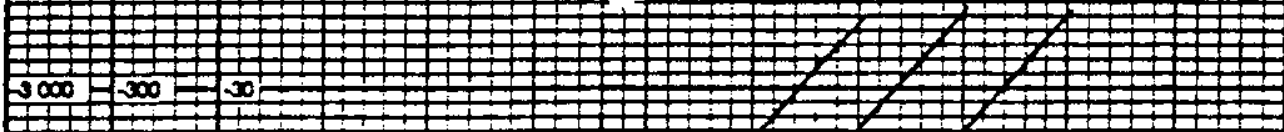
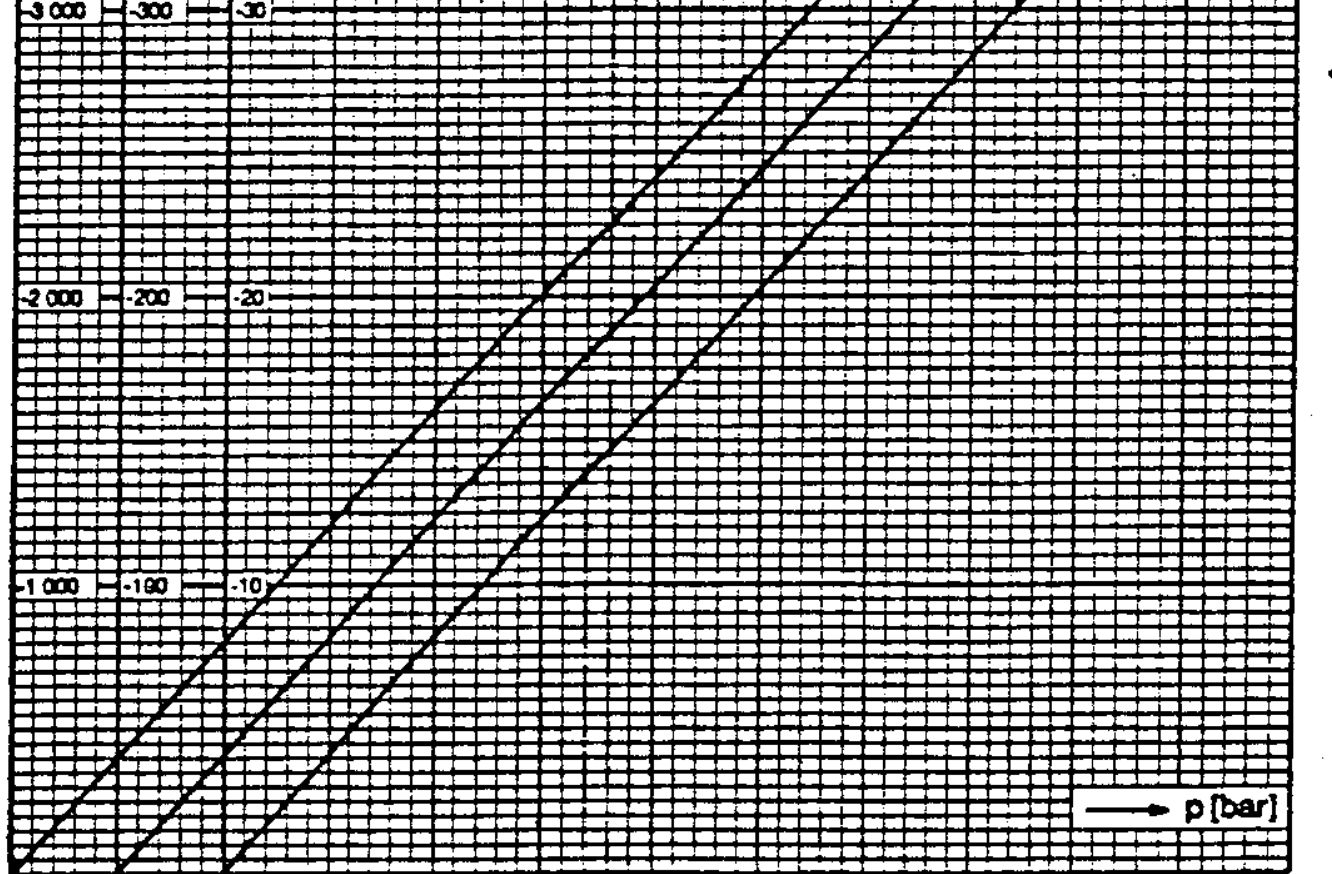

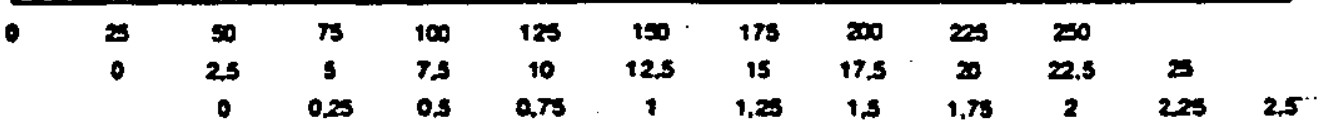

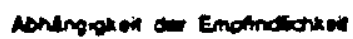

wan Tomperser

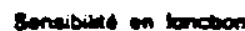

a ta imparate

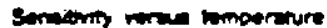

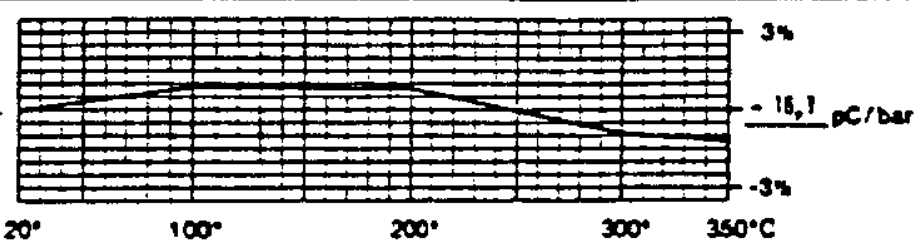

0. $3 \pi$

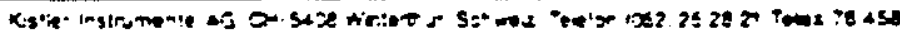

Fig 1. (cont'd) 


\section{APPENDIX VII}

\section{Product Specification}

This appendix contains the product specification and calibration sheet for the D. J. BIRCHALL $A / 20 / T$ accelerometer used for the recording of engine vibration. 
Piezo-Ceramic Accelerometers Specification

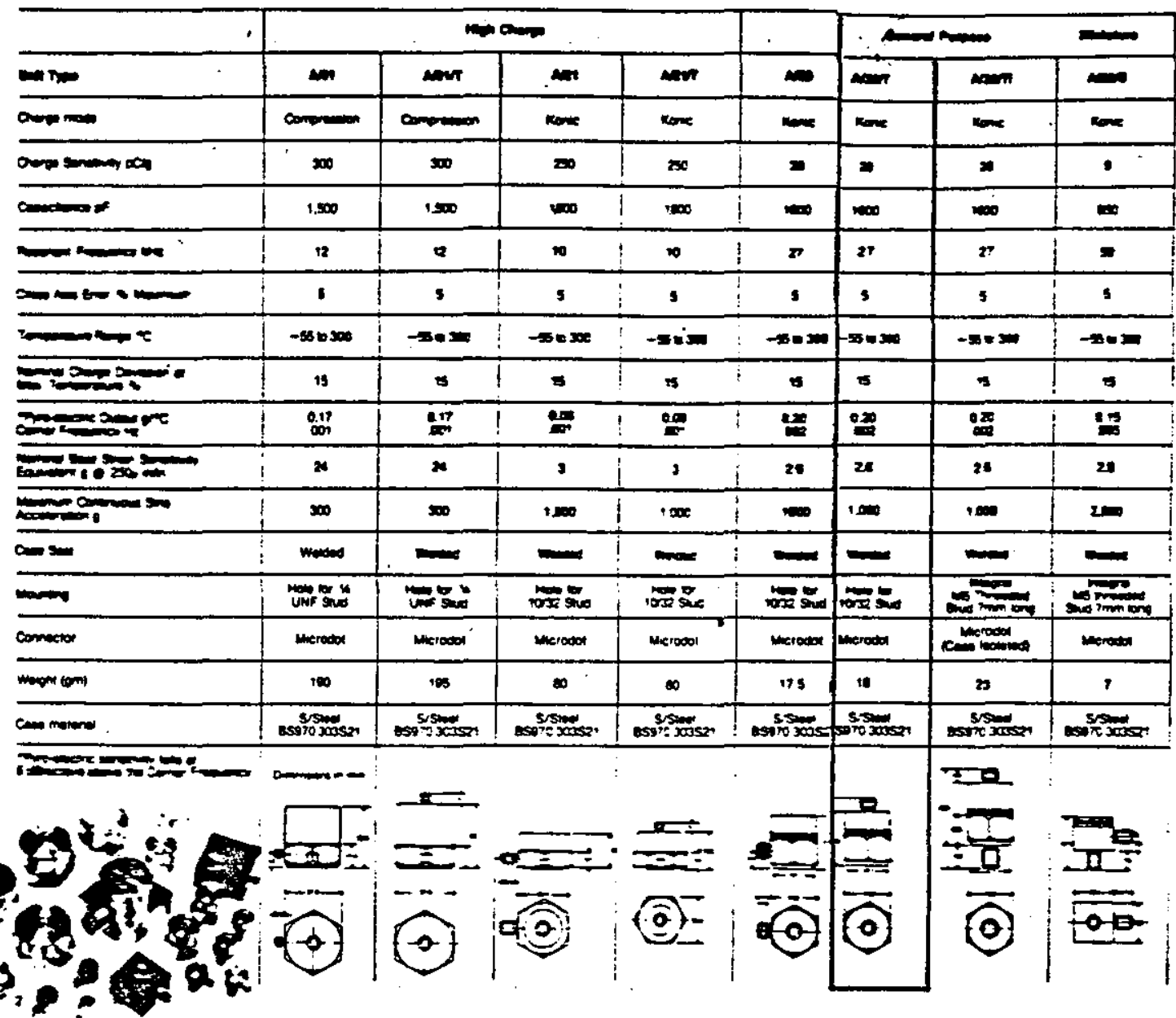

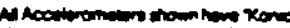

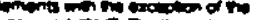

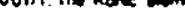

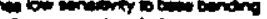

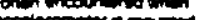

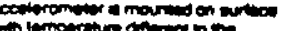
Them

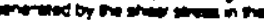

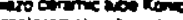

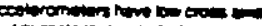

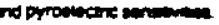

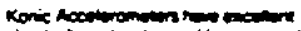

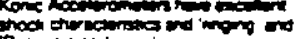

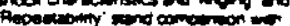

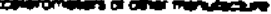

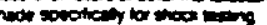
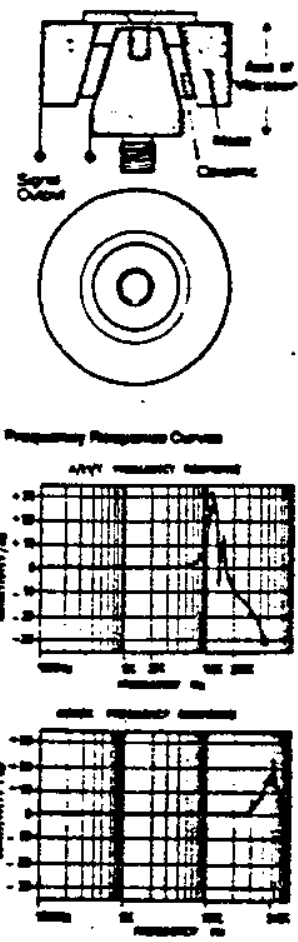

Fig 1. Specification of Vibration Accelerometer Used. 


\section{Accelerometer Calibration Certificate}

D.J. Birchall Ltd., Finchley Avenue Industrial Estate, Mildenhall, Suffolk.

Telephone: Mildenhall 712288

Date 9.2.8?

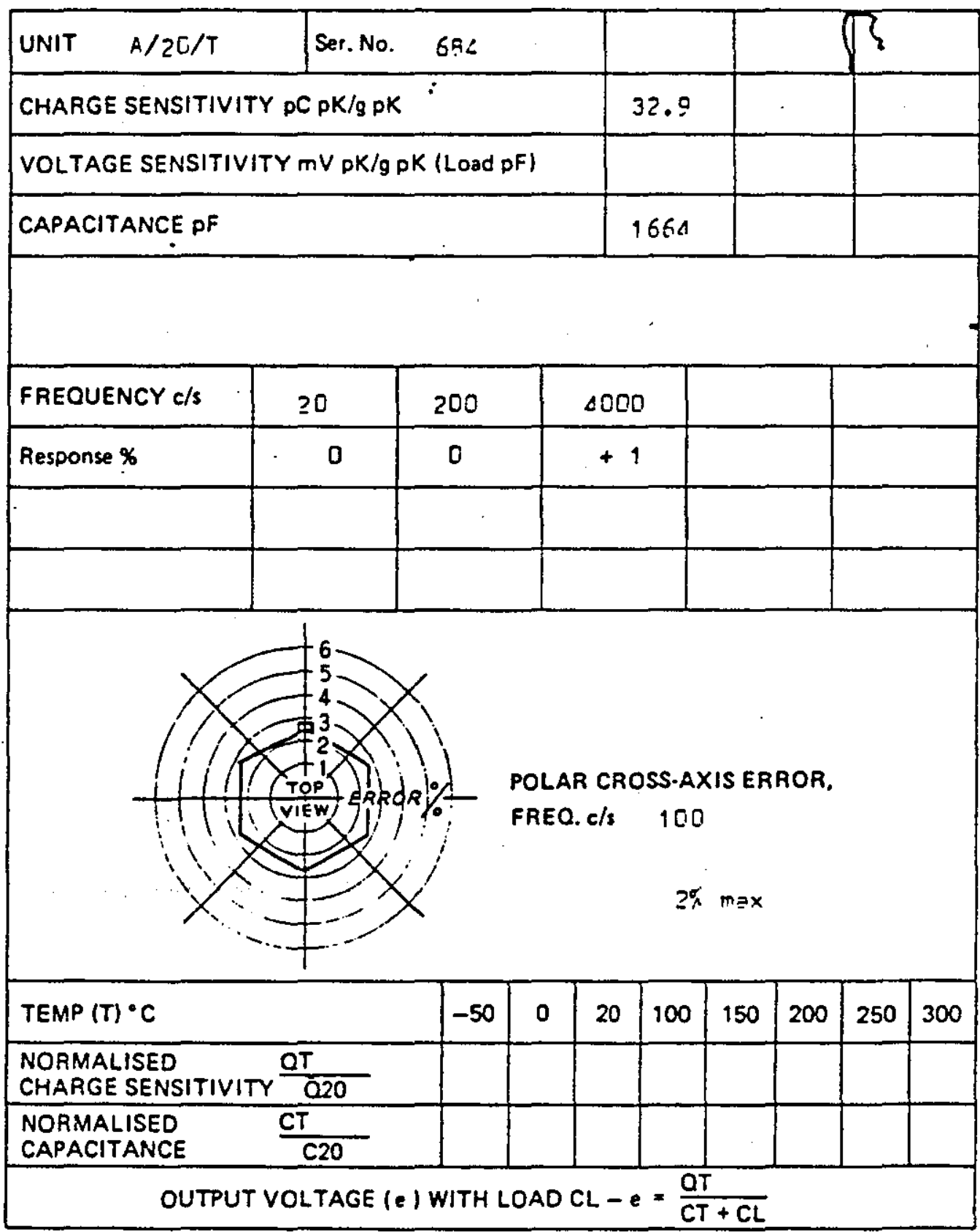

Fig 2. Vibration Accelerometer Calibration Sheet. 
